Xuliang He

Mandarin-accented Dutch Prosody
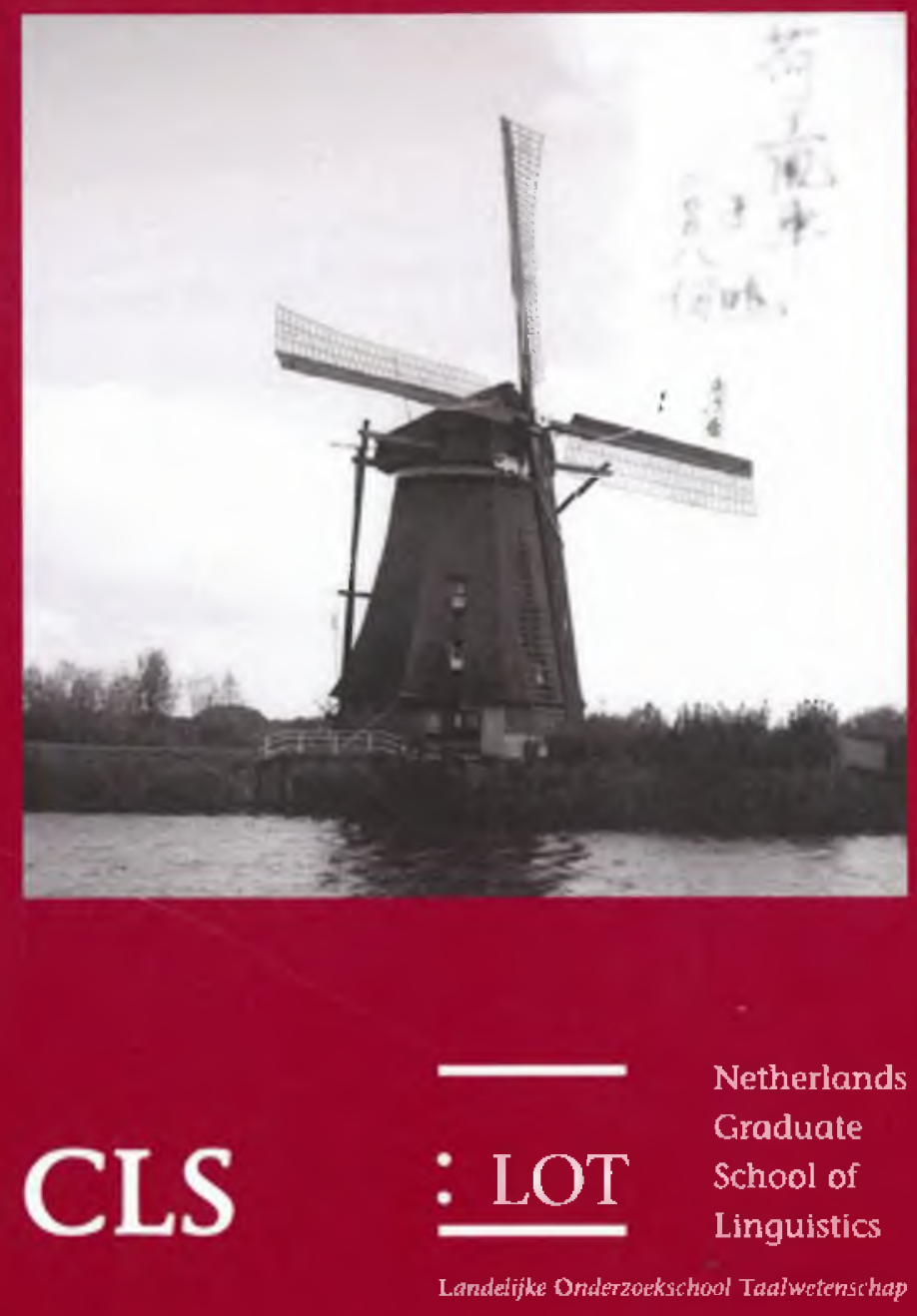


\section{MANDARIN-ACCENTED DUTCH PROSODY}


Published by

LOT

Janskerkhof 13

3512 BL Utrecht

The Netherlands

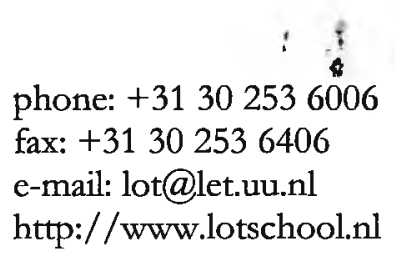

phone: +31302536006

fax: +31302536406

http://www.lotschool.nl

Cover illustration: Photo taken by the author. The text translates as "Windmill in the Netherlands photographed by He Xuliang in 2008 (the time the project began)."

ISBN: 978-94-6093-093-5

NUR: 616

COPYRIGHT (C) 2012: XULIANg HE. AlL RIgHTS RESERVED. 


\section{MANDARIN-ACCENTED DUTCH PROSODY}

Een wetenschappelijke proeve op het gebied van de Letteren

\section{Proefschrift}

ter verkrijging van de graad van doctor aan de Radboud Universiteit Nijmegen

op gezag van de rector magnificus prof. mr. S.C.J.J. Kortmann, volgens besluit van het College van Decanen in het openbaar te verdedigen op 3 december 2012 om 10.30 uur precies

door

$$
\text { Xuliang He }
$$

geboren op 9 augustus 1971

te Huanggang, provincie Hubei, China 


\section{Contents}

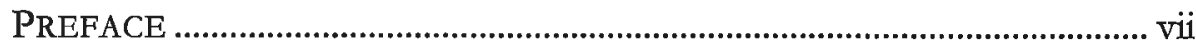

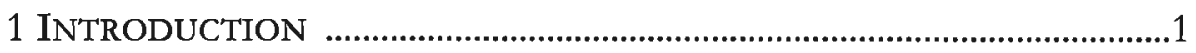

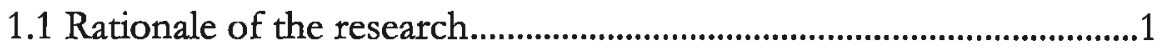

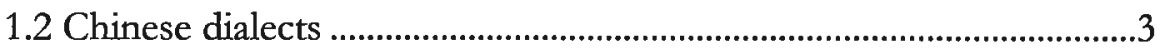

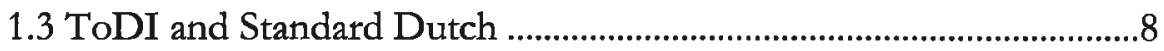

1.4 Relevant issues.............................................................................. 12

1.4.1 Perception and production............................................................. 13

1.4.2 Models of phonological acquisition................................................ 14

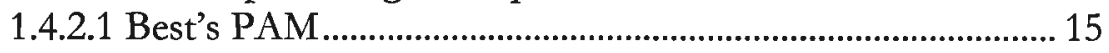

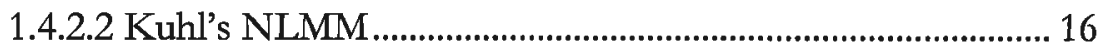

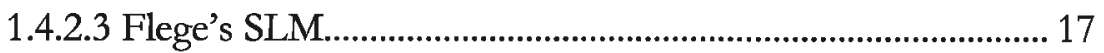

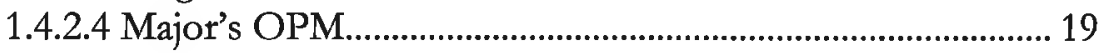

1.4.2.5 Eckman's $\mathrm{MDH}$ and $\mathrm{SCH}$................................................ 20

1.4.2.6 Optimality Theory.................................................................... 21

1.4.3 The age issue .................................................................................... 24

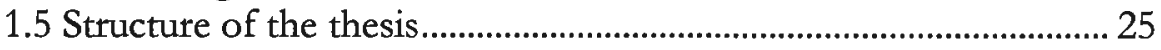

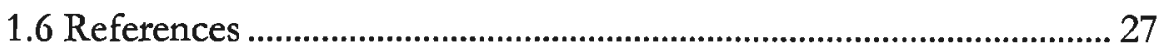

2 CHOOSING THE OPTIMAL PITCH ACCENT LOCATION IN DUTCH ..... 37

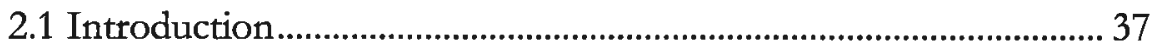

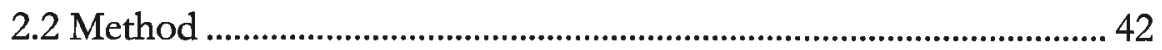

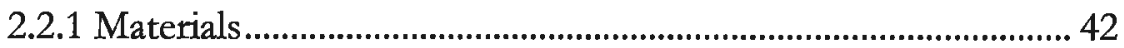

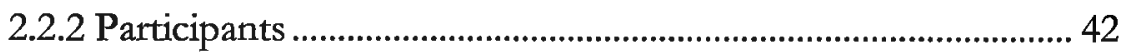

2.2.2.1 General information ........................................................... 42

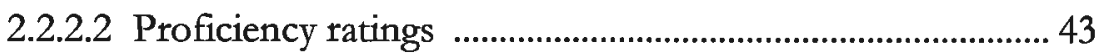

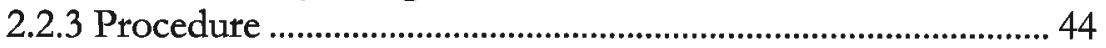

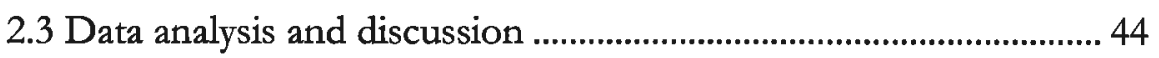

2.3.1 Analysis and discussion of correctness scores ........................... 44

2.3.2 Analysis and discussion of confidence scores............................ 49

2.3.3 Other factors correlated with correctness scores and confidence scores........................................................................... 49

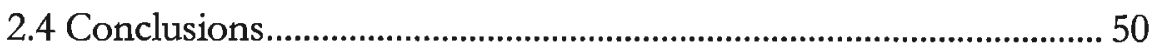

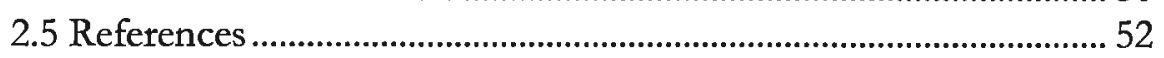




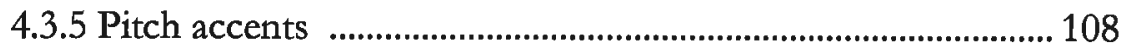

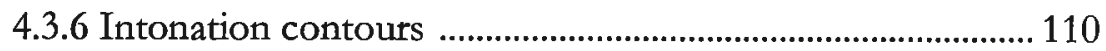

4.3.6.1 Analyses of nuclear contours ............................................. 110

4.3.6.2 Nuclear accent errors and boundary tone errors ............ 116

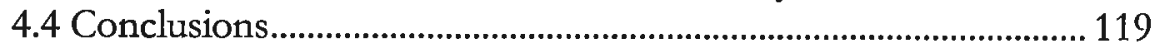

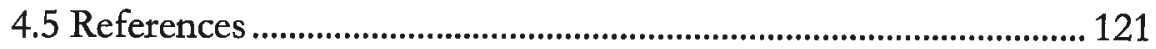

5 MANDARIN-ACCENTED FALL, RISE AND FALL-RISE F0 CONTOURS

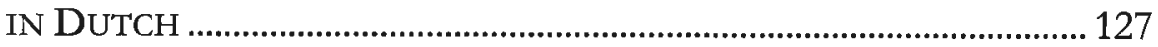

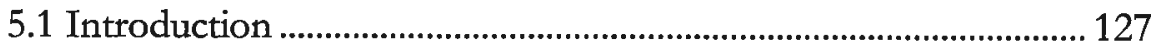

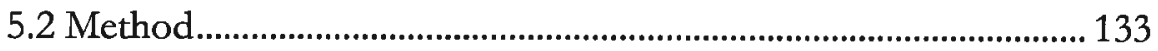

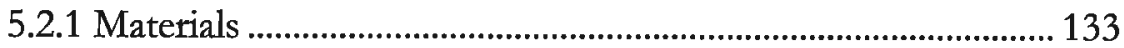

5.2.2 Subjects .......................................................................................... 134

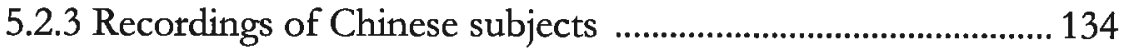

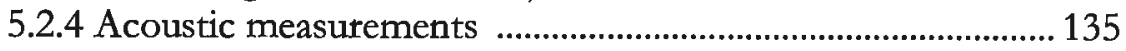

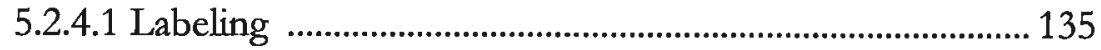

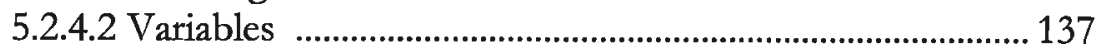

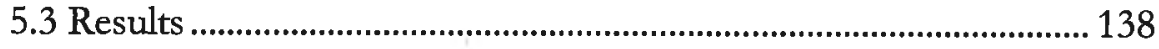

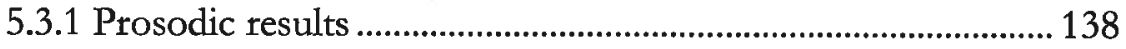

5.3.2 Sonorant rime comparisons ................................................... 139

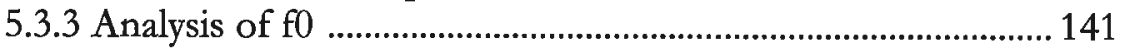

5.3.3.1 Peak alignments in Fall, Rise and Fall-rise........................ 148

5.3.3.2 Comparison of excursions of Fall, Rise and Fall-rise ...... 150

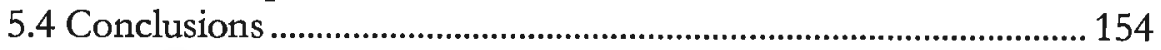

5.5 References ................................................................................... 157

6 PROSODIC EFFECTS OF FOCUS IN DUTCH DECLARATIVES

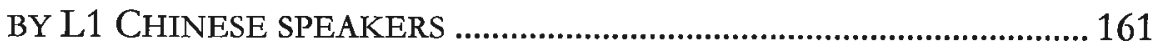

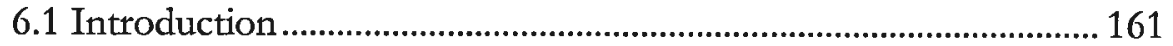

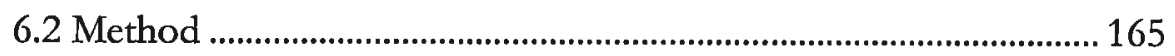

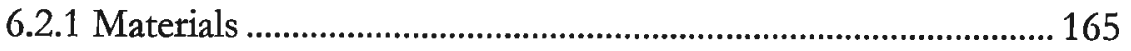

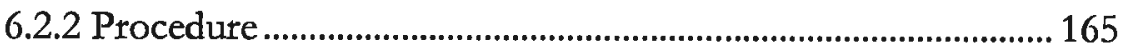

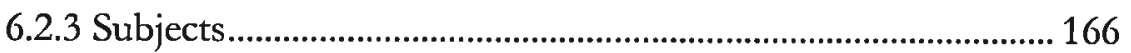

6.2.4 Acoustic measurements and analysis ........................................ 166

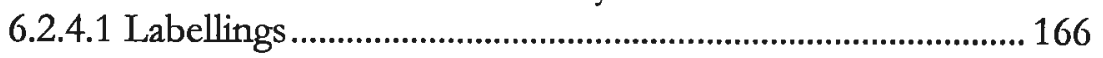

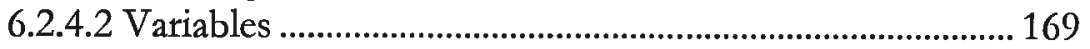

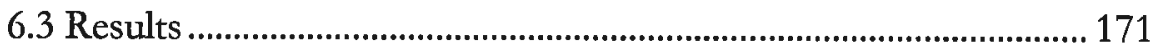

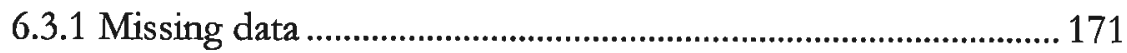

6.3.2 Comparing focus effects across groups.................................. 172

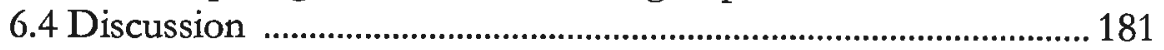




\section{Chapter 1}

\section{Introduction}

\subsection{Rationale of the investigation}

There are about 120,000 Chinese (about $0.82 \%$ of the total population) living in the Netherlands, who immigrated from Mainland China (35\%), Hong Kong (23\%), Indonesia (20\%), Surinam (6\%) and other areas $(16 \%)$, according to the Chinese Embassy in the Netherlands and the investigation by $\mathrm{Li}$ (1999). Most of those who are from Mainland China originate from Shenzhen and Dapeng (Canton Province), Wenzhou and Qingtian (Zhejiang Province), Fuzhou and Changle (Fujian Province). They have formed Chinese communities in Amsterdam, Rotterdam, The Hague, Eindhoven and other places. With the development of China, more and more Chinese are coming to the Netherlands to work or study. They learn Dutch and have mastered the language with a certain level of proficiency. A study of how Chinese people speak Dutch is therefore a significant enterprise, and this is. one of the reasons why the research programme 'Intonation of varieties of Dutch' (NWO 360-70-180) contains a sub-project 'Mandarin-accented Dutch'. The present research represents the main result of this sub-project. It focuses on the prosody of Dutch spoken by Mandarin learners from the northern part of Mainland China.

It is generally accepted that individuals will be found to speak a second language (L2) with detectable foreign accents when they learn it after a certain age (Flege, Patkowski, 1990; Scovel, 1988; Major 2001; Munro 2008, Munro \& Mackay, 1995). Perceptually, the foreign accent is defined as "the extent to which an L2 learner's speech is perceived to differ from native speaker norms" (Munro \& Derwing, 1998: 160). The severity of the foreign accent is influenced by age of learning, length of residence, gender, motivation, aptitude, use of language, speech rate, instruction and social factors (Flege, 1988; Flege, Munro \& MacKay, 1995; Gut, 2009; Hansen Edwards, 2008; Moyer, 2004). Foreign- 
speakers of English increased significantly by replacing original durations and the original $\mathrm{f} 0$ contour by the durations taken from those of a native speaker of English and with durationally manipulated monotones, respectively. The results showed that the Dutch speakers of English used segment durations and f0 contours that signalled foreign accent to native English listeners and that the accent was stronger when the learners spoke than when they sang (Hagen, Kerkhoff \& Gussenhoven, 2011). If less foreign accent in sung speech is specific to Dutch speakers of English, it would be reasonable to assume that language pairs like Chinese and Dutch, which are typologically more different, show even greater such effects due to the greater difference in their prosodic features. If the relative contributions of duration and $\mathrm{f} 0$ contours to foreign accent vary with language-relatedness, the question is whether the prediction is right for the Mandarin-accented Dutch. In other words, the differences in prosody between Mandarin and Dutch naturally lead us to focus on the prosodic aspects of the Mandarin-accented Dutch.

In the present thesis, I will compare the performance of Mandarin speakers of Dutch with that of native speakers of Dutch in order to uncover the prosodic characteristics of Mandarin-accented Dutch in terms of sentence pitch accent, intonation, phrasing, pitch range, pauses, rhythm, speech rate and articulation rate.

\subsection{Chinese dialects}

Chinese is spoken in Mainland China, Taiwan, Hong Kong, Malaysia, Singapore, Vietnam, and the United States by more people than any other language in the world. Chinese has been an official language of the United Nations since the founding of the organization in 1945. Chinese speakers speak different varieties of Chinese. They all belong to the SinoTibetan family of languages and each one has its own dialects and subdialects, which are more or less mutually intelligible. The dialects of the language differ from each other in pronunciation, vocabulary and grammar. And the difference in pronunciation is the most outstanding. It is not unusual to distinguish the nine dialects of Chinese, as shown in the map in Figure 1.1. They are Wu, Min, Yue, Xiang, Gan, Jing Yu, Hui Yu, Hakka and Mandarin. 
symbols adapted from the Roman alphabet, was adopted in 1958. Its main aims are to facilitate the spread of Putonghua and the learning of Chinese characters..

China is a large country with more than a billion inhabitants, and having a common language is good for its administration as well as for cultural exchange and information transmission between ethnic groups and people in different places. More than 2000 years ago, the Chinese had realized that a common language should be used in social intercourse. Putonghua serves those purposes well and allows for efficient communication between people in different areas and from different ethnic groups. The Chinese government attaches great importance to popularizing Mandarin and encourages people to learn it. Today, it is the main language of government, the media and education in both China and Taiwan, and one of the four official languages in Singapore.

As the map in Figure 1.2 shows, Mandarin has developed into eight subdialects: Northeastern, Beijing, Ji Lu, Jiao Liao, Zhongyuan, Lan Yin, Jianghuai and Southern Mandarin. There can be variations in pronunciation, vocabulary and grammar, but the language remains understandable to people from other regions within the Mandarin area (Tang, 2009; Tang \& van Heuven; 2009).

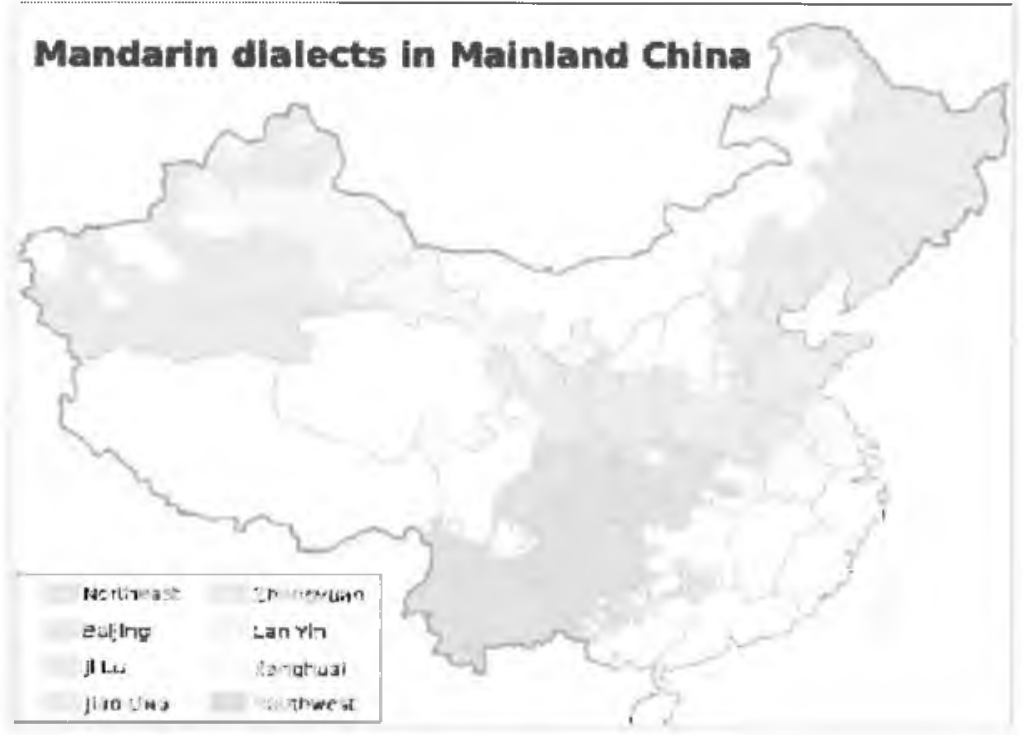

Figure 1.2. Mandarin dialects in Mainland China 
linguistic common ground and are used to facilitate communication between people from widely separated regions.

All Chinese dialects are tonal. This means that each syllable can have a number of different meanings depending on the tone with which it is pronounced. For example, Mandarin has 4 tones, (1) high level tone; (2) rising tone; (3) low dipping tone; (4) falling tone. The southern dialects have richer tone inventories than Mandarin. For example, Cantonese has between 6 and 9 tones (depending on the local dialect and in the depth of the analysis), Min between 6 and 8 and Wu between 7 and 8 (Hou, 2002).

Phonologically speaking, most Chinese in the Netherlands come from the regions of Cantonese, Min and Wu dialects, and many of them can speak or have been exposed to the Standard Chinese. We chose our participants for our experiments from the places around Beijing area in order to reduce the deviations caused by participants' dialects. Eleven of them are from Beijing, one from Tianjin, and two from Hebei. Tianjin and Hebei are very close to Beijing, so they are all Beijing Mandarin speakers. One participant grew up in Henan (Zhongyuan Mandarin) and educated in Shandong (Ji Lu and Jiao Liao Mandarin). Another one is from Xi'an (Zhongyuan Mandarin). The other four are from the northeast of China (Northern east Mandarin). That is to say, all participants in our experiments are all Mandarin speakers. As Hou (2002) put it, Mandarin speakers, though living several thousands of $L i$ away from each other (one $L i$ equals 500 metres), have no problem in communication while non-Mandarin speakers cannot understand each other even if they live only several $L i$ away. This traditional idea about intelligibility of Chinese dialects is supported by the quantitative data on mutual intelligibility of Mandarin and non-Mandarin Chinese dialects (Tang, 2009; Tang \& van Heuven, 2009). On the other hand, all participants, aged from 17 to 53, are very proficient in Putonghua (selfreport and checked by the present author in the interview before experimenting) because they received formal education in schools in Mainland China when they were young. 
$! \mathrm{H}^{*}$

$\mathrm{H}^{*} \mathrm{LH}$

Lowered level from accented syllable (downstepped level) Pre-nuclear steep fall followed by a gradual rise towards the next accented syllable (pre-nuclear fall-rise)

L delayed peak)

$\mathrm{L} * \mathrm{H} \quad$ Rise from low from accented syllable

$\mathrm{H}^{*} ! \mathrm{H} \quad$ Vocative chant

The seven nuclear pitch accents listed above (i.e. all except $\mathrm{H}^{*} \mathrm{LH}$ ) can form 21 nuclear contours in combination with the three final boundary conditions.

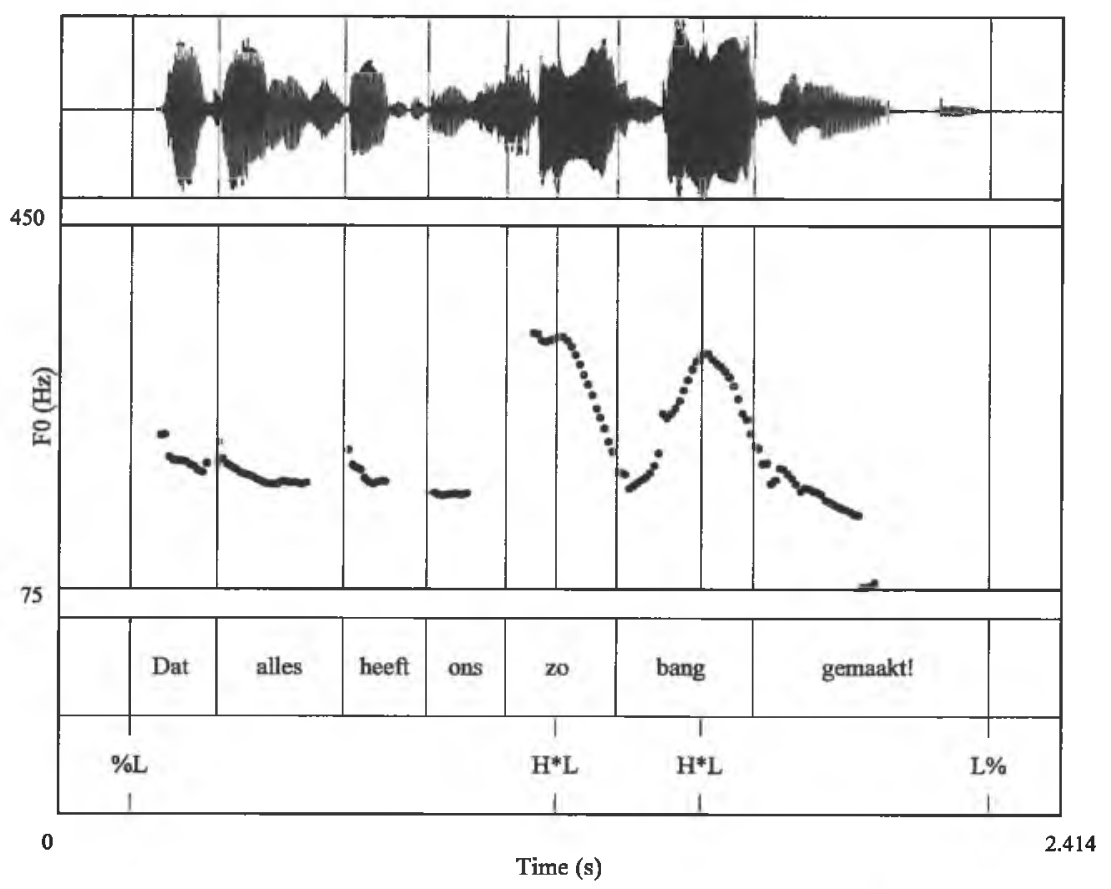

Figure 1.3. An example of Dutch sentence Dat alles heeft ons zo bang gemaakt! transcribed in ToDI.

The Fall is transcribed as $\mathrm{H}^{*} \mathrm{~L} \mathrm{~L} \%$, as in an alternative question: 
with high pitch. Functionally, the occurrence of $\mathrm{H}^{*} \mathrm{~L} \mathrm{H} \%$ may signal a question, or a reminder, or a suggestion which may have a ring of selfevidence. It often goes with toch 'not' or with modal particles bè or hoor, as in the following two examples:

\section{Je boeft niet meer te werken. Je bebt toch al genoeg gedaan deze week?

$\% \mathrm{~L} \quad \mathrm{H}^{*} \mathrm{~L} \quad \mathrm{H} \%$

You don't have to work anymore. Haven't you done enough this week?

5. Het wordt laat. Maar je moet wel je eten opeten, boor!

$\% \mathrm{~L} \quad \mathrm{H} * \mathrm{~L} \quad \mathrm{H} \%$

It's getting late. But you should finish you meal!

The IP-final high rise auditorily begins at mid pitch, which continues until a rise at the IP-boundary. The mid pitch is usually reached late in the accented syllable while the beginning is low, as is commonly the case for $\mathrm{H}^{*}$. The contour is mostly used in questions or frequently used utterance-internally to indicate that another IP follows. We transcribe it as $\mathrm{H}^{*} \mathrm{H} \%$.

\section{Zei je nou echt dat je naar buiten wilde? In de regen?

$$
\% \mathrm{~L} \quad \mathrm{H}^{*} \mathrm{H} \%
$$

Did you really say you were going to go out? In the rain?

The vocative chant consists of a high level and a mid level tone. The $\mathrm{H}^{*}$ begins on the accented syllable, and the $! \mathrm{H}$, the mid level, is realized on the last syllable, or on a stressed syllable if there is one between the accented syllable and the last syllable. The accented syllable and the syllable on which the $! \mathrm{H}$ begins are often lengthened. When the accented syllable is the last syllable, the two levels are both pronounced on that syllable, which as a result is broken into two sections. The lengthening does not occur when the level pitch of $\mathrm{H}^{*}$ is spread over more than two syllables. No lengthening is used when the contour is used to mark continuation, which sometimes occurs in instructions which the speaker wishes to sound unproblematic. The vocative chant is also used on utterances with an early accent in which case each of the following 
consonant and vowel contrasts that are not present in the ambient languages, but they lose the ability and can only distinguish the contrasts of their native language like adults by the end of the first year when they can produce the first words due to the exposure to the native language (Kuhl \& Iverson, 1995). The language-specific phonetic perception is robust and automatic because adults require few cognitive resources to extract the phonetic information from the acoustic signal (Fikkert, 2007; Ohala, 2008; Strange \& Shafer, 2008).

As a result, for almost all late $\mathrm{L} 2$ learners, their oral production is foreign accented. We do not know whether L2 learners have difficulty in perceiving the phonological features, such resulting in the foreign accents in their production. It is generally thought that a major determinant of the foreign accent in production is the underlying problem in perceiving the L2 phonological structures (Flege, 1995). If learners cannot hear given contrasts the way native speakers do, the perceptual problems will cause problems in pronunciation. They sometimes have more difficulty perceiving the difference in an L2 sound which is relatively close to a sound in L2 than a new sound in L2 which is completely distinct from any sound in the L1 inventory (Best, 1995; Flege, 1995). Native Japanese listeners with different learning experience are found to have extreme difficulty in producing the English consonant contrast $/ r / \sim / 1 /$ and to perform significantly poorer than the native English speaker in judging in a variety of stimulus materials and tasks (Bradlow, 2008; Strange \& Shafer, 2008). However, not all mispronunciation is caused by erroneous perception. For articulatory reasons, L2 learners may not produce certain contrasts though they perceive accurately their representation in the L2. But in some studies, L2 sound production was found to surpass perception (Bohn \& Flege, 1996; Brière, 1966; Gass, 1984; Kluge et al. 2007; Neufeld, 1988; Sheldon \& Strange, 1982; Strange, 1995), indicating that production of L2 sounds can be more accurate than perception. For example, the ability for many Japanese learners of English to produce the English $/ \mathrm{r} / \sim / 1 /$ contrast accurately was stronger than the ability to perceive them, particularly in the early stages of acquisition (Yamada, Strange, Magnuson, Pruitt \& Clarke, 1994). Pedagogically, leamers' perceptual skills may be as important as their production ability. Studies have shown that perceptual training can improve production (Chun, Hardison \& Pennington, 2008). The relation between perception and production is too complex to make a straight-forward conclusion that production precedes perception, or 
Actually, CA has seen a resurgent interest and importance in second language acquisition research since the 1980s (Major, 2008).

Besides the linguistic transfers, L1 skills can also transfer into L2 learning and proficiency. In a recent study by Sparks, Patton, Ganschow and Humbach (2009), high school students transferred their L1 English skills in reading, spelling, vocabulary, phonological awareness and listening comprehension to L2 Spanish, French or German, and their early L1 skills played an important role in their L2 attainment.

Transfer plays different roles in different theories or models of phonological acquisition, which can be seen from the following theories or models.

\subsubsection{Best's PAM}

The Perceptual Assimilation Model (PAM) (Best, 1993, 1994a, 1994b, 1995; Best, McRoberts \& Sithole, 1988) employs the metaphor of a phonological space in which native categories (gestural constellations) are arrayed according to similarities/differences in their articulatoryphonetic structure. PAM was developed primarily to account for patterns of nonnative segmental perception by naive listeners with no experience with the L2. Best \& Tyler (2007) later extended the PAM to predict patterns of speech perception by more advanced L2 learners (PAM-L2). It incorporates a combination of perception and production factors. In the very early stages of language acquisition, an infant establishes categories for native language sounds by learning to articulate them. Once the categories have been established, phonemic categories that are non-native will be assimilated to native categories on the basis of perceived similarities.

There are six possible assimilation scenarios in this model, depending on how each member of a non-native contrast is assimilated into native categories: Two-Category (TC) contrasts, where each member is assimilated into a different native category; Single-Category (SC) contrasts, where both members are assimilated into a single native category (equally well or poorly); Category-Goodness (CG) contrasts, where both members are assimilated into the same native category but with one being a closer match to that category; Uncategorized- 
sound, the prototype forces the learner to perceive the new sound as the L1 prototype.

The model also predicts the difficulty in discrimination of L2 sound contrasts. Under the proximity principle (Kuhl, 1991), the accuracy to discriminate more prototypical exemplars of a phonetic category is lower than that to discriminate less prototypical exemplars. The difficulty in discriminating L2 sound contrasts increases as the similarity to L1 sounds increases.

The explanatory power of the model was challenged in some studies (Lacerda, 1995; Lively \& Pisoni, 1997), but the influence of early language experience on the L2 sound perception cannot be denied.

\subsubsection{Flege's SLM}

Flege's (1995, 1999, 2002) Speech Learning Model (SLM) consists of four postulates and seven hypotheses to account for age-related pronunciation of vowels and consonants in an L2. The four postulates are: (i) The mechanisms and processes used in learning the $\mathrm{L} 1$ sound system, including category formation, remain intact over the life span and can be applied to L2 learning; (ii) Language-specific aspects of speech sounds are specified in long-term memory representations called 'phonetic categories'; (iii) Phonetic categories established in childhood for L1 sounds evolve over the life span reflect the properties of all L1 and L2 phones identified as a realization of each category; (iv) Bilinguals strive to maintain contrast between L1 and L2 phonetic categories, which coexist in a common phonological space. The four postulates mean that speakers use the same cognitive resources in L1 and L2 learning, share and have mental representations of the contrastive sounds of their native language, and can create new categories in L1 and modify them in L2 acquisition though they strive not to mix the categories in L1 and L2. The acquisition of L2 sounds that do not exist in their L1 is to establish new categories and the categories in L1 work as filters in the L2 phonological acquisition.

The seven hypotheses in SLM predict the preconditions and stages of phoneme acquisition. The mechanisms needed to produce new sounds remain intact, but perception changes with development. Language 
means the evolutionary development of groups of organisms. Similarly, when they are borrowed into language, the former means the life cycle of an individual's language and the later the life cycle of all languages and language types (Major, 1994, 1996, 2001; Major \& Faudree, 1996). So OPM deals with both individual and evolutionary development of languages. It incorporates markedness and predicts longitudinal phonological acquisition of L2 or dialects by individuals or groups of speakers over generations. It holds that an interlanguage is composed of elements of L1, the required L2 and universals. If L2 acquisition increases, L1 transfer decreases, and universals increase and then decrease. For similar phenomena in L1 and L2, L2 acquisition proceeds slowly, transfer persists, and consequently the role of universals gets relatively small, compared to the norm which is neither similar nor marked. For marked phenomena, L2 acquisition increases slowly; L1 transfer decreases slowly, while the influence of universals increases rapidly and then decreases slowly. Different from the other models, individuals' difference, social and demographic factors affecting L2 phonology are considered important in this model.

OPM was supported in the studies on the acquisition of phonemes and syllable structure, however, no evidence was found to support the claim L1 transfer decreases with increasing degree of L2 formality of speech style. The model can be applied not only in phonological acquisition but also in non-phonological fields. However, 'universals' are not clearly defined and the interrelation of the three proposed elements in interlanguage remains open to speculation. Nor does OPM offer a psycholinguistic account for how L2 phonological learning takes place over time during which the learning is considered as progressing from non-target to target $\mathrm{L} 2$ forms through variable performance by trial and error (Trofimovich, Gatbonton \& Segalowitz, 2007). Though nonlinguistic factors are considered important in the model, it does not specify how such factors influence learning over time.

\subsubsection{Eckman's MDH and SCH}

The difference between L1 and L2 is insufficient to explain the learner error, and should be supplemented by the explanatory principle of typological markedness. Eckman's (1977, 1984, 1985, 2008) Markedness Differential Hypothesis (MDH) states that a structure $\mathrm{A}$ is more marked 
Both $\mathrm{MDH}$ and $\mathrm{SCH}$ claim that learners have fewer difficulties and proceed faster in acquisition of unmarked patterns than in the acquisition of marked ones. Due to their scope and explanatory power, the limitation of both hypotheses can be seen. Relying on the concept of linguistic universals, their scope is restricted to linguistic areas such as syllable structures or the frequency of segmental speech sounds for which linguistic universals have been proposed. Other phonological features, phonological process and the prosodic phenomena have not been classified in term of typological markedness, so the two hypotheses cannot predict acquisition phenomena in those fields. Non-linguistic factors influencing phonological acquisition are not put into consideration.

\subsubsection{Optimality Theory}

Since Prince and Smolensky's seminal manuscript on Optimality Theory (O'T) was introduced in 1993, numerous efforts have been made to test and develop the theory in the areas of phonology, syntax and discourse studies. Phonology is greatly impacted by the theory and applied linguists have begun to adopt an OT approach to understand observed phenomena in L2 phonological acquisition, though most of the studies focus on L2 syllable structure (Hancin-Bhatt, 2008).

OT grammars consist of a universal set of constraints divided into two subgroups: Markedness and Faithfulness. The Markedness constraints are generalizations on the marked and unmarked patterns in a language. Linguistic patterns that commonly occur in natural languages are unmarked and those that do not are marked. Faithfulness constraints ensure the congruence between patterns in the input and those in the output. The two types of inherently conflicting constraints can be violable, and ranked relatively to each other. The higher the ranking of a constraint is, the more serious its violation. The candidate in the outputs which has the least serious constraint violations is the most optimal and wins. The constraint rankings are language-specific, so acquisition is to learn the constraint rankings that hold for the target language (Boersma, 1998; Hancin-Bhatt, 2008). In the OT framework, L2 acquisition starts from the existing L1 constraint ranking and then proceeds from the least marked to the most marked rankings. Transfer takes place from L1 ranking, but patterns that are like neither L1 nor L2 are the result of 


\begin{tabular}{|c||c|c|c|}
\hline$/$ vig/ & NO VOICED OBS CODA & MAX, DEP & IDENT (VOI) \\
\hline \hline vig & $* !$ & & \\
\hline vi $<\mathrm{g}>$ & & ${ }^{*} !$ & \\
\hline vi.gE & & ${ }^{*} !$ & \\
\hline vik & & & ${ }^{*}$ \\
\hline
\end{tabular}

OT takes interlanguage grammars as natural and dynamic systems which can accommodate new inputs and as the consequence of L1 influence and markedness effects. By the re-ranking the constraints, the interlanguage development can be explained without any other extra special rules.

Though the above models or theories are all based upon the studies on segmentals, they can be employed to explain the suprasegmental or prosodic acquisition. Theoretically, both segmental and suprasegmental learning may be driven by similar learning mechanisms (Pierrehumbert, 2003) and may be influenced by common factors (Trofimovich \& Baker, 2006; Wang, Spence, Jongman \& Sereno, 1999). Since they intend to explain some phenomenon in certain aspects, it would be partial to explain all phenomena by exploiting any of them individually due to their respective limitations. Interlanguage is the interactive result of the linguistic factors (L1, L2, universals and transfer) and non-linguistic factors like the individual differences of learners (linguistic aptitude, age of learning, length of residence, motivation and other social factors).

\subsubsection{The age issue}

Age is a crucial variable in the second language acquisition, especially in pronunciation (Flege, Yeni-Komshian \& Liu, 1999; Ioup 1984). Previous studies confirm that later learners are not likely to achieve native-like pronunciation and show that native-like L2 phonology is normally found only with a very early onset of L2 learning; the likelihood to be nativelike diminishes as the onset age increases. As Lenneberg (1967) predicted in his critical period hypothesis (CP), the end of neural plasticity and the completion of hemispheric lateralization of human brain at puberty results in a decline of the ability to pronounce foreign languages in a native-like fashion. Of the early Spanish learners of Swedish in a large- 
to have detectable accents in their L2. Except the continued use of L1, some other individual differences contributed to the learner's foreign accent. These are the amount of L2 use, length of residence, target language input, instruction or training, attitude, the cognitive variables of field independence and right hemispheric specialization, social identity and aptitude (Abrahamsson \& Hyltenstam, 2008; Ioup, 2008). Due to such individual differences, some adults may be judged more native-like than others and can even outperform children. Though it is still a hot debate whether biological factors or non age-related individual differences lead to foreign accents, Ioup (2008: 57) concluded that "by and large both the nature of the accent and the degree to which it is manifest is influenced primarily by the age at which language acquisition began".

\subsection{Structure of the thesis}

The present Chapter 1 has sketched the research background and identified relevant issues to the present research on the phonology. Chapters 2 and 3 will describe two perception tests.

Chapter 2 is on pitch accent location. A set of sentences were presented in two versions, each with a different location of the pitch accent, one correct and one incorrect, as informed by different linguistic generalizations. The purpose of the test is to study how well Chinese learners of Dutch identify the correct accentuation pattern in Dutch sentences in a forced choice decision task.

Chapter 3 deals with melody choice. An 'ideal' reading of the fable Winterkoninkje was divided into 26 fragments and produced naturally with a number of alternative 'incorrect' intonations. Each fragment was presented to a group of 20 native Dutch and 20 Chinese-Dutch listeners with four intonation contours. One of these was the intended best intonation contour, and the other three were intended as less felicitous versions with different melodies. Working chronologically through the story, the participants listened to the four versions of each fragment and its preceding context as often as they wished, and then selected the best contour for each fragment. The hypothesis is that Dutch listeners show greater agreement in carrying out this task than Chinese listeners. 


\subsection{References}

Abrahamsson, N. \& Hyltenstam, K. (2008). The robustness of aptitude effects in near-native second language acquisition. Studies of Second Language Acquisition, 30, 481-509.

Abrahamsson, N. \& Hyltenstam, K. (2009). Age of onset and nativelikeness in a second language: listener perception versus linguistic scrutiny. Language Learning, 59, 249-306.

Anderson, J. (1987). The markedness differential hypothesis and syllable structure difficulty. In G. Ioup \& S. Weinberger (Eds.), Interlanguage Phonology: The Acquisition of a Second Language Sound System (pp. 279291). New York: Newbury House/Harper \& Row.

Anderson-Hsieh, J., Johnson, R. \& Koehler, K. (1992). The relationship between native speaker judgements of non-native pronunciation and deviance in segmentals, prosody and syllable structure. Language Learning, 42, 529-555.

Aoyama, K., Flege, J. E., Guion, S. G., Akahane-Yamada, R. \& Yamada, T. (2004). Perceived phonetic dissimilarity and L2 speech learning: The case of Japanese / $\mathrm{r} /$ and English /1/. Journal of Phonetics, 32, 233-250.

Aoyama, K. \& Guion, S. G. (2007). Prosody in second language acquisition. Acoustic analyses of duration and F0 range. In O-S. Bohn \& M. J. Munro (Eds.), Language experience in second language Learning: In bonor of James Emil Flege (pp. 281-297). Amsterdam: John Benjamins.

Archibald, J. A. (1994). A formal model of learning L2 prosodic phonology. Second Language Research, 10, 215-240.

Asher, J. \& Garcia, R. (1969). The optimal age to learn a foreign language. Modern Language Journal, 53, 1219-1227.

Ausubel, D. P. (1963). The psychology of meaningful verbal learning. New York: Grune \& Stratten.

Beckman, M. E. \& Ayers, G. M. (1994). Guidelines for ToBI Labelling. Unpublished manuscript, Ohio State University. [the English ToBI homepage at http://ling.ohio-state.edu/Phonetics/main.mod.html].

Beckman, M. E., Hirschberg, J. \& Shattuck-Hufnagel, S. (2005). The original ToBI system and the evolution of the ToBI framework. In S.-A. Jun (Ed.), Prosodic Typology: The Pbonology of Intonation and Pbrasing (pp. 9-54). Oxford: Oxford University Press.

Best, C. T. (1993). Emergence of language-specific constraints in perception of non-native speech contrasts: A window on early 
Brière, E. (1966). An investigation of phonological interference, Language, $42,769-796$.

Broselow, E., Chen, S. \& Wang, C. (1998). The emergence of the unmarked. Studies in Second Language Acquisition, 20, 261-280.

Chen, H. (2008). On Chinese EFL learner's English intonation pattern. Shanghai: Shanghai Foreign Language Education Press.

Chun, D. M., Hardison, D. M. \& Pennington, M. C. (2008). Technologies for prosody in context: Past and future of L2 research and practice. In J. G. Hansen Edwards \& M.L. Zampini (Eds.), Phonology and second language acquisition (pp. 322-346). Amsterdam: John Benjamins.

Chinese Academy of Social Sciences \& Australian Academy of the Humanities. (1990). Language Atlas of China. Hong Kong: Hong Kong Longman Press.

Derwing, T.M. \& Munro, M. J. (1997). Accent, intelligibility, and comprehensibility: Evidence from four L1s. Studies in Second Language Acquisition, 19, 1-16.

Derwing, T.M., Munro, M. J. \& Wiebe, G. (1998). Evidence in favor of a broad framework for pronunciation. Language Learning, 48, 393-410.

Derwing, T. M. \& Rossiter, M. J. (2003). The effects of pronunciation instruction on the accuracy, fluency, and the complexity of L2 accented speech. Applied Language Learning, 13, 1-17.

Eckman, F. R. (1977). Markedness and the contrastive analysis hypothesis. Language Learning, 27, 315-350.

Eckman, F. R. (1984). Universals, typologies and interlanguage. In W. Rutherford (Ed.), Language universals and second language acquisition (pp. 79-105). Amsterdam: John Benjamins.

Eckman, F. R. (1985). Some theoretical and pedagogical implications of the Markedness Differential Hypothesis. Studies in Second Language Acquisition, 7, 289-307.

Eckman, F. R. (1991). The Structural Conformity Hypothesis and the acquisition of consonant clusters in the interlanguage of ESL learners. Studies in Second Language Acquisition, 13, 23-41.

Eckman, F. R. (2008). Typological markedness and second language phonology. In J. G. Hansen Edwards \& M. L. Zampini (Eds.), Phonology and second language acquisition (pp. 95-115). Amsterdam: John Benjamins.

Fikkert, P. (2007). Acquiring phonology. In P. de Lacy (Ed.), Handbook of phonological theory (pp. 537-554). Cambridge: Cambridge University Press. 
Flege, J., Munro, M. \& MacKay, I. (1995). Factors affecting degree of perceived foreign accent in a second language. Journal of the Acoustical Society of America, 97, 3125-3134.

Flege, J., Schirru, C. \& MacKay, I. (2003). Interaction between the native and second language phonetic subsystems. Speech Communication, 40, $467-491$.

Flege, J., Yeni-Komshian, G. \& Liu, S. (1999). Age constraints on second language learning. Journal of Memory and Language, 41, 78-104.

Fries, C. C. (1945). Teacbing and learning English as a foreign language. Ann Arbor: University of Michigan Press.

Gass, S. (1984). Development of speech perception and speech production in adult second language learners. Applied Psycholinguistics, $5,51-74$.

Gussenhoven, C. (2005). Transcription of Dutch intonation. In Sun-Ah Jun (Ed.), Prosodic Typology: The Phonology of Intonation and Phrasing (pp. 118-145). Oxford: Oxford University Press.

Gussenhoven, C., Rietveld, A., Kerkhoff, J. \& Terken, J. (2002). Transcription of Dutch Intonation. Second Edition.

$<$ http://todi.let.kun.nl/>

Guion, S. G., Flege, J. E., Liu, S. H. \& Yeni-Komshian G. H. (2000). Age of learning effects on the duration of sentences produced in a second language. Applied Psycholinguistics, 21, 205-228.

Gut, U. (2000). On the acquisition of rhythmic structure. Proceedings of New Sounds 2000, Amsterdam, The Netherlands, 148-154.

Gut, U. (2003). Non-native speech thythm in German. Proceedings of the $15^{\text {th }}$ International Congress of Phonetic Sciences, Barcelona, Spain, 24372440.

Gut, U. (2005). Nigerian English prosody. English World-Wide, 26, $153-$ 177.

Gut, U. (2009). Non-native speech. Frankfurt: Peter Lang.

Hagen, M., Kerkhoff, J. \& Gussenhoven, C. (2011). Singing your accent away, and the way it works. Proceedings of the $17^{\text {th }}$ International Congress of Phonetic Sciences, Hong Kong, 799-802.

Hanci-Bhatt, B. (2008). Second language phonology in Optimality Theory. In J. G. Hansen Edwards \& M. L. Zampini (Eds.), Phonology and second language acquisition (pp.117-146). Amsterdam: John Benjamins.

Hansen Edwards, J. G. (2008). Social factors and variation in production in L2 phonology. In J. G. Hansen Edwards \& M. L. Zampini (Eds.), 
Kuhl, P. K. (2000). A new view of language acquisition. Proceedings of the National Academy of Sciences, 97, 11850-11857.

Kuhl, P. K. \& Iverson, P. (1995). Linguistic experience and the "perceptual magnet effect". In W. Strange (Ed.), Speech perception and linguistic experience: Issues in cross-language research (pp.121-154). Timonium, MD: York Press.

Lacerda, F. (1995). The perceptual-magnet effect: An emergent consequence of exemplar-based phonetic memory. In K. Elenius \& P. Branderud (Eds.), Proceedings of the 13th International Congress of Phonetic Sciences, Vol. 2, Stockholm, 140-147.

Lado, R. (1957). Linguistics across cultures. Ann Arbor: Universtity of Michigan Press.

Lenneberg, E. (1967). Biological foundation of language. New York: John Wiley \& Son.

$\mathrm{Li}$, Minghuan. (1999). We need two worlds: Cbinese immigration association in a western society. Amsterdam: Amsterdam University Press.

Lively, S. E. \& Pisoni, D. B. (1997). On prototypes and phonetic categories: A critical assessment of the perceptual magnet effect in speech perception. Journal of Experimental Psychology: Human Perception and Performance, 23, 1665-1679.

Llisterri, J. (1995). Relationships between speech production and speech perception in a second language. In K. Elenius \& P. Branderud (Eds.), Proceedings of the 13th International Congress of Phonetic Sciences, Vol. 4, Stockholm, 92-99.

Magloire, J. \& Green, K. P. (1999). A cross-language comparison of speaking rate effects on the production of voice onset time in English and Spanish. Phonetica, 56, 158-185.

Major, R. C. (1986). The ontogeny model: Evidence from L2 acquisition of Spanish. Language Learning, 36, 453-503.

Major, R. C. (1992). Losing English as a first language. The Moderm Language Journal, 76, 190-208.

Major. R. C. (1994). Chronological and stylistic aspects of Brazilian Portuguese, Language Learning, 36, 453-504.

Major. R. C. (1996). Markedness in second language acquisition of consonant clusters, In R. Bayley \& D. Preston (Eds.), Second Language Acquisition and Linguistic Variation (pp. 75-96). Amsterdam: John Benjamins.

Major. R. C. (2001). Foreign accent: The ontogeny and phylogeny of second language bomology. Mahwah, NJ: Lauwrence Erlbaum Associates. 


\section{MANDARIN-ACCENTED DUTCH PROSODY}

Een wetenschappelijke proeve op het gebied van de Letteren

\section{Proefschrift}

ter verkrijging van de graad van doctor aan de Radboud Universiteit Nijmegen

op gezag van de rector magnificus prof. mr. S.C.J.J. Kortmann, volgens besluit van het College van Decanen in het openbaar te verdedigen op 3 december 2012 om 10.30 uur precies

door

$$
\text { Xuliang He }
$$

geboren op 9 augustus 1971

te Huanggang, provincie Hubei, China 
Promotiecommissie

Promotores: $\quad$ Prof. dr. C. H. M. Gussenhoven

Prof. dr. V. J. J. P. van Heuven

(Leiden University)

Overige leden: $\quad$ Prof. dr. A. H. Neijt (chair)

Prof. dr. J. Peters

(Oldenburg University, Germany)

Prof. dr. Hua Chen

(Nanjing University, China) 


\section{Acknowledgements}

At the final phase of the writing, I find it difficult to write this part. I am indebted to so many people that I do not know how to express my gratitude to them in words. They lent me a helpful hand on many occasions and in different manners. Without their generous help, finishing the project would not have been possible.

To begin with, I would like to Professor Hua Chen, who first led me into the field of phonological acquisition and encouraged me to apply for a Ph.D. position at Radboud University Nijmegen. I am also most grateful to my dissertation supervisors. I greatly appreciate Professor Carlos Gussenhoven's support from the very beginning until the end of this project. I am grateful for the time he patiently spent checking the labellings and reading my work, and for always being ready to offer his guidance when needed. I am grateful to my second supervisor, Professor Vincent van Heuven for his patient guidance, revision of papers and for statistical help.

I am also thankful to Professor Anneke Neijt, Professor Jörg"Peters and Professor Hua Chen for being willing to serve as members of my manuscript committee and for their valuable comments.

I also benefited from discussions with colleagues in the phonology group. I thank Judith Hanssen for her preparation of the Dutch corpus, the Dutch data and her recordings for the experiments. I thank Joop Kerkhoff for technical support. I thank Professor Jörg Peters for his adaption of the story 't Winterkoninkje, which I used in the second perception experiment. I am thankful to Professor Roeland van Hout and Dr. Frans van der Slik for their statistical help. I am grateful to all of the participants who agreed to take part in my experiments, and not only for their participation, but also for taking a genuine interest.

I would like to express my thanks to my two supervisors and Professor Anneke Neijt for judging the Dutch proficiency of Chinese participants. I would like to thank my colleagues in the secretary's office of the Linguistics Department of Radboud University Nijmegen: Hella, Christel, 
and Wies, who were always warm-hearted and resourceful. I would like to thank the Faculty of Arts of the university for their financial support, which allowed me to attend workshops, linguistic schools and academic conferences all over the country and the world. This gave me a great deal of academic and linguistic experience and contributed directly to the development of this dissertation.

I got help from Dr. Yi Xu, who generously gave me his Chinese research data of four tones. Dr. Johanneke Caspers sent me several papers which I needed in the writing the thesis. I am very grateful to them.

I am thankful to people with whom I could talk about the work on different occasions at work or at conferences, so that I was able to clarify my ideas. For that I especially thank: Yan Gu, Ishmael Kimirei, Rongjia Cui, Wencui Zhou and Liusheng Wang.

As grateful as I am for the help of all those mentioned above, none of them is to be blamed for the flaws in this dissertation.

Last but not least, I would like to thank my family. I could not have done this without the constant love, support and encouragement from my wife, parents and siblings.

This project was part of the research programme Intonation in Varieties of Dutch, awarded by the Netherlands Organisation for Scientific Research (NWO project number 36070-180), and was co-funded by the Arts Faculty of Radboud University Nijmegen. 


\section{Preface}

Language is mysterious.

In 2003, I went to work in Nantong University, which borders on the Wu and Jianghuai Mandarin Dialect areas, after I had completed my three-year MA programme in Xi'an, a city in the north-west of the Zhongyuan Dialect area. When I talked with the students there, they assumed I was from the northern part of China, because they thought I spoke with a northern accent. But I spoke, or intended to speak, in the Standard Chinese pronunciation (Putonghua). During my stay in Xi'an, I had been told I spoke with a strong southern accent. When the teacher of a course in 'translation' commented on a presentation of mine, he said my English was easier to understand than my Chinese. After having been away for about ten years from my hometown - a small town whose dialect is influenced by Jianghuai Mandarin and the Gan Dialect - my relatives teased me, because I could not speak the local dialect well enough when I visited my relatives in my hometown. How mysterious language is! Language intrigued me. At that time, I dreamed of studying speech and uncovering its mysterious veil someday.

Luckily enough, Professor Hua Chen, the first Chinese scholar who applied modern computer technology to the study of how Chinese learners speak English, introduced me to the field of phonological acquisition. Enlightened by the literature on phonetics and phonology she gave to her work team, I began to work for her research project. Later, I got the Ph.D. position in the Netherlands to work on the subprogramme 'Mandarin-accented Dutch' of the research programme 'Intonation of Varieties of Dutch' (NWO 360-70-180, 2006-2010) with Professor Carlos Gussenhoven as the principal investigator.

In the sub-programme, I studied the prosody in Dutch by Chinese speakers who live in the Netherlands but originally hailed from areas of Mandarin dialects in Mainland China. Geographically, they are from places around Beijing. The research questions are: How do they accentuate words in Dutch sentences? How do they produce different 
intonation contours some of which do not exist in Mandarin? Do speakers of Mandarin, a tone language, transfer their native-language (L1) knowledge to their target language (L2) Dutch? Do learners with higher proficiency in Dutch perform better than the ones with lower proficiency? Are the findings in line with previous findings in this general field? Five experiments (two perception tests and three production tests) were designed to answer the questions. Chapter 2 and Chapter 3 give an account of the two perception tests. The former is on pitch accents in Dutch sentences and the latter is on the acceptability of Dutch intonation patterns in a fable for children. Chapter 4, 5 and 6 describe the three production tests. Chapter 4 deals with unconstrained readaloud production intended to study melodic choices. Chapters 5 and 6 are about controlled speech production after a brief training session before recording. Chapter 5 studies the phonetic strategies adopted by speakers in the production of melodies ( $\mathrm{H}^{*} \mathrm{~L} \mathrm{~L} \% ; \mathrm{L} * \mathrm{H} \mathrm{H} \% ; \mathrm{H}^{*} \mathrm{~L} \mathrm{H} \%$ ) under time pressure created by phonologically different vowels and codas. Chapter 6 studies the effects of three types of focus (broad focus, narrow focus, and corrective focus) in falling intonation contours $\left(\mathrm{H}^{*} \mathrm{~L}\right.$ $\mathrm{L} \%$ ). The last chapter is the summary.

Though I have finished the project, I do not feel I removed the mysterious veil, even though I may have lifted one of two corners. I still have long way to go. 


\section{Acknowledgements}

At the final phase of the writing, I find it difficult to write this part. I am indebted to so many people that I do not know how to express my gratitude to them in words. They lent me a helpful hand on many occasions and in different manners. Without their generous help, finishing the project would not have been possible.

To begin with, I would like to Professor Hua Chen, who first led me into the field of phonological acquisition and encouraged me to apply for a Ph.D. position at Radboud University Nijmegen. I am also most grateful to my dissertation supervisors. I greatly appreciate Professor Carlos Gussenhoven's support from the very beginning until the end of this project. I am grateful for the time he patiently spent checking the labellings and reading my work, and for always being ready to offer his guidance when needed. I am grateful to my second supervisor, Professor Vincent van Heuven for his patient guidance, revision of papers and for statistical help.

I am also thankful to Professor Anneke Neijt, Professor Jörg Peters and Professor Hua Chen for being willing to serve as members of my manuscript committee and for their valuable comments.

I also benefited from discussions with colleagues in the phonology group. I thank Judith Hanssen for her preparation of the Dutch corpus, the Dutch data and her recordings for the experiments. I thank Joop Kerkhoff for technical support. I thank Professor Jörg Peters for his adaption of the story 't Winterkoninkje, which I used in the second perception experiment. I am thankful to Professor Roeland van Hout and Dr. Frans van der Slik for their statistical help. I am grateful to all of the participants who agreed to take part in my experiments, and not only for their participation, but also for taking a genuine interest.

I would like to express my thanks to my two supervisors and Professor Anneke Neijt for judging the Dutch proficiency of Chinese participants. I would like to thank my colleagues in the secretary's office of the Linguistics Department of Radboud University Nijmegen: Hella, Christel, 
and Wies, who were always warm-hearted and resourceful. I would like to thank the Faculty of Arts of the university for their financial support, which allowed me to attend workshops, linguistic schools and academic conferences all over the country and the world. This gave me a great deal of academic and linguistic experience and contributed directly to the development of this dissertation.

I got help from Dr. Yi Xu, who generously gave me his Chinese research data of four tones. Dr. Johanneke Caspers sent me several papers which I needed in the writing the thesis. I am very grateful to them.

I am thankful to people with whom I could talk about the work on different occasions at work or at conferences, so that I was able to clarify my ideas. For that I especially thank: Yan Gu, Ishmael Kimirei, Rongiia Cui, Wencui Zhou and Liusheng Wang.

As grateful as I am for the help of all those mentioned above, none of them is to be blamed for the flaws in this dissertation.

Last but not least, I would like to thank my family. I could not have done this without the constant love, support and encouragement from my wife, parents and siblings.

This project was part of the research programme Intonation in Varieties of Dutch, awarded by the Netherlands Organisation for Scientific Research (NWO project number 36070-180), and was co-funded by the Arts Faculty of Radboud University Nijmegen. 


\section{Contents}

PREFACE vii

\section{INTRODUCTION}

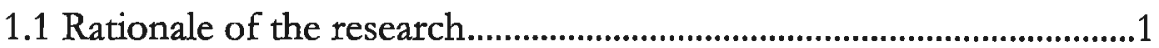

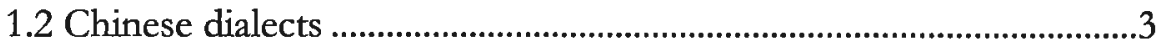

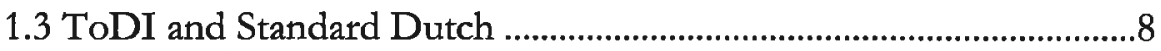

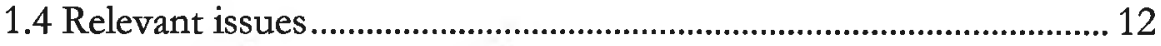

1.4.1 Perception and production....................................................... 13

1.4.2 Models of phonological acquisition ............................................... 14

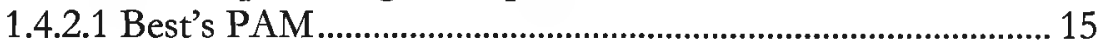

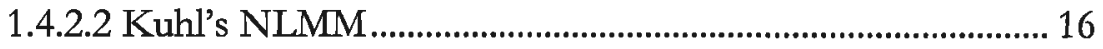

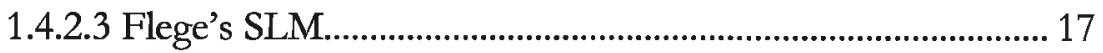

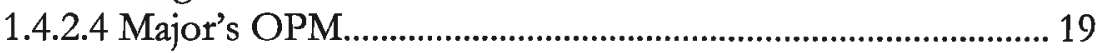

1.4.2.5 Eckman's MDH and SCH ................................................ 20

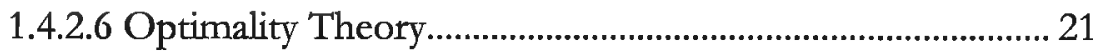

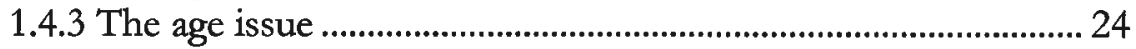

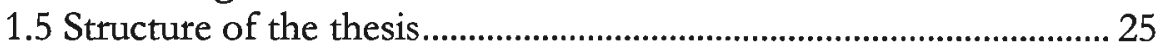

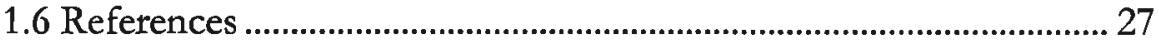

2 Choosing THE OPTIMAL PITCH ACCENT LOCATION IN DUTCH ..... 37

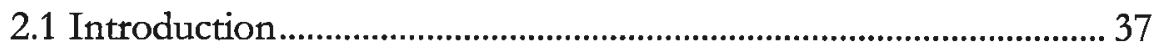

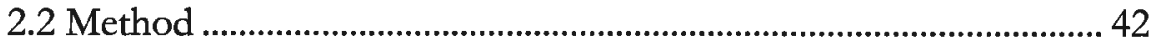

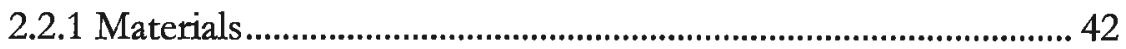

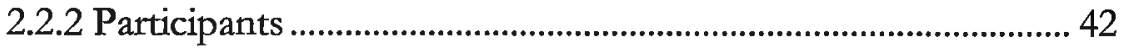

2.2.2.1 General information ............................................................. 42

2.2.2.2 Proficiency ratings ................................................................. 43

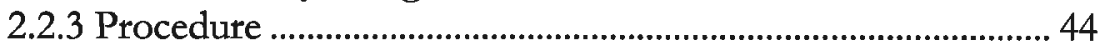

2.3 Data analysis and discussion ................................................................. 44

2.3.1 Analysis and discussion of correctness scores .......................... 44

2.3.2 Analysis and discussion of confidence scores............................. 49

2.3.3 Other factors correlated with correctness scores and

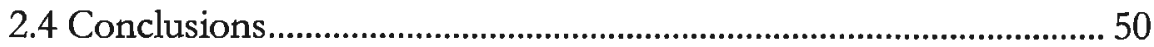

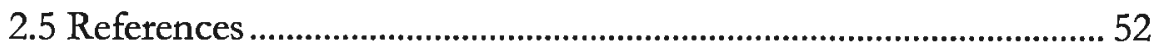


3 THE SELECTION OF INTONATION CONTOURS BY CHINES SPEAKERS OF DUTCH: ORTHOGRAPHIC CLOSURE VS PROS KNOWLEDGE

\subsection{Introduction}

3.1.1 Intonation in West Germanic languages and tones i

3.1.2 Research on prosodic production and perception

3.1.3 Research questions.

3.2 Method

3.2.1 Material

3.2.2 Participants

3.2.3 Procedure

3.3 Data analysis

3.3.1 Overall analysis

3.3.2 An orthographic strategy....

3.3.3 Overall contour preferences

3.3.4 Correlations with speaker variables

3.4 Conclusions

3.5 References.

4 A PROSODIC ANALYSIS OF MANDARIN-ACCENTED DUTCH INTONATIONAL IDIOMS

4.1 Introduction.

4.2 Phrasing

4.3 Pitch range

4.4 Speech rhythm.

4.5 Speech rate and articulation rate

4.6 Pitch accents

4.7 Intonation contours

4.2 Method

4.2.1 Materials

4.2.2 Procedure.

4.2.2.1 Subjects

4.2.2.2 Labellings

4.2.2.3 Variables

4.3 Results.

4.3.1 Phrasing

4.3.2 Pitch range.

4.3.3 Speech rate and articulation rate

4.3.4 Speech rhythm 


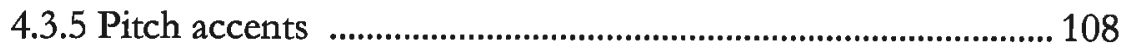

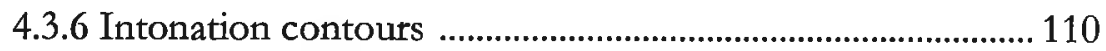

4.3.6.1 Analyses of nuclear contours ............................................. 110

4.3.6.2 Nuclear accent errors and boundary tone errors ............ 116

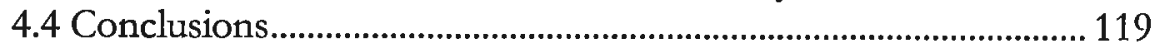

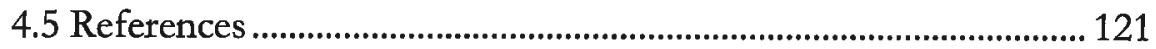

5 MANDARIN-ACCENTED FALL, RISE AND FALL-RISE F0 CONTOURS

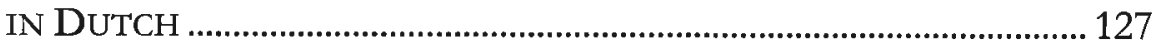

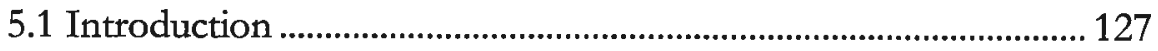

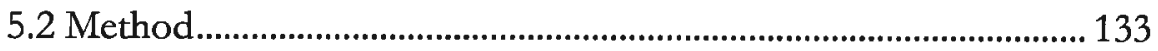

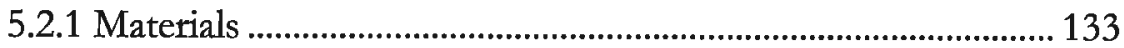

5.2.2 Subjects .......................................................................................... 134

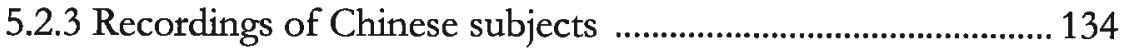

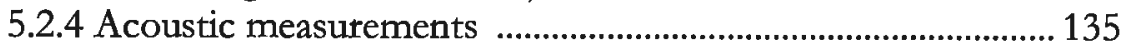

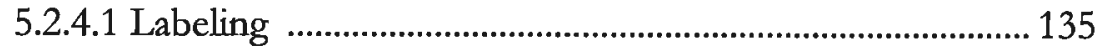

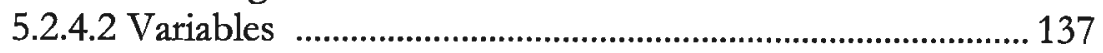

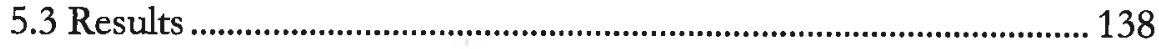

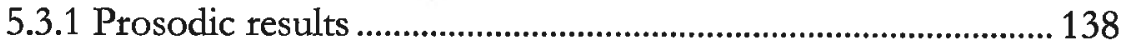

5.3.2 Sonorant rime comparisons ................................................... 139

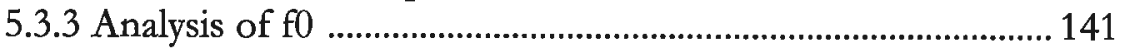

5.3.3.1 Peak alignments in Fall, Rise and Fall-rise........................ 148

5.3.3.2 Comparison of excursions of Fall, Rise and Fall-rise ...... 150

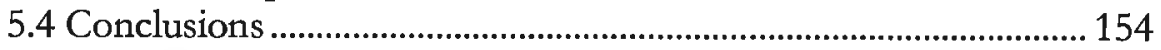

5.5 References ................................................................................... 157

6 PROSODIC EFFECTS OF FOCUS IN DUTCH DECLARATIVES

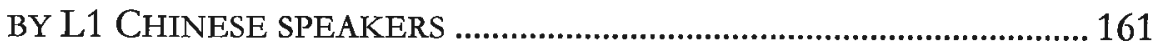

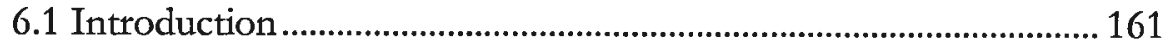

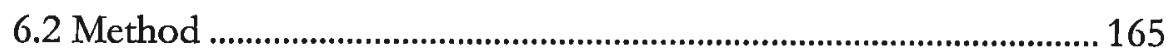

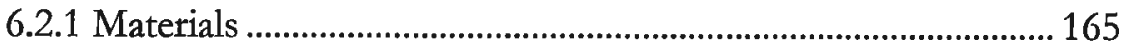

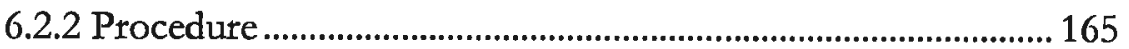

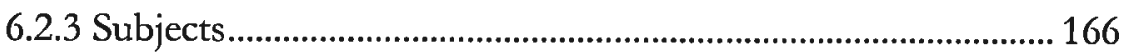

6.2.4 Acoustic measurements and analysis ........................................ 166

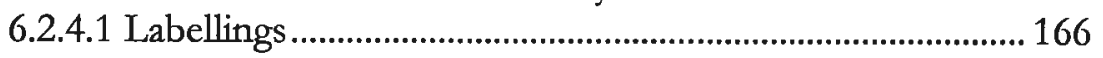

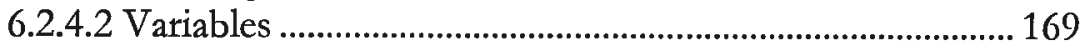

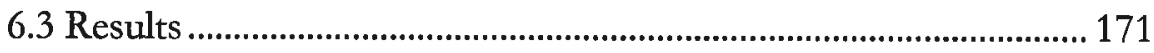

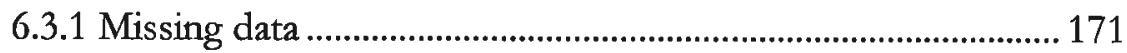

6.3.2 Comparing focus effects across groups.................................. 172

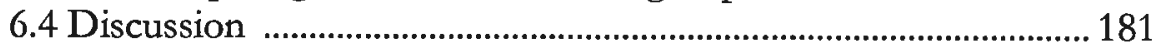




\subsection{References}

7 Conclusions

SAMENVATTING

SAMENVAT'TING IN HET CHINEES.

APPENDICES

Appendix 1: Corpus belonging to Chapter 2

Appendix 2: Corpus belonging to Chapter 3

Appendix 3: Corpus belonging to Chapter 4

Appendix 4: Corpus belonging to Chapter 5 .

Appendix 5: Corpus belonging to Chapter 6 .

Curriculum Vitae. 


\section{Chapter 1}

\section{Introduction}

\subsection{Rationale of the investigation}

There are about 120,000 Chinese (about $0.82 \%$ of the total population) living in the Netherlands, who immigrated from Mainland China (35\%), Hong Kong (23\%), Indonesia (20\%), Surinam (6\%) and other areas (16\%), according to the Chinese Embassy in the Netherlands and the investigation by $\mathrm{Li}$ (1999). Most of those who are from Mainland China originate from Shenzhen and Dapeng (Canton Province), Wenzhou and Qingtian (Zhejiang Province), Fuzhou and Changle (Fujian Province). They have formed Chinese communities in Amsterdam, Rotterdam, The Hague, Eindhoven and other places. With the development of China, more and more Chinese are coming to the Netherlands to work or study. They learn Dutch and have mastered the language with a certain level of proficiency. A study of how Chinese people speak Dutch is therefore a significant enterprise, and this is. one of the reasons why the research programme 'Intonation of varieties of Dutch' (NWO 360-70-180) contains a sub-project 'Mandarin-accented Dutch'. The present research represents the main result of this sub-project. It focuses on the prosody of Dutch spoken by Mandarin learners from the northern part of Mainland China.

It is generally accepted that individuals will be found to speak a second language (L2) with detectable foreign accents when they learn it after a certain age (Flege, Patkowski, 1990; Scovel, 1988; Major 2001; Munro 2008, Munro \& Mackay, 1995). Perceptually, the foreign accent is defined as "the extent to which an L2 learner's speech is perceived to differ from native speaker norms" (Munro \& Derwing, 1998: 160). The severity of the foreign accent is influenced by age of learning, length of residence, gender, motivation, aptitude, use of language, speech rate, instruction and social factors (Flege, 1988; Flege, Munro \& MacKay, 1995; Gut, 2009; Hansen Edwards, 2008; Moyer, 2004). Foreign- 
accented speech shows different pronunciation patterns segmental and suprasegmental levels compared with the nativ norm. At the segmental level, numerous studies show that the speech differs from native speech in consonant articulation (A 2007) and vowel articulation (Bohn \& Flege, 1992; Flege, Boh 1997; McAllister, Flege \& Piske, 2002). For example, Voice O (VOT) for stop consonants (Flege, 1987; Flege \& Eefti Magloire \& Green, 1999; Major, 1992; Schmidt \& Flege, 1996) articulation (Aoyama, Flege, Guion, Akahane-Yamada \& Yam: Major, 1986) have been shown to differ between native and I At the suprasegmental level, non-native speakers generally del or substitute one phone for another (Gut, 2009; Munro, 2008; 2008), have different patterns of stress placement (Archibald, 1 1997 ) and other prosodic features besides stress patterns (A Guion, 2007; Chen, 2008; Guion, Flege, Liu \& Yeni-Komsh Gut, 2000, 2003, 2005, 2009; Trouvain \& Gut, 2007). Studies prosodic errors contribute significantly to ratings of foreign acc and are more detrimental to listeners' comprehensibility and in than segmental errors (Anderson-Hsieh, Johnson \& Koeh Derwing \& Munro, 1997; Hash, 1972; Johansson, 1978; Derwing, 1995; Rasier \& Hiligsmann, 2007; Trofimovitch 2006). Pedagogically, a global pronunciation instruction that $f$ prosodic factors (stress, intonation and rhythm) improved comprehensibility and fluency significantly better than a segm instruction (Derwing \& Rossiter, 2003; Derwing, Munro \& Wie Furthermore, prosody-focused instruction may also improve oral production at the segmental level (Chun, Hardison \& Pe 2008). On the other hand, there are few studies at the supra level in L2 phonological acquisition, especially when it comes rhythm, intonation and utterance stress. Most of the existir focus on English as an L2, but the studies on other phonological acquisition as L2s are relatively few (G Trofimovitch \& Baker, 2007; Zampini, 2008).

Mandarin Chinese and Dutch belong to different language fa former belongs to the Sino-Tibetan family and the latter is a language. The linguistic distance between Mandarin Chinese a is clearly larger than the distance between English and Dutcl accents may be related to the linguistic distance between the $\mathrm{m}$ the language pairs. For instance, the authenticity of English 
speakers of English increased significantly by replacing original durations and the original $\mathrm{f} 0$ contour by the durations taken from those of a native speaker of English and with durationally manipulated monotones, respectively. The results showed that the Dutch speakers of English used segment durations and f0 contours that signalled foreign accent to native English listeners and that the accent was stronger when the learners spoke than when they sang (Hagen, Kerkhoff \& Gussenhoven, 2011). If less foreign accent in sung speech is specific to Dutch speakers of English, it would be reasonable to assume that language pairs like Chinese and Dutch, which are typologically more different, show even greater such effects due to the greater difference in their prosodic features. If the relative contributions of duration and $\mathrm{f} 0$ contours to foreign accent vary with language-relatedness, the question is whether the prediction is right for the Mandarin-accented Dutch. In other words, the differences in prosody between Mandarin and Dutch naturally lead us to focus on the prosodic aspects of the Mandarin-accented Dutch.

In the present thesis, I will compare the performance of Mandarin speakers of Dutch with that of native speakers of Dutch in order to uncover the prosodic characteristics of Mandarin-accented Dutch in terms of sentence pitch accent, intonation, phrasing, pitch range, pauses, rhythm, speech rate and articulation rate.

\subsection{Chinese dialects}

Chinese is spoken in Mainland China, Taiwan, Hong Kong, Malaysia, Singapore, Vietnam, and the United States by more people than any other language in the world. Chinese has been an official language of the United Nations since the founding of the organization in 1945. Chinese speakers speak different varieties of Chinese. They all belong to the SinoTibetan family of languages and each one has its own dialects and subdialects, which are more or less mutually intelligible. The dialects of the language differ from each other in pronunciation, vocabulary and grammar. And the difference in pronunciation is the most outstanding. It is not unusual to distinguish the nine dialects of Chinese, as shown in the map in Figure 1.1. They are Wu, Min, Yue, Xiang, Gan, Jing Yu, Hui Yu, Hakka and Mandarin. 


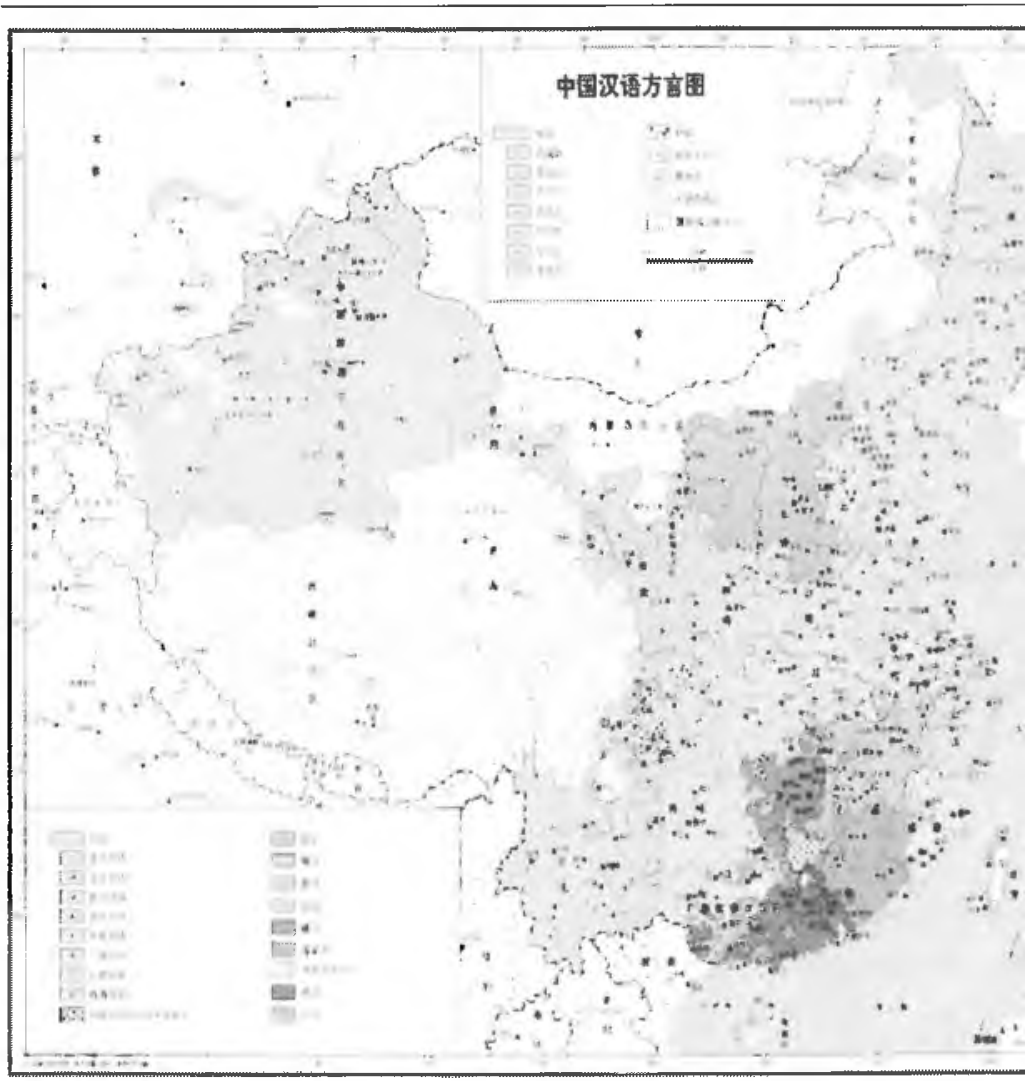

Figure 1.1. The distribution of Chinese dialects (Chinese Academy of Socia Australian Academy of the Humanities, 1990)

The name "Mandarin" was first used by the Portuguese to $\mathrm{rc}$ magistrates of the Imperial Chinese Court and the language $t$ Mandarin has a wide range of dialects in the northern, $\mathrm{c}$ western regions. North Mandarin, as found in Beijing, is the $b$ modern standard language, Putonghua (common language). T was chosen as a standard for the whole of China, a promulgated under this name after the establishment of th Republic of China in 1949. It embodies the pronunciation of $\mathrm{F}$ grammar of the Mandarin dialects and the vocabulary of Chinese literature. In 1956, it became the medium of instruc schools, and a policy of promoting its use began. It is now widely used form of spoken Chinese, and is the normal writte for almost all kinds of publication. Pinyin, a writing systen 
symbols adapted from the Roman alphabet, was adopted in 1958. Its main aims are to facilitate the spread of Putongbua and the learning of Chinese characters.

China is a large country with more than a billion inhabitants, and having a common language is good for its administration as well as for cultural exchange and information transmission between ethnic groups and people in different places. More than 2000 years ago, the Chinese had realized that a common language should be used in social intercourse. Putonghua serves those purposes well and allows for efficient communication between people in different areas and from different ethnic groups. The Chinese government attaches great importance to popularizing Mandarin and encourages people to learn it. Today, it is the main language of government, the media and education in both China and Taiwan, and one of the four official languages in Singapore.

As the map in Figure 1.2 shows, Mandarin has developed into eight subdialects: Northeastern, Beijing, Ji Lu, Jiao Liao, Zhongyuan, Lan Yin, Jianghuai and Southern Mandarin. There can be variations in pronunciation, vocabulary and grammar, but the language remains understandable to people from other regions within the Mandarin area (Tang, 2009; Tang \& van Heuven; 2009).

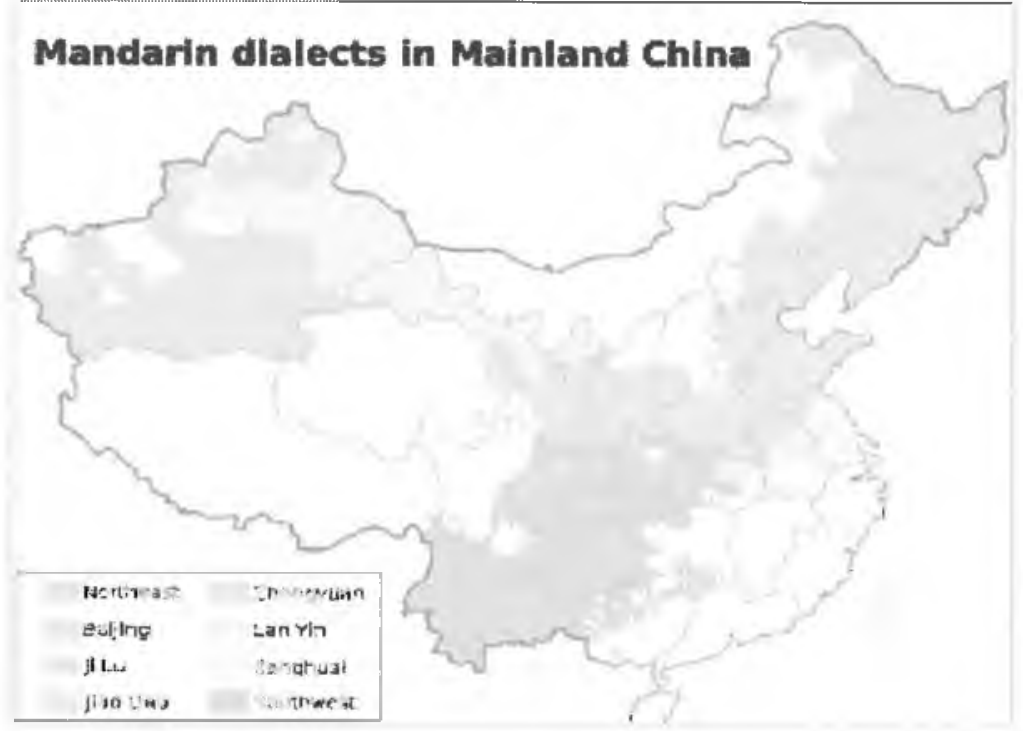

Figure 1.2. Mandarin dialects in Mainland China 
Wu is spoken in Zhejiang and Jiangsu provinces, parts Province, Shanghai and Hong Kong.

Cantonese is spoken in Guangdong and Guangxi provinces ar Island in China, and also in Hong Kong, Macau, Singapore, $\mathrm{Mz}$ many other countries.

Min can be divided into Min Nan (Southern Min), Min Bei Min), Min Dong (Eastern Min) and Min Zhong (Central Min). is in the south of Fujian province, Guangdong Province, Hainan Island, the south of Zhejiang and Jiangxi provinces, $T$ a also in Singapore and many other countries. Min Bei is spoken Northern Fujian Province and Singapore. Min Dong is spoken east central Fujian Province and also in Brunei, Indonesia (Java Malaysia (Peninsular), Singapore, Thailand. Min Zhong is spok in central Fujian Province.

Jin $\mathrm{Yu}$ is spoken mainly in Shanxi Province and also in Sh Henan provinces. Hui $\mathrm{Yu}$ is spoken in southern Anhui and Zhejiang provinces. They used to be considered as dialects of but now are thought to be separate varieties of Chinese (Hou, 2

Hakka is widespread, especially between Fujian and Guar spoken in south eastern China, parts of Taiwan and in Territories of Hong Kong. There are also significant comm Hakka speakers in such countries as the USA, French Guiana, and the UK.

Xiang (Hunanese) is spoken mainly in Hunan Province, an Sichuan, Guangxi and Guangdong provinces. Gan is spoken Province and in parts of Hubei, Anhui, Hunan and Fujian prov

Because there has long been a single writing system for Chin common literary and cultural history, the main varieties of China are traditionally referred to as dialects. The same characters are used for the different dialects and can even be basic communication in Japanese. But they are in fact diffe each other mainly in pronunciation and vocabulary. Speake dialects except Mandarin speakers will not be able to easily con with each other, so the written Chinese and Standard Mandarin 
linguistic common ground and are used to facilitate communication between people from widely separated regions.

All Chinese dialects are tonal. This means that each syllable can have a number of different meanings depending on the tone with which it is pronounced. For example, Mandarin has 4 tones, (1) high level tone; (2) rising tone; (3) low dipping tone; (4) falling tone. The southern dialects have richer tone inventories than Mandarin. For example, Cantonese has between 6 and 9 tones (depending on the local dialect and in the depth of the analysis), Min between 6 and 8 and Wu between 7 and 8 (Hou, 2002).

Phonologically speaking, most Chinese in the Netherlands come from the regions of Cantonese, Min and Wu dialects, and many of them can speak or have been exposed to the Standard Chinese. We chose our participants for our experiments from the places around Beijing area in order to reduce the deviations caused by participants' dialects. Eleven of them are from Beijing, one from Tianjin, and two from Hebei. Tianjin and Hebei are very close to Beijing, so they are all Beijing Mandarin speakers. One participant grew up in Henan (Zhongyuan Mandarin) and educated in Shandong (Ji Lu and Jiao Liao Mandarin). Another one is from Xi'an (Zhongyuan Mandarin). The other four are from the northeast of China (Northern east Mandarin). That is to say, all participants in our experiments are all Mandarin speakers. As Hou (2002) put it, Mandarin speakers, though living several thousands of $L i$ away from each other (one $L i$ equals 500 metres), have no problem in communication while non-Mandarin speakers cannot understand each other even if they live only several $L i$ away. This traditional idea about intelligibility of Chinese dialects is supported by the quantitative data on mutual intelligibility of Mandarin and non-Mandarin Chinese dialects (Tang, 2009; Tang \& van Heuven, 2009). On the other hand, all participants, aged from 17 to 53, are very proficient in Putonghua (selfreport and checked by the present author in the interview before experimenting) because they received formal education in schools in Mainland China when they were young. 


\subsection{ToDI and Standard Dutch}

ToDI (Transcription of Dutch Intonation), a phonologica developed for Dutch was used in all reports (Gussenhoven et Gussenhoven, 2005). Unlike MAEToBI (Mainstam America Tones and Break Indices) (Beckman \& Ayers, 1994; Hirschberg \& Shattuck-Hufnagel, 2005), which was deve American English, ToDI uses no break indices, which are indi prosodic boundary strength for four levels of phrasing. T indicates intonational phrases and tones, as other boundaries at be not relevant for the tonal transcription. Since the intonation is similar to that of other standard West Germanic langus MAEToBI and ToDI can in principle be used for those (Gussenhoven, 2005).

In the ToDI transcription system (http://todi.let.kun.nl/), an contour is a melodic pattern which occurs in an Intonational $P$ Each contour consists of a number of High $(\mathrm{H})$ and Low $(\mathrm{L})$ symbol $\mathrm{T}$ is used to refer to either $\mathrm{H}$ or $\mathrm{L}$. The tones occur at of IPs and at accented syllables. IPs are demarcated by $\%$. edge has a tone. Tones occurring at IP edges are transcrib (initial boundary tone) or T\% (final boundary tone). Every syllable is marked by a tone, or a cluster of tones, called a "pitc The first tone of a pitch accent is transcribed as $\mathrm{T}^{*}$. A T followed by further tones to describe the movement from th syllable onward. An example is given in Figure 1.3.

The full set of symbols used in the ToDI system is the followir $\mathrm{H}^{*}, \mathrm{~L}^{*}$

$\mathrm{H}, \mathrm{L}$

$\mathrm{H} \%, \mathrm{~L} \%$ high/low accent

$\% \mathrm{H}, \% \mathrm{~L}$ upward/downward movement after $\mathrm{L}^{*} / \mathrm{H}^{*}$

$\% \mathrm{HL}$ $\%$

! $\mathrm{H}^{*}$ rising/low ending of an IP high/low beginning of an IP initial falling pitch half-completed fall/rise at end of an IP downstepped $\mathrm{H}^{*}$

The pitch accents in the system are:

$\mathrm{H}^{*} \mathrm{~L}$ High fall from accented syllable

!H*L $\mathrm{H}^{*}$ Low fall from accented syllable (downstepped $f$ High level from accented syllable 
! $\mathrm{H}^{*}$

Lowered level from accented syllable (downstepped level)

$\mathrm{H}^{*} \mathrm{LH}$

Pre-nuclear steep fall followed by a gradual rise towards the next accented syllable (pre-nuclear fall-rise)

L*!HL Low rise fall from accented syllable (downstepped delayed peak)

L*H Rise from low from accented syllable

$\mathrm{H}^{*} ! \mathrm{H} \quad$ Vocative chant

The seven nuclear pitch accents listed above (i.e. all except $H^{*} \mathrm{LH}$ ) can form 21 nuclear contours in combination with the three final boundary conditions.

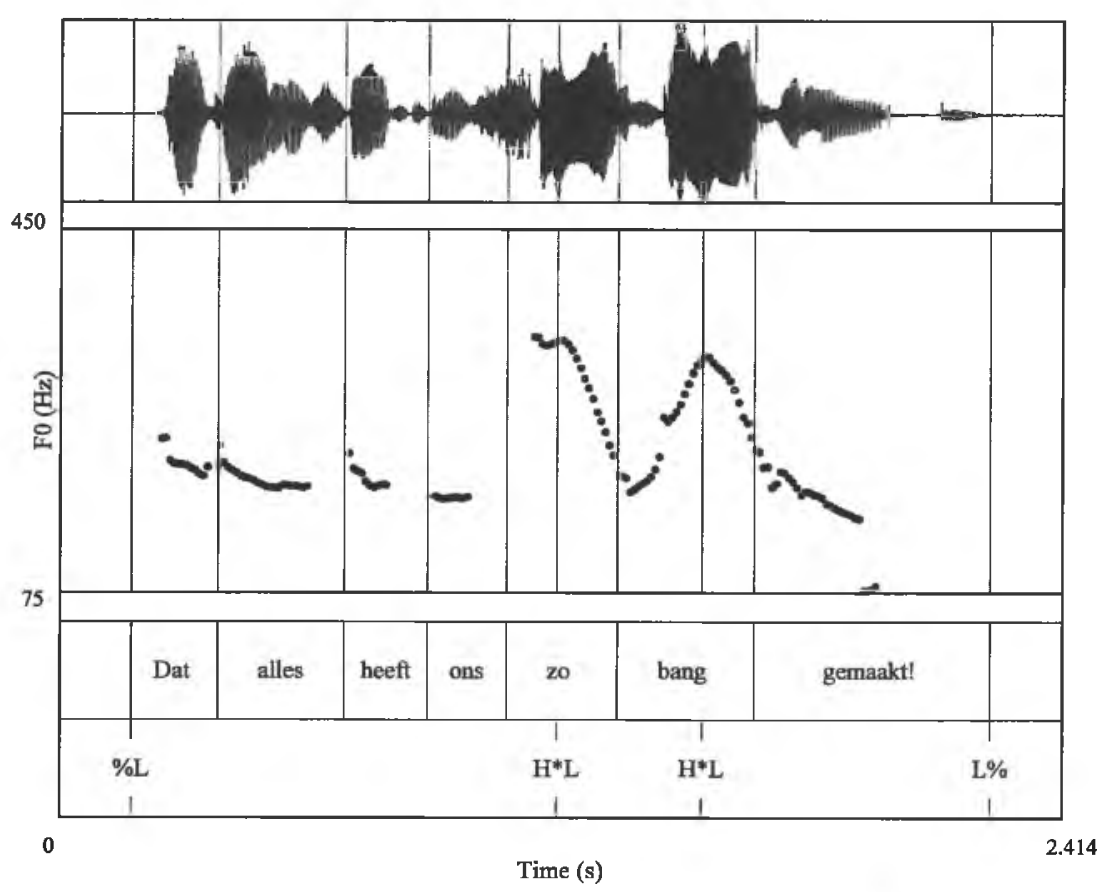

Figure 1.3. An example of Dutch sentence Dat alles beeft ons zo bang gemaakt!' transcribed in ToDI.

The Fall is transcribed as $\mathrm{H}^{*} \mathrm{~L} \mathrm{~L} \%$, as in an alternative question: 


\section{Je moet kieqen: wil je liever fruitsalade of wil je liever ijs?

$$
\% H \quad H^{*} L L \%
$$

You have to choose: would you rather have fruit salad or

The contour $\mathrm{H}^{*} \mathrm{~L} \%$ is different from the contour $\mathrm{H}^{*} \mathrm{~L} \mathrm{~L} \%$. falls to low pitch, while the final $\mathrm{H}^{*} \mathrm{~L}$ does not go down all t low pitch in $\mathrm{H}^{*} \mathrm{~L} \%$. Such contours are called "half-complete often happens that speakers use a more gradual fall ending at The effect may be that the speaker sounds more tentative, or express that what is said is not terrifically important. In non such suspended falls may be used just to indicate non-fir instance,

2. Hij keek ons de hele tijd strak aan. Toen qei-die: Dat nooit!

$$
\text { । }{ }^{*} H^{*} L
$$

He looked hard at us the whole time. Then he said: That, ne

In some utterances with more than one IP, there may be a not which has no accent. Such unaccented IPs may consist of clauses (zei Jan), or of a rewording of the contents of a pre Unaccented IPs usually have the same post-accentual tones they are attached to. For example, if the preceding IP ends in the unaccented IP will have $\mathrm{L}$ L\%, and similarly $\mathrm{H}^{*} \mathrm{~L} \mathrm{H}^{\prime}$ followed by $\mathrm{L} \mathrm{H} \%$. To indicate the close connection be unaccented IP and the preceding IP, the initial \% is not transcr

Either $\mathrm{H}^{*} \mathrm{~L} \%$ or $\mathrm{H}^{*} \mathrm{~L} \mathrm{~L} \%$ can be used in an exclamation v Dutch like in the following sentence:

\section{Kijk daar 's! Wat is dat een rare fiets!

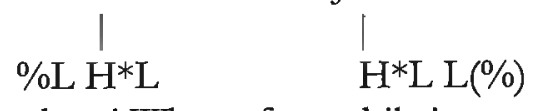 \\ Look over there! What a funny bike!}

In the IP of $\mathrm{H}^{*} \mathrm{~L} H \%$ with toch (not) or with a modal particle " the pitch after the last $\mathrm{H}^{*} \mathrm{~L}$ goes down to mid or low at the intonation phrase. But it is also possible to pronounce a bour in which case the last syllable has rising pitch, or is entirely p 
with high pitch. Functionally, the occurrence of $\mathrm{H}^{*} \mathrm{~L} \mathrm{H} \%$ may signal a question, or a reminder, or a suggestion which may have a ring of selfevidence. It often goes with toch 'not' or with modal particles bè or hoor, as in the following two examples:

\section{Je boeft niet meer te werken. Je bebt toch al genoeg gedaan deze week?

$\% \mathrm{~L} \quad \mathrm{H}^{*} \mathrm{~L} \quad \mathrm{H} \%$

You don't have to work anymore. Haven't you done enough this week?

5. Het wordt laat. Maar je moet wel je eten opeten, boor!

$\% \mathrm{~L} \quad \mathrm{H} * \mathrm{~L} \quad \mathrm{H} \%$

It's getting late. But you should finish you meal!

The IP-final high rise auditorily begins at mid pitch, which continues until a rise at the IP-boundary. The mid pitch is usually reached late in the accented syllable while the beginning is low, as is commonly the case for $\mathrm{H}^{*}$. The contour is mostly used in questions or frequently used utterance-internally to indicate that another IP follows. We transcribe it as $\mathrm{H}^{*} \mathrm{H} \%$.

\section{Zei je nou echt dat je naar buiten wilde? In de regen?

$$
\% \mathrm{~L} \quad \mathrm{H}^{*} \mathrm{H} \%
$$

Did you really say you were going to go out? In the rain?

The vocative chant consists of a high level and a mid level tone. The $\mathrm{H}^{*}$ begins on the accented syllable, and the $! \mathrm{H}$, the mid level, is realized on the last syllable, or on a stressed syllable if there is one between the accented syllable and the last syllable. The accented syllable and the syllable on which the $! \mathrm{H}$ begins are often lengthened. When the accented syllable is the last syllable, the two levels are both pronounced on that syllable, which as a result is broken into two sections. The lengthening does not occur when the level pitch of $\mathrm{H}^{*}$ is spread over more than two syllables. No lengthening is used when the contour is used to mark continuation, which sometimes occurs in instructions which the speaker wishes to sound unproblematic. The vocative chant is also used on utterances with an early accent in which case each of the following 
unaccented words is likely to have a pitch level. These levels c the same way that series of downstepped accents descend. Sin pitch level has mid pitch, rather than low pitch, the right-hand is transcribed as toneless $\%$. Vocative chants with $\mathrm{L} \%$ and $\mathrm{H}^{\circ}$ \% but are rare. The one with $\mathrm{L} \%$ has a fully low-pitched final $\mathrm{p}$ and may make the speaker sound exasperated. The vocative $c$ $\mathrm{H} \%$ is like $\mathrm{H} * ! \mathrm{H} \%$ with an added rise in the last part of the level. It may give an impression of wheedling. It is sometim call somebody by name as in the following example.

\section{Schat-je! We bebben weer kaa-aas! \\ $\% \mathrm{~L} \quad \mathrm{H} * \mathrm{H} \%$ \\ Honey! We have cheese again!}

The above examples are all from Experiment 3, Chapter 4. All in the thesis are transcribed in ToDI.

\subsection{Relevant issues}

In this part, some relevant issues to the present research are They are the relationship between perception and productic basis of which $I$ intend to motivate why there are two perce three production experiments in the study, and will introd theories or models in the field of phonological acquisition wh potentially used to explain the results in the experiments.

\subsubsection{Perception and production}

Phonetic perception is the internal mental process of $t$ phonetic segments as tokens of phonological categories by sel integrating multiple acoustic parameters. Infants are sensitive t aspects of the ambient language before birth and their becomes sharper after birth (Ohala, 2008). Prosody stands acoustic cue for infants to distinguish a foreign language ambient language or discriminate between two foreign langu: perception ability develops from language-general to langua within the first year of life. Infants are initially able to discri 
consonant and vowel contrasts that are not present in the ambient languages, but they lose the ability and can only distinguish the contrasts of their native language like adults by the end of the first year when they can produce the first words due to the exposure to the native language (Kuhl \& Iverson, 1995). The language-specific phonetic perception is robust and automatic because adults require few cognitive resources to extract the phonetic information from the acoustic signal (Fikkert, 2007; Ohala, 2008; Strange \& Shafer, 2008).

As a result, for almost all late $\mathrm{L} 2$ learners, their oral production is foreign accented. We do not know whether L2 learners have difficulty in perceiving the phonological features, such resulting in the foreign accents in their production. It is generally thought that a major determinant of the foreign accent in production is the underlying problem in perceiving the L2 phonological structures (Flege, 1995). If learners cannot hear given contrasts the way native speakers do, the perceptual problems will cause problems in pronunciation. They sometimes have more difficulty perceiving the difference in an L2 sound which is relatively close to a sound in L2 than a new sound in L2 which is completely distinct from any sound in the L1 inventory (Best, 1995; Flege, 1995). Native Japanese listeners with different learning experience are found to have extreme difficulty in producing the English consonant contrast $/ r / \sim / 1 /$ and to perform significantly poorer than the native English speaker in judging in a variety of stimulus materials and tasks (Bradlow, 2008; Strange \& Shafer, 2008). However, not all mispronunciation is caused by erroneous perception. For articulatory reasons, L2 learners may not produce certain contrasts though they perceive accurately their representation in the L2. But in some studies, L2 sound production was found to surpass perception (Bohn \& Flege, 1996; Brière, 1966; Gass, 1984; Kluge et al. 2007; Neufeld, 1988; Sheldon \& Strange, 1982; Strange, 1995), indicating that production of L2 sounds can be more accurate than perception. For example, the ability for many Japanese learners of English to produce the English $/ \mathrm{r} / \sim / 1 /$ contrast accurately was stronger than the ability to perceive them, particularly in the early stages of acquisition (Yamada, Strange, Magnuson, Pruitt \& Clarke, 1994). Pedagogically, learners' perceptual skills may be as important as their production ability. Studies have shown that perceptual training can improve production (Chun, Hardison \& Pennington, 2008). The relation between perception and production is too complex to make a straight-forward conclusion that production precedes perception, or 
vice versa. Their relation depends upon the stage of the acq the L2, the sound class, the acoustic properties, the contextr the similarity between L1 and L2 and social factors (Llisterri, 19

The observations above are all related to segmentals, bu encompasses a wide range of speech phenomena and is more to convey the intended meanings in communication than segr discussed in 1.1. It is worthwhile investigating whether L2 le: choose certain pitch accents and intonation contours in ser textual context. Therefore Chapter 2 in the present study whether Chinese learners of Dutch can judge the correct $p$ accents in different types of Dutch sentences and Chapter 3 ir whether they can choose the optimal intonation contours ac textual context. The other chapters focus on the production $c$ by Chinese L2 speakers of Dutch.

\subsubsection{Models of phonological acquisition}

Transfer is omnipresent in learning (Ausubel, 1963), and is an issue in the second language acquisition research. The knowledge of L1 works like a sieve to filter learners' L2 acq phonological, morphological, syntactic, semantic and lexi Influenced by behaviourism and structuralism in the midc twentieth century, the research on transfer in second acquisition focused on Contrastive Analysis (CA), which cla transfer could explain and predict all errors (Fries, 1945; La But not all errors are caused by transfer and the differences in As Selinker (1972) pointed out, the interlanguage, i.e. a linguistic system in between the learner's L1 and the target result of many factors and transfer is merely one of then transfer errors, learners' errors are also made due to uni developmental factors so that they are similar or identical to that are observed in the course of L1 acquisition. Wardhat distinguished a trong and weak version of CA. The stror predicted errors and the weak version explained the errors afte CA is very easy to be falsified if prediction is defined in th sense that all individual learners would or would not make a ce It is alive and well today if prediction is defined in probabili 
Actually, CA has seen a resurgent interest and importance in second language acquisition research since the 1980s (Major, 2008).

Besides the linguistic transfers, L1 skills can also transfer into L2 learning and proficiency. In a recent study by Sparks, Patton, Ganschow and Humbach (2009), high school students transferred their L1 English skills in reading, spelling, vocabulary, phonological awareness and listening comprehension to L2 Spanish, French or German, and their early L1 skills played an important role in their L2 attainment.

Transfer plays different roles in different theories or models of phonological acquisition, which can be seen from the following theories or models.

\subsubsection{Best's PAM}

The Perceptual Assimilation Model (PAM) (Best, 1993, 1994a, 1994b, 1995; Best, McRoberts \& Sithole, 1988) employs the metaphor of a phonological space in which native categories (gestural constellations) are arrayed according to similarities/differences in their articulatoryphonetic structure. PAM was developed primarily to account for patterns of nonnative segmental perception by naive listeners with no experience with the L2. Best \& Tyler (2007) later extended the PAM to predict patterns of speech perception by more advanced L2 learners (PAM-L2). It incorporates a combination of perception and production factors. In the very early stages of language acquisition, an infant establishes categories for native language sounds by learning to articulate them. Once the categories have been established, phonemic categories that are non-native will be assimilated to native categories on the basis of perceived similarities.

There are six possible assimilation scenarios in this model, depending on how each member of a non-native contrast is assimilated into native categories: Two-Category (TC) contrasts, where each member is assimilated into a different native category; Single-Category (SC) contrasts, where both members are assimilated into a single native category (equally well or poorly); Category-Goodness (CG) contrasts, where both members are assimilated into the same native category but with one being a closer match to that category; Uncategorized- 
Categorized (UC) contrasts, where one member is identifi native category while the other falls between two (or mo categories; Uncategorized-Uncategorized (UU) contrasts whi of two uncategorized sounds; and Non-Assimilable (NA) where both non-native phones are perceived as non-speech sol the case of American English listeners perceiving Zulu clicks ( 1988). Importantly, the model makes specific discrimination $p$ for each assimilation type. For naïve listeners, L2 phonetic seg perceptually assimilated to L1 phonological categories on th their gestural similarity to $\mathrm{L} 1$ phonetic segments unless th phonetically disparate that they are heard as uncategorizab sounds or are not perceived as speech at all. Of the six as scenarios, three patterns of perceptual assimilation predi discrimination difficulties. SC contrasts are predicted to be mo than TC or CG contrasts in which the members of a contrastir assimilated by nonnative listeners into two separate native cat into a single native category with different degrees of goodn respectively; therefore a SC should be the most difficult kind c for nonnative listeners to acquire.

\subsubsection{Kuhl's NLMM}

Kuhl's Native Language Magnet Model (NLMM) (Kuhl, 19 1993b, 1994, 2000; Kuhl \& Iverson, 1995), is a model of assimilation. Though it originally intended to explain the $p$ that infants progress through general-language perception to specific perception by the end of the first year of life, it may be to account for the perception in an L2.

Language exposure may cause changes in the phonolog according the model. Each instance of a phoneme heard is st exemplar and the best exemplar becomes a prototype (an representation of phonetic category) and will act as a phonetic The prototype, like a magnet, attracts other similar exemplars the perceptual space near the category centre. All new instance are classified according to the existing prototype categories. T prototypes shape the mapping between acoustics and perce reduce perceptual sensitivity near the distributional peak of the When the L2 learner encounters a new sound that is similar 
sound, the prototype forces the learner to perceive the new sound as the L1 prototype.

The model also predicts the difficulty in discrimination of L2 sound contrasts. Under the proximity principle (Kuhl, 1991), the accuracy to discriminate more prototypical exemplars of a phonetic category is lower than that to discriminate less prototypical exemplars. The difficulty in discriminating L2 sound contrasts increases as the similarity to L1 sounds increases.

The explanatory power of the model was challenged in some studies (Lacerda, 1995; Lively \& Pisoni, 1997), but the influence of early language experience on the L2 sound perception cannot be denied.

\subsubsection{Flege's SLM}

Flege's (1995, 1999, 2002) Speech Learning Model (SLM) consists of four postulates and seven hypotheses to account for age-related pronunciation of vowels and consonants in an L2. The four postulates are: (i) The mechanisms and processes used in learning the L1 sound system, including category formation, remain intact over the life span and can be applied to L2 learning; (ii) Language-specific aspects of speech sounds are specified in long-term memory representations called 'phonetic categories'; (iii) Phonetic categories established in childhood for L1 sounds evolve over the life span reflect the properties of all L1 and L2 phones identified as a realization of each category; (iv) Bilinguals strive to maintain contrast between L1 and L2 phonetic categories, which coexist in a common phonological space. The four postulates mean that speakers use the same cognitive resources in L1 and L2 learning, share and have mental representations of the contrastive sounds of their native language, and can create new categories in L1 and modify them in L2 acquisition though they strive not to mix the categories in L1 and L2. The acquisition of L2 sounds that do not exist in their L1 is to establish new categories and the categories in L1 work as filters in the L2 phonological acquisition.

The seven hypotheses in SLM predict the preconditions and stages of phoneme acquisition. The mechanisms needed to produce new sounds remain intact, but perception changes with development. Language 
learners are able to perceive at least some of the phonetic between two L1 and L2 sounds. The ability to discern new decreases with age because children do not have the native perceptual categories as firmly fixed in their phonological syste learners do. As a result, the younger the learner, the greater likelihood that sounds in the $\mathrm{L} 2$ will be perceived on their o without reference to the L1. The likelihood of category forn function of the learner's age of arrival (AOA). Furtherm predicted that those phones that do not contrast in the L1 ones that are difficult to perceive in the L2, and that the simila identical sounds in both languages will be hardest to $\mathrm{m}$ : accuracy of L2 perception constrains that of L2 production. Fo for Spanish listeners, both American English /a/ and /o/ perceptually assimilated to Spanish $/ \mathrm{a} /$, resulting in di discriminating this contrast and in the production of both I This is the process called 'equivalence classification' in whic cannot form the category for the sounds and end up representation of a single phonetic category for both sounds. $C$ the greater the difference between the L1 and L2 phones, the 1 the learner will notice the difference and thus not rely on produce the L2 phone. French / y/ is a new vowel for America and L2 French learners will produce it accurately and p differentiate it from both back, rounded and front, unround vowels and from English vowels (Flege \& Hillenbrand, 198 sufficient exposure to the $\mathrm{L} 2$ sounds (which may take up years)

However, SLM neither tells us what type of linguistic or change is responsible for the decline in perceptual ability as matures nor does it offer insight into the mechanisms that allo learners to acquire phonology more easily than later L2 leat SLM does not make any explicit prediction about the acq prosody due to its limited scope on phoneme and allophones.

\subsubsection{Major's OPM}

The Ontogeny Phylogeny Model (OPM) is proposed by Maj colleagues. "Ontogeny" and "phylogeny" are originally biolog "Ontogeny" refers to the life cycle of single organism and " $\mathrm{f}$ 
means the evolutionary development of groups of organisms. Similarly, when they are borrowed into language, the former means the life cycle of an individual's language and the later the life cycle of all languages and language types (Major, 1994, 1996, 2001; Major \& Faudree, 1996). So OPM deals with both individual and evolutionary development of languages. It incorporates markedness and predicts longitudinal phonological acquisition of L2 or dialects by individuals or groups of speakers over generations. It holds that an interlanguage is composed of elements of L1, the required L2 and universals. If L2 acquisition increases, L1 transfer decreases, and universals increase and then decrease. For similar phenomena in L1 and L2, L2 acquisition proceeds slowly, transfer persists, and consequently the role of universals gets relatively small, compared to the norm which is neither similar nor marked. For marked phenomena, L2 acquisition increases slowly; L1 transfer decreases slowly, while the influence of universals increases rapidly and then decreases slowly. Different from the other models, individuals' difference, social and demographic factors affecting L2 phonology are considered important in this model.

OPM was supported in the studies on the acquisition of phonemes and syllable structure, however, no evidence was found to support the claim L1 transfer decreases with increasing degree of L2 formality of speech style. The model can be applied not only in phonological acquisition but also in non-phonological fields. However, 'universals' are not clearly defined and the interrelation of the three proposed elements in interlanguage remains open to speculation. Nor does OPM offer a psycholinguistic account for how L2 phonological learning takes place over time during which the learning is considered as progressing from non-target to target $\mathrm{L} 2$ forms through variable performance by trial and error (Trofimovich, Gatbonton \& Segalowitz, 2007). Though nonlinguistic factors are considered important in the model, it does not specify how such factors influence learning over time.

\subsubsection{Eckman's MDH and SCH}

The difference between L1 and L2 is insufficient to explain the learner error, and should be supplemented by the explanatory principle of typological markedness. Eckman's (1977, 1984, 1985, 2008) Markedness Differential Hypothesis (MDH) states that a structure $\mathrm{A}$ is more marked 
than $B$ if the existence of $A$ in a language necessitates the exist but not vice versa. For example, final voiced obstruents im] obstruents in initial and medial position but not vice versa; number of the segments in the onset and coda clusters implic number in medial position. Markedness also refers to frequencies. Pharyngeal fricatives are more marked than $/ \mathrm{p} /$, a of American English is more marked than /1/. It is predic marked rule is more difficult to learn than an unmarked acquisition and that in L2 acquisition marked L2 patterns th marked than in L1 should not be difficult, unmarked patterns likely to be transferred to $\mathrm{L} 2$ than the marked ones. These $\mathrm{F}$ have found support in numerous studies on segmental acqu voicing contrasts, epenthesis in consonant clusters, and co deletion (Major, 2008). It was difficult for German learners of acquire the word final voiced consonant in English whil learners of German had no difficulty in producing the voiceless consonant in German. Because Chinese does complex codas, Chinese-speaking subjects were less nati pronouncing English coda clusters than Abrabic-speaking su the difficulty they experienced correlated with degree of marke with the amount of difference between the native language and language (Anderson, 1987).

However, $\mathrm{MDH}$ cannot explain L2 patterns which are marke in the area of a difference between L1 and L2. It developed f Structural Conformity Hypothesis (SCH), which states universal generalizations that hold for primary languages hol interlanguage" (Eckman, 1991: 24). An interlanguage, a stage acquisition process that is located along the continuum betwe and a target language, obeys certain patterns in some of $\mathrm{t}]$ languages. The studies on consonant clusters in onsets or co allow both a greater number of clusters and thus more marked an L2 than in an L1, showed that the cluster types were more c interlanguage grammars than those allowed in the L1, b complex as those required in the L2. So the findings of the support SCH (Eckman, 2008). SCH predicts the nature of int grammars rather than learning difficulty and expands the don hypothesis beyond the difference between L1 and L2; ther overcomes the shortcomings of $\mathrm{MDH}$. 
Both $\mathrm{MDH}$ and $\mathrm{SCH}$ claim that learners have fewer difficulties and proceed faster in acquisition of unmarked patterns than in the acquisition of marked ones. Due to their scope and explanatory power, the limitation of both hypotheses can be seen. Relying on the concept of linguistic universals, their scope is restricted to linguistic areas such as syllable structures or the frequency of segmental speech sounds for which linguistic universals have been proposed. Other phonological features, phonological process and the prosodic phenomena have not been classified in term of typological markedness, so the two hypotheses cannot predict acquisition phenomena in those fields. Non-linguistic factors influencing phonological acquisition are not put into consideration.

\subsubsection{Optimality 'Theory}

Since Prince and Smolensky's seminal manuscript on Optimality Theory (OT) was introduced in 1993, numerous efforts have been made to test and develop the theory in the areas of phonology, syntax and discourse studies. Phonology is greatly impacted by the theory and applied linguists have begun to adopt an OT approach to understand observed phenomena in L2 phonological acquisition, though most of the studies focus on L2 syllable structure (Hancin-Bhatt, 2008).

OT grammars consist of a universal set of constraints divided into two subgroups: Markedness and Faithfulness. The Markedness constraints are generalizations on the marked and unmarked patterns in a language. Linguistic patterns that commonly occur in natural languages are unmarked and those that do not are marked. Faithfulness constraints ensure the congruence between patterns in the input and those in the output. 'The two types of inherently conflicting constraints can be violable, and ranked relatively to each other. The higher the ranking of a constraint is, the more serious its violation. The candidate in the outputs which has the least serious constraint violations is the most optimal and wins. The constraint rankings are language-specific, so acquisition is to learn the constraint rankings that hold for the target language (Boersma, 1998; Hancin-Bhatt, 2008). In the OT framework, L2 acquisition starts from the existing L1 constraint ranking and then proceeds from the least marked to the most marked rankings. Transfer takes place from L1 ranking, but patterns that are like neither L1 nor L2 are the result of 
universals. For example, $A$ and $B$ are the constraint rankings $f$ Mandarin Chinese and in English as in (1), where " $>>$ " me ranking; MAX I, DEP (V) and IDENT (VOI) are faithfulness c NO OBS CODA, No VOICED OBS CODA are markedness constr

Faithfulness constraints

MAX I: Maximize the consonants in the input (not delete the co DEP (V): The vowels in the output should depend on the inpu vowels)

IDENT (VOI): An output segment should be identical in voic corresponding input segment.

Markness constraints

NO OBS CODA: Syllables may not contain obstruents.

No VOICED OBS CODA: Syllable codas may not conta obstruents

(1) A: No coda obstruents allowed (Mandarin): */vig/, */vik/ NO ObS CODA, No VOICED OBS CODA >> MAX I, DEP ( (VOI)

B: Both voiced and voiceless coda obstruents allowed /vig/, / vik/

MaX I, DeP (V), IDENT (VOI) >> No Obs CODA, No Vo CODA

Chinese learners of English were found to avoid obstruents i through either deletion or epenthesis, because the $F$ constraints MAX I and DEP (V), re-ranked lower than the $\mathrm{M}$ constraints (Broselow, Chen \& Wang, 1998). But some Chine devoiced the coda, thus producing an unmarked form that Chinese nor English because they re-ranked the No OBs COI to NO VOICED OBS CODA and IDENT (VOI) was the minimal v the Faithfulness constraints (Broselow et al., 1998). The tab. shows the representational evaluation of /vig/ by Chinese s English, where the full stop in the third candidate indicates boundary. Asterisks indicate constraint violations and an ex mark signifies a fatal violation, as usual.

(2) Devoicing in Obstruent Codas: No OBS CODA, No Vc CODA $>>$ MAX I, DEP (V), IDENT (VOI) 


\begin{tabular}{|c||c|c|c|}
\hline$/$ vig/ & NO VOICED OBS CODA & MAX, DEP & IDENT (VOI) \\
\hline \hline vig & $* !$ & & \\
\hline vi $<\mathrm{g}>$ & & ${ }^{*} !$ & \\
\hline vi.gE & & ${ }^{*} !$ & \\
\hline vik & & & ${ }^{*}$ \\
\hline
\end{tabular}

OT takes interlanguage grammars as natural and dynamic systems which can accommodate new inputs and as the consequence of L1 influence and markedness effects. By the re-ranking the constraints, the interlanguage development can be explained without any other extra special rules.

Though the above models or theories are all based upon the studies on segmentals, they can be employed to explain the suprasegmental or prosodic acquisition. Theoretically, both segmental and suprasegmental learning may be driven by similar learning mechanisms (Pierrehumbert, 2003) and may be influenced by common factors (Trofimovich \& Baker, 2006; Wang, Spence, Jongman \& Sereno, 1999). Since they intend to explain some phenomenon in certain aspects, it would be partial to explain all phenomena by exploiting any of them individually due to their respective limitations. Interlanguage is the interactive result of the linguistic factors (L1, L2, universals and transfer) and non-linguistic factors like the individual differences of learners (linguistic aptitude, age of learning, length of residence, motivation and other social factors).

\subsubsection{The age issue}

Age is a crucial variable in the second language acquisition, especially in pronunciation (Flege, Yeni-Komshian \& Liu, 1999; Ioup 1984). Previous studies confirm that later learners are not likely to achieve native-like pronunciation and show that native-like L2 phonology is normally found only with a very early onset of L2 learning; the likelihood to be nativelike diminishes as the onset age increases. As Lenneberg (1967) predicted in his critical period hypothesis (CP), the end of neural plasticity and the completion of hemispheric lateralization of human brain at puberty results in a decline of the ability to pronounce foreign languages in a native-like fashion. Of the early Spanish learners of Swedish in a large- 
scale study, only a few were actually native-like in their compe behaviour under detailed acoustic-phonetic scrutiny measurements, although they were judged by native speakers like (Abrahamsson \& Hyltenstam, 2009).

Compared to other variables like the quality of the input, residence, the degree of motivation and the amount of the use $\mathrm{L} 2$, the most important variable to predict degree of foreign ac onset of age of L2 learning (Asher \& Garcia, 1969; Flege, Bol 1997; Flege \& Fletcher, 1992; Flege, Munro \& MacKay, 19 Yeni-Komshian \& Liu, 1999; Munro, Flege \& MacKay, 199 1976; Patkowski, 1990; Piske, MacKay \& Flege, 2001; Thomps In these studies, the production of the adult subjects, who we into sub-groups according to the age at which they began to st was judged by native speakers using a scale indicating the foreign accent. Tokens by native speakers were interspersed : nonnative speech for control. Other studies on acoustic mea of speech also showed that age was a determining factor in th produce native-like VOT and vowels. It was found that the V of the English phoneme / $t$ / produced by early Spanish 1 English were equivalent to those of monolingual English nativ while the late learners' VOT values were located midway monolingual Spanish and English values (Flege, 1991; Thor Ryalls, 1998). The accuracy of English vowels by Italian imn Canada was inversely correlated with age of arrival (A equivalent with onset age of learning), and only the subgro earliest arrivers produced native-like English vowels (Flege, I Meador, 1999; Flege, Schirru \& MacKay, 2003). Kim (1995 Korean immigrant learners of English into $\mathrm{AOA}$ before and a compared the English /i/ /I/ distinction, which is absent fro She found that early arrivers use both vowel length an differences to distinguish the vowel pairs as the monolingu native speakers while the late learners only used vowel length.

Some studies, however, conclude that the acquisition of pronunciation was not guaranteed by early onset of learn learners were identified as immigrants since they had a detect: in their pronunciation in two large-scale studies of Italian imr Canada (Flege, Frieda \& Nozawa, 1997; Flege, MacKay \& Pi Those who often used their native language were found to be 
to have detectable accents in their L2. Except the continued use of L1, some other individual differences contributed to the learner's foreign accent. These are the amount of L2 use, length of residence, target language input, instruction or training, attitude, the cognitive variables of field independence and right hemispheric specialization, social identity and aptitude (Abrahamsson \& Hyltenstam, 2008; Ioup, 2008). Due to such individual differences, some adults may be judged more native-like than others and can even outperform children. Though it is still a hot debate whether biological factors or non age-related individual differences lead to foreign accents, Ioup (2008: 57) concluded that "by and large both the nature of the accent and the degree to which it is manifest is influenced primarily by the age at which language acquisition began".

\subsection{Structure of the thesis}

The present Chapter 1 has sketched the research background and identified relevant issues to the present research on the phonology. Chapters 2 and 3 will describe two perception tests.

Chapter 2 is on pitch accent location. A set of sentences were presented in two versions, each with a different location of the pitch accent, one correct and one incorrect, as informed by different linguistic generalizations. The purpose of the test is to study how well Chinese learners of Dutch identify the correct accentuation pattern in Dutch sentences in a forced choice decision task.

Chapter 3 deals with melody choice. An 'ideal' reading of the fable Winterkoninkje was divided into 26 fragments and produced naturally with a number of alternative 'incorrect' intonations. Each fragment was presented to a group of 20 native Dutch and 20 Chinese-Dutch listeners with four intonation contours. One of these was the intended best intonation contour, and the other three were intended as less felicitous versions with different melodies. Working chronologically through the story, the participants listened to the four versions of each fragment and its preceding context as often as they wished, and then selected the best contour for each fragment. The hypothesis is that Dutch listeners show greater agreement in carrying out this task than Chinese listeners. 
Chapter 4 describes an unrestricted read-aloud production test the melodic choices based on seven sets of sentences, compos elicit particular pitch accents and intonation patterns. Th consisting of sentences that typically have a specific nuclear co recorded by 20 Chinese speakers of Dutch. To establish 'correct' contours (baseline) are, we used readings of the sam by a small group of five native speakers of Standard Dutch.' readings show variation; 'errors' by Chinese readers should be more heavily as the variation is smaller in the Dutch group. ' to be counted in terms of (a) correct pitch placement and nuclear tune. Phrasing, pitch range, speech rhythm, speech articulation rate will be investigated and compared in this chap

Chapters 5 and 6 present two studies on the phonetic $f$ Mandarin-accented Dutch. Mandarin-accented prosody will be a corpus of read speech by 20 speakers of Dutch with a Chinese background and compared with existing data on Dutch. The sentences are chosen from the Intonation in V Dutch (IVAN) corpus. Chapter 5 studies the impact of time $p$ the production of melodies $\left(\mathrm{H}^{*} \mathrm{~L} \mathrm{~L} \%\right.$; $\mathrm{L}^{*} \mathrm{H} \mathrm{H} \%$; H*L $\mathrm{H}$ pressure was created through the use of long and short vowels words $(/ 0 /$ and $/ 0 /$, spelled as $o$ and $o o$, respectively), an versus presence of a sonorant in the coda $(/ \mathrm{f} /$ versus $/ \mathrm{m} /)$. T comprised 12 test sentences: four declaratives, four questions rhetorical questions. Chapter 6 targets focus effects in falling $(\mathrm{H} * \mathrm{~L} \mathrm{~L} \%)$. The corpus for this experiment consists of thre sentences with target words in three different focus conditic focus, narrow focus, and corrective focus). The rhythmic patte alternation of emphasized and non-emphasized syllables) re same in these sentences. Chapter 7, the last part, pre conclusions of my experimental work and identifies topics research. 


\subsection{References}

Abrahamsson, N. \& Hyltenstam, K. (2008). The robustness of aptitude effects in near-native second language acquisition. Studies of Second Language Acquisition, 30, 481-509.

Abrahamsson, N. \& Hyltenstam, K. (2009). Age of onset and nativelikeness in a second language: listener perception versus linguistic scrutiny. Language Learning, 59, 249-306.

Anderson, J. (1987). The markedness differential hypothesis and syllable structure difficulty. In G. Ioup \& S. Weinberger (Eds.), Interlanguage Phonology: The Acquisition of a Second Language Sound System (pp. 279291). New York: Newbury House/Harper \& Row.

Anderson-Hsieh, J., Johnson, R. \& Koehler, K. (1992). The relationship between native speaker judgements of non-native pronunciation and deviance in segmentals, prosody and syllable structure. Language Learning, 42, 529-555.

Aoyama, K., Flege, J. E., Guion, S. G., Akahane-Yamada, R. \& Yamada, T. (2004). Perceived phonetic dissimilarity and L2 speech learning: The case of Japanese / $\mathrm{r} /$ and English /1/. Journal of Phonetics, 32, 233-250.

Aoyama, K. \& Guion, S. G. (2007). Prosody in second language acquisition. Acoustic analyses of duration and F0 range. In O-S. Bohn \& M. J. Munro (Eds.), Language experience in second language Learning: In bonor of James Emil Flege (pp. 281-297). Amsterdam: John Benjamins.

Archibald, J. A. (1994). A formal model of learning L2 prosodic phonology. Second Language Research, 10, 215-240.

Asher, J. \& Garcia, R. (1969). The optimal age to learn a foreign language. Modern Language Journal, 53, 1219-1227.

Ausubel, D. P. (1963). The psychology of meaningful verbal learning. New York: Grune \& Stratten.

Beckman, M. E. \& Ayers, G. M. (1994). Guidelines for ToBI Labelling. Unpublished manuscript, Ohio State University. [the English ToBI homepage at http://ling.ohio-state.edu/Phonetics/main.mod.html].

Beckman, M. E., Hirschberg, J. \& Shattuck-Hufnagel, S. (2005). The original ToBI system and the evolution of the ToBI framework. In S.-A. Jun (Ed.), Prosodic Typology: The Pbonology of Intonation and Pbrasing (pp. 9-54). Oxford: Oxford University Press.

Best, C. T. (1993). Emergence of language-specific constraints in perception of non-native speech contrasts: A window on early 
phonological development. In B. de Boysson-Bardies, S. de Sc Jusczyk, P. MacNeilage \& J. Morton (Eds.), Developmental net Speech and face processing in the first year of lefe (pp. 289-304). I Kluwer Academic Publishers.

Best, C. T. (1994a). The emergence of language-specific influences in infant speech perception. In J. Goodman Nusbaum (Eds.), Development of speech perception: The tra speech sounds to spoken words (pp. 167-224). Cambridge, Press.

Best, C. T. (1994b). Learning to perceive the sound pattern c In C. Rovee-Collier \& L. Lipsitt (Eds.), Advances in Infang (pp. 217-304). Hillsdale, NJ: Ablex Publishers.

Best, C. T. (1995). A direct realist view of cross-langua perception. In W. Strange, (Ed.), Speech perception an experience: Theoretical and methodological issues (pp. 171-206). MD: York Press.

Best, C. T., McRoberts, G. W. \& Sithole, N. N. (1988). The ph basis of perceptual loss for non-native contrasts: Maint discrimination among Zulu clicks by English-speaking infants. Journal of Experimental Psychology: Human Per Performance, 14, 345-360.

Best, C. T. \& Tyler, M. (2007). Nonnative and second-langua perception: Commonalities and complementarities. In C M. Munro (Eds.)., Language Experience in Second langz Learning. In bonor of James Emil Flege (pp.13-34). Amsterc Benjamins.

Boersma, P. (1998). Functional phonology. The Hague: Holland Graphics.

Bohn, O. -S. \& Flege, J. E. (1992). The production of new vowels by adult German learners of English. Studies Language Acquisition, 14, 131-158.

Bohn, O.-S. \& Flege, J. E. (1996). Perception and productior vowel category by adult second language learners. In A. H. Leather (Eds.), Second language speech. Structure ar (pp. 53-73). New York: Mouton de Gruyter.

Bradlow, A. R. (2008). Training non-native language sounc Lessons from training Japanese adults on the Englis contrast. In J. G. Hansen Edwards \& M. L. Zamp Phonology and second language acquisition (pp. 288-308). A John Benjamins. 
Brière, E. (1966). An investigation of phonological interference, Language, $42,769-796$.

Broselow, E., Chen, S. \& Wang, C. (1998). The emergence of the unmarked. Studies in Second Language Acquisition, 20, 261-280.

Chen, H. (2008). On Chinese EFL learner's English intonation pattern. Shanghai: Shanghai Foreign Language Education Press.

Chun, D. M., Hardison, D. M. \& Pennington, M. C. (2008). Technologies for prosody in context: Past and future of L2 research and practice. In J. G. Hansen Edwards \& M.L. Zampini (Eds.), Phonology and second language acquisition (pp. 322-346). Amsterdam: John Benjamins.

Chinese Academy of Social Sciences \& Australian Academy of the Humanities. (1990). Language Atlas of China. Hong Kong: Hong Kong Longman Press.

Derwing, T.M. \& Munro, M. J. (1997). Accent, intelligibility, and comprehensibility: Evidence from four L1s. Studies in Second Language Acquisition, 19, 1-16.

Derwing, T.M., Munro, M. J. \& Wiebe, G. (1998). Evidence in favor of a broad framework for pronunciation. Language Learning, 48, 393-410.

Derwing, T. M. \& Rossiter, M. J. (2003). The effects of pronunciation instruction on the accuracy, fluency, and the complexity of L2 accented speech. Applied Language Learning, 13, 1-17.

Eckman, F. R. (1977). Markedness and the contrastive analysis hypothesis. Language Learning, 27, 315-350.

Eckman, F. R. (1984). Universals, typologies and interlanguage. In W. Rutherford (Ed.), Language universals and second language acquisition (pp. 79-105). Amsterdam: John Benjamins.

Eckman, F. R. (1985). Some theoretical and pedagogical implications of the Markedness Differential Hypothesis. Studies in Second Language Acquisition, 7, 289-307.

Eckman, F. R. (1991). The Structural Conformity Hypothesis and the acquisition of consonant clusters in the interlanguage of ESL learners. Studies in Second Language Acquisition, 13, 23-41.

Eckman, F. R. (2008). Typological markedness and second language phonology. In J. G. Hansen Edwards \& M. L. Zampini (Eds.), Phonology and second language acquisition (pp. 95-115). Amsterdam: John Benjamins.

Fikkert, P. (2007). Acquiring phonology. In P. de Lacy (Ed.), Handbook of phonological theory (pp. 537-554). Cambridge: Cambridge University Press. 
Flege, J. E. (1987). The production of "new" and "similar" $p$ foreign language: Evidence for the effect of $\mathrm{e}$ classification. Journal of Phonetics, 15, 47-65.

Flege, J. (1988). Factors affecting degree of perceived foreign English sentences. Journal of the Acoustical Society of America, Flege, J. (1991). Age of learning affects the authenticity of $v$ time (VOT) in stop consonants produced in a second Journal of the Acoustical Society of America, 89, 395-411.

Flege, J. (1995). Second-language speech learning: theory, fin problems. In W. Strange (Ed.), Speech perception and linguisti Issues in cross-language research (pp. 233-277). Timonium, Press.

Flege, J. (1999). Age of learning and second-language spee Birdsong (Ed.), Second Language Acquisition and the Critical Perioc (pp. 101-132). Hillsdale, NJ: Lawrence Erlbaum.

Flege, J. (2002). Interactions between the Native and secon phonetic systems. In P. Burmeister, T. Piske \& A. Rohde Integrated View of Language Development: Papers in Honor of $\mathrm{He}$ (pp.217-244). Trier: Wissenschaftlicher Verlag.

Flege, J., Bohn, O-S. \& Jang, S. (1997). The effect of exp nonnative subjects' production and perception of Engli Journal of Phonetics, 25, 437-470.

Flege, J. \& Eefting, W. (1988). Imitation of a VOT continuum speakers of English and Spanish: Evidence for phoneti formation. Journal of the Acoustical Society of America, 83, 729

Flege, J. \& Fletcher, K. (1992). Talker and listener effec perception of degree of foreign accent. Journal of the Acon of America, 91, 370-389.

Flege, J., Frieda, A. \& Nozawa, T. (1997). Amount of nativ (L1) use affects the pronunciation of an L2. Journal of $P$ 169-186.

Flege, J. \& Hillenbrand, J. (1984). Limits on pronunciation a adult foreign language speech production. Journal of th Society of America, 76, 708-721.

Flege, J., MacKay, I. \& Meador, D. (1999). Native Italian production and perception of English vowels. Journal of th Society of America, 106, 2973-2987.

Flege, J., MacKay, I. \& Piske, T. (2002). Assessing bilingual c Applied Psycholinguistics, 23, 567-598. 
Flege, J., Munro, M. \& MacKay, I. (1995). Factors affecting degree of perceived foreign accent in a second language. Journal of the Acoustical Society of America, 97, 3125-3134.

Flege, J., Schirru, C. \& MacKay, I. (2003). Interaction between the native and second language phonetic subsystems. Speech Communication, 40, $467-491$.

Flege, J., Yeni-Komshian, G. \& Liu, S. (1999). Age constraints on second language learning. Journal of Memory and Language, 41, 78-104.

Fries, C. C. (1945). Teacbing and learning English as a foreign language. Ann Arbor: University of Michigan Press.

Gass, S. (1984). Development of speech perception and speech production in adult second language learners. Applied Psycholinguistics, $5,51-74$.

Gussenhoven, C. (2005). Transcription of Dutch intonation. In Sun-Ah Jun (Ed.), Prosodic Typology: The Phonology of Intonation and Phrasing (pp. 118-145). Oxford: Oxford University Press.

Gussenhoven, C., Rietveld, A., Kerkhoff, J. \& Terken, J. (2002). Transcription of Dutch Intonation. Second Edition.

$<$ http://todi.let.kun.nl/>

Guion, S. G., Flege, J. E., Liu, S. H. \& Yeni-Komshian G. H. (2000). Age of learning effects on the duration of sentences produced in a second language. Applied Psycholinguistics, 21, 205-228.

Gut, U. (2000). On the acquisition of rhythmic structure. Proceedings of New Sounds 2000, Amsterdam, The Netherlands, 148-154.

Gut, U. (2003). Non-native speech thythm in German. Proceedings of the $15^{\text {th }}$ International Congress of Phonetic Sciences, Barcelona, Spain, 24372440.

Gut, U. (2005). Nigerian English prosody. English World-Wide, 26, $153-$ 177.

Gut, U. (2009). Non-native speech. Frankfurt: Peter Lang.

Hagen, M., Kerkhoff, J. \& Gussenhoven, C. (2011). Singing your accent away, and the way it works. Proceedings of the $17^{\text {th }}$ International Congress of Phonetic Sciences, Hong Kong, 799-802.

Hanci-Bhatt, B. (2008). Second language phonology in Optimality Theory. In J. G. Hansen Edwards \& M. L. Zampini (Eds.), Phonology and second language acquisition (pp.117-146). Amsterdam: John Benjamins.

Hansen Edwards, J. G. (2008). Social factors and variation in production in L2 phonology. In J. G. Hansen Edwards \& M. L. Zampini (Eds.), 
Phonology and second language acquisition (pp. 252-279). A John Benjamins.

Hou, J. (2002). Introduction to dialects in Modern Cbinese. Shanghai Education Press.

Ioup, G. (1984). Is there a structural foreign accent? A com syntactic and phonological errors in second language a Language Learning, 34, 1-17.

Ioup, G. (2008). Exploring the role of age in the acquisition of language phonology. In J. G. Hansen Edwards \& M. L (Eds.), Phonology and second language acquisition (pp. 19-39). A John Benjamins.

Johansson, S. (1978). Studies in error gravity. Gothenburg: G University.

Kim, R. (1995). The effect of age-of-L2 onset on ultimate L2 1 The English /i-I/ distinction made by Korean speake Teacbing, 50, 257-279.

Kluge, D. C., Rauber, A. S., Reis, M. S. \& Bion, R. A. H. (2 relationship between the perception and production $c$ nasal codas by Brazilian learners of English. Proceedings o 2007, Antwerp, Belgium, 2297 -2300.

Kuhl, P. K. (1991). Human adults and human infants show a " magnet effect" for the prototypes of speech categories, $m$ not. Perception \& Psychophysics, 50, 93-107.

Kuhl, P. K. (1992). Infants' perception and representation Development of a new theory. In J. Ohala, T. Nearey, B M. Hodge \& G. Wiebe (Eds.), Proceedings of the Second 1 Conference on Spoken Language Processing (pp. 449-456). I Canada: University of Alberta Press.

Kuhl, P. K. (1993a). Infant speech perception: A wi psycholinguistic development. International of Psycholinguisi 56.

Kuhl, P. K. (1993b). Innate predispositions and the effects of in speech perception: The native language magnet theory Boysson-Bardies, S. de Schonen, P. Jusczyk, P. McNe Morton (Eds.), Developmental neurocognition: Speech and face the first year of life (pp. 259-274). Dordrecht: Kluwer Publishers.

Kuhl, P. K. (1994). Learning and representation in speech anc Current Opinion in Neurobiology, 4, 812-822. 
Kuhl, P. K. (2000). A new view of language acquisition. Proceedings of the National Academy of Sciences, 97, 11850-11857.

Kuhl, P. K. \& Iverson, P. (1995). Linguistic experience and the "perceptual magnet effect". In W. Strange (Ed.), Speech perception and linguistic experience: Issues in cross-language research (pp.121-154). Timonium, MD: York Press.

Lacerda, F. (1995). The perceptual-magnet effect: An emergent consequence of exemplar-based phonetic memory. In K. Elenius \& P. Branderud (Eds.), Proceedings of the 13th International Congress of Phonetic Sciences, Vol. 2, Stockholm, 140-147.

Lado, R. (1957). Linguistics across cultures. Ann Arbor: Universtity of Michigan Press.

Lenneberg, E. (1967). Biological foundation of language. New York: John Wiley \& Son.

$\mathrm{Li}$, Minghuan. (1999). We need two worlds: Cbinese immigration association in a western society. Amsterdam: Amsterdam University Press.

Lively, S. E. \& Pisoni, D. B. (1997). On prototypes and phonetic categories: A critical assessment of the perceptual magnet effect in speech perception. Journal of Experimental Psychology: Human Perception and Performance, 23, 1665-1679.

Llisterri, J. (1995). Relationships between speech production and speech perception in a second language. In $\mathrm{K}$. Elenius \& $\mathrm{P}$. Branderud (Eds.), Proceedings of the 13th International Congress of Phonetic Sciences, Vol. 4, Stockholm, 92-99.

Magloire, J. \& Green, K. P. (1999). A cross-language comparison of speaking rate effects on the production of voice onset time in English and Spanish. Phonetica, 56, 158-185.

Major, R. C. (1986). The ontogeny model: Evidence from L2 acquisition of Spanish. Language Learning, 36, 453-503.

Major, R. C. (1992). Losing English as a first language. The Modern Language Journal, 76, 190-208.

Major. R. C. (1994). Chronological and stylistic aspects of Brazilian Portuguese, Language Learning, 36, 453-504.

Major. R. C. (1996). Markedness in second language acquisition of consonant clusters, In R. Bayley \& D. Preston (Eds.), Second Language Acquisition and Linguistic Variation (pp. 75-96). Amsterdam: John Benjamins.

Major. R. C. (2001). Foreign accent: The ontogeny and phylogeny of second language bomology. Mahwah, NJ: Lauwrence Erlbaum Associates. 
Major. R. C. (2008). Transfer in second language phonology Hansen Edwards \& M. L. Zampini (Eds.), Pbonology language acquisition (pp. 19-39). Amsterdam: John Benjamir

Major. R. C. \& Faudree, M. (1996). Markedness universa acquisition of voicing contrasts by Korean speakers 0 Studies in Second Language Acquisition, 18, 69-90.

McAllister, R. (2007). Strategies for realization of L2-Categori /s / - / z/. In O-S. Bohn \& M. J. Munro (Eds.), Language second language learning: In honor of James Emil Flege (pp. Amsterdam: John Benjamins.

McAllister, R., Flege, J. \& Piske, T. (2002). The influence of the acquisition of Swedish vowel quantity by native $\mathrm{s}$. Spanish, English and Estonian. Journal of Phonetics, 30, 229-

Moyer, A. (2004). Age, accent, and experience in second language Clevedon, UK: Multilingual Matters Ltd.

Munro, M. J. (2008). Foreign accent and speech intelligibilit Hansen Edwards \& M. L. Zampini (Eds.), Phonology language acquisition (pp. 193-218). Amsterdam: John Benjar

Munro, M. J. \& Derwing, T. M. (1995). Processing time, a comprehensibility in the perception of native and foreig speech. Language and Speech, 38, 289-306.

Munro, M. J. \& Derwing, T. M. (1998). The effects of speaki listener evaluations of native and foreign-accented speecl Learning, 48, 159-182.

Munro, M. J. \& Derwing, T. M. (2001). Modelling percepti comprehensibility and accentedness of L2 speech: Th speaking rate. Studies in Second Language Acquisition, 23, 451

Munro, M., Flege, J. \& MacKay, I. (1996). The effect of age language learning on the production of English vowe Psycholinguistics, 17, 313-334.

Nash, R. (1972). Phonetic and prosodic interference and their intelligibility. Proceedings of the 7 th International Congress of $P b c$ The Hague: Mouton, 837-839.

Neufeld, G. G. (1988), Phonological asymmetry in secon learning and performance. Language Learning, 38, 531-559.

Ohala, D. K. (2008). Phonological acquisition in a first langua Hansen Edwards \& M. L. Zampini (Eds.), Phonology language acquisition (pp. 19-39). Amsterdam: John Benjamin

Oyama, S. (1976). A sensitive period of the acquisition of a phonological system. Journal of Psycholinguistic Research, 5, 20 
Pater, J. V. (1997). Metrical parameter missetting in second language acquisition. In S. J. Hannahs \& M. Young-Scholten (Eds.), Focus on phonological acquisition (pp. 235-261). Philadelphia: John Benjamins.

Patkowski, M. (1990). Age and accent in second language: A reply to James Emil Flege. Applied Linguistics, 11, 73-89.

Pierrehumbert, J. B. (2003). Phonetic diversity, statistical learning, and acquisition of phonology. Learning and speech, 46, 115-154.

Piske, T., MacKay, I. \& Flege, J. (2001). Factors affecting degree of foreign accent in an L2: A review. Journal of Phonetics, 29, 191-215.

Rasier, L. \& Hiligsmann, P. (2007). Prosodic transfer from L1 to L2. Theoretical and methodological issues. Nouveaux Cabiers de Linguistique Française, 28, 41-46.

Scovel, T. (1988). A time to speak: A psycholinguistic investigation into the critical period for buman speech. New York: Harper \& Row.

Schmidt, A. M. \& Flege, J. E. (1996). Speaking rate effects on stops produced by Spanish and English monolinguals and Spanish/English bilinguals. Phonetica, 53, 162-179.

Selinker, L. (1972). Interlanguage. International Review of Applied Linguistics, 10, 209-231.

Sheldon, A. \& Strange, W. (1982). The acquisition of $/ \mathrm{r} /$ and $/ 1 /$ by Japanese learners of English: Evidence that speech production can precede speech perception. Applied Psycholinguistics, 3, 243 -261.

Sparks, R., Patton, J., Ganschow, L. \& Humbach, N. (2009). Long-term crosslinguistic transfer of skills from L1 to L2. Language Learning, 59, 203-243.

Strange, W. (1995). Phonetics of second language acquisition: past, present and future. Proceedings of the 13th International Congress of Phonetic Sciences, 4, Stockholm, 84 -91.

Strange, W. \& Shafer, V. (2008). Speech perception in second language learners: The re-education of selective perception. In J. G. Hansen Edwards \& M. L. Zampini (Eds.), Phonology and second language acquisition (pp. 153-191). Amsterdam: John Benjamins.

Tang, Chaoju (2009). Mutual intelligibility of Chinese dialects, an experimental approach. LOT dissertation series No. 228. Utrecht: LOT.

Tang, Chaoju \& V. J. van Heuven (2000). Mutual intelligibility of Chinese dialects experimentally tested. Lingua, 119, 709-732.

Thompson, I. (1991). Foreign accents revisited: The English pronunciation of Russian immigrants. Language Learning, 41, 177204. 
Thomburgh, D. \& Ryalls, J. (1998). Voice onset time in Spani bilinguals: Early versus late learners of English. Communication Disorders, 31, 215-229.

Trofimovitch, P. \& Baker, W. (2006). Learning second supramentals. Effects of L2 experience on prosody ar characteristics of L2 speech. Studies in Second Language Acq $1-30$.

Trofimovich, P. \& Baker, W. (2007). Learning prosody at characteristics of second language speech: Effects of exp child learners' acquisition of five suprasegmentals Psycholinguistics, 28, 251-276.

Trofimovich, P., Gatbonton, E. \& Segalowitz, N. (2007). look at L2 phonological learning: Seeking processing ex for implicational phenomena. Studies in Second Language $29,407-448$.

Trouvain, J. \& Gut, U. (2007). Learner corpora in second langz research and teaching. Non-native prosody, phonetic description practice. Berlin: Mouton de Gruyter.

Wang, Y., Spence, M. M., Jongman, A. \& Sereno, J. A. (1999 American listeners to perceive Mandarin tones. Journal of Society of America, 106, 105-122.

Wardhaugh, R. J. (1970). The contrastive analysis hypothesi Quarterly, 4, 123-130.

Werker, J. F., Gilbert, J. H. V., Humphrey, G. K. \& Tees, R. Developmental aspects of cross-language speech percep Development, 52, 349-355.

Volín, J. \& Skarnitzl, R. (2010). The strength of foreign accen English under adverse listening conditions. Speech commu 1010-1021.

Yamada, R. A., Strange, W., Magnuson, J. S., Pruitt, J. S. \& Cla I. (1994). The intelligibility of Japanese speakers' prod American English /r/, /1/ and /w/, as evaluated by nativ of American English. Proceedings of the 1994 International $C$ Spoken Language Processing, 2023-2026. Acoustical Society Yokohama.

Zampini, M. L. (2008). L2 speech production research: findi and advances. In J. G. Hansen Edwards \& M. L. Zamt Phonology and second language acquisition (pp. 219-249). A John Benjamins.

http://www.chinalanguage.com/content/?pageID=Book:29 


\section{Chapter 2}

\section{Choosing the optimal pitch accent location in Dutch ${ }^{1}$}

\subsection{Introduction}

Speakers of non-native languages (L2 speakers) often have difficulties in producing acceptable stress and accentuation patterns, in part depending on the difference between L1 and L2. Incorrect prominence patterns often persist despite long exposure to the L2. It would appear that such 'stress deafness' is not merely the result of major stress typology differences. One situation in which it has been observed is that of Chinese learners of English (Gut, Trouvain \& Barry, 2007). Germanic languages generally have sentence prosodic patterns that are the result of the inherent stress patterns of words and a rather complex set of rules for the placement of pitch accents on a subset of the stressed syllables. Variation in the distribution of pitch accents is strongly contextdependent, but even in reading tasks with isolated sentences, differences between native speakers and Chinese L2 speakers are striking (Chen Hua, 2008). The question we attempt to address in this investigation is, first, whether the apparent difficulties Chinese learners of Dutch (CSD) have with the correct placement of prominences in Dutch sentences is due to their inability to produce those patterns or rather in their ignorance of what an acceptable pronunciation of an isolated sentence is. The question, therefore, is whether they can recognize the correct location of pitch accents in a listening task. Additionally, given that the explanation for the presence or absence of a pitch accent on a given syllable may vary from morphology to information structure, our interest is in whether the acceptability of some accent placements is easier to establish by Chinese

\footnotetext{
${ }^{1}$ This chapter is based on a publication by $\mathrm{He}$, van Heuven \& Gussenhoven in $\mathrm{M}$. Wrembel, M. Kul \& K. Dziubalska-Kolaczyk (Eds.), Acbievements and perspectives in SLA of speech: New Sounds 2010 (pp. 125-137). Frankfurt am Main: Peter Lang Verlag.
} 
learners of Dutch than other accent placements. To this enc classified the accent placements according to the linguistic gen that lies at their basis.

Accent is a place marker in the phonological structure wh known as pitch accents, are to be inserted (Goldsmith, 197 1978). Pitch accents in an English, German or Dutch set determined by lexical, phonological and morphological infor addition to semantic and pragmatic factors (Gussenhoven, chose six categories of accentuation problems in sentence participants to judge in the experiment, henceforth refer 'accentuation types' (See Appendix 1).

The first accentuation type concerns primary word stress, Dutch falls on the antepenult, the penult, or the final syllable o if the penult is open, and on the penult or the final syllable if is closed (Booij, 1999; Gussenhoven, 1999). In the word ooiev whose penult is open, the antepenult and the last syllable ar and the primary stress falls on the antepenult $o o$ and not on th Because final VVC syllables regularly take the primary stress, e words like ooievaar, Spanjaard 'Spaniard', olifant 'elephant' $\mathrm{m}$ difficulties to foreign learners, even though such words are fr the case of ooievaar, (1a) is the correct reading and (1b) the inco

(1) a. Er staat een OOievaar in de wei.

b. Er staat een ooieVAAR in de wei.

'There's a stork in the meadow.'

The second problem category comprises compound nouns. constituents in the compound, the second loses its pitch a example, the pitch accent in groentetuin 'kitchen garden' is o component groente rather on the second tuin, which means th (2a) is correct and (2b) incorrect.

(2) a. Ze bebben een grote GROENTEtuin.

b. Ze bebben een grote groenteTUIN.

'They have a large kitchen garden.' 
The third problem area is that of phrasal proper names. In the Netherlands and Belgium, people's names generally consist of a given name, a surname and an optional surname prefix. The prefix is a function word (or a combination of function words), which remains unstressed and is part of the surname, even though in alphabetic orderings it is ignored. Some surnames, particularly those that were apparently reluctantly - adopted as a result of the compulsory registration of the Dutch population during the French occupation of $1806-1813^{2}$, are etymologically phrases, like Vroegindewei, which goes back to Vroeg in de wei 'early in the field'. The primary stress of a phrasal surname generally falls on the first syllable, but on the last if the same words are used as a common phrase. That is, (3a) is the correct reading and $(3 \mathrm{~b})$ the incorrect one.

\section{(3) a. Dit is mevroun VROEGindewei.}

b. Dit is mevroun vroegindeWEI.

'This is Mrs Vroegindewei.'

Gussenhoven (1983) made a distinction between eventive and noneventive sentences, where eventive sentences involve the reporting of a change in the world. Following Schmerling (1976), the Sentence Accent Assignment Rule (SAAR) says that in eventive sentences, predicates lose their pitch accent if they are adjacent to one of their arguments. For instance, if a single accent falls upon dogs in the sentence [DOGS must be carried $]_{\text {EVENTIVE, }}$ all relevant people will have to carry a dog. A noneventive sentence would retain accents on both the argument dogs and the predicate must be carried, in which 'contingency' reading only those people who happen to have a dog are obligated to carry it (Gussenhoven, 1983; Ladd, 2008). The fourth and the fifth categories are eventive and non-eventive sentences, respectively. In (4a), the argument of the verb WERken 'works' is accented and the verb aangekocht 'acquired' is deaccented. This is the reason why (4a), an eventive sentence, is correct. However, despite the identical pitch accent distribution, the (a) version is

\footnotetext{
2 The public registration of births, marriages and deaths became compulsory in 1811 . Before that time, any registration was done by the churches. The resistance against the registration of surnames was strongest in the north and east of the country, where people often didn't have one. Later, many regretted their choice of name, and had it changed. For instance, the larger part of the Aap 'monkey' family changed their name into Davids in 1860 (Hulshof, 2011).
} 
the correct reading in the case of (5), because schade 'damage' potentially, so that the verb MELden 'report' is accented.

(4) a. Ze bebben een aantal nieuwe WERken aangekocht.

b. Ze bebben een aantal nieuwe WERken $A A N$ gekocht. 'They've acquired a number of new works of art.'

(5) a. U wordt verzocht eventuele SCHAde te MELden.

b. U wordt verzocht eventuele $S C H A$ de te melden. 'You are requested to report any damage.'

Deaccenting for 'givenness' and accenting for 'newness' is ill (6), where jas 'coat' is given information in the first sentence, 'black' is the new information. That is, (6a) is correct, wh incorrect.

(6) a. Ik beb wel een mooie bruine jas gezien. Maar ik zocht ZWARTE jas.

b. Ik heb wel een mooie bruine jas gezien. Maar ik zocht eigenlijk $J A S$.

'I did see a nice brown coat. But I was really looking coat'

Mandarin Chinese is traditionally analysed as having two accentuation: grammatical and logical (Gao, 1984). Grammati are claimed to be determined by the structure of syntactic phr logical accents depend upon the meanings speakers intend to grammatical accent is not as strong phonetically as a logi Unlike what is the case in languages like English and Dutch, th to be no consistent phonetic correlates of what has been chara grammatical stress. Possibly, stress differences identified by 1 Liao (1991), among others, may resolve as phrasing differenc occurrence of neutral tone vs. lexical tone. Be that as it following stress relations have been identified, whereby the phonetic strength for (i) the predicate verb than for the subject VP]-phrase; (ii) for the adjective in an [Adj Noun]-phrase, a adverb in an [Adv Verb]-phrase as well as in an [Verb-Adv]for the head of a prepositional phrase than for the prepositic the object in an [NP Verb]-phrase, and (v) to an interrogativ 
or demonstrative than to their head (Huang \& Liao 1991). These phonetic strength differences are not really comparable to the melodically prominent effect of a pitch accent in Dutch. Moreover, unlike the alternation between short unstressed and long stressed syllables in Dutch, syllable duration in Mandarin remains relatively constant, which is why it has been characterized as 'syllable-timed' (Clark \& Yallop, 1995; van Santen \& Shih, 2000). The only prominence pattern in the above list that corresponds to a Dutch prominence pattern created by the absence of a pitch accent is that of an object-verb combination, represented by the 'eventive' category exemplified in (4). However, Mandarin speakers may not be sensitive to the meaning distinction in non-eventive and eventive sentences, because that distinction will be expressed in different words or syntactic structures.

The effect of the logical accents in Mandarin sentences is phonetically closer to pitch accent distributions in Dutch sentences. In Mandarin, 'logical accents' are often given to words which are to be emphasized, like the new information, or else serve to express strong emotion (Huang \& Liao 1991). In effect, the rule for the realization of post-focal words, the phonetic reduction of the pitch range, is phonetically similar to that of deaccenting in West Germanic languages ( $\mathrm{Xu} \& \mathrm{Xu}, 2005)$. This means that the 'focus' category, exemplified in (6), should be the easiest case for Mandarin listeners to deal with.

Chinese speakers of Dutch are inevitably influenced, to greater or lesser extents, by their L1 Chinese when they speak Dutch. We know from the field of second language acquisition that the majority of second-language learners cannot acquire a native-like oral ability, but less is known about the extent to which non-native speakers acquire the prosodic knowledge of the target language even in a situation in which they cannot produce it correctly. The answer to that question is important, because the cause of any mispronunciations will need to be attributed either to a lack of knowledge of the L1 prosodic structure or to an inability to pronounce such structures. The present perception experiment was conducted to study how well Chinese speakers of Dutch identify the correct accentuation pattern in the six categories of Dutch sentences. The first question we addressed is whether Chinese learners of Dutch are less often correct and less confident in their judgment of the appropriateness of accent patterns in Dutch than native Dutch listeners, and if their 
performance varies over the six accent placement categories. T question is whether and to what extent Chinese speakers $\mathrm{x}$ overall proficiency in Dutch do better on the accent judgmen their counterparts with lower proficiency in Dutch.

\subsection{Method}

\subsubsection{Materials}

We composed six sentences in each of the six accentua described in section 1 and recorded these in a sound-treatec Radboud University Nijmegen with $\mathrm{H}^{*} \mathrm{~L}$ L\% pitch accents, ar of accent to recognize for Chinese listeners in English, which closely related to Dutch (Rosenberg, Hirschberg \& Manis, 201 the sentences were read with correct accentuation and half wit accentuation by a male speaker of Dutch, while the complen of incorrect and correct sentences was read by a female Dutch. Seventy-two $[6$ sentences $\times 2$ (correct and incor categories] stimuli with each sentence read with correct anc accentuation by different speakers were divided into two mirro stimuli. Each set thus contained 36 stimuli, and had the san order of sentences, such that a correct stimulus always occur set where the incorrect version occurred in the other set. We best token of each pair of recordings as stimuli to be preser listeners.

\subsubsection{Participants}

\subsubsection{General information}

A group of 20 native and 20 Chinese speakers of Dutch part the perception experiment. All Chinese participants $(3$ male, aged from 17 to 53, were native speakers of Mandarin and the northern part of China, where the local dialects have ton similar to those of Standard Chinese (Yuan, 1983). Their pro Dutch varied greatly, but all of them had had sufficient expo language to be able to do the experiment. At the time of the $\mathrm{e}$ 
they had lived in the Netherlands for periods between three months and 22 years. The two subjects who had lived in the country for three months had studied Dutch in China for more than two years. The Dutch participants (4 male, 16 female) were self-declared native speakers of standard Dutch, aged between 18 and 54 .

\subsubsection{Proficiency ratings}

In order to answer our third research question, which concerned the hypothesis that more proficient speakers would be better judges of what is an appropriate intonation contour, the twenty Chinese subjects were asked to read a text of 42 brief Dutch sentences, which were recorded in a professional studio of the Arts Faculty of Radboud University Nijmegen. From the recordings by each speaker, we selected the readings of seven randomly chosen sentences. Their mean sentence length was 11 words. We presented these 140 utterances to three experts on Dutch phonetics, using a different random order for each expert. We did this twice. The first time, the judges were asked to rate the intonational proficiency of the speaker on a scale from ' 1 ' to ' 10 ', where ' 1 ' is 'extremely bad' and '10' is 'extremely good', with the intermediate boxes representing intermediate judgments. Judgements were given for each utterance. The judges were instructed to take into account whether speakers used a correct melody, produced correct word stresses, accented the words which should be accented in the sentence, and produced prosodic breaks somewhere in the middle of the sentences whenever that seemed appropriate. The second time, we asked the experts to rate the segmental proficiency; they were instructed to pay attention to the articulation of the vowels and consonants, including their duration, together with an estimate of whether the speakers pronounced the words clearly and fluently and use the 10-point scale described above. Mean scores of prosodic and segmental proficiency were obtained for each subject by aggregating the scores over the seven items per judge. Pearson's correlations between segmental proficiency and prosodic proficiency are .81 for Expert 1, .96 for Expert 2 and .87 for Expert 3 (a mean $r$ of .88). This suggests that segmental proficiency and prosodic proficiency are highly correlated. Cronbach's alpha's are very high for both measures $\left(\right.$ Cronbach ${ }_{\text {pro }}=.94$, Cronbach $_{\text {seg }}=.92$ ) reflecting high agreement among the judges. Correlations for each of the scores between experts are $\mathrm{r}_{\mathrm{pro1}}$, pro2 $=.97, \mathrm{r}_{\mathrm{pro} 1, \mathrm{pro} 3}=.85, \mathrm{r}_{\mathrm{pro}}$, pro3 
$=.88 ; r_{\text {seg } 1, \mathrm{seg} 2}=.82, \mathrm{r}_{\mathrm{seg} 1}, \mathrm{seg} 3=.76, \mathrm{r}_{\mathrm{seg}} 2, \mathrm{seg} 3=.97$. We divide the Chinese group of speakers into a higher ("Chine Dutch': CHD) and a lower (CLD) subgroup on the basi subject's mean score over their segmental and prosodic 1 scores. One subject, who had come to the Netherlands at the appeared to be so proficient in Dutch that one of the thr considered her a native speaker. She had high scores of segr. prosodic quality (9.6 and 9.1 respectively). Two subjec1 tenth/eleventh place with a score of 5.6, who we randomly a one group each.

\subsubsection{Procedure}

The participants were divided into two groups to do the for task. Ten Chinese subjects and ten Dutch subjects listened to Set I and the other half in Set II.

Either the stimuli in Set I or those in Set II were pro participants in individual sessions on a computer scre participant was asked to listen to the stimuli and judge w reading was correct or not. The listener wore a GH632 h Subjects first listened to 8 trial stimuli and then proceed experiment proper. They could replay any stimulus before judgment. The correct and incorrect tokens were rando participant across categories. The listeners first clicked either buttons marked 'correct' and 'incorrect', and then ind confidence in the judgment on a scale from 1 (poor confid (high confidence).

\subsection{Data analysis and discussion}

\subsubsection{Analysis and discussion of correctness scores}

We conducted a repeated measures Analysis of Variance (RM using accentuation type (WDS: word stress, CMP: compo proper names, EVS: eventive sentences, NES: non-eventive FOC: focus) as a within-subjects variable and the differen 
groups as a between-subjects factor. The results show that correctness scores (Table 2.1) are significantly different $(\mathrm{F}[5,190]=4.9, \mathrm{p}<.05)$ across accentuation types. Pairwise comparisons (Bonferroni corrected) reveal that mean differences between WDS and EVS, and between EVS and FOC are significant ( $\mathrm{p}=.014, \mathrm{p}=.002$, respectively). There is no significant interaction between accentuation type and language group $(F$ $[5,190]=1.4, \mathrm{p}>.05$ ). The mean correctness scores (Figure 2.1) for each stress type obtained by Chinese learners are significantly lower than those of the native Dutch group $(F[1,38]=39.4, \mathrm{p}<.05)$. This means that the native speakers of Dutch outperformed the Chinese speakers of Dutch. Patterns WDS and FOC are easier to identify, while EVS is the most difficult pattern.

Table 2.1. Mean correctness (Cor) and confidence (Conf) scores of Chinese learners of Dutch (CSD) and Dutch listeners to Dutch (NSD) broken down by accentuation type (WDS: word stress, CMP: compound, PRN: proper names, EVS: eventive sentences, NES: non-eventive sentences, FOC: focus). For explanation of negative confidence scores see text.

\begin{tabular}{|c|c|c|c|c|c|c|c|c|c|c|}
\hline \multirow{2}{*}{$\begin{array}{l}\text { Accent. } \\
\text { type }\end{array}$} & \multirow{2}{*}{$\begin{array}{l}\text { Lang. } \\
\text { group } \\
(\mathrm{N}=20)\end{array}$} & \multicolumn{2}{|c|}{ Mean } & \multicolumn{2}{|l|}{ Sd } & \multirow{2}{*}{$\begin{array}{l}\text { Profic. } \\
\text { group } \\
(\mathrm{N}=10)\end{array}$} & \multicolumn{2}{|c|}{ Mean } & \multicolumn{2}{|l|}{ sd } \\
\hline & & Cor & Conf & Cor & Conf & & Cor & Conf & Cor & Conf \\
\hline \multirow[t]{2}{*}{ WDS } & CSD & 3.95 & 1.45 & 1.60 & 2.17 & CLD & 3.20 & .25 & 1.69 & 1.82 \\
\hline & NSD & 5.80 & 4.38 & .41 & .50 & $\mathrm{CHD}$ & 4.70 & 2.65 & 1.16 & 1.84 \\
\hline \multirow[t]{2}{*}{ CMP } & CSD & 4.10 & 1.50 & 1.25 & 1.81 & CLD & 3.70 & .70 & .95 & .94 \\
\hline & NSD & 5.15 & 3.38 & .67 & .96 & CHD & 4.50 & 2.30 & 1.43 & 2.14 \\
\hline \multirow[t]{2}{*}{ PRN } & CSD & 3.90 & 1.38 & 1.29 & 1.79 & CLD & 3.10 & .15 & .99 & 1.03 \\
\hline & NSD & 5.25 & 3.06 & .79 & 1.04 & $\mathrm{CHD}$ & 4.70 & 2.62 & 1.06 & 1.52 \\
\hline \multirow[t]{2}{*}{ EVS } & CSD & 3.55 & .80 & 1.23 & 1.76 & CLD & 3.00 & -.05 & 1.05 & 1.13 \\
\hline & NSD & 4.75 & 2.73 & .85 & 1.05 & $\mathrm{CHD}$ & 4.10 & 1.65 & 1.20 & 1.91 \\
\hline \multirow[t]{2}{*}{ NES } & CSD & 3.45 & .71 & 1.23 & 1.74 & CLD & 2.90 & -.18 & 1.29 & 1.53 \\
\hline & NSD & 4.90 & 2.67 & 1.02 & 1.36 & CHD & 4.00 & 1.60 & .94 & 1.51 \\
\hline \multirow[t]{2}{*}{ FOC } & CSD & 4.45 & 1.98 & 1.05 & 1.59 & CLD & 4.20 & 1.32 & 1.03 & 1.17 \\
\hline & NSD & 5.30 & 3.52 & .80 & 1.11 & $\mathrm{CHD}$ & 4.70 & 2.63 & 1.06 & 1.73 \\
\hline
\end{tabular}




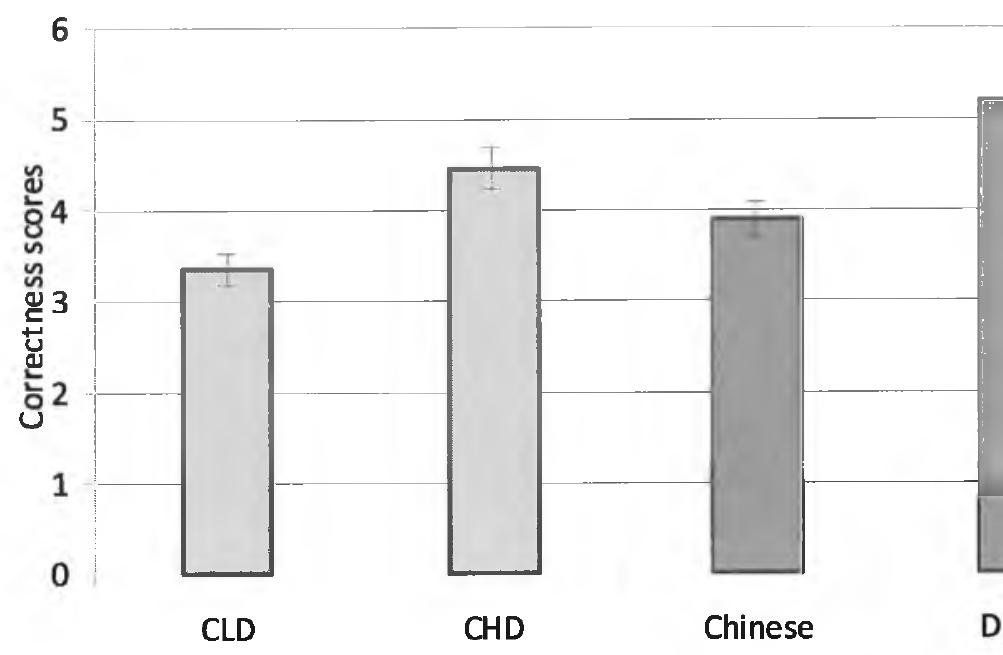

Figure 2.1. Overall mean correctness scores of Chinese subjects divid proficiency Chinese learners of Dutch (CLD), high-proficiency Chinese Dutch (CHD) and Dutch subjects.

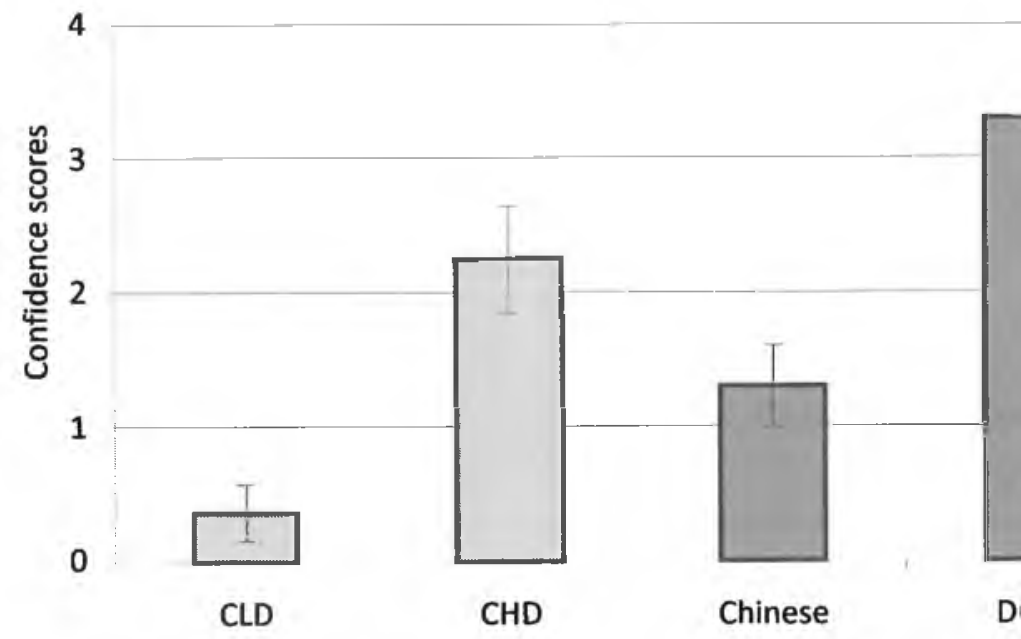

Figure 2.2. Overall mean confidence scores of Chinese subjects divid proficiency Chinese learners of Dutch (CLD), high-proficiency Chines Dutch (CHD) and Dutch subjects. 
As Table 2.1 shows, native listeners of Dutch obtained an overall mean correctness score above 5 points. Accentuation types EVS and NES were below that value, at 4.8 and 4.9 , respectively. The highest mean correctness score is 5.8 (WDS) and the second highest is 5.3 (FOC). In the group of Chinese listeners of Dutch, the mean correctness scores are all below 5 points. The mean correctness scores of types CMP and FOC are higher (4.1 and 4.5, respectively) than other accentuation types; the lowest is 3.5, which goes to type NES. Both the CSD and NSD groups have lower mean correctness scores for types EVS and NES, and higher mean correctness scores for type FOC (the highest for CSD). The NSD group got the highest mean score for type WDS, while this is not the highest for the CSD group. CSD got a higher mean score for type CMP. This means that Chinese speakers of Dutch have the most problems with the identification of correct word stress. But their ability to judge the correctness stresses of compound words and focus information in sentences is higher than that of other types. Both language groups have problems with the accentuation of EVS and NES.

We also conducted an RM-ANOVA using accentuation type as a withinsubjects variable and different Chinese proficiency groups as a betweensubjects factor. Correctness scores (Table 2.1) are significantly different across accentuation types $(\mathrm{F}[5,90]=2.3, \mathrm{p}=.05)$. Pairwise comparisons reveal that types EVS and FOC differ significantly $(p=.004)$. There is no significant interaction between accentuation type and proficiency group $(\mathrm{F}[5,90]<1)$. The mean correctness scores (Figure 2.1) for each accentuation type obtained by CLD are significantly lower than those of $\mathrm{CHD}(\mathrm{F}[1,18]=14.6, \mathrm{p}<.05)$. This means that the $\mathrm{CHD}$ group outperformed the CLD group. Type FOC is easiest to identify, while type EVS is generally difficult for Chinese listeners.

From Table 2.1, we also learn that CHD subjects got mean correctness scores above 4 points for all six accentuation types while CLD subjects obtained mean correctness scores around 3 points for all categories except FOC. Both CLD and CHD subjects got the highest mean correctness score for FOC, and lower mean correctness scores for EVS and NES. Not surprisingly, CLD subjects have more problems with the correct identification of word stress than CHD. Like the Dutch native speakers, CLD and CHD have problems with types EVS and NES. All groups have significantly higher mean correctness scores for FOC, 
showing that identifying the correct accentuation of sentences information is relatively easy.

\subsubsection{Analysis and discussion of confidence scores}

For the analysis of confidence scores, each response wa positively if the accompanying judgment was correct. Otheru weighed negatively. We computed mean confidence scores $\mathrm{t}$ across accent patterns. We wanted to know how confident th were when they made their judgments.

We again conducted an RM-ANOVA using accentuation within-subjects variable and language group as a between-subj Confidence scores (Table 2.1) are significantly differe accentuation types $(\mathrm{F}[5,190]=7.4, \mathrm{p}<.05)$. Pairwise co reveal that the difference between WDS on the one hand and and NES on the other are significant $(p<.05)$, as is the between FOC on the one hand and EVS and NES on the othe no significant interaction between accentuation type and lang? $(\mathrm{F}[5,190]=1.8, \mathrm{p}>.05)$. The mean confidence scores (Figu accentuation type obtained by the Chinese subjects are s. lower than those of the Dutch counterparts $(\mathrm{F}[1,38]=37.4$ This means that the native Dutch listeners were more confides Chinese listeners when they made their judgments. Both langu were more confident when they judged WDS and FOC than accentuation type.

As Table 2.1 shows, the mean confidence scores for the Dutch all above 3 points, except for EVS and NES, whose mean scores are 2.73 and 2.67 , respectively. NSD are most confide judgment of WDS (4.4), followed by their judgment of type The mean confidence scores of CLD are above 1 poi accentuation types except EVS (.8) and NES (.7).

An RM-ANOVA with accentuation type as a within-subjec and proficiency as a between-subjects factor shows that scores (Table 2.1) differ significantly across accentuation type $=2.6, \mathrm{p}<.05)$. Only the difference between FOC and NES is 
(pairwise comparison, $\mathrm{p}<.05$ ). There is no interaction between accentuation type and proficiency $(\mathrm{F}[5,90]<1)$. Mean confidence scores (Figure 2.2) for each stress type obtained by the CLD are significantly lower than those of the $\mathrm{CHD}(\mathrm{F}[1,18]=17.4, \mathrm{p}<.05)$. This means that CHD were more confident in their judgments than CLD. Both language groups were more confident judging type FOC and less so when judging type NES.

Table 2.1 shows that $\mathrm{CHD}$ are most confident judging WDS (2.7), CMP (2.6) and FOC (2.3), but less confident with types EVS (1.7) and NES (1.6, lowest). Not surprisingly, CLD are not confident when judging type WDS (.3), and like CHD subjects, they are not confident in their judgment of EVS (-.05) and NES (-.18).

Comparing mean correctness and mean confidence scores for the six accentuation types, we find that the two sets of scores correlate very strongly $(\mathrm{r}=.98, \mathrm{p}<.01)$. For the Dutch group, the mean correctness score of type EVS is the lowest even though the corresponding confidence score is not: the lowest confidence is for type NES. However, the differences are small between these two types, which are both related to the deaccentuation rule applying in Dutch eventive sentences. For the Chinese listeners, whether CLD or CHD, the correctness scores and their confidence scores are in agreement with each other across all types of accentuation. It follows from the above comparisons that all listeners took the experiment seriously and that their knowledge of Dutch accentuation patterns is truly reflected by their judgments.

\subsubsection{Other factors correlated with correctness and confidence scores}

In this section, we answer the question whether other factors like the age of participants, the length of residence (LOR) in the Netherlands, or the age of arrival in the country (AOA) explains their performance in the perception test. The correctness score has no relation with LOR $(r=.40$, n.s.) or with age $(r=-.43$, n.s.). However, AOA does correlate significantly with the correctness scores $(r=-.72, \mathrm{p}<.01)$. The confidence score behaves in a similar way, showing no correlation with 
LOR $(r=.43$, n.s. $)$ or age $(r=-.42, n . s)$, while correlating si with AOA $(\mathrm{r}=-.75, \mathrm{p}<.01)$. This suggests that choosing $\mathrm{t}$ pitch accent location in Dutch sentences is influenced by which learners are first exposed to realistic language use. exposure to Dutch cannot be said to have a positive effect The case here looks simple: the younger they were when the the Netherlands, the higher their correctness and confidence $\mathrm{s}$ in the perception test, supporting the 'younger-is-better' positi studies which have investigated the effects of age on pronunci: 1994: 489; Ioup, 2008).

\subsection{Conclusions}

Native speakers' correctness scores on the location of pitch Dutch sentences were significantly better than the scores by proficiency Chinese speakers of Dutch, and those of the significantly higher than those of low proficiency Chinese Dutch. Clearly, greater proficiency in the language improve ability to identify correct accent locations. Along with the scores, confidence ratings decreased significantly from the na via the high proficiency Chinese group to the low proficien group. Moreover, the earlier learners are exposed to the tar language, the more correct and the more confident they are in the correctness of accent location.

There were differences between the linguistic categories, sh some accent patterns are easier to judge - and thus presumab learn - than others. Native speakers find it easiest to identi word stress $(5.8$ correct, where 6.0 is the highest possible Chinese L2 speakers of Dutch find it easiest to judge the cor the focus condition (4.5). This reflects the fact that the 1 primary word stress in the words we used is a language specifi fact, whereas the focus structure of the sentences we used is $\mathrm{g}$. context. The Chinese learners evidently derived the correct ac pattern in the focus condition from the pragmatics of the min that constituted the stimuli. In this, they were helped by th post-focal pitch range reduction is a feature of Mandarin s resembles post-focal deaccentuation in Dutch. 
Judging accentuation of eventive and non-eventive sentences is the most difficult for both native speakers (4.8) and for Chinese L2 speakers of Dutch (3.5). This is understandable, since both correct and incorrect accentuations in fact constitute natural accentuation patterns, given some adjustments in the context. Our results show that the accentuation patterns of Dutch sentences are language specific and must be learnt. This need is most obvious for the five morpho-syntactically governed accentuation types, but is apparent even for the focus category. Here, Chinese listeners did decidedly better than in the other accentuation types, but the relatively low performance of the Chinese listeners with lower proficiency in Dutch shows that deaccentuation of given information must be learnt. 


\subsection{References}

Chen, Hua (2008). On Chinese EFL learner's English intonati Shanghai: Shanghai Foreign Language Education Press.

Ellis, R. (1994). The study of second language acquisition. Oxfor University Press, 482-492.

Booij, G. (1999). The phonology of Dutch. Oxford: Oxford Press.

Clark, J. \& Yallop, C. (1995). An introduction to pho phonology, 2nd ed. Cambridge, MA: Blackwell.

Gao Qiaoyang. (1984). Grammatical Stress in Mandarin Teaching and Research, 2, 65-76.

Goldsmith, J. (1976). Autosegmental phonology. Ph.D. Dissertation Gussenhoven, C. (1999). Illustrations of the IPA: Dutch. Hano International Phonetic Association. Cambridge: Cambridge Press, 74-77.

Gussenhoven, C. (1983). Focus, mode and the nucleus. Linguistics, 19, 377-417.

Gussenhoven, C. (2011). Sentential prominence in English. I Oostendorp, E. Hume \& K. Rice (Eds.), The Blackwell o phonology, 5 vols (pp. 2780-2806). Malden, MA \& Oxfc Blackwell.

Gut, U., Trouvain, J. \& Barry, W. J. (2007). Bridging re phonetic descriptions with knowledge from teaching pr: case of prosody in non-native speech. In J. Trouvain \& U. Non-native prosody, phonetic description and teaching practice Berlin: Mouton de Gruyter.

Huang B. R. \& Liao, X. D. (1991). Modern Cbinese. Beiji Education Press.

Hulshof, D. L. (2011, April 28). Moeder aller registratie viert jaar burgerlijke stand. NRC Handelsblad, p. 24.

Hyman, L. M. (1978). Tone and/or accent. In D. J. Na Elements of tone, stress and intonation (pp. 1-20). Washingto town University Press.

Ioup, G. (2008). Exploring the role of age in the acquisition language phonology. In J. G. Hansen Edwards \& M. I (Eds.), Phonology and second language acquisition (pp. 19-39). A John Benjamins.

Ladd, D.R. (2008). Intonational phonology. Cambridge: University Press. 
Rosenberg, A., Hirschberg, J. \& Manis, K. (2010). Perception of English prominence by native Mandarin Chinese speakers. Speech Prosody 2010. $<$ http://eniac.cs.qc.cuny.edu/andrew/>.

Schmerling, S. (1976). Aspects of English sentence stress. Austin: University of Texas Press.

Van Santen, J. \& Shih, C. (2000). Suprasegmental and segmental timing models in Mandarin Chinese and American English. Journal of the Acoustical Society of America, 107, 1012-1026.

$\mathrm{Xu}$, Yi \& Xu, Ching X. (2005). The phonetic realization of focus in English. Joumal of Phonetics, 33, 159-197. 


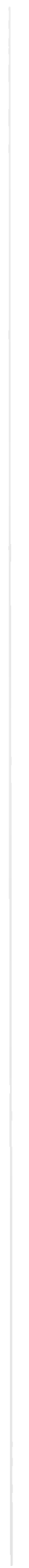




\section{Chapter 3}

\section{Selection of intonation contours by Chinese L2 speakers of Dutch: orthographic closure vs. prosodic knowledge ${ }^{1}$}

\subsection{Introduction}

We report an experiment that explored the question how well Chinese L2 speakers of Dutch select the correct intonation contour for sentences in a reading text, as well as the extent to which their choices reflect their language proficiency. Our motivation for carrying out the experiment was a desire to get a perspective on the extent to which the low quality of Chinese L2 performance in Dutch was due to an inability to produce appropriate pitch contours as opposed to their ignorance of what intonation contour to aim for. A second reason for doing the experiment was to address the issue of melody choice in L2 Dutch in a coherent text, a topic that has not been addressed so far. In section 1, we provide the necessary background information on the intonation of Dutch and discuss the general task we used, while section 2 briefly situates our topic in the context of second language acquisition studies. Section 3 presents our research questions.

\subsubsection{Intonation in West Germanic languages and tones in Chinese}

Descriptions of West Germanic intonation (Halliday, 1970; Pierrehumbert, 1980; Fox, 1984; 't Hart et al., 1990; Grabe, 1998; Grice \& Baumann, 2005; Gussenhoven, 2005; Peters, 2006; Ladd, 2008),

\footnotetext{
${ }^{1}$ This chapter appeared in Second Language Research 28, 283-318 (He, van Heuven \& Gussenhoven 2012).
} 
generally distinguish between the location of pitch accents (a as 'sentence accents' or 'accented syllables') and the tones o accents that are inserted in the accented syllables and the bour that are inserted at the phrase end, i.e., the tone string that $m$. melody. In addition, descriptions account at least to some ext phonetic realization of the intonation contour, given some accent locations and melodies. However, native speaker c goes wel beyond what these descriptions have to offer pragmatic context and communicative intention, a compete will not only choose an appropriate syntactic structure morphologically correct and semantically appropriate words a but also insert appropriate pitch accents in appropriately acce and appropriate boundary tones. Moreover, the pronunciat linguistic structure that arises will be adequate and confo detailed phonological and phonetic standards of the language For L2 speakers, each of these aspects poses a challenge, sin them is likely to be different from comparable systems in thei morphosyntactic structure is given, as in a reading task, there 1 challenging task of assigning appropriate intonation conto consecutive sentences of the text. The assignment of the contour is not well understood, and the least studied aspect choice of melody. Importantly, even when the distribution o accents is kept constant, considerable melodic variation is West-Germanic languages, because of the large number of pi and the relative freedom with which they combine in the sam The aim of the investigation reported here is to investigate th which L2 learners of Dutch cope with melody choice, give contextualized sentence. The other two aspects of i competence, i.e. pitch accent location and phonetic reali covered for the same group of subjects in research publishec (He et al., 2011a, 2011b).

Native speaker competence in melodic structure can be exp finite state tone grammar (Pierrehumbert, 1980). Gussenho proposed (1) as the grammar of Dutch. It lists two options fo boundary tone, five options for the prenuclear pitch accent, $f$ for nuclear pitch accents and three options for the final bou $(\mathrm{L} \%, \mathrm{H} \%$ and $\%$, the latter indicating absence of a tone). $\mathrm{Fc}$ accented syllable in the Intonational Phrase, 5 (pitch acc (boundary tone options) $=15$ melodies are allowed. A pren 
accent is pronounced over the stretch of speech up to the next accent, by pronouncing its last tone rightmost, i.e. just before the tone of the next pitch accent (Displacement', to use Grabe's (1998) term). Within pitch accents, tones are connected by linear interpolations. Any remaining longer stretches of speech between the initial boundary tone and the first pitch accent, between a monotonal pitch accent and a following pitch accent, or between the last pitch accent and the final boundary tone, are filled up by a doubling of the target of the tone on the left, which thus has a leftmost and a rightmost target ('Continuation'). This means that $\mathrm{H}^{*}$ and $\mathrm{L}^{*}$ are always realized as level pitch, while prenuclear $\mathrm{H}^{*} \mathrm{~L}$ and $\mathrm{L} * \mathrm{H}$ are realized as slowly falling and rising pitch, respectively, if the next accent is some distance away. In the absence of the final boundary tone, the $\mathrm{L}$ of nuclear $\mathrm{H}^{*} \mathrm{~L}$ is pronounced rightmost, creating a fall from high to mid pitch. The vocative chant, analyzed as $\mathrm{H}^{*}+\mathrm{H}$, is realized as a high pitch followed by a lengthened mid (downstepped) pitch. In (2) we give an example of a sentence which illustrates the Displacement of the $\mathrm{L}$ of prenuclear $\mathrm{H}^{*} \mathrm{~L}$ and Continuation, for the initial $\% \mathrm{~L}$ as well as for the prenuclear $\mathrm{H}^{*}$, which is pronounced as high level pitch until just before the target of nuclear L*. We follow van de Ven \& Gussenhoven (2010) representing the rightmost target of a tone with Continuation as an open circle.

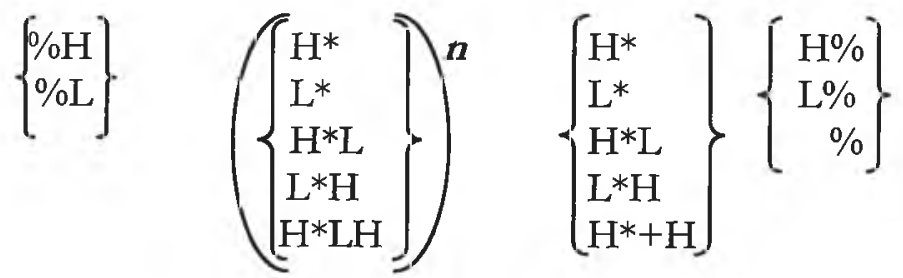

(2)

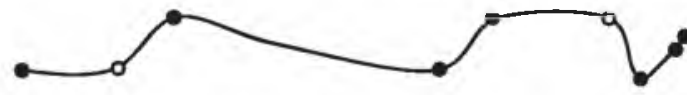

Maar de leeuw trok zich er niets van aan

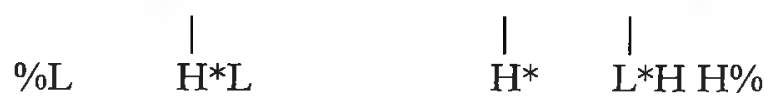

But the lion acted as if be didn't notice [the uren]'

In addition, $\mathrm{H}^{*}$-tones may be downstepped (indicated by $! \mathrm{H}^{*}$ ) after an initial $\% \mathrm{H}$ or an $\mathrm{H}$-tone in a prenuclear pitch accent, adding 3 (pitch accents) $\times 3$ (boundary tone options) $=9$ contours to the set of 15 possible nuclear contours. Finally, a $\mathrm{H}^{*} \mathrm{~L}$ or $\mathrm{H}^{*}+\mathrm{H}$ pitch accent may be 
prefixed with an $L^{*}$, causing a delayed peak. When $L^{*}$ is prefix over the role of $\mathrm{H}^{*}$, giving $\mathrm{L}^{*} \mathrm{HL}$ instead of unprefixed prefixation adds a further 4 (downstepped or non-downstepp $\left.\mathrm{H}^{*}+\mathrm{H}\right) \times 3$ (boundary tone options) $=12$ contours, giving ways of saying any expression containing a single pitch acc evidence for the reality of this grammar was collected by $\mathrm{Gu}$ \& Rietveld (1991).

In addition to this competence concerning possible forms, speaker is capable of choosing an appropriate form for a give Even though there have been proposals as to the semantics of contours (Liberman \& Sag, 1974; Ladd, 1980; Gussenho Pierrehumbert \& Hirschberg, 1991; Gunlogson, 2003), none of accounting for these choices in any comprehensive sense. give four possible ways of saying a Dutch two-accent sentenc 'And we were so frightened by all that!', as spoken by a child to after explaining how he and the other children had been frig the look and comportment of a passing lion during their fathe Each of them has an initial ring of plausibility. Example (3a) ha fall, indicating the firmness of the statement, and a final rise, at the father's understanding of the seriousness of the threat; ex lacks that final rise; example (3c) had two rising pitch accen boundary rise, indicating a stronger appeal to the father, would appear to emphasize the desperation of the speaking ch tracks and speech waveforms of the stimuli corresponding to (3c) and (3d) are shown in panels a, b, c and d of Figure 3.1, re It is not clear from any theory on the market why 19 out of speakers chose (3a) as the most appropriate contour in a forced choice task in which the other three contours competitors. It is beyond the scope of this paper to sum semantic literature, but some indication of the limited underst has been reached can be given, whereby we concentrate on West Germanic languages. 
(3)

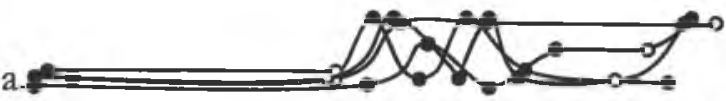

Dat alles heeft ons zo bang gemaakt!

$\% \mathrm{~L}$

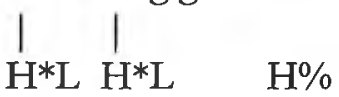

b.

Dat alles heeft ons zo bang gemaakt!

$\% \mathrm{~L}$<smiles>C1=CCCC1</smiles>

$\mathrm{H}^{*} \mathrm{~L} \mathrm{H}^{*} \mathrm{~L} \quad \mathrm{~L} \%$

c.

Dat alles heeft ons zo bang gemaakt!

$\% \mathrm{~L}$

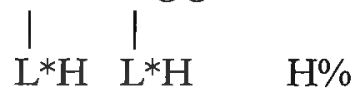

d.

$\begin{array}{llll}\text { Dat alles heeft ons zo bang gemaakt! } \\ \% \mathrm{~L} & \mathrm{H}^{*} & \mathrm{H}^{*} & \%\end{array}$

While generally the focus in a sentence should be accented while the background information after the focus is not, pitch accents have been claimed to signal different degrees or types of focus. Chen (2007) shows that both $\mathrm{H}^{*} \mathrm{~L}$ and $\mathrm{H}^{*}$ are used in Dutch to realize the sentence-initial focus, but with a preference for $\mathrm{H}^{*} \mathrm{~L}$. Pierrehumbert \& Hirschberg (1990) propose that new information in English sentences is marked by $\mathrm{H}^{*}$ or $\mathrm{L}+\mathrm{H}^{*}$ (often equivalent to $\mathrm{H}^{*} \mathrm{~L}$ in Gussenhoren's analysis), while $\mathrm{L}^{*}$ (often equivalent to $\mathrm{L}^{*} \mathrm{H}$ or $\mathrm{L}^{*} \mathrm{HL}$ in Gussenhoven's analysis) marks given information. Some support for this position is given by Chen et al. (2007), even though $\mathrm{L}^{*} \mathrm{HL}$ in that experiment sides semantically with $\mathrm{H}^{*} \mathrm{~L}$, not with $\mathrm{L}^{*} \mathrm{H}$. High ending utterances often signal continuations or questions, while low ending utterances signal finality or assertions (Bolinger, 1978; Pierrehumbert \& Hirschberg, 1991; Haan, 2002) in the standard varieties of English and Dutch. High endings can be used to mark a statement in English dialects (Grabe, 2004; van Leyden \& van Heuven, 2006), and yes/no questions Dutch dialects may end in falls 
(Gussenhoven, 2000). Baumann (2006) shows that downsi pitch accents are functionally intermediate between non-do $\mathrm{H}^{*}$-pitch accent and deaccentuation. The gist of this work is $\mathrm{tl}$ shape can signal shades of information novelty, but it does $t$ native speaker responses to data like those in (3). If v nevertheless that these choices are based on linguistic however elusive, the prediction is that L2 speakers of the lat fail to produce the same degree of agreement in their preferen

a

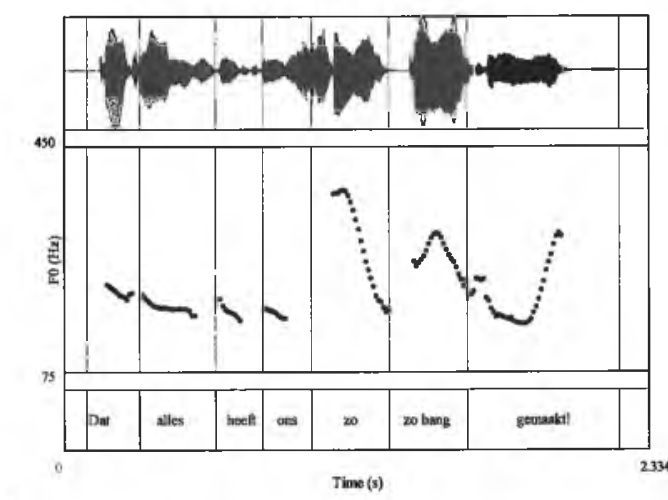

c

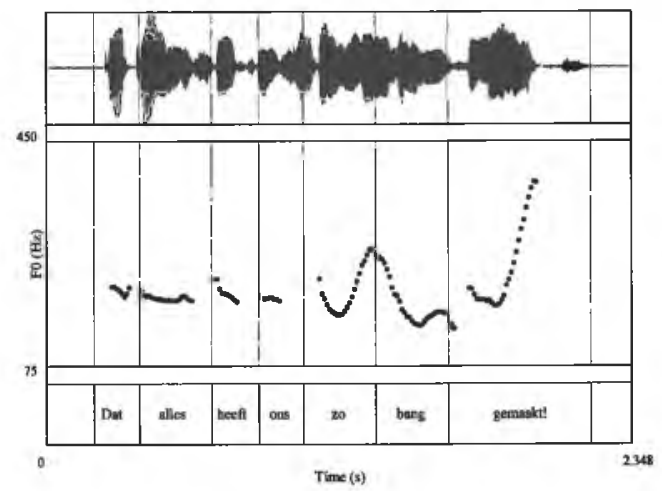

b

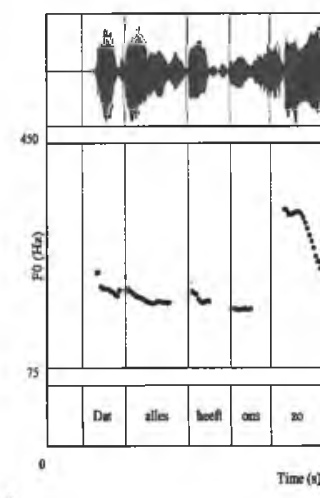

d

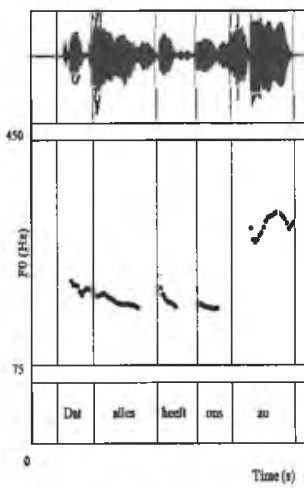

Figure 3.1. f0 tracks and speech wave forms of the stimuli corresponding $(3 \mathrm{c})$ and $(3 \mathrm{~d})$, respectively, representing the sentence Dat alles beeft ons zo ba

The questions we wanted investigated then are, first, the exter native speakers agree on the optimal intonation contour 
contextualized morphosyntactic expression, and second, to what extent L2 speakers whose L1 has a different prosodic organization deviate from the native speaker behavior, and if so, what generalizations can be made about the differences between the two language groups.

It is, of course, impractical to test all 36 nuclear contours of Dutch for acceptability for any one sentence. For one thing, a large number of these contours would probably strike native speakers as wildly inappropriate for the sentence concerned, something which might jeopardize their motivation to do the test. Quite apart from the arduousness of the task, the time it would take would seriously restrict the number of sentences that could be investigated. We decided to strike a balance between these two factors, and selected 26 contiguous fragments from a story entitled Het Winterkoninkje 'The willow wren', testing a varying set of four contours for each of them. For each fragment, the second author and a another trained native Dutch intonologist (Judith Hanssen) selected the most plausible intonation contour, henceforth the 'optimal contour'. In this contour, we then judiciously replaced a boundary tone and/or a nuclear pitch accent, so as to arrive at three competing contours that seemed less optimal, yet not obviously implausible. Our assumption was that if the optimal contour is chosen as the 'best' contour out of the four by a majority of the 20 native listeners, we would have reasonable ground for assuming that the optimal contour is in fact maximally appropriate for the sentence concerned.

In order to see how L2 speakers with a prosodically different L1 perform the same task, we recruited 20 Chinese speakers of Dutch. Mandarin Chinese has four lexical tones, with some words being toneless ("neutral tone'), providing a sharp typological contrast with Dutch. Intonationally, there are some broad similarities. Traditionally, Mandarin is analysed as having two types of accentuation: 'grammatical' and 'logical' (Gao, 1984). Grammatical accents are determined by the structure of syntactic phrases, while logical accents depend upon the information structure speakers intend to express. The effect of logical accent placement is phonetically close to the pitch accent distributions of Dutch sentences. Logical accent is given to words which are selectively focused or else serve to express strong emotion (Huang \& Liao, 1991). Since the pitch range of words is drastically reduced after the focus, the post-focal words are phonetically similar to deaccented words in West Germanic 
languages (Xu \& Xu, 2005). As for melodic intonation, two tones, $\mathrm{H}$ and $\mathrm{L}$, corresponding to Chao' $\mathrm{s}$ Rising and Fallin have been identified for Putonghua (Standard Mandarin in China), Guoyu (Standard Mandatin in Taiwan), and in the Bez which is very close to Standard Mandarin (Peng et al., 2005; where $\mathrm{H}$ is for questions and $\mathrm{L}$ for statements. However, $\mathrm{P}$ pronunciations of the four lexical tones in questions and reveal a consistent upward shift in the register of the $\mathrm{c}$ questions (cf. Shen, 1990), as shown in Figure 3.2. It shows $f$ utterance-final tokens of the words for 'mother', 'hemp', 'scold', all of which consist of the syllable [ma], spliced off short Chinese sentences with interrogative and declarative The left panel shows four Chinese sentences with in intonation: (1) Ta shi nide ma? (She is your mother?); (2) Ta shi is your hemp?); (3) Ta shi nide ma? (It is your horse?); (4) $N$ (You are scolded by her?). The right panel illustrates the same but with declarative intonation. The time scales and $\mathrm{Hz}$-scales panels are identical. At the level of the syllable, the prosodic are substantial. Unlike what is the case in languages like E Dutch, metrical strength differences are not really compara melodically prominent effect of a pitch accent in Dutch. Fo the syllable duration in Mandarin remains relatively constan why it has been characterized as a 'syllable-timed' language Yallop, 1995; van Santen \& Shih, 2000). Clearly, other than pitch range compression, there is little if anything in their nativ that Chinese listeners of Dutch can use in their choice of pitch 


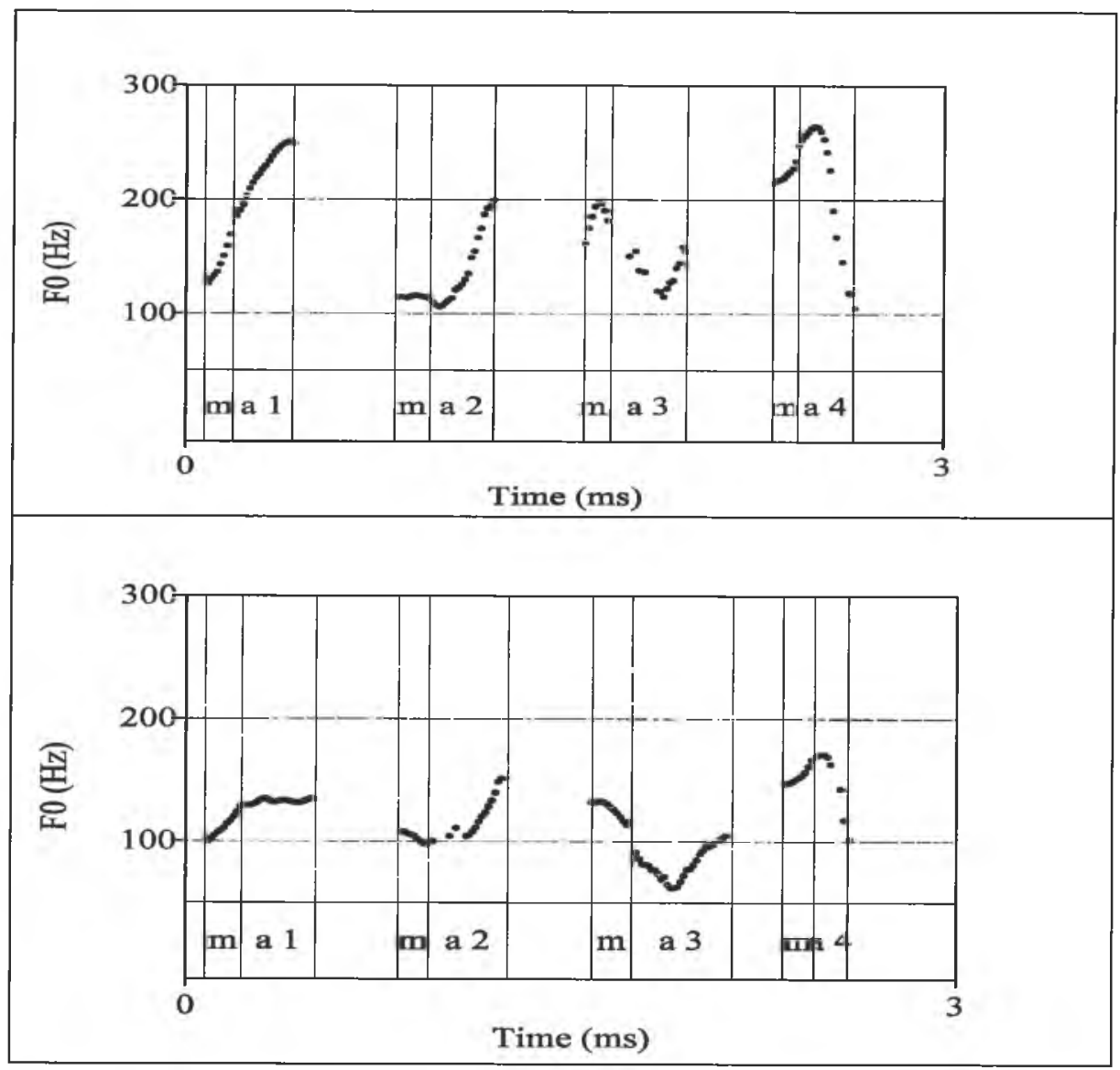

Figure 3.2. fo tracks of four standard Chinese lexical tones with interrogative (top) and declarative intonation (bottom) on the syllable [ma] spliced from the four Chinese sentences: (1) Ta shi nide ma 'She is your mother?'; (2) Ta shi nide ma It is your hemp?'; (3) Ta sbi nide ma 'It is your horse?'; (4) Ni bei ta ma 'You are scolded by her?'

\subsubsection{Research on prosodic production and perception}

There is abundant evidence that L2 speakers retain a foreign accent in their L1 prosody (e.g., Banjo, 1979; Willems, 1982; van Els \& de Bot, 1987; Cruz-Ferreira, 1989; Grosser, 1989; Ellis, 1994; Wennerstrom, 1994; Jilka, 2000; Trouvain \& Gut, 2007; Gut, 2009; Hincks et al., 2009). L2 learners have been shown to perform suboptimally in tasks in which 
they must identify, manipulate or interpret prosodic ph elements like stress, accent, rhythm, pauses or phonological to 2003, 2006; Rasier \& Hiligsmann, 2007; Trouvain \& Gut, 2 2008; Gut, 2009). They have also been found to be incapable c the phonological elements in the L2 in the way that native st and often make errors in their use of contour types and bou in production (Trofimovich \& Baker, 2006; Rasier \& Hiligsm Gut, 2009; O'Brien \& Gut, 2010). It has been claimed (F Rochet, 1995) that non-native speakers' production errors 1 errors in speech perception. An indication of this can be fo way that L2 learners cannot judge the appropriateness of the 1 the pitch accent as well as native speakers can. In a experiment that was conducted to see how well Chinese 1 Dutch identify the correct accentuation patterns in six cat Dutch sentences reflecting different grammatical regularit location of the pitch accent, He et al. (2011a) found that the scores by native listeners of Dutch were significantly higher by the Chinese learners with high proficiency in Dutch, correctness scores of the latter were significantly higher obtained for the low-proficiency learners. Along with the scores, confidence ratings decreased from the native listener o Chinese listeners with higher proficiency in Dutch to the ones proficiency. As for the melodic meaning, L2 learners fail intonational meaning like native speakers (e.g., Cruz-Ferr Wennerstrom, 1994; Munro \& Derwing, 1995; Chun, 2002; C Atoye, 2005; Niioka et al., 2005; Chen, 2009). Cruz-Ferr identified three strategies that were adopted by Portugue learners of English and English learners of Portuguese who to indicate meaning differences in intonational minimal pairs the nuclear contour, the placement of the pitch accent or th Respondents transferred patterns from the L1, relied on pi and adopted lexico-syntax-dependent strategies. The first tw were also reported by Chen (2009), who analyses the pitch he as a reflection of the universal biological codes (Chen et Gussenhoven, 2004; Chen, 2007). An effect of this kind was by Niioka et al. (2005) for a group of intermediate Japanese s Dutch, who attached more weight to rising intonation $t$ speakers did when the perception of interrogativity in Dutch As for transfer, L1 transfer is an important factor both in L2 and perception (Grabe, 2003; Rasier \& Hiligsmann, 2007). I 
have been found to transfer their prosodic knowledge from L1 to L2 when intonational meaning was processed in a way that depended on the L1 prosodic system (Braun, 2010). Prosodic transfer can be both phonological and phonetic. The phonological transfer results from differences in the inventory of phonological tones, their forms and the meanings assigned to them (Mennen, 2007), and phonetic transfer from a difference in the phonetic realisation of an equivalent phonological tone or tone complex (Mennen, 2007; Gut, 2009; O’Brien \& Gut, 2010).

\subsubsection{Research questions}

Our first concern was to study intonation contour choice in context. Native speakers vary greatly in their choice of intonation contour (van Bezooijen, 1989; Haan, 2002; Wells, 2006). In a discussion of the intonation of isolated written Dutch sentences closed by the question mark, Haan (2002: 36) observes that "any intonation that can occur with a statement, in a command, or an exclamation can also occur with a question" and that "questions may be found with all intonation curves." That is, there appears to be no such thing as a specific intonation for questions. Similarly, van Bezooijen (1989) reports individual differences in accentuation preferences in an accent assignment production task. This means that there may well be no single intonation melody and no single accent structure which can be considered uniquely adequate and is preferred by all subjects. While these findings were made with the help of production experiments, there is no reason for believing that the variability is principally different in perception. Crystal (1969) selected twenty utterances from a corpus of British English speech and asked six subjects to read three sentences with intonation contours that matched each of twenty attudinal labels. Quite apart from the degree of variation among the subjects, it was striking that when they were asked to assign those labels to the utterances in a perception test, little between-listener agreement was found. When they repeated the labeling task several weeks later, there was even little within-listener agreement between the two tests. Results like these suggest that intonation contour choice is profoundly contextual and cannot fruitfully be studied on the basis of isolated sentences. Studies that have counted the distribution of rises and falls on yes-no questions in English have in fact found that the occurrence of one or the other is heavily dependent on the type of situation involved (Chun, 2002). We expect to find far greater agreement 
among native speakers in contextualized sentences, but th research we know of that bears on this issue.

Second, we decided to study intonation contour choice interpretation of intonation contours, as in Crystal (1969). Lea exploit semantic context and their knowledge of the comprehend the $\mathrm{L} 2$ in the absence of any accurate percept phonological information in foreign utterances, so that the might show up in isolated stimuli may not be easily recogni 1991). Third, we decided to provide the textual and situational the judges by simulating a reading task on the basis of a stor that required no speech production. By asking subjects to cho set of possible contours instead of having them read the themselves, we tapped more directly into their 'linguistic com opposed to their perhaps inadequate phonetic execution of th expressions they would have wanted to use. While it is cle majority of second language learners cannot acquire nativ ability, less is known about the extent to which non-nativ acquire the prosodic knowledge of the target language even in in which they cannot produce it correctly. If Chinese learner were to demonstrate an ability to pick the 'best' intonation co a set of four, any failure on their part to produce adequate contours must be sought in the way they produce speech, rat a principled inability to select an adequate intonation Conversely, if they appear to be unable to select an appropria in any given context, their inability to produce correct prosod. and foremost be sought in their lack of knowledge of the sen pragmatics of the intonation system. Accordingly, in the test given some time to read each sentence in silence, enabling the a mental representation of the intonation contour, and were an opportunity to listen to the four options. By pacing the way, subjects were provided a fair opportunity to demon linguistic competence.

In sum, there are three questions we wanted to address. W with our hypotheses.

I. To what extent do native speakers of Dutch agree on $t$ choices in Dutch sentences in context? Operationalizing $t$ in a forced four-choice task, we hypothesize that native $j$ 
high agreement on which is the best choice out of the four, provided that an adequate choice is available among the set of four options. Additionally, it should be the case that they show a high level of agreement on the extent to which each of the three less adequate choices is to be rejected.

II. To what extent do Chinese L2 speakers of Dutch approach the behavior of the native speakers? Given the near-absence of nonlexical melodic variation in Mandarin and given the evident difficulty of identifying the regularities in the relation between pragmatics and melodic shape as outlined in section 1.1, we hypothesize that their choices only very partly reflect the judgements by the native speakers and are otherwise random.

III. Is there any difference between a more advanced group and a less advanced group of Chinese L2 speakers Dutch? Assuming that despite the absence of formal instruction, L2 speakers of Dutch increase their knowledge of the morphology and phonology of the intonation of Dutch along with increases in the proficiency in Dutch, we hypothesize that the performance of the advanced group falls between that of the native speakers and the less advanced group.

\subsection{Method}

\subsubsection{Material}

We chose a text of 366 words, 't Winterkoninkje, which was translated and edited by Jörg Peters from an original Low Saxon story. ${ }^{2}$ Carlos Gussenhoven (CG) and Judith Hanssen $(\mathrm{JH})$, both native Dutch intonation experts, transcribed the whole text on the basis of a reading by $\mathrm{JH}$ as well as their own judgement of what was the most appropriate way of reading that text. This transcription will be referred to as the

2 The original version of the story, De Tunkrüper, was taken from Plattdeutsche Volksmärchen by Wilhelm Wisser. It was rewritten by Jörg Peters with the aim of eliciting a large variety of intonation contours from native speakers of different varieties of Dutch. 
'consensus transcription'. Subsequently, the text was divide fragments, 26 of which were used as test items. Within each test items, we selected a brief experimental fragment from one of the intonational phrases, ranging from one to ten word In fifteen cases, these contained one pitch accent, in ten case in one case three. Starting from the consensus transcription ( the A-version), we freely produced three variations on it by ch last pitch accent, the boundary tone or both of these, so as three new versions whose phonology did not deviate greatly $\mathrm{fr}$ the A-version. The A-version was thus always included amor contours that judges could choose from. In no case did we fe of the competing intonation contours was wildly implausit example in (3); the full set of test items and the four trans given in an appendix). Subsequently, $\mathrm{JH}$ recorded the tex model transcription as well as with each of the rival contc studio in the Arts Faculty of Radboud University Nijmegen. F same sentence with four pre-determined intonation contou task that not even an intonation specialist will find easy. The for each version of each sentence was monitored by $\mathrm{CC}$ repeated any item for which either of them was not entirely s: items were produced naturally and smoothly; in the case of co $\%$, the suspended fall or half-completed fall, which occurred in the A-versions, we decided to have $\mathrm{JH}$ read them in a blocl found it hard to 'get into' the contour on a number of occas gave us four speech wave files with a reading of each of fragments.

In order to produce four stimuli for each text fragment, we the sections of the four speech wave forms which correspon variable parts, the experimental sections, in the case of 15 text and pasted these onto the non-variable section of one of the $f$ files for each item. This was done in order to avoid any varia non-experimental sections of the text fragments from biasing In 11 cases, of which (3) is an example, the text of the fragm

\footnotetext{
${ }^{3}$ We have found on more than one occasion that speakers can generally a rut, finding it hard to abandon a particular intonation contour in a rec conversely fail to produce a particular contour. Often, the next day, conto hard are easy, while contours that kept coming back may be hard to pro case of the half-completed fall, there may also be regional variation. $\mathrm{S}$ bilingual with Dutch and Sittard Limburgish.
} 
short that splicing was felt to be uncalled for. In one case, item 19, we edited the variable sections in order to remove pauses. We took care to select the non-variable sections randomly from the four readings, thereby avoiding an overrepresentation of non-variable sections taken from the model version, which would have introduced a possible artifact in the stimuli.

\subsubsection{Participants}

The same participants as in Chapter 2 participated in the perception experiment (Section 2.2.2 for detailed information). The 20 native speakers of Standard Dutch served as the control group. It was used in two ways. First, a validation of the consensus transcription was to be based on the judgments of the control group: if the native listeners failed to choose the consensus version as the most acceptable intonation contour, that fragment should not be taken into account when establishing the performance of the Chinese group, and must therefore be removed from the experiment. Second, the control group served as the baseline against which the performance of the Chinese subjects was to be assessed.

\subsubsection{Procedure}

All 104 stimuli were presented to subjects together with their texts on a computer screen. Before the experiment proper, participants saw a text screen on which they were instructed to silently read the text of the entire story, presented to them on four successive screens, in order to familiarize them with its contents. One of the four screens contained a part of the story which was not used for segmentation into experimental fragments. On this screen they were instructed to listen to a reading of that passage by the same speaker who had pronounced the stimuli. This was done to enable judges to familiarize themselves with her voice and reading style. The subjects then did four trial items, which were identical to the first experimental fragments. Subsequently, they were presented with the written fragments chronologically through the story. They were instructed to read the fragment, and then to play each of the four versions by clicking one of four buttons numbered 1, 2, 3 and 4 . The position of the consensus version was randomly located in the row for 
each fragment and for each subject. Subjects were allowed tc of the four stimuli for each fragment as often as they wished, correct their choice before moving on to the next fragment.

\subsection{Data analysis}

We report 'correct' votes, defined as votes for the consensus well as agreement and entropy scores in section 1, so as to answer our three research questions. Moreover, in sections 2, will discuss other factors that are correlated with performa Chinese subjects.

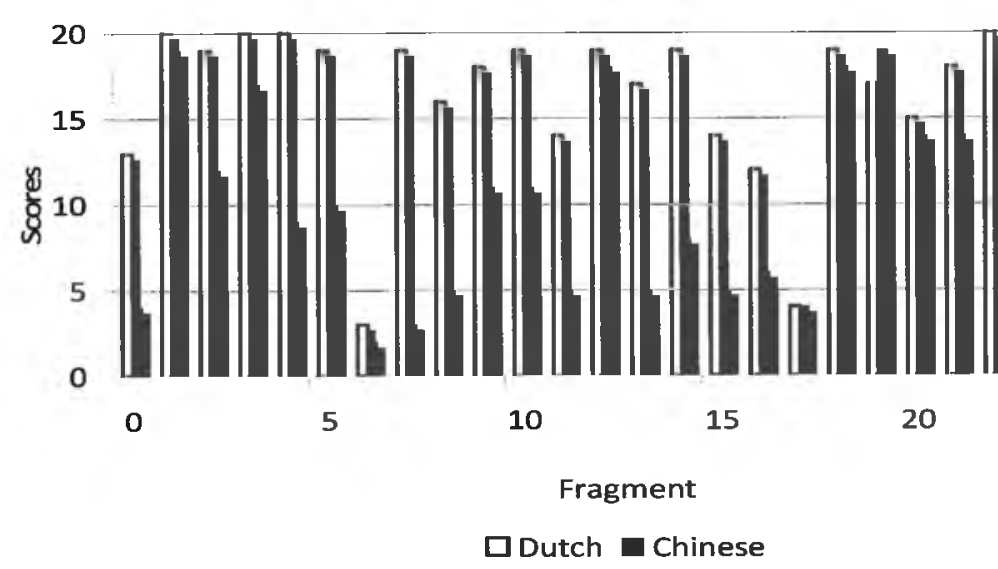

Figure 3.3. Correct scores by the Dutch and Chinese listeners. 


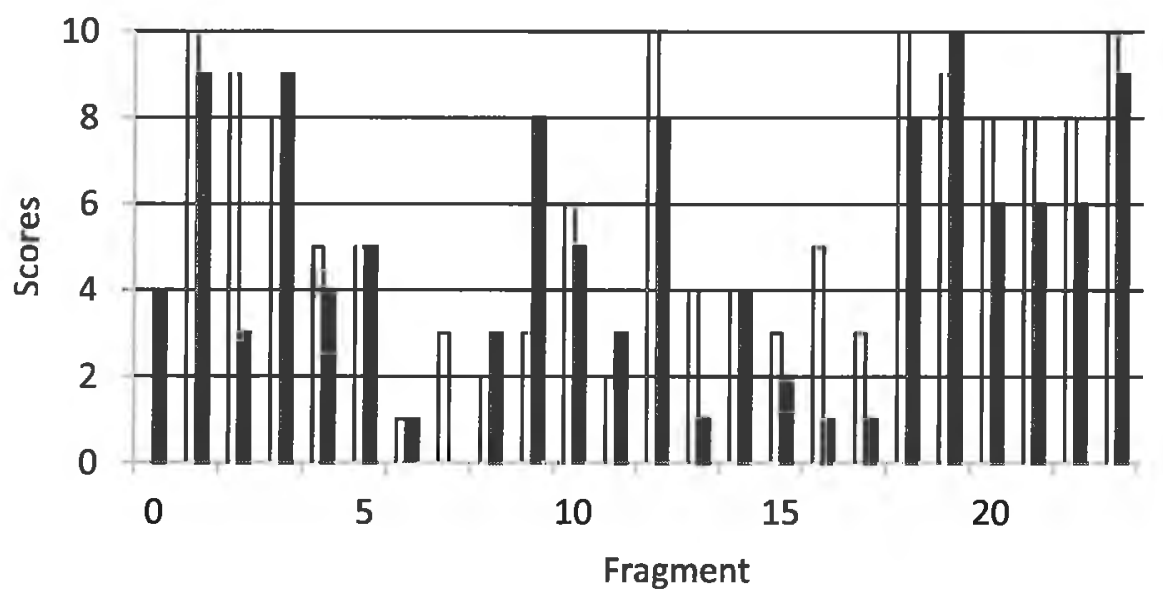

$\square$ CHD $\square$ CLD

Figure 3.4. Correct scores by CLD (Chinese speakers with lower proficiency in Dutch, and CHD (Chinese speakers with higher proficiency in Dutch).

\subsubsection{Overall analysis}

Nineteen or more out of 20 Dutch listeners chose the consensus version, the A-version, in 14 out of 26 items. Stimulus A for an additional four items was selected by 17 or more judges, and for another four items by 14 or more judges. The A-version of items 0 and 16 were selected by 13 and 12 judges, respectively. In the case of two items, 6 and 17, the Aversions attracted less than $60 \%$ of the scores. We felt that an A-score of less than $60 \%$ disqualified the consensus version as a standard for the Chinese listeners; the scores for these two items will therefore not be used to assess their performance. However, they will be retained in the calculation of the entropy and agreement measures. This means that overall, the consensus version was chosen as the best version by the Dutch judges in $83.3 \%$ of the cases. Without items 6 and 17 , this percentage rises to 88.8. We conclude that with the exception of items 6 and 17, the test provides a viable instrument for assessing a listener's ability to select an appropriate contour for a contextualized Dutch sentence. Of the Chinese participants, $80 \%$ chose the A-version as the best version for six items, and $70 \%$ did so in three further items. Overall, the consensus version was selected by the Chinese participants in $53.3 \%$ of the cases, and 56.5\% without items 6 and 17. A univariate Analysis of 
Variance shows that the difference with the control group is $\left(\mathrm{F}[1,958]=144.5, \mathrm{p}<.001, \eta^{2}=.13\right)$. Within the Chinese subjects with higher proficiency in Dutch had higher correct $\mathrm{s}$ than those with lower proficiency $(52 \%)(\mathrm{F}[1,478]=4.5$, $=.01$ ), not counting items 6 and 17. This means that native s better than Chinese speakers of Dutch, and that Chinese Dutch with high proficiency (CHD) did better than the one proficiency (CLD) (see Figures 3.3 and 3.4).

Because the total correct score by the Chinese participant chance level (25\%) and Chinese participants with higher prc Dutch performed better than those with less proficiency, correct score must be due to their knowledge of Dutch. Kno language, as revealed by the subjects' evaluation of the appr of intonation contours, will also be reflected in the exten inappropriate choices are rejected. Therefore, we expect control group to show high agreement in their selection or 1 the B-, C- and D-versions, but expect the Chinese groups to agreement on the $\mathrm{B}, \mathrm{C}$ and $\mathrm{D}$ versions. Moreover, the expected to show less agreement than the $\mathrm{CHD}$. Putting this way, the distribution of responses over the 'inappropriate' stir be more even in the groups with less knowledge than in the more knowledge. The evenness of the distribution of vo expressed by an entropy measure, essentially an uncertain (Shannon, 1948; Attneave, 1959). We computed the entrop item, and then took the mean entropy across all items per list as the overall measure of agreement. Entropy, expressed as $\mathrm{H}$, maximum value if all options are equally probable. If $\mathrm{H}=0$, are in complete agreement that just one specific option correct choice. We used the formula in (4) to compute H. For an alternative in a binary choice situation is chosen in $50 \%$ o then the entropy in the responses to the item equals $.50 *{ }^{2} \mathrm{lo}$ bit.

(4) $\mathrm{H}=-\sum_{i=1}^{n} p_{i}^{2} \log \left(p_{i}\right)$

where $p_{i}$ is the probability of each alternative $i$ and $n$ is the response categories. 
We arranged the $\mathrm{H}$-values for the 26 items for Chinese and Dutch listeners side by side. When an item was missing (which occurs when the item got $100 \% \mathrm{~A}$ responses), its contribution to overall entropy is zero. We then ran a paired t-test on the items and found that the Dutch $\mathrm{H}$ values are much smaller $(\mathrm{H}=.25 \mathrm{bit})$ than the Chinese counterparts $(\mathrm{H}$ $=.79 \mathrm{bit})(\mathrm{t}[25]=4.01 ; \mathrm{p} .<.001)$. This shows that the scores of the Chinese listeners are more evenly distributed over the incorrect alternatives than those of the Dutch listeners. Similarly, we calculated the entropies of CLD and CHD, which were .74 and .50, respectively. There is a significant difference between Dutch group and CHD $(t[25]=-2.46$, $\mathrm{p} .=.011$, one-tailed) as well as between CHD and CLD (t $[25]=-2.04$, p. $=.026$, one-tailed). This means that native listeners show fairly high agreement over what are the best and the worst choices as compared to $\mathrm{CHD}$, and that the CHD show higher agreement than the CLD.

\subsubsection{An orthographic strategy}

An investigation of the choices by the Chinese subjects brought one further factor to light which must have played a role in their choices. Table 3.1 gives the percentage of choices for contours ending in a fall $\left(\mathrm{H}^{*} \mathrm{~L} \mathrm{~L} \%\right)$ or half-fall $\left(\mathrm{H}^{*} \mathrm{~L} \%\right)$ by the Dutch listeners, the high performing Chinese subjects and low performing Chinese subjects as a function of the punctuation used to mark the closure of the orthographic sentence fragment, '?' on the one hand, versus '?, '., ',' or no closure punctuation on the other. The Dutch responses are close to the frequency of occurrence of those contours in the A-versions, as given in the first data column, which indicates that the native speakers agreed to a high degree with the assignment of falling intonation contours over sentences closed by the question mark and other sentences. The Chinese choices for falling contours are more strongly biased towards sentence fragments not closed by '?', with the CHD falling between the CLD and the native speakers. This strongly suggests that the less the Chinese subjects know about Dutch, the more they rely on a spelling-based strategy with rises for fragments ending in '?' and falls for fragments with other closure punctuations. Since questions do not necessarily end in a rise and statements do not necessarily end in a fall, the Chinese group must have relied on cross-linguistic tendencies to associate questions 
with rising intonation and non-questions with falling intonat 2005).

Table 3.1. Percentage of choices for contours ending in $\mathrm{H}^{*} \mathrm{~L} \mathrm{~L} \%$ or function of closure punctuation for native Dutch, high-performing Chines low-performing Chinese (CLD) listeners, together with the percent frequency of occurrence of those contours in the A-versions, for all items 17.

\begin{tabular}{|l|c|c|c|}
\hline Closure punctuation & $\begin{array}{l}\text { Consensus } \\
\text { version }\end{array}$ & Dutch & CHD \\
\hline '?' & 50.0 & 47.1 & 40.0 \\
\hline$? ! /$ ' ' ', & 65.0 & 67.3 & 76.5 \\
\hline
\end{tabular}

Orthography was claimed earlier to influence L2 listeners' b van Heuven (1986) and Escudero et al. (2009). They found th and Spanish listeners, respectively, attributed greater weigh duration than native Dutch listeners and suggested that an 6 might be provided by the spelling of long vowels in Dutch monosyllabic words are written with two graphemes to distin from their short counterparts, which are written with grapheme.

\subsubsection{Overall contour preferences}

Finally, we consider the question whether the Dutch an subjects showed different preferences for nuclear contours re whether their choices were for the A-version or for a compe group selected 480 contours. Overall, $46 \%$ were for falling nu $18 \%$ for downstepped tunes, $20 \%$ for the fall-rise, and $16 \% \mathrm{f}$ level tunes. However, the two groups do not share the same $d$ Figure 3.5 gives the total number of choices broken down type $(\mathrm{N}=480)$. We merged the data for $\mathrm{H}^{*} \mathrm{~L} \%$ and $\mathrm{H}^{*} \mathrm{~L}$ constitute the class of non-downstepped falls, and those fo and $\mathrm{H}^{*} \mathrm{H} \%$, which constitute the rises. Both of these have hi in the Chinese group, while the downstepped falls and the $f$ chosen less frequently. A Chi-square test shows that the Chi and the native groups differ significantly in their choice of co $=30.9, \mathrm{p}<.01$ ). The post-hoc comparisons reveal that the 
make significantly different choices for the non-downstepped falls $\left(\chi^{2}[1]\right.$ $=8.2, \mathrm{p}<.01)$, the downstepped fall $\left(\chi^{2}[1]=7.3, \mathrm{p}<.01\right)$, the fall-rise $\left(\chi^{2}[1]=4.7, \mathrm{p}<.05\right)$, and the rises $\left(\chi^{2}[1]=6.9, \mathrm{p}<.01\right)$. However CHD and CLD's choices of the contours are not significantly different $\chi^{2}[4]=$ 1.5 , n.s.). These results arguably support the Markedness Differential Hypothesis of Eckman (2008), which predicts that while a marked rule or element is more difficult to learn than an unmarked one in L1 acquisition, in $\mathrm{L} 2$ acquisition patterns that are less marked in L2 than in L1 should not be difficult, while more marked patterns in L2 are hard to learn, and the more so the more marked they are. Since rises and falls are present in Mandarin as the usual realizations of Tone 2 and Tone 4, respectively, there is no equivalent to the Dutch fall-rise. (Mandarin Tone 3 lacks the substantial fall-part of the Dutch fall-rise, and has the rise-part only phrase-finally.) Although Post-Focus Compression may produce contours that are broadly similar to downstepped falls, there is no equivalent to the downstepped fall in focused pronunciations. Thus, these data can be understood on the basis of the familiarity of the Chinese subjects with the general shapes of the non-downstepped falls and rising contours in Mandarin and their relative unfamiliarity with downstepped falls and falling-rising contours.

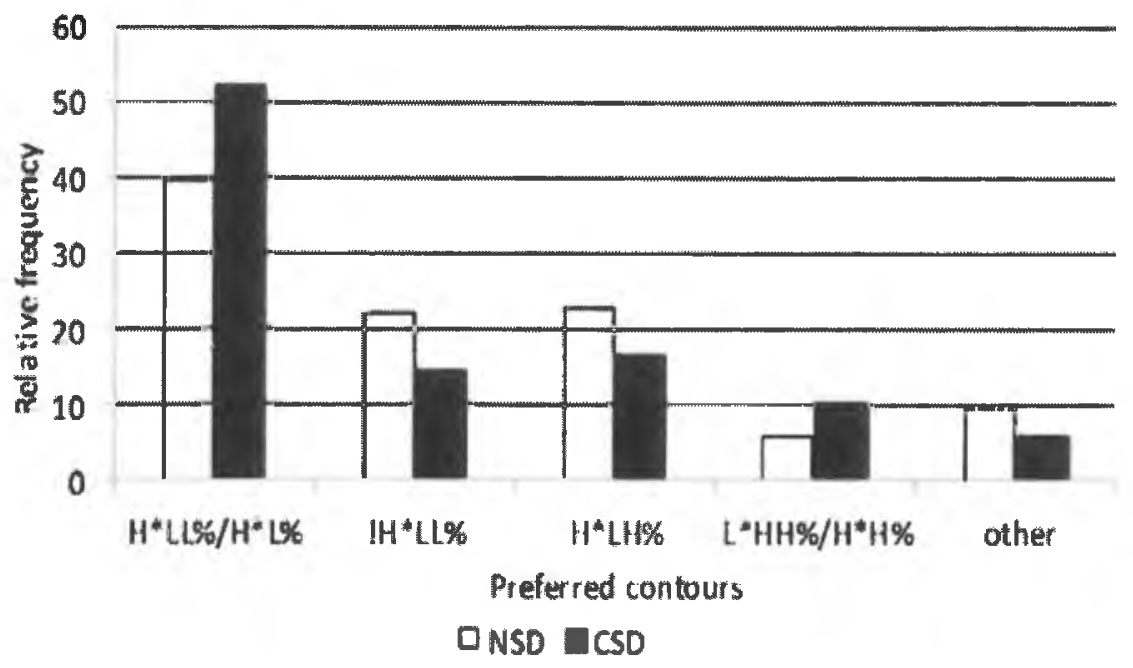

Figure 3.5. Distribution of preferences for six classes of contours over all test items except fragments 6 and 17 by 20 Chinese (CSD) and 20 native Dutch (NSD) listeners $(\mathbf{N}=20 \times 24=480)$. 


\subsubsection{Correlations with speaker variables}

In this section, we address the question whether the perform Chinese subjects is explained by their proficiency in Dutch, as the basis of their performance in a production task by three $e$ whether the age of the subjects, the length of residence ( $L$ Netherlands, or the age of the arrival in country (AOA) ex performance in the acceptability test. The correctness sco Chinese subjects are significantly correlated with the segment $=.69, \mathrm{p}<.05)$ and the prosody scores $(\mathrm{r}=.75, \mathrm{p}<.001)$, which the extent to which they chose the A-version is to a la explained by their proficiency in Dutch, supporting the interp the differences in correctness and entropy scores between Their correctness scores has no relation with LOR $(r=.33, \mathrm{n}$ age $(r=-.40$, n.s.). However, AOA correlates significantly correctness scores $(\mathrm{r}=-.64, \mathrm{p}<.01)$, suggesting tha proficiency is influenced by the age at which learners are first realistic language use. Length of exposure to Dutch cannot have a positive effect, however. Negative correlations were between AOA and the proficiency scores on the segmental $t$ prosodic test $(\mathrm{r}=-.75$ and $\mathrm{r}=.-76$, respectively, both $\mathrm{p}<.0$ the younger they were when they came to the Netherlands, subjects did in the experiment as well as in the profici supporting the 'younger-is-better' position held by studies investigated the effects of age on pronunciation (Ellis, 1994: 1988; Flege et al., 1995).

\subsection{Conclusions}

Our Contour Acceptability Experiment has shown that nati of Dutch obtained higher correctness scores than the Chine of Dutch and that within the Chinese group, the highChinese subgroup had higher correctness scores than proficiency subgroup, where 'correctness' is defined as th choice that was earlier identified as the most appropriate contour (the 'consensus contour' or 'A-version') for a sente short story. Second, it was shown that higher scoring groups agreement in their selection of less adequate contours than lo groups, as measured by an entropy measure. This suggests th 
who are better at identifying the most appropriate contour are also better at judging the relative appropriateness of the less appropriate contours. Chinese participants' choices of intonation contours in context are in part explained by their proficiency in Dutch, as established by an independent measure of their segmental and prosodic proficiency. Their performance has no relation with their length of residence in the Netherlands, nor is it related to their age. However, it does correlate with AOA, meaning that the earlier they came to the country, the higher is their segmental proficiency, the higher is their prosodic proficiency and the higher are their scores on the intonation acceptability test reported here. This is in accordance with early studies of second language acquisition (e.g. Ellis, 1994; Ioup, 2008).

An analysis of the Chinese preferences revealed that the lower-scoring subjects relied to a greater extent on closure punctuation than did higherscoring subjects. Where knowledge of Dutch was lacking, the strategy used was to choose contours with rises or level pitch whenever there was a question mark at the end of the sentence and contours with falls $\left(\mathrm{H}^{*} \mathrm{~L}\right.$ $\%$ or $\mathrm{H}^{*} \mathrm{~L} \mathrm{~L} \%$ ) whenever this was not the case. A further analysis of the overall preferences for particular nuclear contours revealed that the Chinese subjects were biased towards non-downstepped falls and $\mathrm{H} \%$ rises at the expense of fall-rises and downstepped falls. We explained these data as resulting from the unfamiliarity with the phonetic shapes of these contours in their native language.

In earlier research (He et al., 2011a), we demonstrated that Chinese learners of Dutch are relatively successful in selecting a correctly accented word if the accent expresses the information structure of the sentence, but are poor at doing so if the accented word is accented for morphosyntactic reasons, like compound formation or predicate accentuation in non-eventive sentences. While information structure has comparable effects in Mandarin in triggering Post-Focus Compression, there is no equivalent in Mandarin to compound deaccentuation, or the deaccentuation of predicates in eventive sentences. Our experiment provides further support for the position that the acquisition of the intonation system of Dutch is a gradual process. An important part of the intonational competence that is required is the ability to choose an appropriate melody for sentences that form part of a coherent text. Breaking down the notion 'intonational competence' through tests or experiments that focus on specific aspect of that competence will help us 
understand the acquisition process. It is clear that the majority language learners cannot produce the native-like pronunciation or prosody, but little is known about the dee of these difficulties, which could lie in their ignorance of wh patterns to select or in their inability to produce the phone that native speakers would use in the same situation. In this we have shown that Chinese second language speakers of I sense, do not know what to say. We should bear in mind that for other language groups may be very different, dependi degree of genetic affiliation between, in this case, Dutch anc the subjects. German and English have been described essentially the same intonation system as Dutch (Bolinger, 19 1998; Gussenhoven, 2005). The Romance languages are mor but not as different as is Chinese. Further research with le other backgrounds should establish to what extent this i Evidently, the question of how to teach and how to practis patterns still leaves ample room for further research, but our suggest that instead of imitating intonation contours from sc it may initially be more fruitful to expose learners to compete of texts in order to increase their chances of learning when tc contour. 


\subsection{References}

Atoye, R. O. (2005). Non-native perception and interpretation of English intonation. Nordic Journal of African Studies, 14, 26-42.

Attneave, F. (1959). Applications of Information Theory to Psychology: $A$ Summary of Basic Concepts, Methods and Results. Holt: New York.

Banjo, A. (1979). Beyond intelligibility in Nigerian English. In E. Ubahakwe (Ed), Varieties and Functions of English in Nigeria, Ibadan (pp. 7-13). Nigeria: African University Press.

Bolinger, D. (1978). Intonation across languages. In J.H. Greenberg (Ed), Universals of Human Languages (2), Phonology (pp. 471-524). Stanford: Stanford University Press.

Braun, B. \& Tagliapietra, L. (2010). On-line interpretation of intonational meaning in L2. Language and Cognitive Processes, 26, 224 235.

Chen, A. (2005). Universal and language-specific perception of paralinguistic intonational meaning. Utrecht: LOT.

Chen, A. 2007: Intonational realisation of topic and focus by Dutchacquiring 4- to 5-year-olds. In J. Trouvain \& W. J. Barry (Eds), Proceedings of the 16th International Congress of Phonetic Sciences, Saarbrücken, 1553-1556.

Chen, A. (2009). Perception of paralinguistic intonational meaning in a second language. Language Learning, 59, 367-409.

Chen, A., den Os, E. \& de Ruiter, J. P. (2007). Pitch accent type matters for online processing of information status: Evidence from natural and synthetic speech. The Linguistic Review, 24, 317-344.

Chen, A., Gussenhoven, C. \& Rietveld, A.C.M. (2004). Language specificity in perception of paralinguistic intonational meaning. Language and Speech, 47, 311-349.

Chen, H. (2008). On Chinese EFL Learner's English Intonation Patterns. Shanghai: Shanghai Foreign Language Education Press.

Chun, D. M. (2002). Discourse Intonation in L2: From Theory and Research to Practice. Amsterdam/Philadelphia: John Benjamins.

Clark, J. \& Yallop, C. (1995). An Introduction to Phonetics and Pbonology, 2nd ed. Cambridge, MA: Blackwell.

Cruz-Ferreira, M. (1989). Non-native interpretive strategies for intonational meaning: An experimental study. In A. James \& J. Leather (Eds.), Sound Patterns in Second Language Acquisition (pp. 103120). Dordrecht: Foris. 
Crystal, D. (1969). Prosodic Systems and Intonation in English. Cambridge University Press.

Eckman, F. R. (2008). Typological markedness and secon phonology. In J.G. Hansen Edwards \& M. L. Zamp Phonology and Second Language Acquisition (pp. 95-115). A John Benjamins.

Ellis, R. (1994). The Study of Second Language Acquisition. Oxfo. University Press.

Escudero, P., Benders, T. \& Lipski, S. C. (2009). Native, non L2 perception cue weighting for Dutch vowels: the case German, and Spanish listeners. Journal of Phonetics, 37, 452Flege, J. (1988). Factors affecting degree of perceived foreig English sentences. Journal of the Acoustical Society of America, Flege, J. (1991). Orthographic evidence for the perceptual id of vowels in Spanish and English. Quarterly Journal of $I$ Psychology, 43, 701-731.

Flege, J., Munro, M. \& MacKay, I. (1995). Factors affecting perceived foreign accent in a second language. Journal of $t$ Society of America, 97, 3125-3134.

Fox, A. (1984). German Intonation: An Outline. Oxford: Oxford Press.

Gao, Q. (1984). Grammatical stress in Mandarin. Language Research, 2, 65-76.

Grabe, E. (1998). Comparative Intonational Phonology: English a $\mathrm{PhD}$ dissertation, Radboud University Nijmegen.

Grabe, E. (2004). Intonational variation in urban dialects spoken in the British isles. In P. Gilles \& J. Peters (Ed $V$ ariation in Intonation (pp. 9-31). Tübingen: Linguistische Grabe, E., Rosner, B. S., Garcia-Albea, J. E. \& Zhou, Perception of English intonation by English, Spanish, a listeners. Language and Speech, 46, 375-401.

Grice, M., Baumann, S. \& Benzmüller, R. (2005). German in autosegmental-metrical phonology. In S.-A. Jun (Ec Typology: The Phonology of Intonation and Phrasing (pp. 55-8 Oxford University Press.

Grosser, W. (1997). On the acquisition of tonal and accentual English by Austrian learners. In A. James and J. Leat Second Language Speech: Structure and Process (pp. 211-2: Mouton de Gruyter. 
Gunlogson, C. (2003). True to Form: Rising and Falling Declaratives as Questions in English. New York: Routledge.

Gussenhoven, C. (2000). The lexical tone contrast of Roermond Dutch in Optimality Theory. In M. Horne (Ed.), Intonation: Theory and Experiment (pp. 129-167). Amsterdam: Kluwer.

Gussenhoven, C. (1984). On the Grammar and Semantics of Sentence Accents. Dordrecht: Foris.

Gussenhoven, C. (2004). The Phonology of Tone and Intonation. Cambridge: Cambridge University Press.

Gussenhoven, C. (2005). Transcription of Dutch intonation. In Jun, S.-

A. (Ed.), Prosodic Typology: The Phonology of Intonation and Phrasing (pp. 118-145), Oxford: Oxford University Press.

Gussenhoven, C. \& Rietveld, A. C. M. (1991). An experimental evaluation of two nuclear tone taxonomies. Linguistics, 29, 423-449.

Gut, U. (2009). Non-native Speech. Frankfurt: Peter Lang. Haan, J. (2002). Speaking of Questions: An Exploration of Dutch Question Intonation. Utrecht: LOT.

Halliday, M. A.K. (1970). A Course in Spoken English: Intonation. London: Oxford University Press.

He, X., van Heuven, V. J. \& Gussenhoven, C. (2011a). Choosing the optimal pitch accent location in Dutch by Chinese learners and native listeners. In M. Wrembel, M. Kul \& K. Dziubalska-Kolaczyk (Eds.), Acbievements and Perspectives in SLA of Speech: New Sounds 2010 (pp. 125-137). Frankfurt am Main: Peter Lang Verlag.

He, X., van Heuven,V. J. \& Gussenhoven, C. (2011b). Phonetic implementation must be learnt: native versus Chinese realization of focal accent in Dutch. Proceedings of the 17th International Congress of Phonetic Sciences, Hong Kong, 843-846.

Hincks, R. \& Edlund, J. (2009). Promoting increased pitch variation in oral presentation with transient visual feedback. Language Learning \& Tecbnology, 13, 32-50.

Huang B. R. \& Liao, X. D. (1991). Modern Chinese. Beijing: Higher Education Press.

Ioup, G. (2008). Exploring the role of age in the acquisition of a second language phonology. In J. G. Hansen Edwards \& M. L. Zampini (Eds.), Pbonology and Second Language Acquisition (pp. 19-39). Amsterdam: John Benjamins.

Jilka, M. (2000). The Contribution of Intonation to the Perception of Foreign Accent (Unpublished doctoral dissertation). Institut für Maschinelle Sprachverarbeitung, Stuttgart University. 
Ladd, D. R. (1980). The Structure of Intonational Meaning. Bloom London: Indiana University Press.

Ladd, D. R. (2008). Intonational Phonology. Cambridge: University Press. $2^{\text {nd }}$ Edition.

Liberman, M. \& Sag, I. (1974). Prosodic form and discourse f Papers from the Tenth Regional Meeting of the Chicago Linguistic 416-427). Chicago: CLS.

Lin, M. (2006). Zhao's view point of Chinese intonation anc tone. Report of Phonetic Research 2006, Bejing: Institute of $1-4$.

Mennen, I. (2007). Phonological and phonetic influences in intonation. In J. Trouvain \& U. Gut (Eds.), Non-na Phonetic Descriptions and Teaching Practice (pp. 53-76). Berli De Gruyter.

Munro, M. J. \& Derwing, T. M. (1995). Foreig comprehensibility, and intelligibility in the speech language learners. Language Learning , 45, 73-97.

Niioka, Y., Caspers, J. \& van Heuven, V. J. (2005). The per interrogativity by Japanese speakers of Dutch as a secon In J. S. Doetjes \& J. M. van de Weijer (Eds.), Ling Netherlands 2005 (pp. 139-150). Amsterdam: John Benjam

O'Brien, M. \& Gut. U. (2010). Phonological and phonetic re different types of focus in L2 speech. Proceedings of the 6 th Symposium on the Acquisition of Second Language Speech, Pozna Odlin, T. (2003). Cross-linguistic influence. In C. Doughty (Eds.), Handbook of Second Language Acquisition (pp. 436-4غ Blackwell.

Peng, S., Chan, M. K M., Tseng, C., Huang, T., Lee, O. Beckman. (2005). Towards a Pan-Mandarin system fo transcription. In S.-A. Jun (Ed.), Prosodic Typology: The Intonation and Phrasing (pp. 230-270). Oxford: Oxford Press.

Peters, J. (2006). Intonation Deutscher Regionalsprachen. New Y Mouton de Gruyter.

Pierrehumbert, J. B. (1980). The Phonetics and Phonology of Englis Ph.D. dissertation, Massachusetts Institute of Technology Pierrehumbert, J. \& Hirschberg, J. (1991). The meaning of contours in the interpretation of discourse. In P. Cohen \& M. Pollack (Eds.), Intentions in Communication (pp. Cambridge, MA: MIT Press. 
Rasier, L. (2003). Le système accentuel de l'interlangue d'apprenants francophones du néerlandais [The accentual system of the interlanguage of French learners of Dutch]. Actes du collque international 'interfaces prosodiques/prosodic interfaces' [Proceedings of the International Colloquium on 'interfaces prosodiques/prosodic interfaces'], 7984.

Rasier, L. (2006). Prosodie en vreemde-taalverwerving. Accentdistributie in het Frans en Nederlands als vreemde taal [Prosody and Foreign Language Acquisition. Accent Distribution in French and Dutch as Second Languages], $\mathrm{PhD}$ diss. Université Catholique Louvain-la-Neuve.

Rasier, L. \& Hiligsmann, P. (2007). Prosodic transfer from L1 to L2. Theoretical and methodological issues. Cahiers de Linguistique Française, 28, 41-66.

Rochet, B. (1995). Perception and production of second-language speech sounds by adults. In W. Strange (Ed.), Speech Perception and Linguistic Experience (pp. 379-410). Timonium, MD: York Press.

Shannon, C. E. (1948). A mathematical theory of communication, Bell System Technical Journal, 27, 379-423.

Shen, X. (1990). The Prosody of Mandarin Chinese. Berkeley: University of California Press.

't Hart, J., Collier, R. \& Cohen, A. (1990). A Perceptual Study of Intonation: An Experimental Phonetic Approach. Cambridge: Cambridge University Press.

Trofimovich, P. \& Baker, W. (2006). Learning second language suprasegmentals: effect of L2 experience on prosody and fluency characteristics of L2 speech. Studies in Second Language Acquisition, 28, $1-30$.

Trouvain, J. \& Gut, U. (2007). Non-native Prosody, Phonetic Description and Teaching practice. Berlin: Mouton de Gruyter.

van Bezooijen, R. (1989). Evaluation of an algorithm for the automatic assignment of sentence accents. In $\mathrm{H}$. Bennis \& A. van Kemenade (Eds.), Linguistics in the Netherlands 1989 (pp. 21-30). Dordrecht: Foris.

van de Ven, M. \& Gussenhoven, C. (2010). The timing of the final rise in falling-rising intonation contours in Dutch. Journal of Phonetics, 39, 225-236.

van Els, T. \& de Bot, K. D. (1987). The role of intonation in foreign accent. Modern Language Journal, 71, 147-155.

van Heuven, V. J. (1986). Some acoustic characteristics and perceptual consequences of foreign accent in Dutch spoken by Turkish im- 
migrant workers. In J. van Oosten \& J. F. Snapper (E Linguistics at Berkeley, Papers Presented at the Dutch Linguistics Held at the University of California, Berkeley on November 9th. 67-84). Berkeley: The Dutch Studies Program, U.C. Berk van Leyden, K. \& van Heuven, V. J. (2006). On the prosody and Shetland dialects. Phonetica, 63, 149-174.

van Santen, J. \& Shih, C. (2000). Suprasegmental and segme models in Mandarin Chinese and American English. $J$ Acoustic Society of America, 107, 1012-1026.

Wennerstrom, A. (1994). Intonational meaning in English d study of non-native speakers. Applied Linguistics, 15, 399-4

Wells, J. C. (2006). English Intonation: An Introduction. Cambridge University Press.

Willems, N. J. (1982). English Intonation from a Dutch Poi Dordrecht: Foris.

$\mathrm{Xu}, \mathrm{Y} . \& \mathrm{Xu}, \mathrm{C} . \mathrm{X}$. (2005). The phonetic realization of focus Journal of Phonetics, 33, 159-197.

Yuan, J. (1983). Introduction to Dialects in Chinese. Beijing: Writ Reform Publishing House. 


\section{Chapter 4}

\section{A prosodic analysis of Mandarin- accented Dutch}

\subsection{Introduction}

Despite the great liberty that speakers of Dutch have in choosing an intonation contour for a given sentence, in many cases this liberty is constrained to the extent that we may speak of 'intonational idioms'. For instance, an alternative question like Wil je koffie of thee? Would you like coffee or tea?' is typically pronounced with a Fall $\left(\mathrm{H}^{*} \mathrm{~L}\right)$ on the final word, indicating that the list of options is complete at that point. In the experiment reported here, we explored the ability of a group of twenty Mandarin-accented speakers of Dutch to read out sentences that were taken to have 'idiomatic intonation'. We defined seven such intonational idioms, each represented by six syntactically similar sentences, resulting in 42 sentences altogether. To place the experimental sentences in some realistic context, they formed part of mini-dialogues. Each of the seven intonational idioms is illustrated in section 4.2.1. The purpose of this approach was not only to see how well the L2 learners were able to produce the right intonation contour with the accented syllable in the right location, but also to collect reasonably controlled free speech. By eliciting intonational idioms, we hoped to ensure that a usable quantity of similar and thus comparable data could be obtained. Such data can be used to study phonetic measures in similar speech conditions. This approach was successful.

The same group of twenty Mandarin-accented participants that was used in Chapter 2 and 3 took part in the experiment. Again, they were further divided into two subgroups: ten with higher proficiency and ten with lower proficiency in Dutch. The twenty Chinese speakers of Dutch were compared with the performances of five native speakers of Standard 
Dutch, who served as a control group. One aim of the expe to see if the Chinese subjects were able to choose $t$ intonational melody (pitch accent plus boundary tone) on the (pitch accent location) in these seven types of sentences. The was to be able to investigate their phonetic realization of the contours, since in this experiment they were left free to say th as they wished. Therefore, we not only report on the success the L2 subjects used the correct intonation contour with location of the nuclear pitch accent, but also report on th phrasing they used, on the pitch range and on speech rhyt these concepts are briefly explained.

\subsection{Phrasing}

Phonological phrasing involves the division of an utte phonological units. As Figure 4.1 shows an utterance $(U)$ con or more international phrases (IP), and an IP is composed more phonological phrases $(\varphi)$, which dominate one or more An utterance is produced so as to reflect its syntactic struct division of IPs in an utterance is not totally syntactically dr may be some hesitations and fillers 'err', 'erm', etc. in ut largely unpredictable points. Intonation phrasing is influence other factors, such as speaking styles, information structure structure and speakers' awareness of listeners' needs (Watson 2004; Gussenhoven \& Jacobs, 2008). Due to their limite knowledge and their proficiency in the L2, second langua would divide sentences into different IPs from native spe causing disfluency in their speech. The representation in Fis be appropriate for a sentence like Often, John seemed sad.

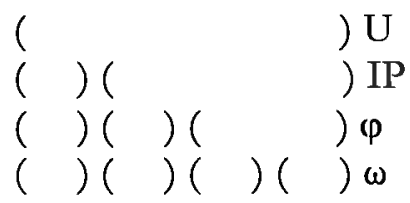

Figure 4.1. Prosodic hierarchical structure of an utterance (after Gussenho 2008) 
IP boundaries can be identified phonetically by pausing, final syllable lengthening, anacrusis and f0 resetting (Cruttenden, 1997). Pauses are longer after larger phonological units than those after minor ones in read speech. Pauses between utterances are longer than the ones after IPs, and pauses between IPs are longer than the ones after phonological phrases if there are any. The length of pauses also depends upon the speaking styles (Keseling, 1992). But pausing is not sufficient to indicate an IP boundary because it can occur in the hesitations. The lengthening of accented final syllables can also help listeners to find the IP boundary (Gussenhoven \& Rietveld, 1992). The final syllable lengthening was found longer at an intonation boundary than at an 'intermediate phrase' boundary (Chavarría, Yoon, Cole \& Hasegawa-Johnson, 2004; Yang, 2004). The fo resetting is visible in instrumental pitch tracking though it is not sensitive to listeners. Pitch is the lowest at an L\% boundary in an IP, and will be raised up higher for the next IP. The pitch of an initial unstressed syllable in the IP which follows an L boundary tone of the preceding $\mathrm{IP}$ will be higher than that of the $\mathrm{L} \%$. Declination, the downward trend of f0 over the course of an utterance (Cohen, Collier \& 't Hart, 1982; Ladd, 1984) is common phenomenon in speech. The last IP indicator, anacrusis, is also concerned with the unstressed syllable in the next IP. Compared with other unstressed syllable in an IP, the unstressed ones before the first pitch accent are often produced more quickly. We annotated all the IPs in the speeches based upon our hearing and the phrasing features shown in the spectrograms.

Earlier research has shown that non-native speakers of English not only produced significantly more and shorter intonation phrases in read speech than native speakers, but also put phrase boundaries in different places (Chen, 2008; Grosser, 1982; Gut, 2000, 2009; Hewings, 1995b). In her corpus-based study of phonological acquisition, Gut (2009) found that non-native speakers of English produced significantly more phrases than native speakers in the read speech, resulting in fewer words in the IPs, while the native speakers of English produced no interrupted phrases in their read speech. Although there were some interrupted phrases in the retellings by the native speakers, the percentage of interrupted phrases was lower and the length of the IP longer than in the case of the non-native speakers. Similar differences were found between native speakers and non-native speakers of German. Although the average number of IP phrases produced by the two groups in the read speech did not differ significantly, the differences in the mean length of 
phrases was significant. The mean length of IP phrases speakers in retellings is longer than that by non-native $s$ German; however, no significant difference was found in the of interrupted phrases by the two groups.

Chen (2008) found that the number of pauses and IP length speech by Chinese learners of English were significantly diff the native speakers, who had fewer pauses and thus longe considering the information status in an utterance, the learnes to employ their L1 Chinese syntactic knowledge in decidin place IP boundaries, more specifically using punctuation. FC they took some adverbials like 'especially', reporting c attributive relative clauses as separate IPs. Conversely, in lis not treat each item as a separate IP, and they had considerabl in reading longer sentences with no punctuation. Advanc performed more like the native speakers than the learner proficiency in English.

The first aim in this study is to find out how Mandarin Chine of Dutch divide an utterance into IPs in read speech and wh are differences in phrasing between Chinese speakers proficiency in Dutch (CHD) and the ones with lower proficie such that makes the CHD group perform closer to the native pauses in the internal-IPs and at the boundaries in the read sp three groups of speakers were also compared.

\subsection{Pitch range}

Pitch range is the difference between the maximum and $\mathrm{m}$ values across an utterance. Patterson (2000) proposed tw measure pitch range. The wide pitch range is the difference $b$ average of a speaker's utterance-final lows and the aver speaker's utterance-initial highs. The small pitch range is the between the non-initial pitch peak and the non-final valley measurement was adopted in the present study.

In her corpus study, Gut (2009) found the pitch range of nati of German and English to be greater than that of their count native Chinese speakers in the read speech and retellings 
research, the pitch range in read speech by Chinese learners of English was also found significantly narrower than that by the native speakers, while the advanced learners' pitch range was more similar to that of the native speakers than that of the learners with lower proficiency in English (Chen, 2008). Chinese speakers adapt their pitch range to convey pragmatic meanings. Expansion of the pitch range typically codes referents that are in focus, while a reduced pitch range is found for nonfocused materials after the focus. Acoustic and auditory studies similarly showed that $\mathrm{f} 0$ variation of $\mathrm{L} 2$ learners was different from that of native speakers in research with Chinese speakers of French, who are claimed to have wider pitch span and higher overall pitch level than native speakers (1990).

The second research question is to see what the differences are in pitch range between native speakers and Chinese speakers of Dutch, and between the Chinese subgroups (CHDs and CLDs).

\subsection{Speech rhythm}

Speech rhythm concerns the temporal distribution of speech events. Languages were claimed to be stress-timed or syllable-timed in earlier research (Abercrombie, 1967; Pike, 1945). Stress-timed languages like English and Dutch have been said to have a rhythm defined by approximately equal intervals of stress, called feet, each of which begins with a stressed syllable. In syllable-timed languages like French and Chinese, the length of each syllable has been claimed to remain approximately the same. No acoustic correlation with this classification was found in later empirical investigations, however. The feet in presumed stress-time languages like English not only have different durations, but their durations also increase linearly with the number of syllables they contain (Dauer, 1983; Fauré, Hirst \& Chafcouloff, 1980; Roach, 1982). Further, Barry (2007) claimed there is in fact no such thing as isochrony. Speech rhythm is a cover term which reflects the variety of syllable structures, phonological vowel length, vowel reduction and lexical stress (Barry, 2007; Dauer, 1983). The presumed stress-timed and syllable-timed languages in fact have different types of syllable structures, resulting in different syllable durations. For insistence, English has $\mathrm{CV}$ (30\%), CVC (34\%), VC (15\%), V (8\%) and CVCC (6\%) while Spanish has majority of $\mathrm{CV}(58 \%)$ syllables. Also, stress-timed languages usually 
have vowel reduction, lexical stress or sentential accents realized by length, pitch and spectral features, while s languages have no lexical stresses or sentential accents, realization depends on the pitch contour (Barry, 2007).

In an attempt to provide phonetic meaning to the distinctic stress-timed and syllable-timed languages, Ramus, Nespor a (1999) classified some languages into categories similar to $s$ and syllable-timed languages by comparing the percentage of V) and the standard deviation of the consonantal intervals claimed that most languages of the world fall somewhere continuum of the two categories at polar ends. Other app measure speech rhythm are the Pairwise Variability Index (P) by Francis Nolan (Low \& Grabe, 1995), the Rhythm Ratio (R) \& Gut, 2001), the Variability Index (VI) (Deterding, 200 Syllabe Ratio (SR) (Gut, 2003). These are given here in (1 respectively.

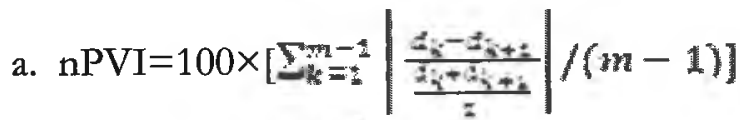

$$
\begin{aligned}
& \text { b. } \mathrm{RR}=100 \cdot \sum_{\mathrm{k}=1}^{\mathrm{m} n-1} \frac{\mathrm{e}_{\mathrm{i}}}{\mathrm{z}} /(\mathrm{m}-1) \\
& \text { c. VI }=\frac{1}{n-2} \sum_{k=1}^{n-1}\left|d_{k+1}-d_{k}\right|
\end{aligned}
$$

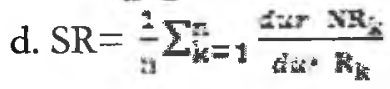

PVI calculates the mean sum of the quotients of the duration of adjacent syllables or vowels in their mean duration, and will be an integral number by multiplying the result by 100 . hundred times of the mean sum of the quotients of adjacent the quotient in the pair is obtained by dividing the shorter $d x$ syllable or vowel by the longer one. The higher the value is different the duration of adjacent pairs is. VI measures duration of adjacent syllables without final syllables, due to lengthening. SR is to measure the average sum of quotients with a full vowel and its immediate adjacent syllable with vowel, and it is obtained by dividing the sum of all quotients number. Also the final syllable and the pre-pause syllables a in SR. 
The finding that Thai, Dutch, German, British English, Tamil and Malay had higher vowel PVI while Mandarin and Spanish had lower vowel PVI means that the former group showed more variation in vowel duration and the latter less variation in vowel duration (Grabe \& Low, 2002). The consonant PVI in Estonian, Romanian, French, Welsh and Luxemburgish was found lower than that in Polish, Catalan, Tamil, Malay and British English. The vowels that should be reduced in British English were pronounced as full vowels in Hong Kong English, and also the weak and unstressed syllables were significantly longer in Hong Kong English than in British English (Setter, 2003). The vowel PVI was significantly lower in the read speech in Taiwan English than in American English. The length of the reduced vowels in Taiwan English was exactly the same length of full vowels (Jian, 2004).

Speech rhythm is a principal factor contributing to 'foreign accent' (Anderson-Hsieh et al., 1992; van Els \& de Bot, 1987) and is difficult for learners to acquire (Adams, 1979; Bond \& Fokes, 1985; Faber 1986; Wennerstrom, 2001). The non-native speech rhythm in English by the syllable-timed L1 language learners was found due to factors like. durations of stressed and unstressed syllables, liaison, inappropriate pauses and stress (Adams, 1979).

Numerous studies showed that L2 learners of English whose L1 was syllable-timed language could not reduce durations of English vowels like the native speakers, resulting in non-native speech rhythm (Bond \& Fokes, 1985; Chen, 2008; Flege \& Bohn, 1989; Ghazali \& Bouchhioua, 2003; Lee, Guion \& Harada, 2006; Mairs, 1989; Wenk, 1985) and the non-native speech rhythm correlated positively with the proficiency in the second language (Chen, 2008; Wenk, 1985; Zborowska; 2000). The more advanced the learners in these investigations were, the more their speech rhythm was native-like. Similar findings are also true for learners of other language. For example, English learners of German mostly reduced the vowels in word-initial unstressed syllables and function words in reading word or phrase lists, while native Russian learners of German only reduced the vowels in word-final syllables, but Japanese learners of German could not reduce the vowels in unstressed syllables (Kaltenbacher, 1998). The SR in the read speech by all Polish, Italian and Chinese learners of German was significantly lower than that by the native speaker of German, and the SR in the retellings by Chinese 
learners was significantly lower than that by the native spe: 2003). In the corpus driven studies by Gut (2009), the syllab native speakers' speech were found to be longer and slower speech, although the non-native speakers of German cou native-like vowels like the native German speakers. Non-nati of English could not sufficiently reduce or delete the unstressed syllables.

The differences in speech rhythm by non-native speakers speakers were attributed so far to the influence of the speakers' L1 (Adams, 1979; Chen, 2008; Gut, 2003, 2 Kaltenbacher, 1998; Lee, Guion \& Harada, 2006; Setter, 2 1985). Chinese has been characterized as a 'syllable-timed' la to its relatively constant syllable duration (Clark \& Yallop; Santen \& Shih, 2000), while Dutch is a stressed-timed lat English, German and other Germanic languages.

In the investigation by Chen (2008) the $\% \mathrm{~V}$ was higher at smaller in the read speech by Chinese learners of English th the English speakers. It meant that there was less reduction of vowels and less variation of consonants in Chinese-accen than in native English. This resulted from their L1 Chinese (C And $\% \mathrm{~V}$ and $\Delta \mathrm{C}$ in advanced learners' read speech were clo of the native speakers.

The third research question in the present study is to cc speech rhythm in the read speech by Mandarin Chinese s Dutch and the native speakers, and to find the nPVI differe speech rhythm by CHDs and CLDs.

\subsection{Speech rate and articulation rate}

Speech rate is often defined as the average number of $s$ second in a whole sentence (Pereira \& Watson, 1998). Artic refers to the average number of syllables per second exclud The difference between speech rate and articulation rate inclusion of the duration of pauses in the former and their the latter. Native speakers of Dutch spoke faster and paused speech than a heterogeneous group of non-native speaker 
Cucchiarini, Strik \& Boves, 2000). The SR (syllable ratio) discussed in above section, was found to correlate with speech rate in both native German and native English, while in non-native speech there was no such correlation (Barry, Andreeva, Russo, Dimitrova \& Kostadinova, 2003; Ramus, 2002; White \& Mattys, 2007)

The fourth research question in the present investigation is to compare the speech rate and the articulation rate in the read speech by the native speakers with those by the CHDs and CLDs.

\subsection{Pitch accents}

Germanic languages, like English, German or Dutch, generally have sentence prosodic patterns that are the result of the inherent stress patterns of words and a rather complex set of rules for the placement of pitch accents on a subset of these stressed syllables. Their placements in sentences are determined by lexical, phonological and morphological information, in addition to semantic and pragmatic factors (Gussenhoven, 2011).

Mandarin Chinese is traditionally analysed as having two types of accentuation: grammatical and logical (Gao, 1984). Grammatical accents are claimed to be determined by the structure of syntactic phrases, while logical accents depend upon the meanings speakers intend to express. A grammatical accent is not as strong phonetically as a logical accent. Unlike what is the case in languages like English and Dutch, there appear to be no consistent phonetic correlates of what has been characterized as grammatical stress. Possibly, stress differences identified by Huang \& Liao (1991), among others, may resolve as phrasing differences and the occurrence of neutral tone vs. lexical tone. Be that as it may, the following stress relations have been identified, whereby there is more phonetic strength for (i) the predicate verb than for the subject in an INP VP]-phrase; (ii) for the adjective in an [Adj Noun]-phrase, and for the adverb in an [Adv Verb]-phrase as well as in an [Verb-Adv]-phrase; (iii) for the head of a prepositional phrase than for the preposition; (iv) for the object in an [NP Verb]-phrase, and (v) to an interrogative pronoun or demonstrative than to their head (Huang \& Liao, 1991). Although there are similarities between the Chinese prominence differences and 
those of Dutch, these phonetic strength differences are $r$ comparable to the melodically prominent effect of a pitch Dutch. Moreover, unlike the alternation between short uns long stressed syllables in Dutch, syllable duration in Manda relatively constant, which is in fact why it has been chara 'syllable-timed' (Clark \& Yallop, 1995; van Santen \& Shih, 200

The effect of the logical accents in Mandarin sentences is $p$ closer to pitch accent distributions in Dutch sentences. In 'logical accents' are often given to words which are to be e because they express new information or strong emotion (Hu 1991). In effect, the rule for the realization of post-focal phonetic reduction of the pitch range, is phonetically similar deaccentuation in West Germanic languages $(\mathrm{Xu} \& \mathrm{Xu}$, means that Chinese learners of Dutch could in principle acc 'focus' in the read speech if they transfer their L1 knowledge production or perception.

Chapter 2 reported on the perception experiment conducted well Chinese learners of Dutch identify the correct accentuati in six categories of Dutch sentences characterized by some $g$ generalization about the distribution of pitch accents. Nativ correctness scores were significantly higher than those by $t$ learners with high proficiency in Dutch, and the correctnes the latter were also significantly higher than those obtained $f$ proficiency learners. Accentuation for new information wa evaluate than accentuations due to morphological rules. In more syllables are generally found to be accented in non-na than in native speech, or to be accented inappropriately. Chin of English produced too many pitch accents in read speech (C Juffs, 1990). One reason is the transfer of word tone from I the other is the fact the learners ignored the context of the accented the given information in the reading (Chen, 2008) learners had a tendency to accent content words and their ac were found similar to those by the native speakers, so th though foreign-accented, was generally intelligible. But les lower proficiency in English accented the functional words their speech sometimes was not intelligible due to the wrong being expressed by inappropriate accents. This means 
interaction between their knowledge of the L1 and L2 resulted in the incorrect accent patterns.

Incorrect accent placements in L2 speech are often reported in the literature (e.g. Adams, 1979; Beckman, 1979; Chen, 2008; Grosser, 1997; Gut, 2009; Juffs, 1990). Spanish speakers of English were found to place the nucleus on the given information and the pitch movement on the nucleus was smaller than the native speakers (Ramirez Verdugo, 2002). Mandarin Chinese speakers could not produce the pitch accents in delivering lectures, ignoring the difference between the given and new information (Wennerstrom, 1998). Nearly half of the cases of given or accessible information were accented in a corpus driven study (Gut, 2009). In pre-nuclear position, more falling contours occur on content words than do rising contours, but falls and rises are equally frequent on function words, which are accented less often.

The fifth research question is to investigate where the Mandarin speakers of Dutch put pitch accents in the sentences and to find the differences in pitch accent placement between CLDs and CHDs.

\subsection{Intonation contours}

Dutch is an intonation-only language in which there are Fall, Rise, Fallrise contours and 21 other nuclear (accent-lending) f0 contours (Gussenhoven, 2005), while Mandarin Chinese is a tone language in which there is no such rich contour inventory. At least two boundary tones have been identified for Guoyu (Standard Mandarin in Taiwan) and Putonghua (Standard Mandarin in mainland China), which have been claimed to correspond with Yuanren Chao's Rising and Falling endings respectively in the Beijing dialect, a dialect very close to Standard Mandarin (Lin, 2006; Peng et al., 2005). As Figure 3.2 shows, the lexical tones are kept intact when the syllable [ma] was uttered with four tones in Mandarin interrogatives and declaratives. We find that the pitch was raised in interrogatives compared to declaratives. That is to say, a falling tone remains a falling tone and a rising tone remains a rising tone when pronounced with either intonation.

Warren (2004) found that Hong Kong English speakers used more Rises in different types of conversations when they communicated with native 
speakers than other contours. No significant difference between the French native speakers and the Chinese learners when 25 native French listeners were asked to judge w questions sounded like questions (Shen, 1990). The striking in the pronunciation of rises for questions lie in the realiza final syllable. The learners either raised the pitch higher than speakers did or lowered it first and then rose late in the sy forming a falling-rising terminal contour rather than a Ris Wennerstrom (1994) found that Thai speakers of English di high ending rise for questions the way the native speakers speech, while the Japanese and Spanish speakers of English differences in the frequency of use or the realization of rises to the native speakers. Japanese and Thai speakers of En produced low or falling pitch in the middle of the utterance were more low or falling pitch in their picture description native speakers' description. But the low or falling pitch was $p$ the Spanish speakers and the native English speakers only at the text or before topic shifts and parentheticals. According (1995a), Falls were produced by Greek, Korean and Indones of English at connective junctures where the native speake Rises instead. Spanish learners were also found to use mo statements and more Rises in tag questions than the nati though they showed no differences in the use of Falls and $R$ questions and yes-no questions (Ramirez Verdugo, 2002). speakers of English or German used a reduced tone invent complex tones on nuclei occurred much less frequently $t$ native speakers' speech. Level tones or simple pitch mover mostly produced on nuclei in non-native speech. And the rea Falls or Rises were phonetically different from the native spe 2009). For example, some Falls by the non-native speakers di their pitch bottom to signal the finality of the utterances.

By studying the intonation contours used in listing, statemen clause in coordinate sentences, imperatives, wh-questions, yes questions in the reading of a story, Chen (2008) found Chin of English could produce the Fall and the Rise according patterns generally, but they could not choose different Rises to express different emotion and pragmatic meanings in the $r$ And sometimes they substituted the Fall and Rise for the especially the subjects with lower English proficiency. 
The longitudinal study led Grosser (1997) to propose that simple tones should be acquired before complex tones (Gut, 2009). If this hypothesis is correct, a complex tone like the Fall-rise in English and Dutch would be difficult for Chinese learners of the two languages. The Dutch intonation contours appear on single syllables and the nuclear accent occurs on the last syllable of the intonational phrase (IP). The Fall-Rise, which is carried out entirely in the syllable rime, does not have a Mandarin counterpart. The intonation contours of Fall and Rise are similar to those of Tone 4 and Tone 2, respectively. The Chinese speakers of Dutch may have no problem with the Fall and Rise, therefore, as they can transfer Tone 4 and Tone 2 to Dutch. Mandarin tone 3, which is low and begins any pitch fall earlier and lower than the Fall-rise, cannot be transferred easily into Dutch and the Fall-Rise will therefore be more difficult than the Fall and Rise.

\subsection{Method}

\subsubsection{Materials}

The subjects were asked to read 42 Dutch sentences (seven types $\times$ six sentences $=42$, cf. Appendix 4) in the way they thought was correct.

The first type is the alternative question as (1) shows, which is transcribed as $\mathrm{H}^{*} \mathrm{~L} \mathrm{~L} \%$.

(1) Je moet kiezen: wil je liever fruitsalade of wil je liever ijs?

$$
\% H \quad H^{*} L L \%
$$

You have to choose: would you rather have fruit salad or ice cream?

The second type is the yes-no question with toch 'not' as in (2), transcribed as $\mathrm{H}^{*} \mathrm{~L} \mathrm{H} \%$.

(2) Je boeft niet meer te werken. Ie bebt toch al genoeg gedaan deze week?

$$
\% \mathrm{~L} \quad \mathrm{H} * \mathrm{~L} \quad \mathrm{H} \%
$$

You don't have to work anymore. Haven't you done enough for the week? 
The third type with echt 'really' in the stimulus sentence is tra $\mathrm{H}^{*} \mathrm{H} \%$, as shown in (3).

(3) Zei je nou echt dat je naar buiten wilde? In de regen?

$$
\% \mathrm{~L} \quad \mathrm{H}^{*} \mathrm{H} \%
$$

Did you really say you wanted to go out? In the rain?

The fourth type is the sentence-initial reporting sentence Standard Dutch is often read with half-fall, transcribed as $\mathrm{H}^{*}$ shows.

(4) Hij keek ons de bele tijd strak aan. Toen zei-die: Dat nooit!

$$
\% \mathrm{~L} \mathrm{H} \mathrm{H}^{*} \mathrm{~L} \quad \%
$$

He looked hard at us for the whole time. Then he said: $\mathrm{Th}$

The fifth type, shown in (5), is the vocative chant, transcribed

(5) Schat-je! We hebben weer kaa-aas!

$\% \mathrm{~L} \quad \mathrm{H}^{*} ! \mathrm{H} \%$

Honey! We have cheese again!

The sixth, as in (6), contains a modal particle bè or boor to tr which has $\mathrm{H}^{*} \mathrm{~L}$ on a preceding word, followed by $\mathrm{H}^{\%}$.

(6) Het wordt laat. Maar je moet wel je eten opeten, boor!

$$
\% \mathrm{~L} \quad \mathrm{H}^{*} \mathrm{~L} \quad \mathrm{H} \%
$$

It's getting late. But you should finish you meal!

The seventh and last type (7) is the exclamation with wat 'wha fall or half fall, transcribed as $\mathrm{H}^{*} \mathrm{~L} \mathrm{~L} \%$ or $\mathrm{H}^{*} \mathrm{~L} \%$, respectively

(7) Kijk daar 's! Wat is dat een rare fiets!

$$
\% \mathrm{~L} \quad \mathrm{H}^{*} \mathrm{~L} \%
$$

Look over there! What a funny bike! 


\subsubsection{Procedure}

\subsubsection{Subjects}

The five female speakers of Standard Dutch were all from Radboud University Nijmegen, aged from 27 to 51 years. They were recorded in the studio in the university.

Twenty Mandarin Chinese speakers of Dutch ( 3 male, 17 female) in the experiment are the same participants as in Chapter 2 and 3. They were recorded with the help of a Zoom H4 Handy Recorder in different places: in the house, in classrooms, or in libraries; one was recorded in the studio in the Arts Faculty of Radboud University Nijmegen and three in a studio at Gronigen University. The 42 test sentences together with their corresponding stimulus sentences were put into a Powerpoint file in a random order and printed in a booklet in the same order with the context and target sentence printed on the same page. To the participants' preference, they could read aloud the sentences page by page from the booklet or from the screen displayed by the Powerpoint file, which they went through by clicking the 'Next' button. They were allowed to repeat sentences whenever they thought were not their best reading.

The Mandarin speakers of Dutch were divided into a higher ("Chinese Higher Dutch': CHD) and a lower (CLD) subgroup on the basis of each subject's mean score over their segmental and prosodic proficiency scores, as explained in Chapter 2. 


\subsubsection{Labellings}

We annotated each target utterance with Praat (Boersma 8 2009), as Figure 4.2 shows.

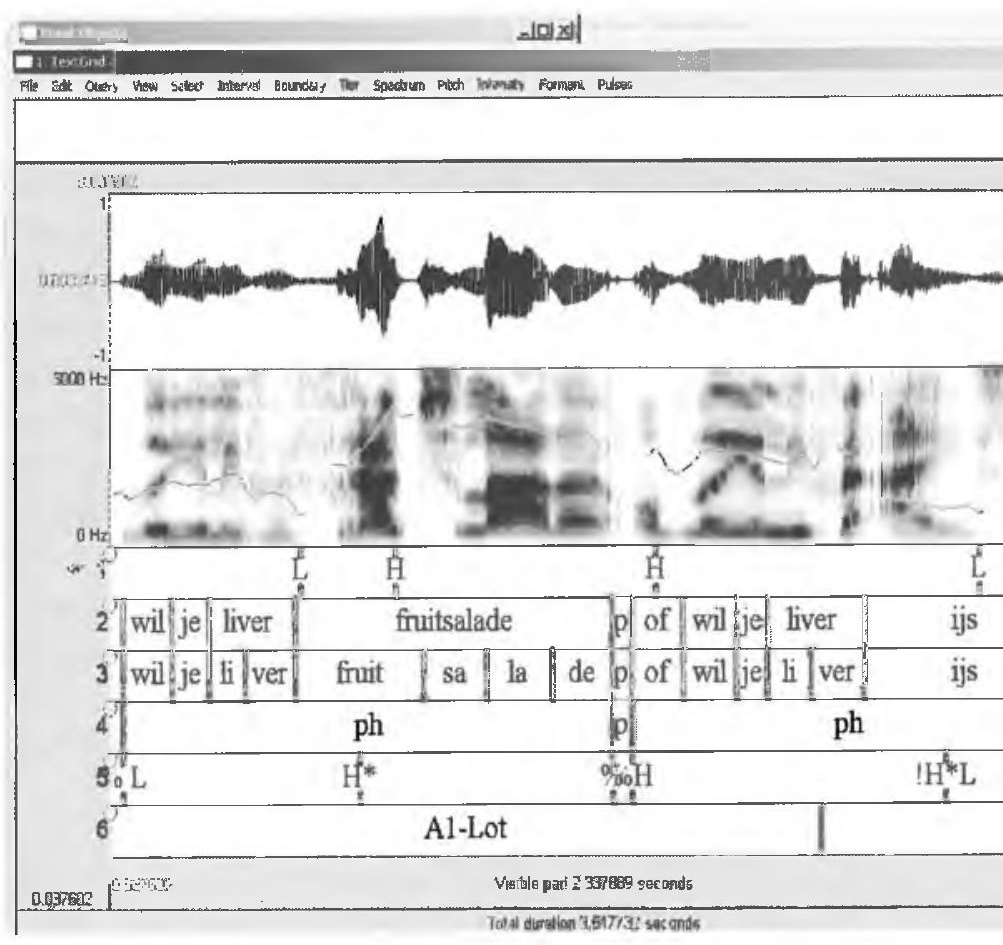

Figure 4.2. An annotation example of the utterance Wil je liever fruitsalade o 'Would you rather have fruit salad or ice cream?' spoken by a native spe: tiers are Pitch tier, Word tier, Syllable tier, Phrase tier, Tone tier and the tier.

(1) Pitch tier. In order to calculate pitch range, two pitch heis first peak of an intonation phrase) and L (final low of the phrase) were marked on the first tier.

(2) Word tier. The beginning and the end of each word were a

(3) Syllable tier. The beginning and the end of each syllable we

(4) Tone tier. Pitch accents and boundary tones were annotate

(5) Phrase tier. Intonational phrases (ph) and pauses (p) were

(6) Miscellaneous tier. The file names were shown and some were made on this tier. 


\subsubsection{Variables}

(1) Numbers of intonation phrases

(2) Pitch range. Pitch range $=\mathrm{H}$ minus $\mathrm{L}$ in semitones (ST)

(3) Nuclear accent placement

(4) Accent placement

(5) Intonation.

(6) nPVI

(7) Speech rate and articulation rate

Speech rate $=$ the numbers syllables/the duration of utterance with pauses

Articulation rate $=$ the numbers of syllables $/$ the duration of utterance without pauses

\subsection{Results}

As there are 20 Chinese subjects which are divided into two subgroups with 10 in each group and only five subjects of the Standard Dutch in the present study, the Gabriel value is referred to if homogeneity of variances is not violated in the following One-way ANOVAs. Otherwise, the Games-Howell value will be used.

\subsubsection{Phrasing}

As Figure 4.3 shows, CLDs have more IPs than CHDs and NSDs, and NSDs have the fewest. A One-way ANOVA test shows that the differences between the three groups in phrases are significant. ( $F[2,22)$ $=6.9, \mathrm{p}=.005)$. The post hoc comparison indicates that native speakers of Dutch have significantly $(p<.05)$ fewer IPs than the Chinese speakers of Dutch, regardless of whether they are proficient or less proficient in Dutch. And there is no significant difference in phrasing between the Chinese subgroups. 


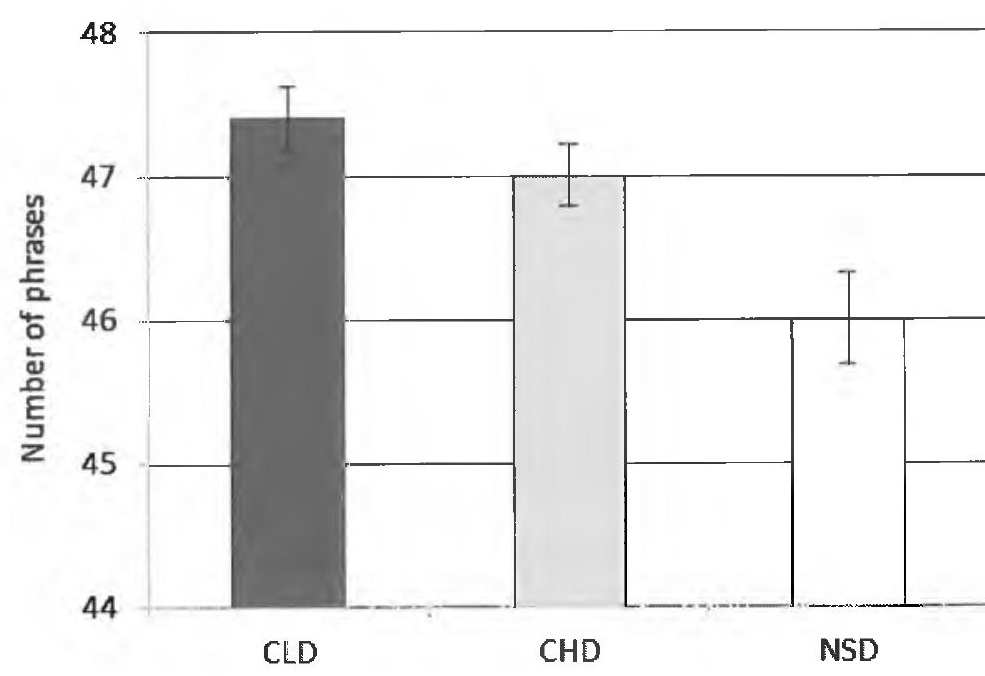

Figure 4.3. Mean number of phrases by CLDs (Chinese speakers of D proficiency), CHDs (Chinese speakers of Dutch with high proficiency (native speakers of Standard Dutch). The error bars enclose \pm 1 standard e

The number of pauses inside IPs between the three significantly different $(F[2,22]=4.3, \mathrm{p}=.026))$. CLDs and found to pause within IPs more frequently than NSDs $\left(p^{<}\right.$ respectively), and no significant differences are found for $\mathrm{pa}$ between CHDs and CLDs, which are shown in Figure 4.4 while pause durations inside IPs decrease and pause dura boundaries increase from CLDs via CHDs to NSDs, a (Figures 4.5 and 4.6 ), these differences fail to reach significanc 


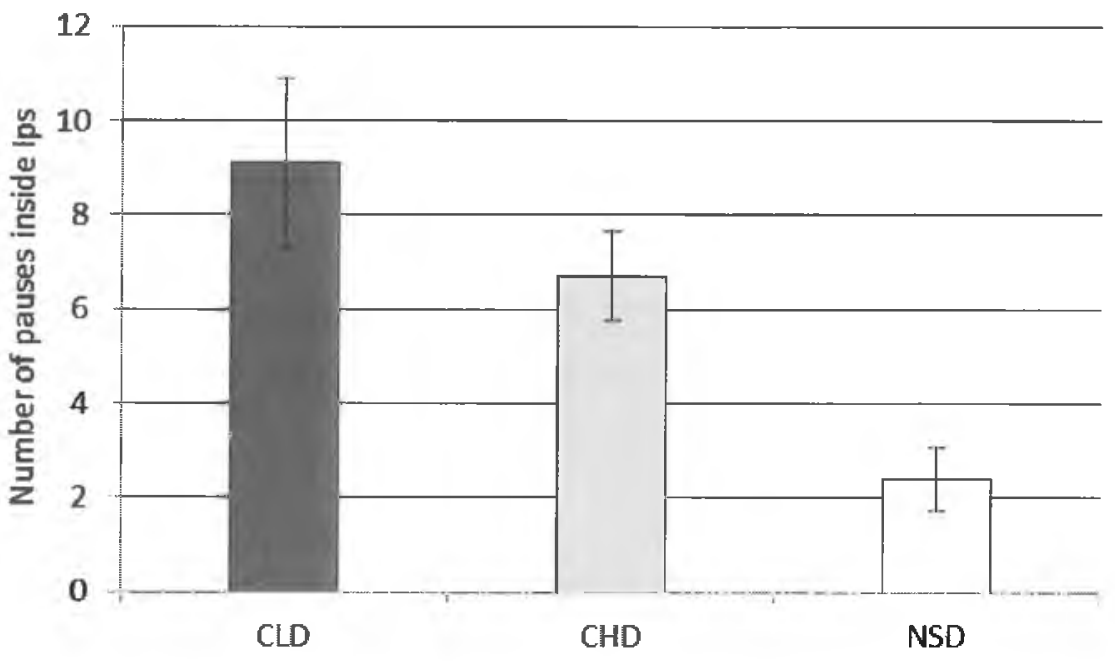

Figure 4.4. Mean number of pauses inside IPs by CLDs (Chinese speakers of Dutch with low proficiency), CHDs (Chinese speakers of Dutch with high proficiency) and NSDs (native speakers of Standard Dutch). The error bars enclose \pm 1 standard error.

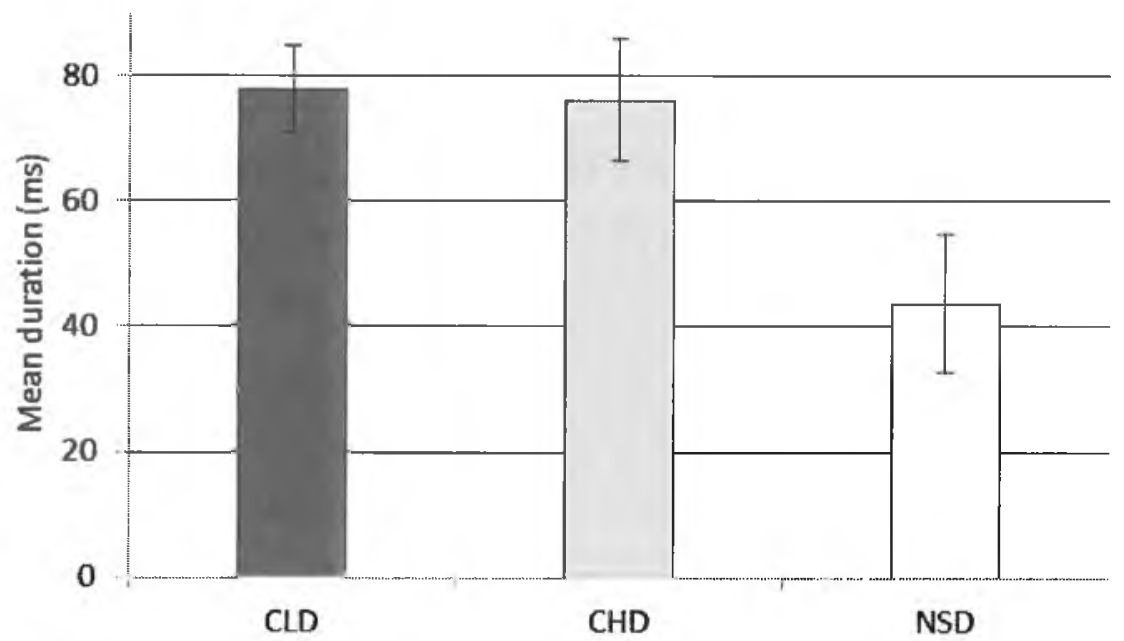

Figure 4.5. Mean duration (ms) of pauses inside IPs by CLDs (Chinese speakers of Dutch with low proficiency), CHDs (Chinese speakers of Dutch with high proficiency) and NSDs (native speakers of Standard Dutch). The error bars enclose \pm 1 standard error. 


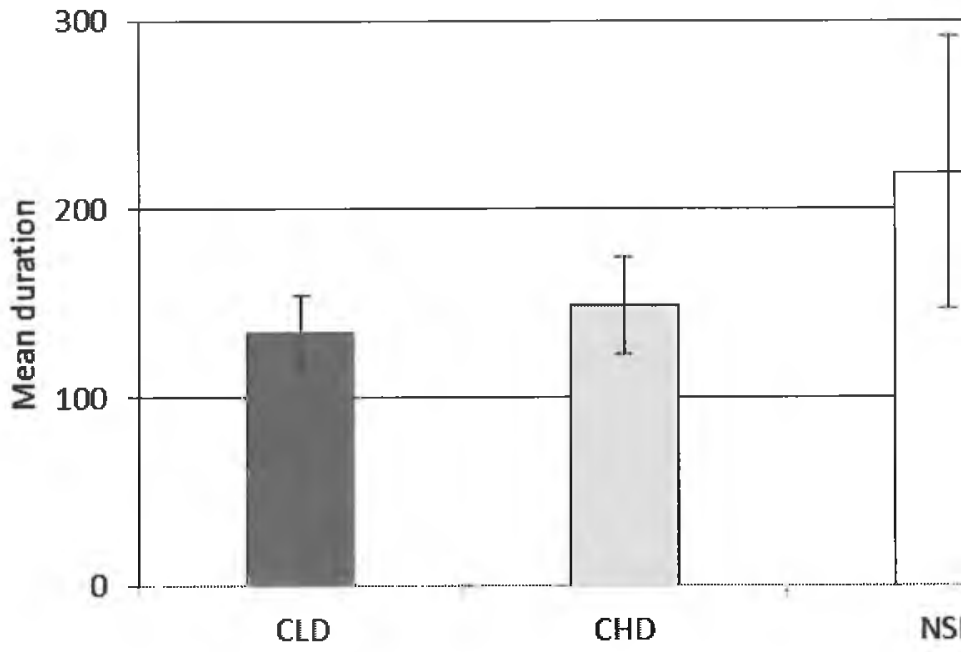

Figure 4.6. Mean duration (ms) of IP boundary pauses by CLDs (Chines Dutch with low proficiency), CHDs (Chinese speakers of Dutch with hig and NSDs (native speakers of Standard Dutch).

The finding that Chinese speakers of Dutch produced more read speech than the native speakers is in accordance with $t$ studies by Chen (2008), Grosser (1982), Gut $(2000,2009)$ at (1995b). In Chen's (2008) study, the subjects were asked to 1 story, and Chinese learners of English were found to have more pauses and shorter IP lengths than the native speakers study, the Chinese speakers of Dutch pause within IPs mor than the native speakers. Their pause duration within IPs is the pause duration at IP boundaries is shorter than those b. speakers, but these differences are not significant. Therefore, of IP-internal pauses is one of factors that contribute to accent of the non-native speakers.

\subsubsection{Pitch range}

From Figure 4.7, we know that pitch range increases from CHDs to NSDs (10.8 st, 11.0 st \& 13.0 st respectively). ANOVA test was conducted, but no significant difference between the three groups $(\mathrm{F}[2,22]=3.0, \mathrm{p}=.088)$. This fin 
from Chen's (2008) and Gut's (2009). The pitch range of native speakers of German and English were found to be significantly greater than that of the non-native speakers in the read speech and retellings (Gut, 2009). The pitch range in the read speech by Chinese learners of English was significantly narrower than by the native speakers and the advanced learners' pitch range was more similar to native speakers' than that of the learners with lower proficiency in English in research by Chen (2008). In Chapter 6, the subjects were asked to read sentences with test words in broad, narrow and corrective focus conditions. The same results were obtained: the pitch range of the test words in the three focus conditions by the native Dutch speakers was wider than that of $\mathrm{CHDs}$, while that of CHDs was wider than that of CLDs although again without reaching significance (He, van Heuven \& Gussenhoven, 2011b). We attribute the fact that the pitch range in the speech of the Chinese subjects is not significantly narrower than that of the native speakers to the fairly narrow pitch range of Dutch (Willems, 1983).

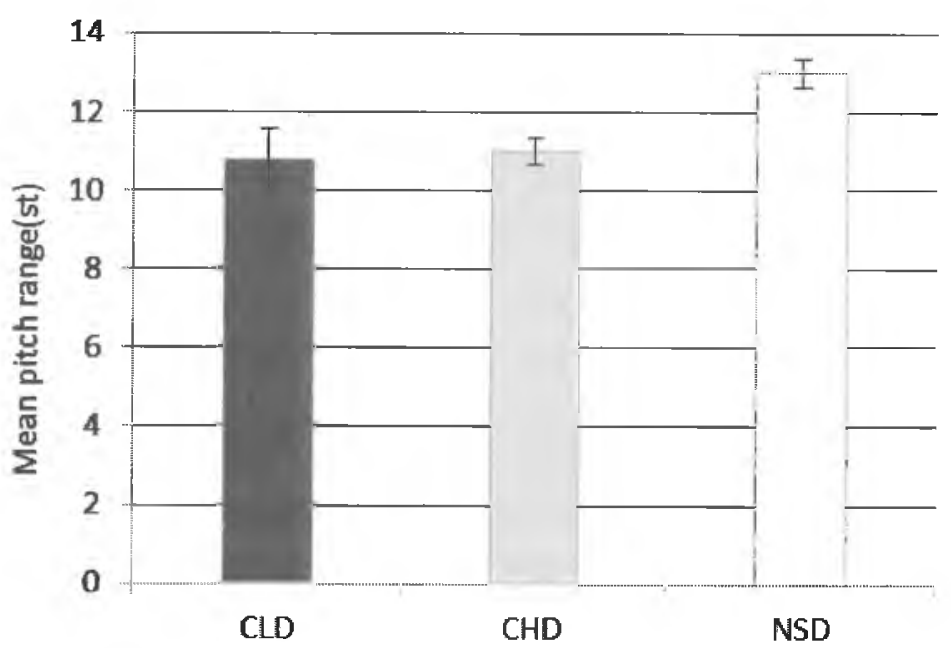

Figure 4.7. Mean pitch range in semi-tones of the three groups across all utterances: CLDs (Chinese speakers of Dutch with low proficiency), CHDs (Chinese speakers of Dutch with high proficiency) and NSDs (native speakers of Standard Dutch). The error bars enclose \pm 1 standard error. 


\subsubsection{Speech rate and articulation rate}

As Figure 4.8 shows, both speech rate and the articulation $r_{:}$ from CLDs via CHDs to NSDs.

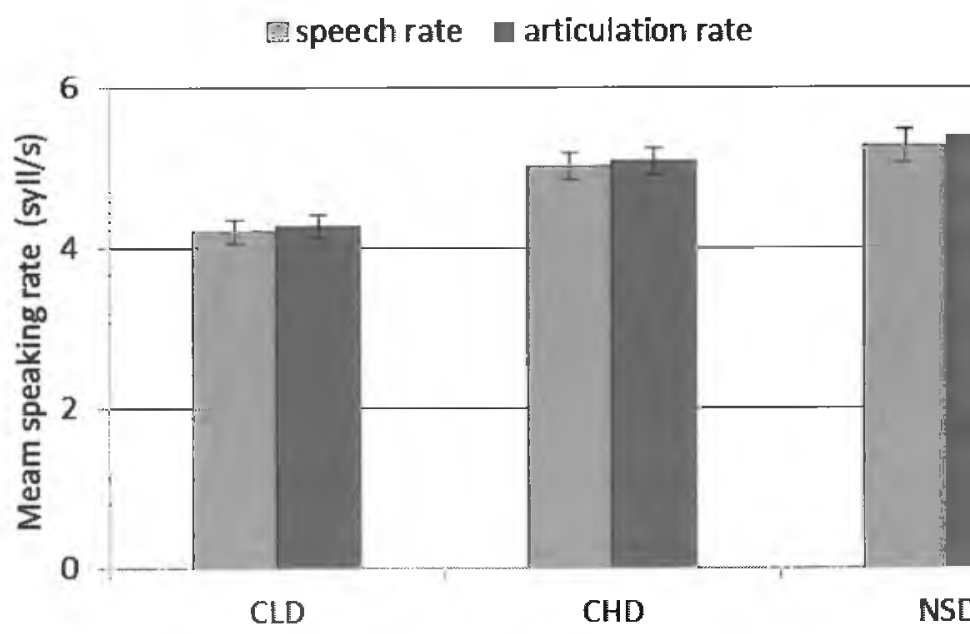

Figure 4.8. Mean speech rate and articulation rate by the three groups: $\mathrm{C}$ speakers of Dutch with low proficiency), CHDs (Chinese speakers of Du proficiency) and NSDs (native speakers of Standard Dutch). The error ba standard error.

One-way ANOVA tests show that both speech rate $(\mathrm{F}[2,22$ $=.001)$ and articulation rate $(\mathrm{F}[2,22]=10.9, \mathrm{p}=.001)$ are different between groups. The speech rate of the native st CHDs are significantly higher than of the CLDs $(p<.01)$, no difference between native speakers and CHDs. Similar to rate, the articulation rate of the native speakers and significantly higher than CLDs $(p<.01)$, while no differen native speakers and CHDs was found. Cucchiarini et al. (2 that native speakers of Dutch spoke faster than the non-nati of Dutch in the read speech task. In present study, native sI speakers with higher proficiency are found to speak faster th with lower proficiency. 


\subsubsection{Speech rhythm}

A One-way ANOVA shows that the three groups differ significantly on the $\mathrm{nPVI}$ (see section 4.4) $(\mathrm{F}[2,22]=12.5, \mathrm{p}<.001)$. The post hoc comparisons indicate that the native speakers' $\mathrm{nPVI}$ is significantly larger than that of CHDs $(\mathrm{p}<.05)$ and CLDs $(\mathrm{p}<.01)$, and that CHDs' nPVI is significantly larger than CLDs' $(p<.05)$, (see Figure 4.9).

The speech rhythm in the utterances by the Mandarin speakers of Dutch is significantly different from that of the native speakers, while CHDs again stand between the native speakers and CLDs. Clearly, when their Dutch proficiency improved, subjects' speech rhythm became more native-like as well. Previous studies showed that speech rhythm was difficult to acquire (Adams, 1979; Anderson-Hsieh, Bond \& Fokes, 1985; Faber 1986; Johnson \& Koehler, 1992; van Els \& de Bot, 1987; Wennerstrom, 2001). When Chinese speakers speak a second language, their L1 Chinese syllabic thythm ('syllable-timed') is transferred to their L2 (stressed-timed), and apparently they are incapable of reducing the duration of the unstressed syllables like other L2 learners, resulting in a non-native speech thythm (Chen, 2008; Bond \& Fokes, 1985; Flege \& Bohn, 1989; Ghazali \& Bouchhioua, 2003; Gut, 2003, 2009; Jian, 2004; Kaltenbacher, 1998; Lee et al., 2006; Mairs, 1989; Wenk, 1985). And the more proficient they are in the second language, the more native-like their speech rhythm is (Chen, 2008; Wenk, 1985; Zborowska, 2000). The results of the present study are in line with the previous studies. 


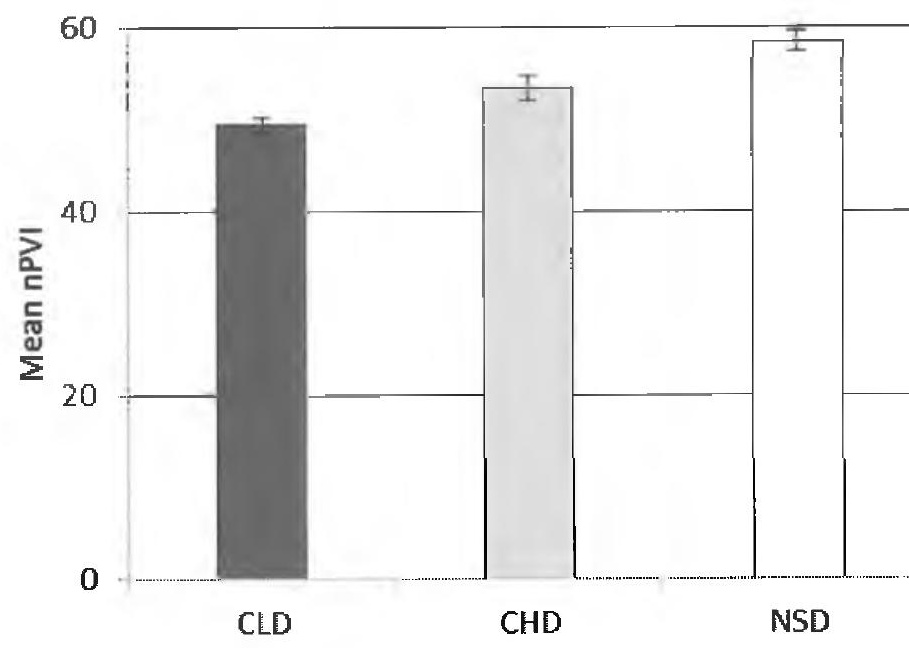

Figure 4.9. Mean nPVI by the three groups: CLDs (Chinese speakers $c$ low proficiency), CHDs (Chinese speakers of Dutch with high proficien (native speakers of Standard Dutch). The error bars enclose \pm 1 standard $e$

\subsubsection{Pitch accents}

A One-way ANOVA of the pitch accent frequencies in our $t$ of speakers reveals that the Chinese speakers of Dutch have more pitch accents in their utterances generally than the $n$ : speakers $(\mathrm{F}[2,22]=6.9, \mathrm{p}=.005)$. The number of pren accents in the utterances produced by the native speakers is less than that produced by the CHDs $(p<.05)$, while no difference was found between the native speakers and the $\mathrm{CF}$ 4.10 shows that more pitch accents can be found in the utter: subjects with lower proficiency in Dutch. 


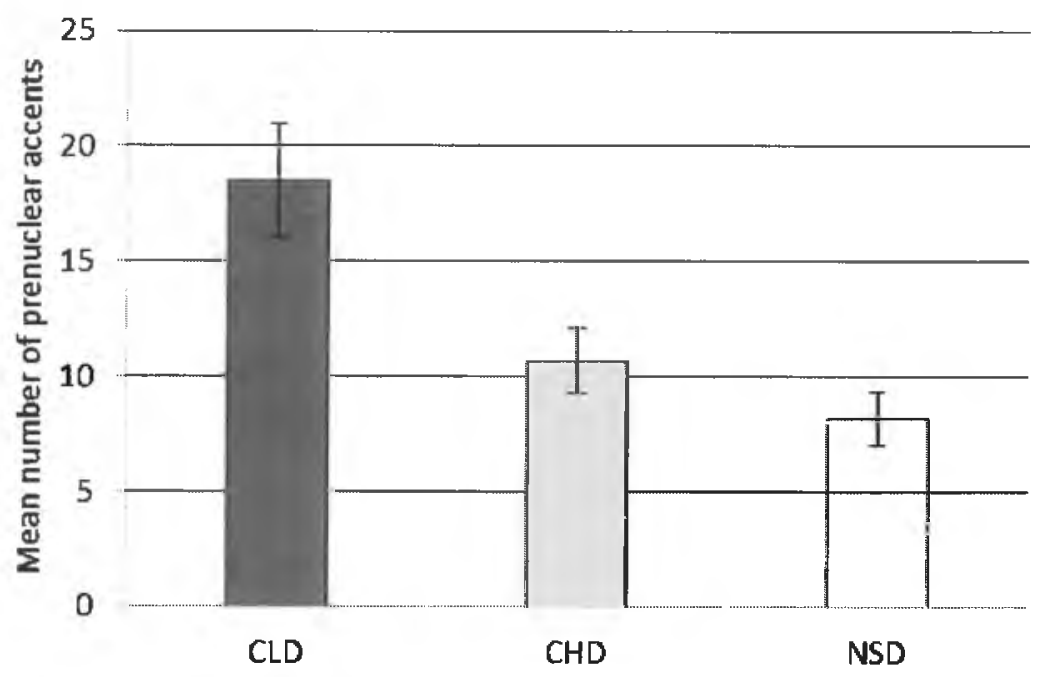

Figure 4.10. Mean prenuclear accents by CLDs (Chinese speakers of Dutch with low proficiency), CHDs (Chinese speakers of Dutch with high proficiency) and NSDs (native speakers of Standard Dutch). The error bars enclose \pm 1 standard error.

This finding is in line with previous studies (e.g. Adams, 1979; Beckman, 1979; Chen, 2008; Grosser, 1997; Gut, 2009; Juffs, 1990; Ramirez Verdugo, 2002). More pitch accents were found in Chinese non-native speech than in native speech. Chinese speakers of Dutch transfer their L1 Chinese phonological patterns, which have a tonal specification on the majority of the syllables, to a language with pitch accents only on some words, and as a result accent every word when they speak Dutch. On the other hand, Chinese speakers of English ignored the prosodic effects of information status and accented the given information in a reading task (Gut, 2009; Wennerstrom, 1998). The CHDs in the present experiment accented some content words which the native speakers of Dutch did not accent at all 67 times, while CLDs did so 95 times. Generally, these superfluously accented words provided old information, and thus no pitch accents should have been assigned to them. Additionally, both CHDs accented 24 and CLDs 34 function words which were not accented by the Dutch subjects. The function words and modal words like liever 'rather', toch 'yet', het 'the', bè 'hey', bebt 'have', etc. often are not accented in Dutch, but the Chinese subjects typically accented them in their reading task. 
We also found that some Chinese speakers of Dutch in both groups could not properly accent some compound words 'pencil', banddoeken 'towel' and witverkoop 'sale', spaailicbten 'flas and accented the second component in them. They even dic where the word stress is in words like elektrisch 'electricity', disyllabic words like daarom 'therefore' jarig 'birthday', regen ' $\mathrm{r}$. made 14 such errors and CLDs 19.

In Chapter 2, an experiment was described testing the Mandarin Chinese speakers of Dutch to choose the opti location (He et al. 2011a). It showed that native speakers significantly better than the $\mathrm{CHDs}$, and the latter performed the CLDs. The confidence ratings similarly decreased from CHDs to CLD. In the present production test, CLDs have accents than and the CHDs, and the CHDs have more pi than the native speakers. This may mean that their uncertaint words are to be accented is solved by over-accentuation. The data and the production data show that the location of pitch Dutch needs to be learnt.

\subsubsection{Intonation contours}

\subsubsection{Analyses of nuclear contours}

We define a correct pitch contour as a correct nuclear placer correct pitch accent and final boundary tone, separately for $\mathrm{e}$ sentences. The 'correctness' was predetermined by a s 'intonational idioms' made by an intonation expert. We c correct nuclear tunes produced for each type of sentence $\mathrm{fc}$ groups of subjects, and calculated their percentages pronunciations (Figure 4.11). 


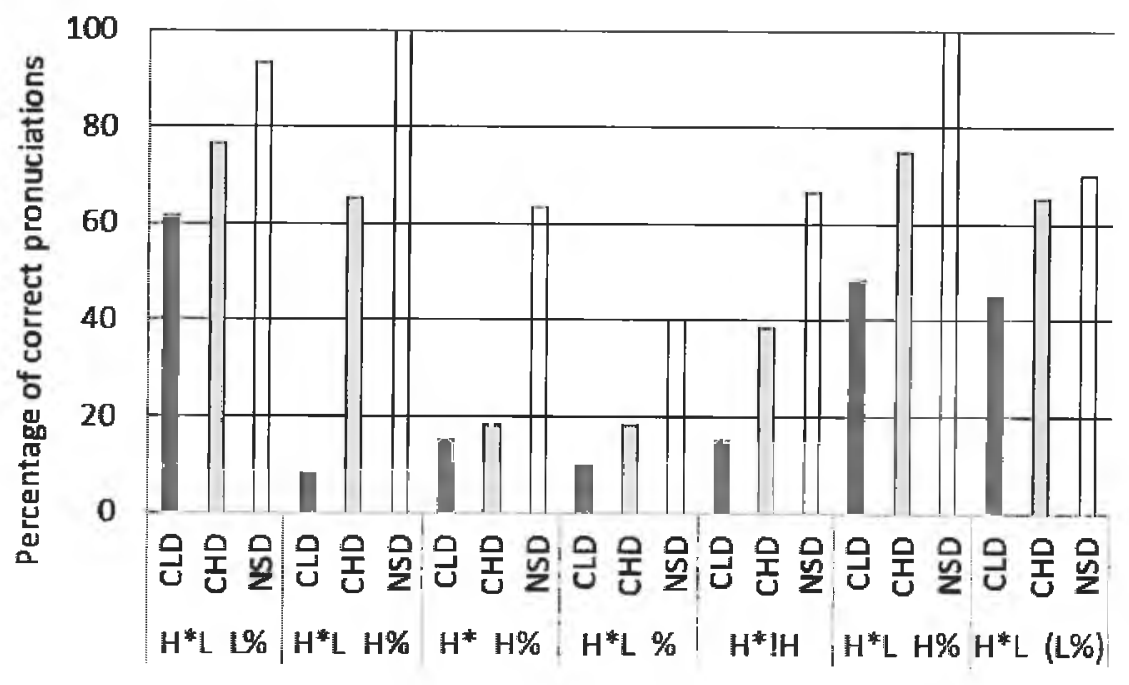

Figure 4.11. Percentages of correct contours by CLDs (Chinese speakers of Dutch with low proficiency), CHDs (Chinese speakers of Dutch with high proficiency) and NSDs (native speakers of Standard Dutch).

In general, correct scores of correct nuclear tunes for each type of sentence by the native speakers are higher than those by the CHDs and CLDs, and those by the CHDs are higher than those by the CLDs. More specifically, the native speaker used $H^{*} \mathrm{~L} \mathrm{H} \%$ unanimously for the $2^{\text {nd }}$ and $6^{\text {th }}$ sentence types. A Chi-square test shows that the percentages of correct pronunciations for CLDs, CHDs and NSDs are significantly different across the sentence types $\left(\chi^{2}[12]=63.4, p<.001\right)$. For each type of sentences, we conducted a separate Chi-square test to check whether the three groups are significantly different. The test results are shown in Table 4.1. As three comparisons were made, the $p$-value was adjusted by using the formula $p^{\prime}=\frac{\mathrm{ccs}}{\mathrm{K} \times \mathrm{K}-\mathrm{1} / 2+1}$, where $\mathrm{k}$ is the number of comparison, and .05 is the original significance level. So the adjusted significance level in Table 4.1 is .013. 
Table 4.1. Results of Chi-square tests for the comparisons of each type o CLDs (the Chinese speakers of Dutch with low proficiency), CHDs speakers of Dutch with high proficiency) and NSDs (the native speaker Dutch).

\begin{tabular}{|c|c|c|c|c|c|c|c|}
\hline \multirow[t]{2}{*}{ contours } & \multicolumn{2}{|c|}{ three groups } & \multicolumn{2}{|c|}{ CLD vs CHD } & \multicolumn{2}{|c|}{ CLD vs NSD } & $\mathrm{CH}$ \\
\hline & $\chi^{2}[2]$ & $\mathrm{p}$ & $\chi^{2}[1]$ & $\mathrm{p}$ & $\chi^{2}[1]$ & $\mathrm{p}$ & $\chi^{2}[1]$ \\
\hline $\mathrm{H} * \mathrm{~L} \quad \mathrm{~L} \%$ & 6.2 & .045 & 1.6 & .023 & 6.2 & .013 & \\
\hline $\mathrm{H}^{*} \mathrm{~L} \quad \mathrm{H} \%$ & 74.8 & $<.001$ & 44.5 & $<.001$ & 78.4 & $<.001$ & \\
\hline $\mathrm{H}^{*} \mathrm{H} \%$ & 45.2 & $<.001$ & .3 & .602 & 29.5 & $<.001$ & \\
\hline $\mathrm{H}^{*} \mathrm{~L} \%$ & 21.3 & $<.001$ & 2.3 & .131 & 18 & $<.001$ & \\
\hline $\mathrm{H}^{*} ! \mathrm{H}$ & 34.0 & $<.001$ & 10.0 & .002 & 33.0 & $<.001$ & \\
\hline $\mathrm{H}^{*} \mathrm{~L} \quad \mathrm{H} \%$ & 18.2 & $<.001$ & 5.9 & .015 & 18.3 & $<.001$ & \\
\hline $\mathrm{H}^{*} \mathrm{~L}(\mathrm{~L} \%)$ & 5.8 & .054 & 3.6 & .057 & 5.4 & .020 & \\
\hline
\end{tabular}

For the first type, $\mathrm{H}^{*} \mathrm{~L} \mathrm{~L} \%$ is the optimal contour for the questions. Actually, all the native speakers read them with except for two accent placement errors. As Table 4.1 shows, percentage of correct pronunciations is significantly lower $t$ the NSDs, but the differences with the CHDs are not signi means that CLDs cannot use Falls to conclude the alternativ like the native speakers. Of 60 alternative questions, $15 \%$ rising tones, as shown in Table 4.2.

Table 4.2. The distribution percentage of erroneous contours in 60 altern by CLDs and CHDs.

\begin{tabular}{lrrr}
\hline Contour chosen & \multicolumn{1}{c}{ CLD } & CHD \\
\hline L*H $\quad \mathrm{H}^{*} \%$ & 15.0 & 3.3 \\
$\mathrm{H}^{*} \mathrm{~L} \quad \mathrm{H} \%$ & 3.3 & 1.7 \\
$\mathrm{~L}^{*} \quad \mathrm{H} \%$ & 1.7 & 1.7 \\
$\mathrm{H}^{*} \mathrm{~L} \quad \%$ & 1.7 & 5.0 \\
$\mathrm{H}^{*} \quad \mathrm{H} \%$ & 5.0 & 0.0 \\
$\mathrm{~L}^{*} \mathrm{H} \quad \%$ & 0.0 & 1.7 \\
\hline
\end{tabular}

$\mathrm{H}^{*} \mathrm{~L} \mathrm{H} \%$ is the predetermined optimal contour for the seco yes-no questions with toch 'not'(rhetorical modal particle, er tag question in English). All NSDs read the question predetermined contour, while very few CLDs used this ce NSDs' percentage of correct pronunciations is significantly that of CHDs and CLDs, and that of the CHDs is higher 
the CLDs. Neither CHDs nor CLDs could use the Fall-rises to read the yes-no questions with toch like the native speakers. As 'Table 4.3 shows, most cases by CLDs were Low rises, High rises and Falls rather than the Fall-rise while most errors made by CHDs were Low rises.

Table 4.3. The distribution percentage of erroneous contours over yes-no questions with toch by CLDs and CHDs.

\begin{tabular}{lcrr}
\hline \multicolumn{2}{c}{ Contours chosen } & CLD & CHD \\
\hline L*H & H\% & 26.7 & 13.3 \\
$\mathrm{H}^{*}$ & $\mathrm{H} \%$ & 20.0 & 3.3 \\
$\mathrm{H}^{*} \mathrm{~L}$ & $\mathrm{~L} \%$ & 30.0 & 5.0 \\
$\mathrm{H}^{*} \mathrm{~L}$ & $\%$ & 0.0 & 3.3 \\
$\mathrm{H}^{*}$ & $\%$ & 0.0 & 3.3 \\
\hline
\end{tabular}

The third type are questions with echt 'really', which are optimally read with $\mathrm{H}^{*} \mathrm{H} \%$. The NSDs read them with $\mathrm{H}^{*} \mathrm{H} \%$ in $63 \%$ of the cases, while both CHDs and CLDs read them with the correct contour in less than $20 \%$ cases. Like NSDs, both CLDs and CHDs substituted $\mathrm{H}^{*} \mathrm{~L}$ $\mathrm{H} \%$ and $\mathrm{L}^{*} \mathrm{H} \mathrm{H} \%$ for it in most cases, as Table 4.4 shows. The differences in correctness percentages are significant between CLDs and NSDs, between CHDs and NSDs, but insignificant between CHDs and CLDs. Neither CLDs nor CHDs could properly use High rises for the sentence type quite like the native speakers.

Table 4.4. The distribution percentage of erroneous contours in yes-no questions with echt by CLDs, CHDs and NSDs.

\begin{tabular}{lcrrr}
\hline \multicolumn{2}{c}{ Contours chosen } & CLD & CHD & NSD \\
\hline $\mathrm{H}^{*} \mathrm{~L}$ & $\mathrm{H} \%$ & 45.0 & 50.0 & 26.7 \\
$\mathrm{~L} * \mathrm{H}$ & $\mathrm{H} \%$ & 31.7 & 18.3 & 10.0 \\
$\mathrm{H} * \mathrm{~L}$ & $\mathrm{~L} \%$ & 3.3 & 0.0 & 0.0 \\
$\mathrm{~L} * \mathrm{H}$ & $\%$ & 1.7 & 0.0 & 0.0 \\
$\mathrm{~L}^{*}$ & $\mathrm{H} \%$ & 0.0 & 3.3 & 0.0 \\
$\mathrm{H}^{*} \mathrm{~L}$ & $\mathrm{~L} \%$ & 0.0 & 3.3 & 0.0 \\
$\mathrm{H}^{*} \mathrm{~L}$ & $\%$ & 0.0 & 1.7 & 0.0 \\
$\mathrm{H}^{*} \mathrm{LH}$ & $\mathrm{H} \%$ & 0.0 & 1.7 & 0.0 \\
\hline
\end{tabular}


The fourth type is the reporting clauses and optimal nuclear the Standard Dutch is the Half-fall, transcribed as $\mathrm{H}^{*} \mathrm{~L} \%$. A shows, only $40 \%$ of the utterances were read by NSDs with $\mathrm{I}$ CHDs and CLDs used this nuclear contour in less than $20 \%$ (with correct nuclear accent and correct contours). Table 4.5 three groups predominantly used $\mathrm{H}^{*} \mathrm{~L} \mathrm{H}^{\%} \%$ to replace $\mathrm{t}$ contour. NSDs also used $\mathrm{H}^{*} \%$, but no CHDs or CLDs did. $\mathrm{H}^{*} \mathrm{~L} \mathrm{~L} \%$ only in few cases $(3.3 \%)$, but CLDs and CHDs use cases $(56.7 \%, 33.3 \%$ respectively).

NSDs' percentage of correct pronunciations of the nuclear significantly higher than that CLDs' and CHDs' as Table 4.1 the difference between CLDs and CHDs is insignificant.

Table 4.5. The distribution percentage of erroneous contours in reporti CLDs, CHDs and NSDs.

\begin{tabular}{lrrrr}
\hline \multicolumn{2}{c}{ Contours chosen } & CLD & CHD & NSD \\
\hline H*L & L $\%$ & 56.7 & 33.3 & 3.3 \\
$\mathrm{H}^{*} \mathrm{~L}$ & $\mathrm{H} \%$ & 8.3 & 28.3 & 26.7 \\
$\mathrm{~L}^{*} \mathrm{H}$ & $\mathrm{H} \%$ & 3.3 & 3.3 & 3.3 \\
$\mathrm{~L}^{*} \mathrm{H}$ & $\mathrm{L} \%$ & 1.7 & 0.0 & 0.0 \\
$\mathrm{~L}^{*} \mathrm{H}$ & $\%$ & 0.0 & 0.0 & 6.7 \\
$\mathrm{H}^{*}$ & $\mathrm{H} \%$ & 0.0 & 0.0 & 3.3 \\
$\mathrm{H}^{*}$ & $\%$ & 0.0 & 0.0 & 16.7 \\
\hline
\end{tabular}

The fifth type is the vocative chant, transcribed as $\mathrm{H}^{*}+! \mathrm{H} .6$ utterances for this sentence type produced by NSDs were $t$ chant as shown in Figure 4.11, but less than $40 \%$ and less t the utterances were produced with the vocative chant by CLDs respectively. The differences between the three grc percentage of correct pronunciation are significant (Table utterances with erroneous nuclear contours shown in Table 4 the NSDs were largely Half falls $\left(\mathrm{H}^{*} \mathrm{~L} \%\right)$, and next they were $\mathrm{L} \%$ ). However, CHDs and CLDs produced largely Falls, in some half falls. 
Table 4.6. The distribution percentage of erroneous contours for vocative chants by CLDs, CHDs and NSDs.

\begin{tabular}{lcrrr}
\hline \multicolumn{2}{c}{ Contours chosen } & CLD & CHD & NSD \\
\hline $\mathrm{H}^{*} \mathrm{~L}$ & $\mathrm{~L} \%$ & 70.0 & 45.0 & 10.0 \\
$\mathrm{H} * \mathrm{~L}$ & $\%$ & 10.0 & 11.7 & 20.0 \\
$\mathrm{H} * \mathrm{~L}$ & $\mathrm{H} \%$ & 3.3 & 3.3 & 0.0 \\
$\mathrm{~L} * \mathrm{H}$ & $\mathrm{H} \%$ & 1.7 & 0.0 & 0.0 \\
$\mathrm{H}+! \mathrm{H}$ & $\mathrm{H} \%$ & 0.0 & 0.0 & 3.3 \\
\hline
\end{tabular}

The sixth sentence type comprises sentences which contain one of the modal particles bè, and boor to trigger a Fall-rise on the preceding accented word, and the optimal nuclear contour for them is therefore $\mathrm{H}^{*} \mathrm{~L} \mathrm{H} \%$. All the utterances by the NSDs had this contour, as shown in Figure 4.11. It was used in $75 \%$ of the utterances by the CHDs and in $48 \%$ of the utterances by the CLDs. The NSDs' percentage of correct pronunciation was significantly higher than that by the CLDs, as shown in Table 4.1. However, the differences with the CHDs were insignificant. As shown in Table 4.7, 1.7\% utterances with the erroneous contours by the CHDs were Low rises and $1.7 \%$ of them were Half falls while the erroneous utterances by the CLDs were either Low rises $(6.7 \%)$ or the full Falls (10\%).

Table 4.7. The distribution percentage of erroneous contours for the sentence type with bè and hoor by CLDs and CHDs.

\begin{tabular}{|c|c|c|}
\hline Contours chosen & CLD & $\mathrm{CHD}$ \\
\hline $\mathrm{L} * \mathrm{H} \quad \mathrm{H} \%$ & 6.7 & 1.7 \\
\hline $\mathrm{H}^{*} \mathrm{~L} \quad \mathrm{~L} \%$ & 10.0 & 0.0 \\
\hline $\mathrm{H}^{*} \mathrm{~L}$ & 0.0 & 1.7 \\
\hline
\end{tabular}

The seventh sentence type is the exclamation with wat 'what' which is intended to elicit the Fall $\left(\mathrm{H}^{*} \mathrm{~L} \mathrm{~L} \%\right)$ or Half fall $\left(\mathrm{H}^{*} \mathrm{~L} \%\right) .70 \%$ of the utterances of this type by NSDs in fact were the optimal contours, Full fall or Half fall, as shown in Figure 4.11 , but $45 \%$ by CLDs and $65 \%$ by CHDs were optimal contours. However, Table 4.1 shows that the 
differences between the three groups were insignificant. All the Full fall or Half falls for this types of sentence but with of wrong accents. The alternative used by NSDs and CLDs ca in Table 4.8. Most utterances by NSDs were $\mathrm{H}^{*} \%$ or $\mathrm{H}^{+}$ erroneous ones by the CLDs are Low rises, Fall-rises and Rise

Table 4.8. The distribution percentage of erroneous contours in wat-ex CLDs and NSDs.

\begin{tabular}{lrrr}
\hline \multicolumn{2}{l}{ Contours chosen } & CLD & NSD \\
\hline $\mathrm{L}^{*} \mathrm{H}$ & $\mathrm{H}^{\circ} \%$ & 8.3 & 0.0 \\
$\mathrm{~L}^{*} \mathrm{H}$ & $\%$ & 1.7 & 3.3 \\
$\mathrm{H}^{*} \mathrm{~L}$ & $\mathrm{H} \%$ & 3.3 & 0.0 \\
$\mathrm{H}^{*}$ & $\mathrm{H} \%$ & 0.0 & 3.3 \\
$\mathrm{H}^{*} ! \mathrm{H}$ & $\%$ & 0.0 & 3.3 \\
$\mathrm{H}^{*}$ & $\%$ & 0.0 & 6.7 \\
\hline
\end{tabular}

\subsubsection{Nuclear accent errors and boundary tone errors}

The Chinese speakers of Dutch cannot use the correct contours in those intonational idioms like the native speaker 4.11 shows. They either put the nuclear accent in a wrong $\mathrm{pl}$ an incorrect tone at the right-hand boundary of the IP. 'I focuses on the nuclear accent errors and the final boundary made by the Chinese speakers of Dutch compared with speakers of the Standard of Dutch.

A One-way ANOVA performed on the data of the nucle: boundary tone errors showed that significant differences ex the three groups for the number of nuclear accent errors $(\mathrm{F}[2$ $\mathrm{p}<.001)$ and final boundary tone errors $(\mathrm{F}[2,22]=15.5, \mathrm{p}$ shown in Figure 4.12. The CLDs made significantly more $n$ accent errors than the CHDs $(p<.01)$ and the NSDs $(p<$. difference between CHDs and NSDs is not significant. Me CLDs made significantly more final boundary tone erros CHDs and the NSDs (both $\mathrm{p}<.01$ ), and the CHDs made more such errors than the NSDs $(p<.05)$. The CLDs made more errors in nuclear pitch accent and the final boundary to NSDs. The CHDs made significantly more final boundary 
than NSDs, but their nuclear pitch accent errors are insignificantly more than NSDs. Therefore it seems that the final boundary tones are more difficult for Chinese speakers of Dutch than the pitch nuclear tones.

\section{nuclear accent errors ending boundary errors}

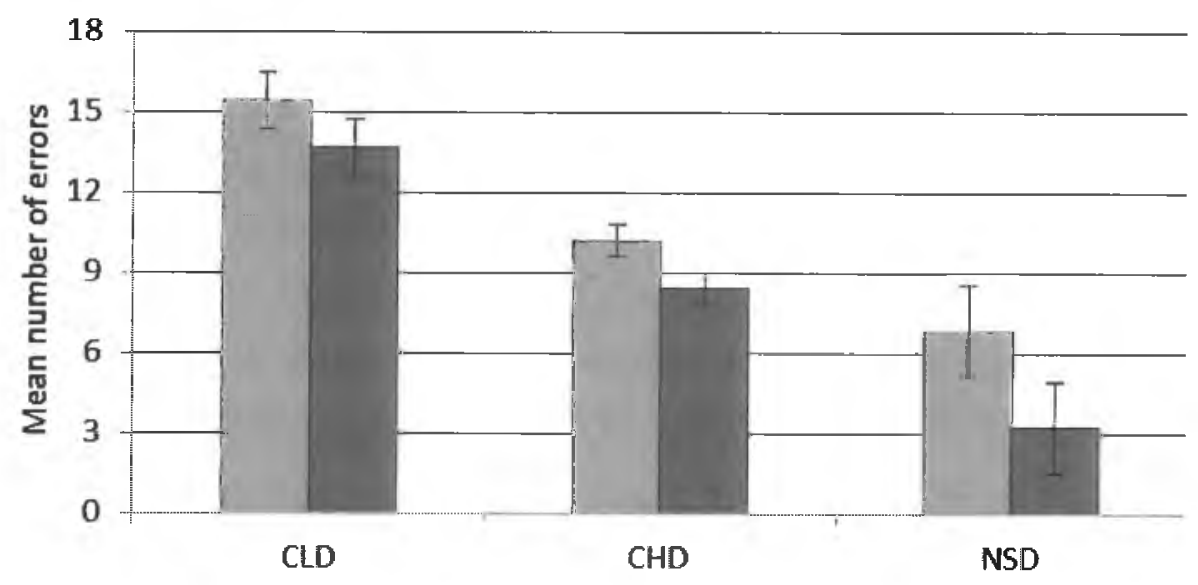

Figure 4.12. The mean number of errors of nuclear pitch accents and final boundary tones made by CLDs (Chinese speakers of Dutch with high proficiency), CHDs (Chinese speakers of Dutch with low proficiency) and NSDs (native speakers of Dutch).

In sum, the percentages of the correct pronunciations of the seven types of Dutch sentences generally decrease from NSD via CHDs to CLDs, but there are some noteworthy differences along this continuum. The NSDs' percentages of the correct pronunciations are significantly higher than the CLDs', except for the wat-exclamations, whose optimal nuclear contour is a Full fall $\left(\mathrm{H}^{*} \mathrm{~L} \mathrm{~L} \%\right)$ or Half fall $\left(\mathrm{H}^{*} \mathrm{~L} \%\right)$. The NSDs' percentages of the correct pronunciations for wat-exclamations and alternative questions are not significantly higher than those of the CHDs. The exclamations and alternative questions are like statements for which the Fall contour is used in Chinese, therefore the Chinese subjects' percentages of the correct pronunciations for the two types of sentences are higher than other sentence types. The difficult sentence types for the Chinese subjects are the rhetorical questions with toch, the surprised questions with echt, the reporting clauses and the vocative chants. For these four types of sentences, the percentages of the correct pronunciations by the NSDs are significantly higher than those of the 
CLDs and CHDs. For the rhetorical questions with toch and $t$ chants, CHDs performed significantly better than CLDs. $\mathrm{CF}$ significantly outperform CLDs for the type of questions with the reporting clauses. Apparently, $\mathrm{H}^{*} \mathrm{H} \%$ for questions w $\mathrm{H}^{*} \mathrm{~L} \%$ for reporting clauses are more difficult for Chinese sl $\mathrm{H}^{*} \mathrm{~L} \mathrm{H} \%$ for questions with toch and $\mathrm{H}^{*} ! \mathrm{H}$ for vocative chant

The optimal nuclear contour is $\mathrm{H}^{*} \mathrm{~L} \mathrm{H} \%$ for sentences endi particles boor and bè as well as the questions with toch. The pe correct contours by the NSDs for the first type is significa than that of the CLDs, but no significant difference with the found. In the second type, NSDs significantly outperforme CLDs and CHDs. Interestingly then, $\mathrm{H}^{*} \mathrm{~L} \mathrm{H} \%$ sentence particles hoor or hè are less difficult than the ones with to located in the middle of the sentence rather than at the end.

As Eckman (2008) predicted, patterns that are less marked in L1 should not be difficult in L2 acquisition, but more marked $\mathrm{L} 2$ are hard to acquire. The marked tones (the Fall-rise, the $\mathrm{H}$ Half fall and the Vocative chant in Dutch) are difficult learners, because in the Chinese tone inventory there are not same pitch contours. The Chinese speakers of Dutch problems with Falls and Rises because there are such lexic Mandarin. These findings on the 'intonational idioms' ar previous intonation studies of Germanic languages as secon (e.g. Chen, 2008; Grosser, 1997; Gut, 2009). Non-native English and German used a reduced tone inventory, and complex tones occurred less frequently than in the nativ speech (Gut, 2009). In the read speech task, Chinese learner: could not choose appropriate intonation to express their pragmatic meanings (Chen, 2008).

The CLDs made significantly more nuclear pitch accent erro boundary tone errors than $\mathrm{CHDs}$ and NSDs. CHDs made more final boundary tone errors than the NSDs, but their $n$ accent errors were not significantly greater. 


\subsection{Conclusions}

The investigation reported here allows a number of generalizations to be made. First, Chinese learners of Dutch produce more IPs than the native speakers. Moreover, they pause within IPs more often than the native speakers, but the durations of the pauses are not significantly different.

Second, while the pitch range in L2 speech by Chinese learners of Germanic languages has generally been found to be narrower and lower that that of the native speakers (Chen, 2008; Gut, 2009), it was found that their pitch range in L2 Dutch is not significantly different from native Dutch. In fact, it is narrower than that of the native speakers. Even if this difference is insignificant, as it was in the study by $\mathrm{He}$ et al. (2011b) (Chapter 6), we may conclude that this finding is related to the low and narrow pitch range of Dutch.

Third, the speech rate and articulation rate of the Chinese speakers with lower proficiency in Dutch are significantly slower than those of their counterparts with higher proficiency and the native speakers. The native speakers' normalized Paiwise Variability Index (nPVI) is significantly larger than that of the Chinese participants, while the nPVI of the Chinese speakers with higher proficiency in Dutch is significantly larger than that of the Chinese speakers of Dutch with lower proficiency. This means that the more proficient they are, the more differentiated syllable durations become, which indicates that advanced speakers are gradually moving away from the 'syllable-timed' rhythm of their mother tongue. Most probably, such factors as speech rate, articulation rate and nPVI contribute to the foreign accent.

Fourth, due to the influence of their mother tongue and their lack of proficiency in the second language, the Chinese speakers with lower proficiency in Dutch have significantly more prenuclear pitch accents than their counterparts with higher proficiency and the native speakers. The Chinese speakers of Dutch with high proficiency can accent words in the sentences in a similar way to the native speakers, even though they sometimes accent function words and words with given information. Our results suggest that with increasing proficiency learners can reduce the influence of their mother tongue here. On the other hand, some Chinese speakers of Dutch, whether they are proficient or less proficient in Dutch, wrongly put pitch accents on the second component in 
compound words, as in potlood 'pencil', handdoeken 'towel' an 'sale'. Some even miss-stressed quite frequent Dutch words, 1 'electric', daarom 'therefore' jarig 'birthday', regen 'rain'. As wa Chapter 2, Chinese speakers of Dutch have problems morphological rules and often do not know the morn determined pitch accent locations in the sentences.

Lastly, Chinese speakers of Dutch can in some cases choose intonation contours in intonational idioms. They had fewe reading wat-exclamations and alternative questions in which $\mathrm{F}$ falls should be used, than with other sentence types. The $\mathrm{m}$ sentence types for the Chinese subjects are questions with toc with echt, reporting clauses and vocative chants. Questions w reporting clauses are the most difficult for Chinese subject percentages of correct pronunciations less than $20 \%$. Chine performed better on sentences with boor and bè than on th questions with toch, even though the same intonation contol rise, is the optimal contour for both sentence categories. This because sentences with the particles boor and bì, which are the final positions in the sentences, are less marked than th toch, which locates in the middle of the sentences. And Chine of Dutch with lower proficiency made significantly more $\mathrm{n}$ accent errors and final boundary tone errors than the Chin with higher proficiency, and the Chinese subjects with higher made significantly more final boundary tone errors than speakers.

Chinese speakers of Dutch thus have some knowledge of idioms' in the reading task as we report here. In Chapt examine how Chinese speakers of Dutch realize Falls, Rise rises in final syllables of the IPs. 


\subsection{References}

Abercrombie, D. (1967). Elements of General Phonetics. Edinburgh: Edinburgh University Press.

Adams, C. (1979). English Speech Rhythm and the Foreign Learner. The Hague: Mouton.

Anderson-Hsieh, J., Johnson, R. \& Koehler, K. (1992). The relationship between native speaker judgments of nonnative pronunciation and deviance in segmentals, prosody, and syllable structure. Language Learning, 42, 529-555.

Backman, N. (1979). Intonation errors in second-language pronunciation of eight Spanish-speaking adults learning English. Interlanguage Studies Bulletion Utrecht, 4, 293-265.

Barry, W. J. (2007). Rhythm as an L2 problem: how prosodic is it? In J. Trouvain \& U. Gut (Eds.), Non-native Prosody, Phonetic Description and Teaching Practice (pp. 97-120). Berlin: Mouton de Gruyter.

Barry, W., Andreeva, B., Russo, M., Dimitrova, S. \& Kostadinova, K. (2003). Do rhythm measures tell us anything about language type? Proceedings of the 15th International Congress of Phonetic Sciences, Barcelona, 2693-2696.

Boersma, P. \& Weenink, D (2009). Praat: Doing phonetics by computer (Version 5.1.05) [Computer program]. <http://www.praat.org>

Bond, Z. S. \& Fokes, J. (1985). Non-native patterns of English syllable timing. Journal of Phonetics, 13, 407-420.

Chavarría, S., Yoon, T., Cole, J. \& Hasegawa-Johnson, M. (2004). Acoustic differentiation of IP and IP boundary level: Comparison of $\mathrm{L}-$ and $\mathrm{L}-\mathrm{L} \%$ in the Switchboard corpus. Proceedings of ICSA International Conference on Speech Prosody 2004, Nara, 333-336.

Chen, H. (2008). On Chinese EFL Learner's English Intonation Pattern. Shanghai: Shanghai Foreign Language Education Press.

Clark, J. \& Yallop, C. (1995). An Introduction to Phonetics and Phonology, 2nd ed. Cambridge, MA: Blackwell.

Cohen, A., Collier R. \& 't Hart J. (1982). Declination: construct or intrinsic feature of speech pitch? Phonetica, 39, 254-273.

Cruttenden, A. (1997). Intonation. Cambridge: Cambridge University Press. Cucchiarini, C., Strik, H. \& Boves, L. (2000). Quantitative assessment of second language learners' fluency by means of automatic speech recognition technology. Journal of the Acoustical Society of America, 107, 989999. 
Dauer, R. M. (1983). Stress-timing and syllable-timing reanaly of Phonetics, 11, 51-69.

Deterding, D. (2001). The measurement of rhythm: a con Singapore and British English. Journal of Phonetics, 29, 217

Faber, D. (1986). Teaching the rhythm of English: A new base. International Review of Applied Lingustics in Language 205-216.

Eckman, F. R. (2008). Typological markedness and secon phonology. In J. G. Hansen Edwards \& M. L. Zam Phonology and Second Language Acquisition (pp. 95-115). John Benjamins.

Fauré, G., Hirst, D. J. \& Chafcouloff, M. (1980). Rhythm Isochronism, pitch, and perceived stress. In L. R. Wau Van Schooneveld (Eds.), The Melody of Language Baltimore: University Park Press.

Flege, J. \& Bohn, O. (1989). An instrumental study of vowe and stress placement in Spanish-accented English. Stuc Language Aquisition, 11, 35-62.

Ghazali, S. \& Bouchhioua, N. (2003). The learning of Engli structures by speakers of Tunisian Arabic: word stres: forms. Proceedings of the 15th International Congress of Pho Barcelona, 961-964.

Gao Qiaoyang. (1984). Grammatical stress in Mandarin. Lang and Research, 2, 65-76.

Gibbon, D. \& Gut, U. (2001). Measuring speech thythm. Eurospeech, Aalborg, 91-94.

Grosser, W. (1997). On the acquisition of tonal and accentua English by Austrian learners. In A. James \& J. Leather (I Language Speech: Stucture and Process (pp. 211-228). Berlin: Gruyter.

Grabe, E. \& Low, E. L. (2002). Duration variability in spec rhythm class hypothesis. In C. Gussenhoven \& N. Wa Laboratory Phonology 7 (pp. 515-546). Berlin: Mouton de

Gussenhoven, C. \& Rietveld, T. (1992). Intonation contou structure and preboundary lengthening. Journal of $P$ 283-303.

Gussenhoven. C. (2005). Transcription of Dutch intonation. (Ed.), Prosodic Typology: the Phonology of Intonation and $I$ 118-145). Oxford: Oxford University Press. 
Gussenhoven, C. \& Jacobs, H. (2008). Understanding Phonology. Beijing: Foreign Language Teaching and Research Press.

Gussenhoven, C. (2011). Sentential prominence in English. In M. van Oostendorp, C. J. Ewen, E. Hume \& K. Rice (Eds.), The Blackwell Companion to Phonology (pp. 2780-2806). Malden, MA \& Oxford: Wiley-Blackwell.

Gut, U. (2000). On the acquisition of rhythmic structure. Proceedings of New Sounds 2000, Amsterdam, 148-154.

Gut, U. (2003). Non-native speech rhythm in German. Proceedings of the 15th International Congress of the Phonetic Sciences, Barcelona, 2437-2440. Gut, U. (2005). Nigerian English prosody. English World-Wide, 26, $153-177$.

Gut, U. (2009). Non-native Speech. Frankfurt: Peter Lang.

He, Xuliang, van Heuven, V. J. \& Gussenhoven, C. (2011a). Choosing the optimal pitch accent location in Dutch by Chinese learners and native listeners. In M. Wrembel, M. Kul \& K. Dziubalska-Kolaczyk (Eds.), Achievements and Perspectives in SLA of Speech: New Sounds 2010 (pp. 125-136). Frankfurt am Main: Peter Lang Verlag.

He, Xuliang, van Heuven, V. J. \& Gussenhoven, C. (2011b). Phonetic implementation must be learnt: native versus Chinese realization of focal accent in Dutch. Proceedings of the 17th International Congress of Pbonetic Sciences, Hong Kong, 843-846.

Hewings, M. (1995a). Tone choice in the English intonation of nonnative speakers. Intermational Review of Applied Linguistics in Language Teaching, 33, 251-265.

Hewings, M. (1995b). The English intonation of native speakers and Indonesian learners: a comparative study. Regional English Language Conference Journal, 26, 27-46.

Huang, B. R. \& Liao, X. D. (1991). Modern Chinese. Beijing: Higher Education Press.

Jian, H. (2004). On the syllable timing in Taiwan English. Proceedings of Speech Prosody 2004, Nara, 247-250.

Kaltenbacher, E. (1998). Zum Sprachrhythmus des Deutschen und seinem Erwerb. In $\mathrm{H}$. Wegener (Ed.), Eine zweite Sprache lernen. Empirische Untersucbungen zum Zweitspracherwerb. [Learning a second language: Empirical investigations of second-language acquisition] (pp.21-38). Tübingen: Narr.

Keseling, G. (1992). Pause and intonation contours in written and oral discourse. In D. Stein (Ed.), Cooperation with Written texts. The 
Pragmatics and Comprehension of Written Texts (pp. 31Mouton de Gruyter.

Ladd, D. R., (1984). Declination: a review and some Phonology Yearbook, 1, 53-74.

Lee, B. Guion, S. G. \& Harada, T. (2006). Acoustic ana production of unstressed English vowels by early and and Japanese bilinguals. Studies in Second Language Acc 487-513.

Lin, M. (2006), Zhao's view point of Chinese intonation an tone. Report of Phonetics, 1-4.

Llisterri, J. (1995). Relationships between speech production perception in a second language. Proceedings of the $13^{\text {th }}$ Congress of Phonetic Sciences, Stockholm, 92-97.

Low, E. L. \& Grabe, E. (1995). Prosodic patterns in Singap Proceedings of the $13^{\text {th }}$ International Congress of Phonetic Sciences, 636-639.

Mairs, J. (1989). Stress assignment in interlanguage pho analysis of the stress system of Spanish speakers learni In S. Gass \& J. Schachter (Eds.), Linguistic Perspectiv Language Acquisition (pp.260-283). Cambridge: Cambridg Press.

Patterson, D. (2000). A Linguistic Approach to Pitch Range Mo diss., Edinburgh University.

Pereira, C. \& Watson, C. (1998). Some acoustic charac emotion. Fifth International Conference on Spoken Langua Sydney, 923-926.

Peng, Shu-hui, M., Chan, K. M., Tseng, Chiu-yu, Huang, Ts Joo \& Beckman, M. E. (2005). Towards a Pan-Mandarir prosodic transcription. In S.-A. Jun (Ed.), Prosodic 1 Phonology of Intonation and Phrasing (pp. 230-270). Oxfc University Press.

Pike, K. (1945). Intonation of American English. Ann Arbor: U Michigan Press.

Ramirez Verdugo, D. (2002). Non-native interlanguage systems: a study based on a computerized corpus learners of English. ICAME Journal, 26, 115-132.

Ramus, F. (2002). Acoustic correlates of linguistic rhythm: $p$ In B. Bel \& I. Marlien (Eds.), Proceedings of Speech Prosoc 115-120). Aix-en-Province, France: Laboratoire Languages. 
Ramus, F., Nespor, M. \& Mehler, J. (1999). Correlates of linguistic rhythm in the speech signal. Cognition, 73, 265-292.

Roach, P. (1982). On the distinction between 'stress-timed' and 'syllabletimed' languages. In D. Crystal (Ed.), Linguistic controversies (pp. 73-79). London: Edward Arnold.

Setter, J. (2003). A comparison of speech rhythm in British and Hong Kong English. Proceedings of the 15th International Congress of Phonetic Sciences, Barcelona, 1875-1877.

Shen, X. S. (1990). Ability of learning the prosody of an intonational language by speakers of a tonal language: Chinese speakers learning French prosody. International Review of Applied Linguistics in Teaching, 28, 119-134.

Van Els, T. \& de Bot, K. (1987). The role of intonation in foreign accent. The Modern Language Journal, 71, 147-155.

Van Santen, J. \& Shih, C. (2000). Suprasegmental and segmental timing models in Mandarin Chinese and American English. Journal of the Acoustical Society of America, 107, 1012-1026.

Warren, M. (2004). A corpus-driven analysis of the use of intonation to assert dominance and control. In U. Connor \& T. Upton (Eds.) Applied Corpus Linguistics: A Multidimensional Perspective (pp. 21-33). Amsterdam: Rodopi.

Watson, D. \& Gibson, D. (2004). The relationship between intonation phrasing and syntactic structure in language production. Language and Cognitive Processes, 19, 713-755.

Wenk, B. (1985). Speech thythm in second language acquisition. Language and Speech, 28, 157-175.

Wennerstrom, A. (1994). Intonation meaning in English discourse: a study of non-native speakers. Applied Linguistics, 15, 399-420.

Wennerstrom, A. (1998). Intonation as cohesion in academic discourse. Studies of Second Language Acquisition, 20, 1-25.

Wennerstrom, A. (2001). The Music of Everyday Speech. Oxford: Oxford University Press.

White, L. \& Mattys, S. L. (2007). Calibrating rhythm: first language and second language studies. Journal of Phonetics, 35, 501-522.

$\mathrm{Xu}, \mathrm{Yi} \& \mathrm{Xu}$, Ching $\mathrm{X}$. (2005). The phonetic realization of focus in English. Joumal of Phonetics, 33, 159- 197.

Young-Scholten, M. (2004). Prosodic constraints on allophonic distribution in adult L2 acquisition. International Journal of Bilingualism, $8,66-77$. 
Zborowska, J. (2000). The acquisition of English speech Polish learners, Proceedings of New Sounds 2000, Amsterdar 


\section{Chapter 5}

\section{Mandarin-accented Fall, Rise and Fall-Rise $\mathbf{f 0}$ contours in Dutch ${ }^{1}$}

\subsection{Introduction}

Dutch is has a large number of nuclear intonation contours, including the Fall, Rise and Fall-rise (Gussenhoven, 2005), while Mandarin Chinese is a tone language with four lexical monosyllabic pitch contours. It therefore lacks the rich inventory of contours of Dutch. This chapter investigates the question how well Chinese learners of Dutch pronounce the Fall, the Rise and the Fall-rise in positions in which they are comparable with the Mandarin lexical tones, i.e. when occurring on the final syllable of the intonational phrase, when the entire contour is realized on one syllable. In this position, variation in the shape of these contours is likely to occur as a function of the availability of voiced, sonorant segmental material. Languages appear to have different strategies to deal with such time-pressure (Grabe, 1998a 1998b; Hanssen, Peters \& Gussenhoven, 2007).

The Dutch intonation contours will be elicited in different types of sentences, like questions and statements. Mandarin, too, makes intonational differences between pragmatically different sentences. Two boundary tones have been identified at least for Guoyu (Standard Mandarin in Taiwan) and Putongbua (Standard Mandarin in mainland China), which were claimed to correspond with Y. R. Chao' Rising and Falling endings respectively in Beijing dialect, a dialect very close to Standard Mandarin (Lin, 2006; Peng et al., 2005). The Rising ending was claimed to be used for asking yes-no questions, and the Falling ending for making statements. More recent descriptions show that Chinese

${ }^{1}$ An earlier and shorter version of this chapter appeared as $\mathrm{He}$, van Heuven \& Gussenhoven (2012) in the Proceedings of the 6th International Conference on Speech Prosody. 
speakers adapt their pitch range to convey pragmatic meanir the difference between declarative and interrogative intonatio pitch contours of the four lexical tones of Putonghua are give 3.2 in Section 3.1.1, Chapter 3 of this dissertation (p. 63). The between declarative intonation and interrogative intonation there cannot obviously be described as due to a low and hig tone, respectively, given that Tone 2 is a rise and Tone 4 both intonations. Expansion of the pitch range typically cod that are in focus, while a reduced pitch range is found for $r$ materials. Beijing Mandarin has comparable Post-Focus C (Xu, 1999).

There are hardly any studies on how Chinese learners $u$ intonation contours in Germanic languages. Warren (2004) Hong Kong English speakers used more rises in differe conversations when they communicated with native speakers contours. In the intonation perception test by Shen (1990) it stimuli were the laryngeal voice output of utterances, $t$ Chinese speakers listening to French, who had never learne language before the perception test, were able to differentiate falling intonation contours extracted from French nativ conversations as well as French native speakers could. Shen that Chinese speakers of French who had more training pronunciation were judged as more native-like in pronc intonations for unmarked questions and statements than tho less training. The stimuli were the laryngeal voice output o (34 unmarked interrogatives and 30 statements) produced by learners of French and a four native speakers of French. In a of the degree of nativeness of the questions by the best Chin and the French speakers, no significance difference was fou of the responses by 25 native French listeners who were ask whether the questions sounded like questions. The striking between the Chinese and French participants for the question realization of the final syllable. The learners either raised its than the native speakers, over-correctly so to speak, or lowe first and then raised it finally, forming a falling-rising termi rather than a Rise terminal. Acoustical and auditory studies the $\mathrm{fO}$ of L2 learners was different from that of native $\mathrm{sp}$ example, Chinese speakers of French are said to have wide and higher overall pitch level than native speakers (Shen, 199 
Chen (2008) found that the Chinese learners of English could produce Falls and Rises according to the syntactic pattern of the sentences, but they could not choose between different kinds of rises in English to express different emotions and pragmatic meanings in a reading task. Sometimes they substituted Falls and Rises for the level tone, especially the subjects with lower English proficiency. The pitch span produced by Chinese learners of English was narrower than that produced by native speakers (Chen, 2008). The pitch spans used by the subjects with higher proficiency were more similar to those used by the native speakers than to those used by the subjects with lower proficiency.

A longitudinal study by Grosser (1997) led to "a tentative proposal of a sequence in the acquisition of tones: simple tones are acquired before complex tones, and falls are produced before rises" (Gut, 2009). If this hypothesis is correct, the Fall-rise in English and Dutch would be difficult for Chinese learners to acquire, because it is the most complex of the three. In addition, it is different from any Mandarin tone. It is carried out entirely in the syllable rime, and as such does not have a direct Mandarin counterpart. Figure 5.1, adapted from Xu (1997), shows that the intonation contours of the Fall, Rise and Fall-rise in Figure 5.2 are broadly similar to those of Tone 4, Tone 2 and Tone 3 , respectively. The Chinese speakers of Dutch will have no problem with the Fall and Rise, because there are no major differences between these intonation contours when used in final position in the intonational phrase and Tone 4 and Tone 2, respectively. In that position, they can transfer Chinese Tone 4 and Tone 2 to Dutch when acquiring the intonation of Dutch. Mandarin Tone 3, however, begins any pitch fall earlier and is lower than the Dutch Fall-rise. Tone 3, therefore, cannot successfully be used as a Dutch Fall-rise. 


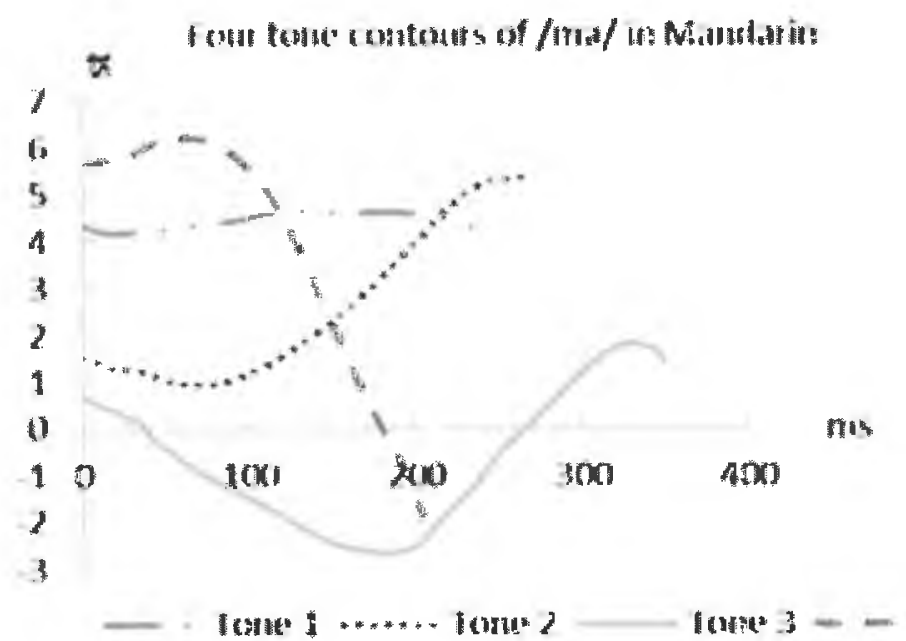

Figure 5.1. Mean f0 contours of four Mandarin tones of monosyllable / 1 in isolation, adapted from Xu (1997).

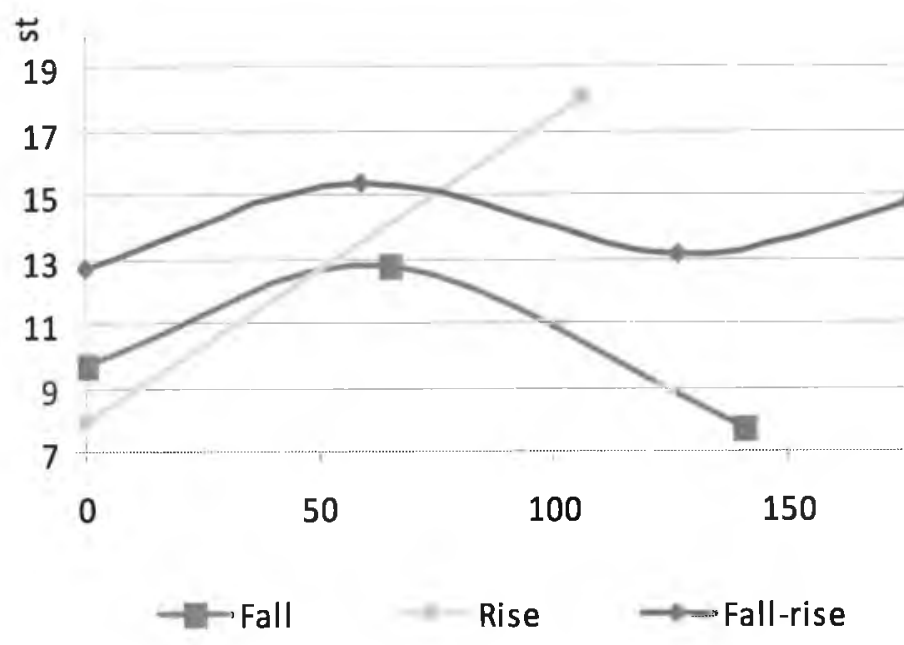

Figure 5.2. Mean fo contours of the proper name Lof read by the nati Dutch in Fall, Rise and Fall-rise. Lof is accented and located in the IP-fina

The availability of phonetic space for the realization of ar contour is a factor which contributes to phonetic variation. $S$ adjust the phonetic shape of a nuclear pitch accent either by 
reduced contour trajectory or by increasing the speed of the pitch movement in order to produce the full contour. The first is known as 'truncation', and the latter as 'rate adjustment' (Erikson \& Alstermark, 1972), and renamed 'compression' by Bannert and Bredvad (1975).

Investigations of the realization of Fall and Rise contours on phrase-final test words with successively less scope for voicing as manipulated by the phonological vowel length of the nucleus (long and short) and the length of the test words (monosyllabic and disyllabic) showed that the adjustment strategies to the reduction in availability of phonetic space were cross-linguistically different and depended upon the contours in the language (Grabe, 1998a, b). Research by Grabe, Post, Nolan \& Farrar (2000) showed that adjustment strategies also differed in varieties of the same language.

In Dutch, Caspers \& van Heuven (1993) found the effects of three types of time pressure on the shape and alignment of the accent-lending rise and fall movement in six intonation contours. The pitch of the accentlending rise and fall were time-compressed rather than frequencycompressed under the time pressure created by increased speech rate. The slope of the pitch fall and the pitch rise were steeper in shorter vowels than in longer vowels. The time pressure for the pitch contours greatly compressed the accent-lending rise, but not the fall in the pitch movements. Under the three types of time pressure, the onset of the rise was likely to be aligned with the onset of the syllable, but the alignment of its end varied due to the presence of a rival fall in the contours. Neither the beginning nor the end of the fall could find anchor points.

Hanssen et al. (2007) investigated the effect of the availability of voiced material on the realization of three nuclear contours in Standard Dutch with three types of Dutch sentences. They used four monosyllabic proper names Loom, Lom, Loof and Lof as test words to elicit three nuclear contours, the Fall, the Rise and the Fall-rise $\left(\mathrm{H}^{*} \mathrm{~L} \mathrm{~L} \%, \mathrm{~L}^{*} \mathrm{H} \mathrm{H} \%\right.$ and $\mathrm{H}^{*} \mathrm{~L} \mathrm{H}^{\%} \%$ ). The test words were phonologically different in the length of the nucleus and did or did not have a sonorant consonant coda. This research suggested that the choice of contour had different effects on the test words. First, the rate of f0 change was higher in Falls and Rises than in Fall-rises, except for Loom. Second, the rate of f0 change tended to increase when the sonorant portion of the accented word was 
shortened in Falls and Rises; for the Fall-rise contour, Loc slightly increased rate of $\mathrm{f} 0$ change, whereas the rate of $\mathrm{f} 0 \mathrm{ch}$ and Lof was smaller than in Loom. The effect of the vov difference was less clear cut. In Rises, words with a short vc to have a higher rate of $\mathrm{f} 0$ change. In Falls, this tendency was Fall-rises, there was the opposite tendency. In this contou falling and the rising movements were shortened. This meant compression of the pitch range. The Fall and the Rise wer compressed as well as somewhat truncated, since the overall was reduced as sonorant portions were shorter.

According to Ladd (2008), the high Fall-rise intonation occ often in Dutch on the penultimate or antepenultimate accen than on the final accented syllable. On final stressed sylla either avoided (replaced by Rises) or, on Ladd's interpretatio and realized as Falls (p. 184) by native speakers in a corpus-ba

Our general research question is how Mandarin speakers whose native language is a tone language, produce the contours of Dutch $\mathrm{H}^{*} \mathrm{~L} \mathrm{~L} \%, \mathrm{~L} * \mathrm{H} \mathrm{H} \%$ and $\mathrm{H}^{*} \mathrm{~L} \mathrm{H} \%$ on IP-fi and whether the systematic variation due to reduced sonoran material that native speakers display is also present in the $\mathrm{L}$ the Mandarin subjects. In the experiment, we thus studied th time pressure on the production of the three contours by th speakers following methodology in the research by Hanssen and Hanssen (forthcoming), so that we can compare the native speakers of Standard Dutch (NSD). Specifically, the $q$ addressed were the following:

(1) Can Mandarin Chinese speakers of Dutch produce contours on IP-final monosyllabic words after pra examples given before they are recorded and to what ext realizations different from those by native speakers of $\mathrm{Dr}$

(2) Do adjustment strategies to diminished availability of ph adopted by the NSD differ from those used by Manda speakers of Dutch with higher proficiency (CHD) and proficiency (CLD)? 


\subsection{Method}

\subsubsection{Materials}

Time pressure was created by the four Dutch monosyllabic proper names Loom, Lom, Loof and Lof with phonologically different length of the nucleus (/o:/ and $/ \mathrm{o} /$ ) and the contrast of obstruent versus coda consonants $/ \mathrm{f}, \mathrm{m} /$ in the test words. The test words were put into short carrier sentences to elicit three different nuclear contours, the Fall, the Rise and the Fall-rise (or $\mathrm{H}^{*} \mathrm{~L} \mathrm{~L} \%, \mathrm{~L} * \mathrm{H} \mathrm{H} \%$ and $\mathrm{H}^{*} \mathrm{~L} \mathrm{H} \%$, following Gussenhoven, 2005). In the corpus, we included three types of sentences: a statement with narrow information focus, a yes-no question, and a rhetorical question with corrective focus as exemplified by (1) to (3) below. They were intended to elicit the Fall, Rise and Fall-rise respectively. The rhythmic structure and the number of syllables before the test word in the carrier sentences were held constant. In order to minimize the speakers' chance to produce prenuclear accents which would result in downsteps (Pierrehumbert, 1980; van den Berg, Gussenhoven \& Rietveld, 1992) and other possible effects on the nuclear contours, the carrier sentences were short and the new information was located in the final target word. All carrier sentences were preceded by a context sentence, with which they formed mini-dialogues. Before the recording, two example mini-dialogues, which were different from the test materials, were provided to the subjects to practise the intonation contour to be elicited in each of three blocks of mini-dialogues. Each block contained two examples plus four test mini-dialogues with the same test contour in the response sentence (see Appendix 5).

(1) Statements

\section{A: Met wie gaat je baas morgen trouwen?}

'Who is your boss going to marry tomorrow?'

B: Hij trount met mevroun de Loom.

'He is going to marry Mrs. de Loom.'

(2) Yes/No questions

A: Ik moet straks naar de baas komen, omdat ik weer te laat was vanmorgen.

'I'll have to see the boss in a minute, because I was late again this morning'.

B: Moet je naar dokter Loom? Oei, maak je borst dan maar nat!

'Do you have to go see doctor Loom? Goodness, then you can expect the worst!' 
(3) Rhetorical questions

A: Dit antieke horloge is nog van opa Thijssen geweest.

'This antique wristwatch belonged to grandfather Thijss

B: Het was toch van opa Loom?

'Wasn't it grandfather Loom's?'

\subsubsection{Subjects}

Twenty ( 3 male, 17 female) Mandarin Chinese speakers of I from 17 to 53 , in the experiment are the same participants as experiments reported in this dissertation. They were divi higher (Chinese Higher Dutch: CHD) and a lower (CLD) s the basis of each subject's mean score over their segmental ar proficiency scores as in previous chapters.

The native subjects (14 female, 9 male) of Standard Dutch from 14 to 49 . The data of the native speakers were all ob the Standard Dutch corpus in the NWO project Intonation $i$ Dutch.

\subsubsection{Recordings of Chinese subjects}

The example dialogues and the context sentences were all different native speakers in the studio of the Arts Faculty University Nijmegen. The two examples and the four rando dialogues for each type of intonation contour were all Powerpoint file with the examples at the beginning of each dialogues. In order to maximize the chances that participar the test words and produced the target contours, they we practice the response sentence in the example dialogues in ea listening to the sound files played from a laptop before recording. If they could reproduce the contour fluently, recording began. During the recording, the experimenter example dialogues and the context sentences in the test dia the subjects read aloud the response sentence from a page in in which only one dialogue was printed on each page. Sr recorded with the help of a Handy Recorder Zoom H4, wi sampling rate and 16 bit stereo format in different places: in 
classrooms, or in libraries; one and three subjects were respectively recorded in sound-treated booths at Radboud University Nijmegen and Groningen University. All response sentences including those in the examples were recorded and the subjects were allowed to repeat any reading which they thought was not their best reading of the response sentence. The sound files were saved in the computer for analysis.

\subsubsection{Acoustic measurements}

\subsubsection{Labelling}

We used the labels in Table 5.1 to annotate our data as Figure 5.3 shows, following Hanssen's (forthcoming) method.

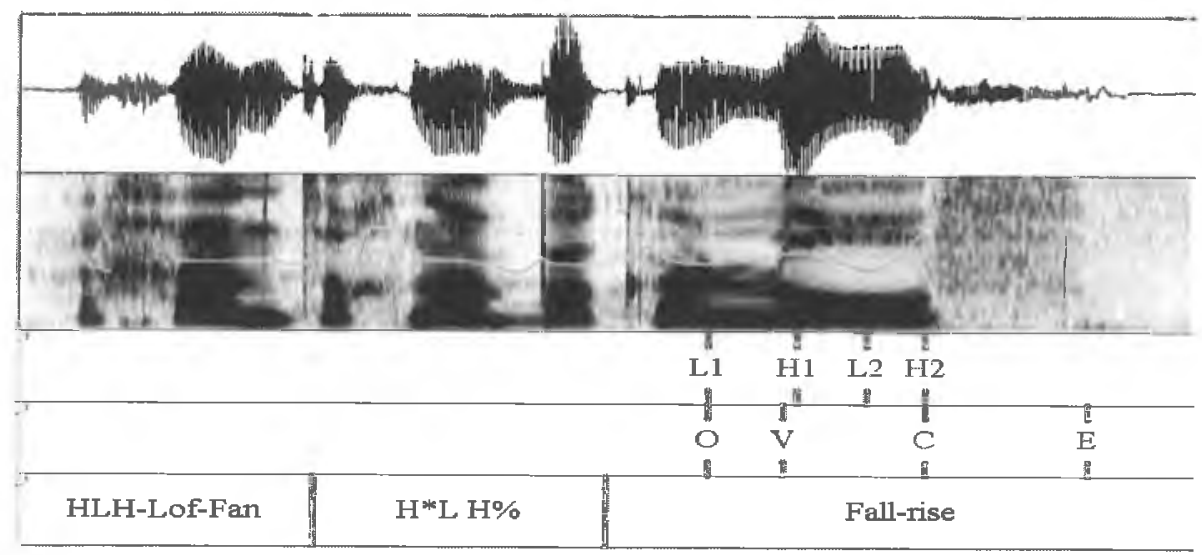

Figure 5.3. An illustration of how tonal and segmental labels on a target word are placed on the basis of the auditory information and visual inspection of the waveform, pitch signal and spectrogram. The panel shows an utterance of the rhetorical question We gaan toch naar bakker Lof? 'Aren't we going to baker Lof?' read by a Chinese speaker of Dutch.

The tonal labels of the fo minima and maxima of the three nuclear contours were placed on the first tier. The segmental boundaries of the test words were labelled on the second. Since the boundaries between segments are rarely clear-cut, the point where phonemes least affected each other was chosen as the location of the boundary and were placed at positive zero-crossings. The name of the test sentence, the nuclear 
contour transcribed with ToDI and comments made if nec provided on the third.

Table 5.1. Overview of tonal and segmental labels

\begin{tabular}{|c|c|c|c|}
\hline Labels & Fall & Rise & Fall-rise \\
\hline L1 & $\begin{array}{l}\text { f0 elbow preceding } \\
\text { nuclear peak }\end{array}$ & $\begin{array}{l}\text { f0 elbow at beginning } \\
\text { of nuclear rise }\end{array}$ & $\begin{array}{l}\text { f0 elbow prec } \\
\text { nuclear peak }\end{array}$ \\
\hline H1 & nuclear $\mathrm{f} 0$ peak & end of nuclear rise & nuclear $\mathrm{f} 0$ pe \\
\hline L2 & end of nuclear fall & - & $\begin{array}{l}\text { elbow betwe } \\
\text { maxima }\end{array}$ \\
\hline $\mathrm{H} 2$ & - & - & $\begin{array}{l}\text { end of nucler } \\
\text { rise }\end{array}$ \\
\hline $\mathrm{O}$ & \multicolumn{3}{|c|}{ beginning of onset of accented word (/1/ for all test words) } \\
\hline $\mathrm{V}$ & \multicolumn{3}{|c|}{$\begin{array}{l}\text { beginning of vowel of accented word }(/ 0 / \text { for } L \text { of and } L o m, / o \text {; } \\
\text { and } L \text { oom })\end{array}$} \\
\hline $\mathrm{C}$ & \multicolumn{3}{|c|}{$\begin{array}{l}\text { beginning of coda of accented word }(/ \mathrm{f} / \text { for Lof and Loof, } / \mathrm{m} / \\
\text { and Loom) }\end{array}$} \\
\hline $\mathrm{E}$ & \multicolumn{3}{|c|}{ end of coda of accented word } \\
\hline
\end{tabular}

The labels for the $\mathrm{f} 0$ maxima ( $\mathrm{H} 1$ and $\mathrm{H} 2)$ in the contours automatically; we used a Praat function that gives the loca highest pitch in a selected interval. Similarly, the location of turning point in Fall-rises (L2) was determined automatically. labels for the $\mathrm{f} 0$ minima at the beginning of all contours (L1 end of the nuclear Fall (L2) was less straightforward Considering that rate of $\mathrm{f} 0$ change (which is calculated by excursion by fo duration) is an important variable in the essential that the labels should not be placed too early or Figure 5.4 shows, the two falling contours (a \& b) differ in the high and low f0 turning points in contour (a) correspor maximum and minimum, they can be automatically labeled w functions, and the average speed of movement closely re actual movement in the speech. However, if the position of target of contour (b) is labeled with the Prat function to s minimum automatically, the rate of fo change will fluctuate $c$ So the elbow is defined as a point in the pitch movement wh 
a sudden change in the f0 slope. Some interruptions and non-tonal signals caused by microprosodic perturbation were ignored in the labelling. As example (c) indicates, the low turning point is therefore labeled manually as the elbow of the f0 contour. The elbow at the start of the rise was determined similarly.

a.

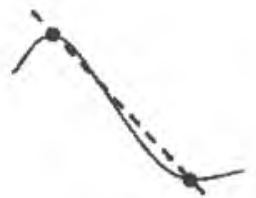

b.

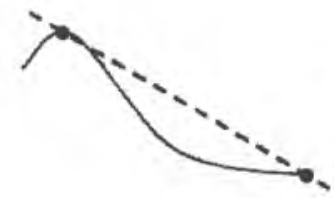

c.

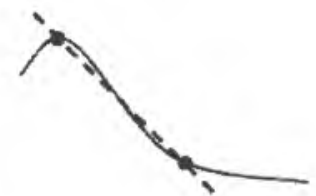

Figure 5.4. Representations of a falling contour, with (a) and without (b, c) a clear elbow. The dotted line represents the average movement between two fo labels (from Hanssen, forthcoming).

\subsubsection{Variables}

We measured the following properties and used them as variables to analyze the data:

a. duration of the sonorant rime $t(E)-t(V)$ for Lom, Loom; $t(C)-t(V)$ for Lof, Loof

b. duration in $\mathrm{ms}$ of the Fall, Rise and Fall-rise

Fall:

$$
\mathrm{t}(\mathrm{L} 2)-\mathrm{t}(\mathrm{H} 1)
$$

Rise:

$$
\mathrm{t}(\mathrm{H} 1)-\mathrm{t}(\mathrm{L} 1)
$$

Fall-rise: $\quad t(\mathrm{~L} 2)-t(\mathrm{H} 1)$ and $t(\mathrm{H} 2)-t(\mathrm{~L} 2)$

c. distance in $\mathrm{ms}$ of $\mathrm{f0}$ maximum to beginning of vowel

d. location (in \%) of $\mathrm{f0}$ maximum relative to duration of vowel

e. excursion in semitones of the Fall, Rise and Fall-rise

Fall:

$$
\mathrm{fO}(\mathrm{L} 2)-\mathrm{fO}(\mathrm{H} 1)
$$

Rise:

$$
\mathrm{fO}(\mathrm{H} 1)-\mathrm{fO}(\mathrm{L} 1)
$$

Fall-rise: $\quad \mathrm{fO}(\mathrm{L} 2)-\mathrm{fO}(\mathrm{H} 1)$ for the first part (falling movement) $\mathrm{fO}(\mathrm{H} 2)-\mathrm{fO}(\mathrm{L} 2)$ for second part (rising movement)

f. speed of movement of Fall, Rise and Fall-rise (fOExc/f0Dur)

g. fo of H1, L2 (Fall), L1, H1 (Rise), andH1, L2, H2 (Fall-rise) 


\subsection{Results}

\subsubsection{Prosodic results}

The percentages of the 80 utterances per contour (4 sent subjects) that were pronounced with correct intonation and a of the target words are shown in Figure 5.5. As for $t$ utterances were produced with a correct (falling) intonation c three incorrect utterances had a Rise, all by the CHDs; how 77 correct utterances, 32 were downstepped falls ( $47 \%$ for $53 \%$ for the CLDs), whose occurrence is related to the acce words prior to the target word. In addition, five target deaccented ( $20 \%$ by the CHDs, $80 \%$ by the CLDs). As for utterances were correctly pronounced as Rises and had acc target words. As for the Fall-rise, 58 utterances (73\%) were rises and with accents on the target words. Twenty-one utter the CHDs, 12 by the CLDs) were produced as Rises and one a CLD; one CHD pronounced the Fall-rise as a Rise and also the target word; three downsteps by two CLDs were found rise.

From Figure 5.5, we know that the Fall-rise was the most $d$ configuration for Chinese learners of Dutch, who had fe with the Fall and Rise, for which they can transfer Tone 4 respectively. Tone 3 in Mandarin, which is a low tone, transferred to Dutch as a pronunciation of the Fall-rise, an its realization to be difficult for Chinese learners to acquire. 


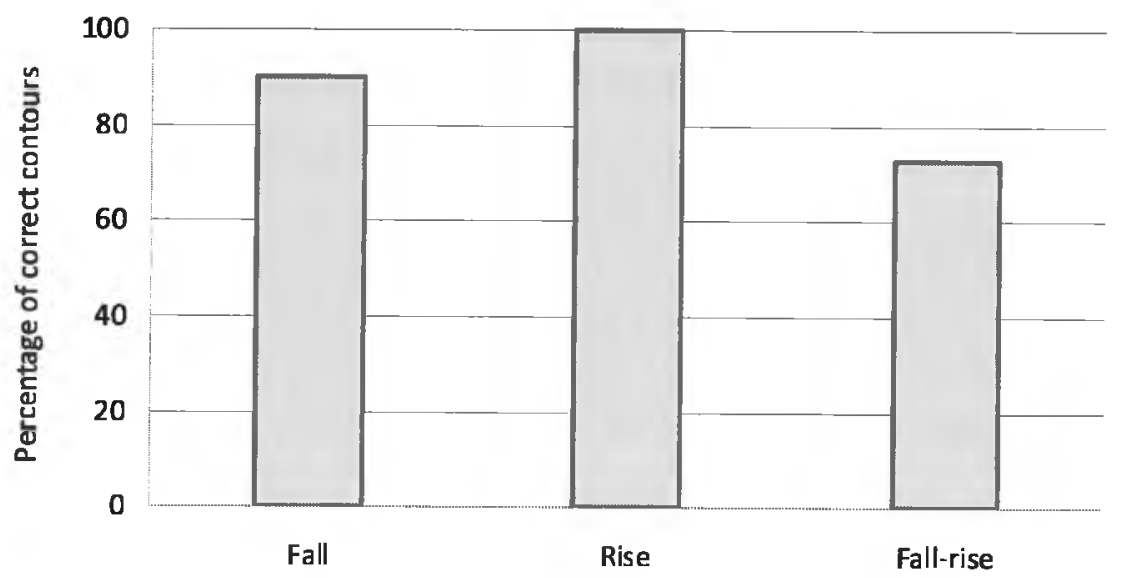

Figure 5.5. Percentage of correct contours produced by Chinese group (Fall, Rise and Fall-rise)

\subsubsection{Sonorant rime comparisons}

The duration of the sonorant rime consists of the duration of vowel and the nasal consonant in our four test words. Since it is an important factor for speakers to realize an intonation contour, we compared the durations of the sonorant rimes produced by different groups or subgroups of subjects in different sentence conditions.

CLDs could not pronounce the short vowel /o/ and the long vowel /o:/ correctly, as Figure 5.6 shows. For the Fall, the mean duration of /o: in Loom was only $4 \mathrm{~ms}$ longer than / $\mathrm{J} /$ in Lom. In the Rise, / / / (194 ms) of Lof was hardly shorter than /o:/ (200 ms) of Loof, and /o/ $(155 \mathrm{~ms})$ in Lom is in fact longer than /o:/ (153 ms) of Loom. In the Fall-rise, both / $/$ in Lof (292 ms) and Lom (268 ms) were longer than their counterparts (/o:/ in Loof $(286 \mathrm{~ms})$ and Loom $(242 \mathrm{~ms})$. By contrast, all CHDs pronounced the short and the long vowels correctly in the three sentence types, quite like the native group. Since Chinese does not exploit length as a vowel feature at the phonological level (Wang \& van Heuven, 2006), it is not surprising that CLDs could not pronounce the vowel quantity contrast correctly. 
The sonorant rime of Loom as produced by CLDs was longe in the Fall and Rise, so they lengthened the coda $/ \mathrm{m} /$ to com the insufficient duration of the long vowel; but in the $\mathrm{Fa}$ rimes of Lof and Lom were longer than those of Loof respectively. The codas of Lom and Loom were longer tha produced by $\mathrm{CHDs}$ and those by $\mathrm{CHDs}$ were longer tha native speakers, except in the case of the Fall-rise, in which $t$ of $/ \mathrm{m} /$ in Lom by CHDs was shortest in the three groups and CLDs was the longest. The durations of the sonorant rimes $\mathrm{p}$ the CLDs were all longer than those by the native speakers a the CHDs with the exception Loof in the case of the Fall and

In the Fall, the sonorant rimes between the three groups are different $\left(\mathrm{F}[2,35]=6.6, \mathrm{p}<.05, \eta^{2}=.27\right)$. Multiple compa that CLDs' sonorant rime durations are significantly longer $(p<.05)$, though the difference with the CHDs is not signific sonorant rimes are also significantly shorter than CHDs' $(\mathrm{p}<$

In the Rise, sonorant rime durations differ significantly $b$ three groups $\left(\mathrm{F}[2,38]=6.6, \mathrm{p}<.05, \eta^{2}=.26\right)$. The dit sonorant rimes between CLDs and CHDs and between NSDs are not significant, but CLDs' sonorant rimes are longer that those by NSDs $(p<.05)$.

In the Fall-rise, the sonorant rimes between the three significantly different $\left(\mathrm{F}[2,38]=34.2, \mathrm{p}<.05, \eta^{2}=.64\right) . \mathrm{T}$ rimes by CLDs are significantly longer than those by $\mathrm{CHDs}$ $(p<.05)$, and those by CHDs are significantly longer $(p<.05$. by NSDs. In short, the lower the proficiency in Dutch, the sonorant rimes in target words are, regardless of contour. 


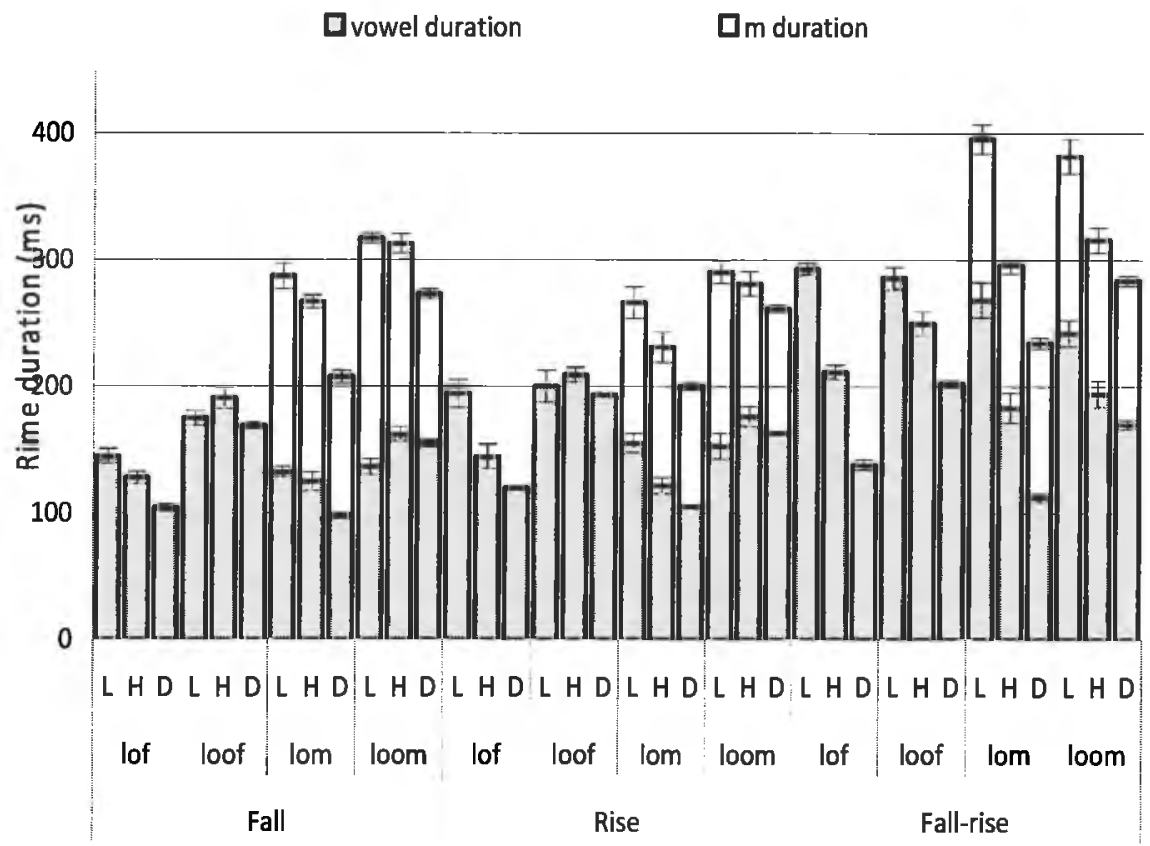

Figure 5.6. The sonorant rime duration of the four target words (Lof, Loof, Lom and Loom) in the three contours (Fall, Rise and Fall-rise), L: Chinese speakers with lower proficiency in Dutch; $H$ : Chinese speakers with higher proficiency in Dutch; D: native speakers of Dutch. The error bars enclose \pm 1 standard error.

\subsubsection{Analysis of $\mathrm{fo}$}

The positions of L1, H1, L2, H2 and onset of the vowels are indicated by marks in the following figures for the relevant contours by the native speakers of Standard Dutch and the Chinese subjects. The pitch in semitone (ST) and the timing in millisecond (ms) are mean values of the target words. The timings of H1, H2, L2 and the onset of the vowel were obtained with reference to the timing of $\mathrm{L} 1$, which was set to zero. L1 is also the zero alignment point for the f0. Figure 5.7 to 5.15 were drawn from averaged data based on the correctly pronounced accents and nuclear pitch contours. 


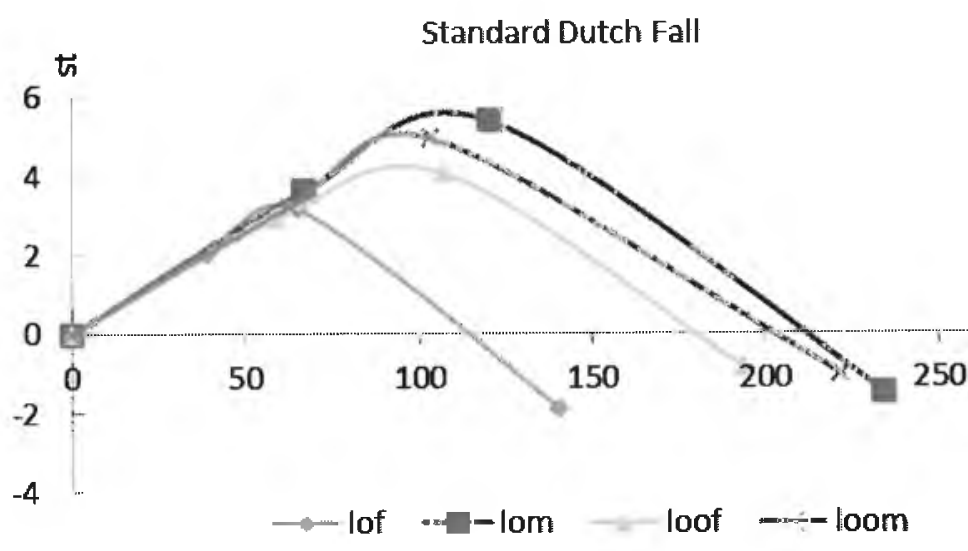

Figure 5.7. The Fall contours with the four target words ( $L$ of, Lom, $L$ produced by the native speakers of Dutch. The landmarks are the posit elbow preceding nuclear peak), the onsets of the vowels in the words, $\mathrm{H}$ fo peak) and L2 (the end of nuclear Fall), respectively. Both the timing at have been set to zero.

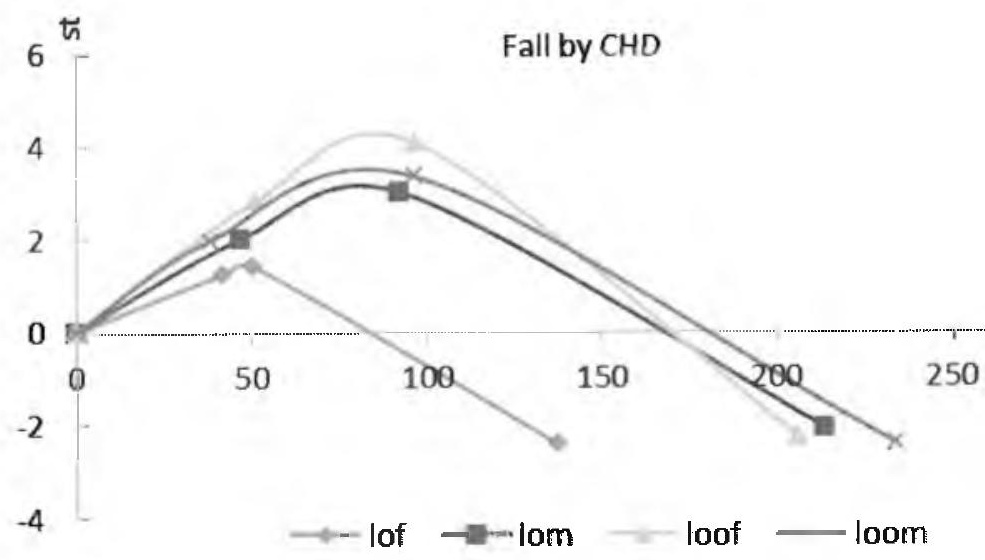

Figure 5.8. The Fall contours with the four target words (Lof, Lom, I produced by $\mathrm{CHDs}$ (Chinese speakers with higher proficiency in landmarks are the positions of $\mathrm{L} 1$ ( $\mathrm{fO}$ elbow preceding nuclear peak), the vowels in the words, H1 (the nuclear f0 peak) and L2 (the end of respectively. Both the timing and pitch of $\mathrm{L} 1$ have been set to zero. 


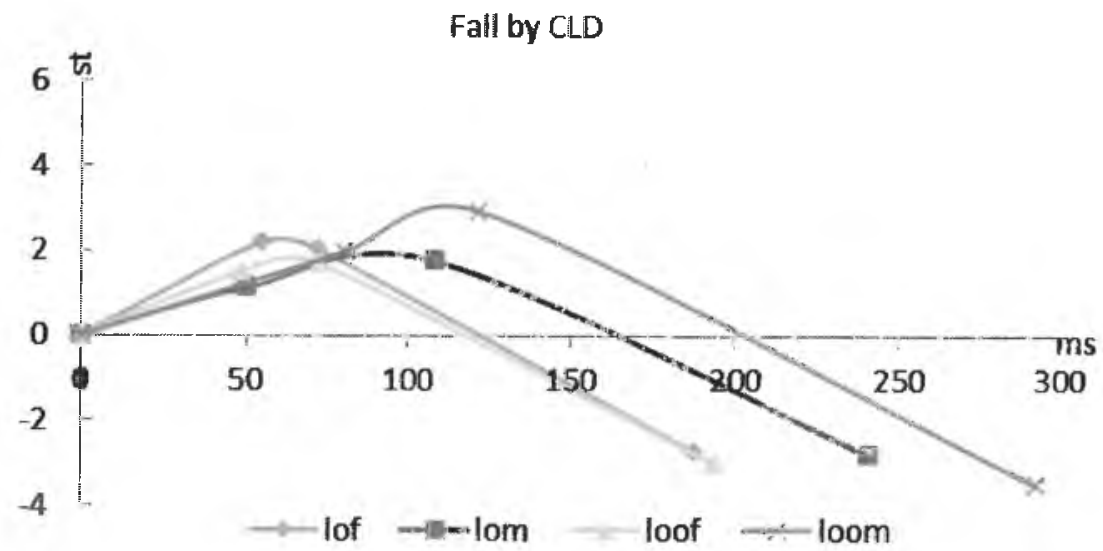

Figure 5.9. The Fall contours with the four target words (Lof, Lom, Loof and Loom) produced by CLDs (Chinese speakers with lower proficiency in Dutch). The landmarks are the positions of L1 (f0 elbow preceding nuclear peak), the onsets of the vowels in the words, H1 (the nuclear f0 peak) and L2 (the end of nuclear Fall), respectively. Both the timing and pitch of L1 have been set to zero.

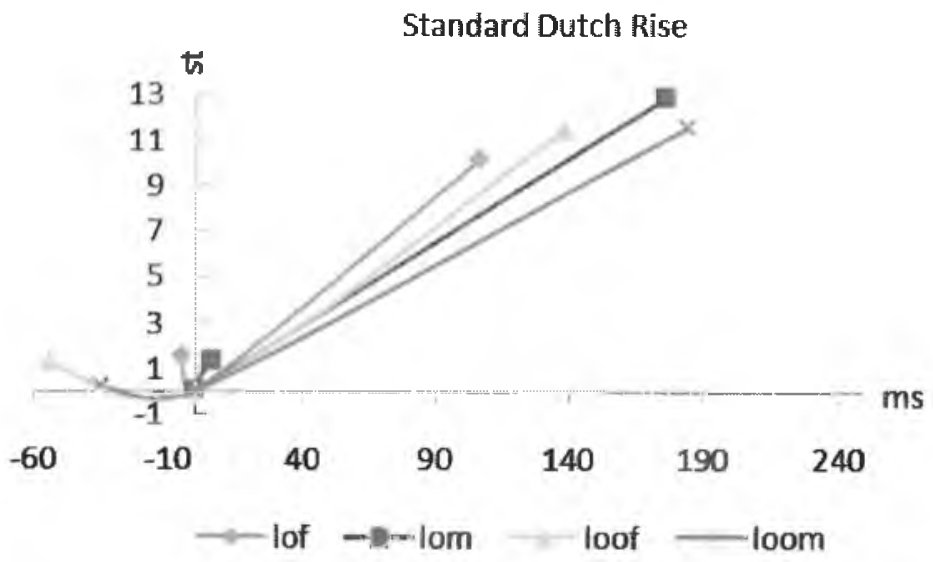

Figure 5.10. The Rise contours with the four target words (Lof, Lom, Loof and Loom) produced by the native speakers of Dutch. The landmarks are the positions of the onsets of vowels in the words, L1 ( $\mathrm{fO}$ elbow at the beginning of the nuclear Rises) and H1 (the end of nuclear Rise), respectively. Both the timing and pitch of L1 have been set to zero. 


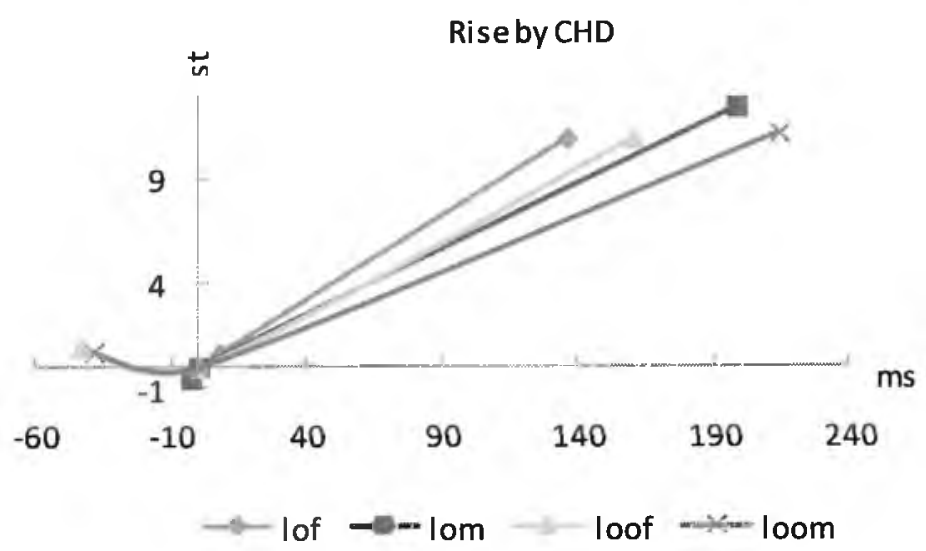

Figure 5.11. The Rise contours with the four target words ( $L$ of, Lom, $I$ produced by CHDs (Chinese speakers with higher proficiency in Dut marks are the positions of the onsets of vowels in the words, L1 (fO beginning of the nuclear Rises) and H1 (the end of nuclear Rise), respect timing and pitch of L1 have been set to zero.

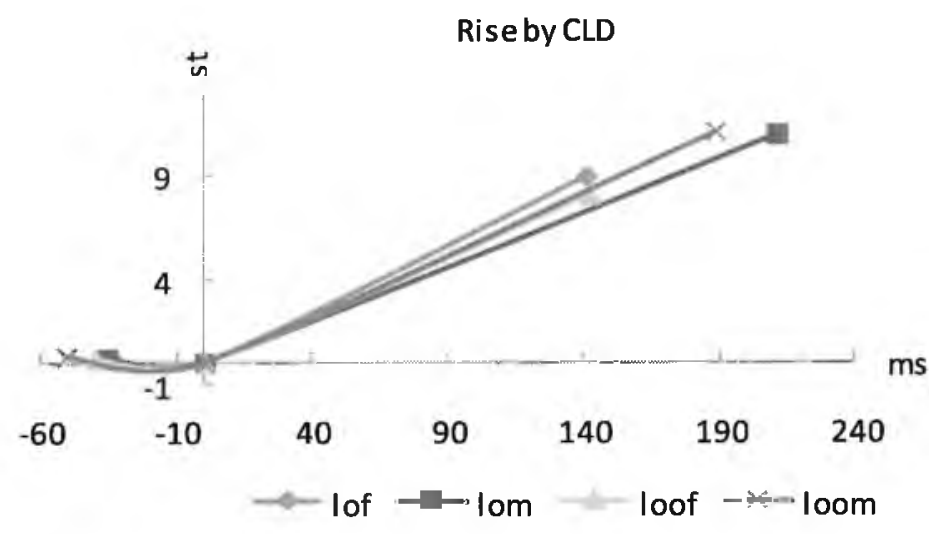

Figure 5.12. The Rise contours with the four target words (Lof, Lom, I produced by CLDs (Chinese speakers with lower proficiency in Dutch). are the positions of the onsets of vowels in the words, L1 ( $\mathrm{fO}$ elbow at th the nuclear Rises) and H1 (the end of nuclear Rise), respectively. Both pitch of L1 have been set to zero. 


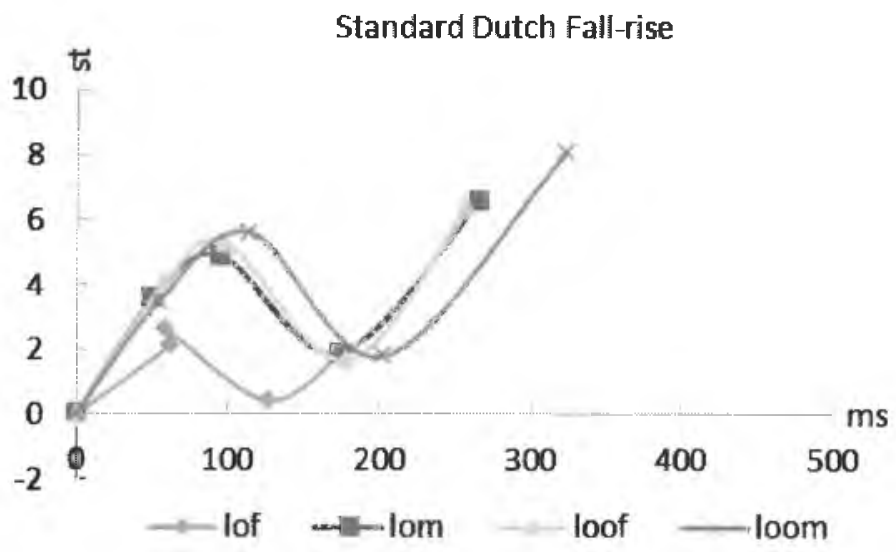

Figure 5.13. The Fall-rise contours with the four target words (Lof, Lom, Loof and Loom) produced by the native speakers of Dutch. The landmarks are the positions of L1 (the f0 elbow preceding nuclear peak), the onset of the vowels in the words, $\mathrm{H} 1$ (the nuclear f0 peak), L2 (the elbow between two f0 maxima) and H2 (the end of nuclear contour), respectively. Both the timing and pitch of L1 have been set to zero.

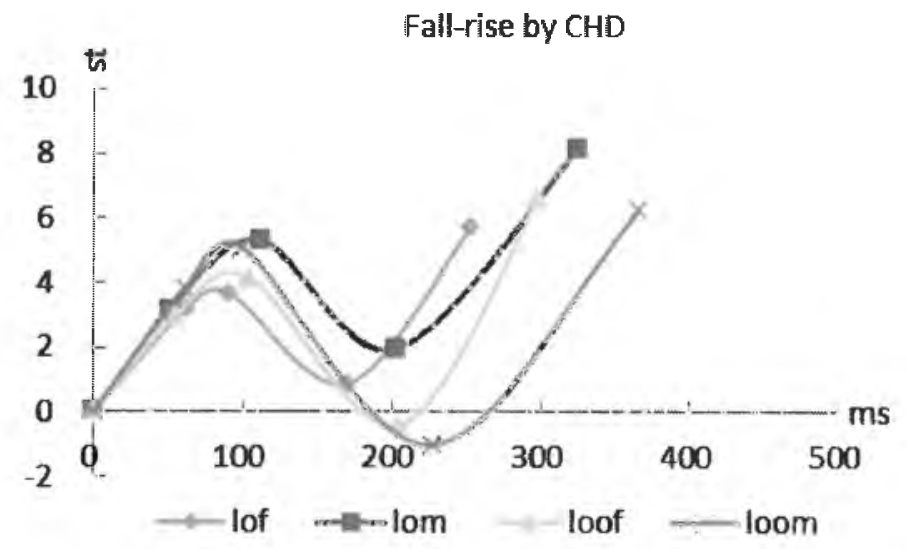

Figure 5.14. The Fall-rise contours with the four target words (Lof, Lom, Loof and Loom) produced by CHDs (Chinese speakers with higher proficiency in Dutch). The landmarks are the positions of L1 (the f0 elbow preceding nuclear peak), the onset of the vowels in the words, $\mathrm{H} 1$ (the nuclear $\mathrm{f0}$ peak), L2 (the elbow between two $\mathrm{f} 0$ maxima) and $\mathrm{H} 2$ (the end of nuclear contour), respectively. Both the timing and pitch of L1 have been set to zero. 


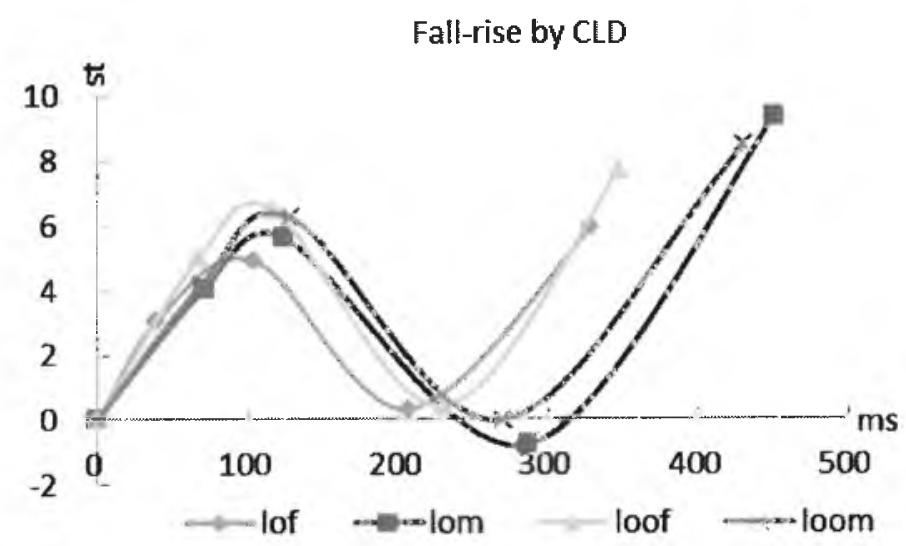

Figure 5.15. The Fall-rise contours with the four target words ( $L \circ f$, Lom, 1 produced by CLDs (Chinese speakers with lower proficiency in Dutch). ' are the positions of $\mathrm{L} 1$ (the f0 elbow preceding nuclear peak), the onset in the words, $\mathrm{H} 1$ (the nuclear $\mathrm{f0}$ peak), $\mathrm{L} 2$ (the elbow between two f0 ma (the end of nuclear contour), respectively. Both the timing and pitch of set to zero.

In the following statistical analyses, we excluded the subjects who could not produce any one of the four target words co: left 8,8 and 22 subjects for the Falls in the CLD, CHD and I respectively, 10, 10 and 21 subjects for the Rises, and 8, subjects for the Fall-rises. In addition, there were missing da subjects for one reason or another. In order to get value missing data, we averaged the values of a variable in wl subjects had full data in the four words and used the a reference. The missing data in any empty cell was obtained $b$ corresponding reference average to the difference betweer data of a speaker with missing data and the corresponding rc get $x$ in Table 5.2, for example, we first selected those parts that have a full data specification (see the shaded cells). We c column means for that selection only, took the mean of th cells in that column (6.73) and added it to the mean differ non-empty cells of Speaker 1 from the corresponding refere means. That is, the mean of $(13.88,12.00,11.02)=12.30$ mean of $(7.90,6.53,6.40)=6.94$. So, Speaker 1 is $12.30 \mathrm{~m}$ 5.36 semitones higher pitched than the reference speakers the $x$ in the cell gets the value $6.73+5.36=12.09$. Re 
procedure for all other empty cells of the same variable, for all other variables in the dataset and for all other datasets (Rise, Fall, Rise-fall), but doing it separately for native speakers and Chinese speakers of Dutch, we obtained substitute values for all the missing data. Percentages of missing data were sometimes high. For the Fall, $37.3 \%$ of the cells were missing in the data for the Chinese subjects and 19\% for the native speaker group. For the Rise, there were no empty cells in the Chinese group, but $33.9 \%$ in the native group. For the Fall-rise, $23.6 \%$ were missing for the Chinese group and $7.6 \%$ for the native group.

Table 5.2. The data points of L1's fo (the f0 elbow preceding nuclear peak) in the four target words (Lof, Lom, Loof and Loom) produced by the NSDs for the Fall. Means in shaded cells are based on actual data, means in non-shaded cells were computed through imputation (see text).

\begin{tabular}{rrrrr}
\hline speaker & L1f0_lof $f$ & L1f0_lom_f & L1f0_loof_f & L1f0_loom_f \\
\hline 1 & 13.88 & $\mathrm{X}$ & 12.00 & 11.02 \\
2 & 13.33 & & 12.51 & \\
3 & 14.87 & 10.27 & 12.68 & 11.56 \\
5 & 4.27 & 5.07 & 0.84 & 2.72 \\
6 & 5.83 & 3.01 & 1.33 & 344 \\
7 & 0.00 & 7.59 & 7.59 & 9.69 \\
8 & & & 10.56 & \\
9 & 6.90 & 0.68 & 2.12 & 0.84 \\
11 & 11.38 & 10.74 & 998 & 9.19 \\
12 & 12.93 & 11.11 & 10.56 & 9.39 \\
13 & 13.25 & 11.20 & 11.83 & 1102 \\
15 & 10.27 & 11.83 & 12.00 & 10.56 \\
16 & 11.20 & 11.91 & 11.20 & 10.46 \\
17 & & -0.71 & -1.07 & -0.53 \\
21 & 1.33 & -1.07 & V0.17 & 0.00 \\
23 & 9.88 & & & 8.14 \\
24 & 5.45 & 3.16 & & 3.16 \\
26 & 2.57 & -1.63 & -1.63 & -202 \\
31 & & 8.98 & 9.49 & 9.39 \\
32 & & 8.98 & 9.79 & 9.79 \\
33 & 15.86 & & & 6.55 \\
36 & & & 3.30 & \\
mean & 7.90 & 6.73 & 6.53 & 6.40 \\
\hline
\end{tabular}




\subsubsection{Peak alignments in the Fall, Rise and Fall-rise}

Peak alignment, a measure indicating the location of an $\mathrm{fO} \mathrm{p}$ to the onset or offset of a syllable or rime, depends on $\mathrm{p}$ prosodic factors (Xu, 2001). The peak moves away from th rime onset along with the syllable offset, if factors like spe vowel length cause the sonorant part of a syllable to leng moves in the opposite direction, closer to the syllable onset offset, if the lengthening of the syllable is caused by prosodic an upcoming stress, pitch accent or phrase boundary (Cas Heuven, 1993; Ladd, Mennen \& Schepman, 2000; Prieto, va Hirschberg, 1995; Xu, 2001).

Studies have shown that peak alignment can disambiguate set It plays a role in disambiguating Hungarian statements questions with a phonetically rising-falling pitch contour, early pitch peak (early in the accented rowel) was asso declaratives and a late peak (in the second half of the acce with interrogatives (Gósy \& Terken, 1994). Studies of que: statement disambiguation in other languages, like Neapo (D'Imperio \& House, 1997) and Swedish (House, 2004), same pattern.

A study by Prieto (1995) showed that onset duration cor peak delay. The conclusion was in accordance with the $f$ English nuclear peak location was influenced by onset and and by their durations, but it went against Silverman and Pier proposal that the peak placement should not be affected by of the onset. Rietveld \& Gussenhoven (1995) found in research that peak location in Dutch moves left when consonant is sonorant as compared to voiceless.

Since our Chinese speakers of Dutch produced longer vow native speakers and the onset of the four target words wer located the peak position relative to the beginning of (thereafter called 'peak delay'), but we also expressed this percentage of the peak delay ('proportional peak delay') duration of the vowel, partly because Chinese speakers proc vowels. 
As for the Fall, the peak occurred later for the three groups of speakers if the sonorant rime was longer. However, the peak of Loom was earlier than that of Lom for all three groups and the peak of CHDs' Loof was later than that of their Loom. Overall, peak delay was significantly different $\left(F[1.7,58.5]=3.57, \mathrm{p}<.05, \eta^{2}=.092\right)$, but there is no interaction between the groups. Differences in peak delay between the three groups were not significant $\left(\mathrm{F}[2,35]=.19, \mathrm{p}>.05, \eta^{2}=.01\right)$. Similarly, the proportional peak delay was significantly different within the groups $\left(\mathrm{F}[2.4,82.9]=8.3, \mathrm{p}<.001, \eta^{2}=.191\right)$, but there was no interaction with the groups. Though the percentages by NSDs were higher than those by CHDs and those by CHDs were higher than those by CLDs, the differences between the three groups were not significant $\left(\mathrm{F}[2,35]=.37, \mathrm{p}>.05, \eta^{2}=.021\right)$. We checked a third alternative measure, the proportions of the peak delay in the rime, only to find the same result.

Because peaks appear at the end of the sonorant rime in the Rise and sonorant rimes vary in duration, it is not surprising that words with longer sonorant rimes had greater peak delays for the Rise in all three groups. An exception was the peak of Loom, which was earlier than that of Lom for the CLDs. The peak delays of the four words by CLDs were larger than those by $\mathrm{CHD}$ s and those by $\mathrm{CHD}$ s were larger than those by NSDs. Overall, differences between targets words were significant $\left(\mathrm{F}[2.7,101.9]=58.47, \mathrm{p}<.001, \eta^{2}=.606\right)$, and there was a significant interaction with the groups $\left(F[5.4,101.9]=4.8, p<.001, \eta^{2}=.202\right)$. The differences in peak delay between the three groups were just significant $\left(\mathrm{F}[2,38]=3.2, \mathrm{p}=.05, \eta^{2}=.15\right)$, with CLDs having longer peak delays in the four words $(p=.055)$. There is no consistent effect of vowel quantity on proportional peak delay: while Loof has a greater proportional peak delay than Lof, in the case of Loom the proportional peak delay is less than in Lom. NSDs had the latest proportional peak delays, while CLDs had the lowest in Lof and Loof. The NSD value in Lom was between CLDs, the lowest, and CHDs, the highest, and their value in Loom was the earliest, before the CHD and the CLD values, respectively. Overall, proportional peak delay was significant across the words $\left(\mathrm{F}[2.6,98.1]=142.36, \mathrm{p}<.001, \eta^{2}=.789\right)$, and there was no interaction with the groups $\left(\mathrm{F}[5.2,98.1]=1.33, \mathrm{p}>.05, \eta^{2}=.065\right)$. Differences between the three groups were insignificant $(\mathrm{F}[2,38]=.13$, $\left.\mathrm{p}>.05, \eta^{2}=.007\right)$. We checked the third alternative measure, peak delay as a proportion of the rime, only to find the same result. 
In the Fall-rise, the words with longer sonorant rimes had la the utterances by the NSDs. For the CLDs, the peaks in coda $/ \mathrm{m} /$ were located later than those in the words with co the peaks in Lom and Lof were later than those in Loom an CHDs, the peak of Lof was earlier than that of Loof, but the $\mathrm{p}$ was earlier than that of Lom and Loof. Within the group, pea significantly different $\left(\mathrm{F}[3,114]=8.30, \mathrm{p}<.001, \eta^{2}=.179\right)$ interaction with groups $\left(\mathrm{F}[6,114]=5.67, \mathrm{p}<.001, \eta^{2}=.2\right.$ ? peak positions were not significantly different among the $t$ $\left(\mathrm{F}[2,38]=1.6, \mathrm{p}>.05, \eta^{2}=.076\right)$. As for the proportional the words with longer sonorant rimes had greater peak de shows that $/ \mathrm{m} /$ causes fo peaks to move right. The percent was lower than that of Lom for both NSDs and CHDs, mear coda $/ \mathrm{m} /$ pulls the peak rightwards more in short vowels $t$ vowels. The percentage in Loof was lower than that of Lof for difference in the percentages were significant $(F[2.4,90.6]$ $\left.<.001, \eta^{2}=.376\right)$, and the interaction with the group significant $\left(\mathrm{F}[4.8,90.6]=4.74, \mathrm{p}<.005, \eta^{2}=.200\right)$, but bet differences were insignificant $\left(F(2,38]=1.7, p>.05, \eta^{2}=\right.$. the proportional peak delay in the rime was not significan $(\mathrm{F}[2,38]<1)$.

In sum, the proportional peak delays, whether measured re vowel or the rime, were not significantly different betwee groups. This means Chinese speaker of Dutch located the pe the native speakers did, even though overall the CHDs be like the native speakers.

\subsubsection{Comparison of excursions of the Fall, Rise and F}

In this analysis, f0 excursion refers to fo differences ir between $\mathrm{H} 1$ and $\mathrm{L} 2$ in the Fall, between $\mathrm{L} 1$ and $\mathrm{H} 1$ i between $\mathrm{H} 1$ and $\mathrm{L} 2$ in the falling movement of the $\mathrm{F}$ between $\mathrm{H} 2$ and $\mathrm{L} 2$ in the rising movement of the Fall-Rise. fo duration is the distance in ms from $\mathrm{H} 1$ to L2 in the Fall, $\mathrm{H} 2$ in Rise, from $\mathrm{H} 1$ to $\mathrm{L} 2$ in the falling movement of the from $\mathrm{L} 2$ to $\mathrm{H} 2$ in the rising movement of that contour. $\mathrm{B}$ excursions by their corresponding $\mathrm{f} 0$ durations, the rate of 
obtained. This can be used to compare how $\mathrm{f} 0$ falls or rises between the various conditions. A stable fo excursion and an increasing rate of change on shorter words can be interpreted as compression, while a decreasing $\mathrm{f} 0$ excursion on shorter words and a stable rate of $\mathrm{f} 0$ change can be taken as evidence of truncation.

\section{The Fall}

The f0 excursions ( $\mathrm{H} 1-\mathrm{L} 2)$ in the four target words produced by the Standard Dutch group were ranked $L m_{\mathrm{H} 1-\mathrm{L} 2}>\operatorname{Loom}_{\mathrm{H} 1-\mathrm{L} 2}>\operatorname{Loof}_{\mathrm{H} 1-\mathrm{L} 2}>$ $L o f_{\mathrm{H} 1-\mathrm{I} 2}$, where the largest difference is between the words ending in $/ \mathrm{m} /$ and those ending in $/ \mathrm{f} /$. The rate $\mathrm{f0}$ change (RC) was ordered $L \mathrm{of}_{\mathrm{RC}}$ $>\operatorname{Loof}_{\mathrm{RC}}>\operatorname{Lom}_{\mathrm{RC}}>\operatorname{Loom}_{\mathrm{RC}}$, as shown in Figure 5.7. This means that native speakers speeded up the rate of $\mathrm{fO}$ change as the sonorant rime got shorter, while their excursions diminished as the sonorant rime got shorter. Concomitantly, NSDs reduced the distance over which the f0 movement was carried out.

As can be perhaps be discerned in Figures 5.8 and 5.9, CHDs ordered fo excursion and rate of $f 0$ change as $\operatorname{Loof}_{\mathrm{H} 1-\mathrm{L} 2}>\operatorname{Lom}_{\mathrm{H} 1-\mathrm{L} 2}>\operatorname{Loom}_{\mathrm{H} 1-\mathrm{L} 2}>$ $\operatorname{Lof}_{\mathrm{H} 1-\mathrm{L} 2}$ and $\operatorname{Lof}_{\mathrm{RC}}>\operatorname{Loof}_{\mathrm{RC}}>\operatorname{Lom}_{\mathrm{RC}}>\operatorname{Loom}_{\mathrm{RC}} ; \mathrm{CLDs}$ ordered them $\operatorname{Loom}_{\mathrm{H} 1-\mathrm{L} 2}>\operatorname{Lom}_{\mathrm{H} 1-\mathrm{I} 2}>\operatorname{Loof}_{\mathrm{H} 1-\mathrm{L} 2}>\operatorname{Lof} f_{\mathrm{H} 1-\mathrm{I} 2}$ and $\operatorname{Lof} f_{\mathrm{RC}}>\operatorname{Loof}_{\mathrm{RC}}>\operatorname{Loom}$ ${ }_{\mathrm{RC}}>\operatorname{Lom}_{\mathrm{RC}}$. However, no significant differences were found in the $\mathrm{f0}$ excursion $\left(\mathrm{F}[2,35]=.43, \mathrm{p}>.05, \eta^{2}=.024\right)$ or rate of $\mathrm{f} 0$ change $(\mathrm{F}[2,35]$ $\left.=1.82, \mathrm{p}>.05, \eta^{2}=.094\right)$ between the three groups. Within groups, it was found that NSDs truncated Lof and Loof, CHDs truncated Lof, CLDs did not truncate any words. The lack of significant differences in f0 excursion ( $\mathrm{H} 1$ to $\mathrm{L} 2$ ) means that the pitch spans of the three groups were not significantly different.

The relevant peaks to L1s (Figures 5.7, 5.8 and 5.9) within group were significantly different $\left(\mathrm{F}[3,105]=8.0, \mathrm{p}<.001, \eta^{2}=.187\right)$. No significant interaction between groups and target words was found $(\mathrm{F}[6$, $\left.105]=2.1, \mathrm{p}=.065, \eta^{2}=.105\right)$. The differences in peaks between group were not significant either $\left(\mathrm{F}[2,35]=2.93, \mathrm{p}>.05, \eta^{2}=.143\right)$. The four target words had effects on the peaks, but there were no significant differences among the groups. Peaks produced by the Mandarin speakers of Dutch were similar to those by the native speakers. 


\section{The Rise}

As shown in Figure 5.10, the fo excursion was ranked Lom ${ }_{\mathrm{L} 1-\mathrm{H} 1}>\operatorname{Loom}_{\mathrm{L} 1-\mathrm{H} 1}>\operatorname{Lof}_{\mathrm{L} 1-\mathrm{H} 1}$ for the native speakers, while th change was ranked $L o f_{\mathrm{RC}}>\operatorname{Loof} f_{\mathrm{RC}}>\operatorname{Lom} \mathrm{RC}>\operatorname{Loom}_{\mathrm{RC}}$. NSDs distance over which the $\mathrm{f} 0$ movement was carried out as $t$ portion was shorter. CHDs increased the rate of change in rimes much like the native speakers and fo excursions vary way. The fo excursions by the CHDs (Figures 5.11) were ranl $>\operatorname{Loom}_{\mathrm{L} 1-\mathrm{H} 1}>\operatorname{Loof}_{\mathrm{L} 1-\mathrm{H} 1}>\log f_{\mathrm{L} 1-\mathrm{H} 1}$ and $\mathrm{f} 0$ durations were rar $\operatorname{Loof}_{\mathrm{RC}}>\operatorname{Lom}_{\mathrm{RC}}>\operatorname{Loom}_{\mathrm{RC}}$. For the CLDs, f0 excursions $\operatorname{Loom}_{\mathrm{L} 1-\mathrm{H} 1}>\operatorname{Lom}_{\mathrm{L} 1-\mathrm{H} 1}>\operatorname{Lof}_{\mathrm{L} 1-\mathrm{H} 1}>\operatorname{Loof}_{\mathrm{L} 1-\mathrm{H} 1}$ and $\mathrm{f0}$ durati Loom $_{\mathrm{RC}}>$ Loof $_{\mathrm{RC}}>\operatorname{Lom}_{\mathrm{RC}}$ (Figure 5.12). But really, CL differentiate the Rises at all much across the four words.

No significant differences were found in $\mathrm{f} 0$ excursion betwe groups $\left(F[2,38]=1.1, p>.05, \eta^{2}=.052\right)$, but the differenc fo change were significant $\left(\mathrm{F}[2,38]=3.8, \mathrm{p}<.05, \eta^{2}=.16\right.$ comparisons showed that differences in the rate of $\mathrm{f} 0$ char NSDs and CLDs were significant $(p<.05)$, but not betweer CHDs or between CHDs and NSDs. Again, this shows tha $\mathrm{CHDs}$ increased the rate of $\mathrm{fO}$ change when the sonorant rir shorter, while CLDs failed to adopt such a strategy in resp reduction in phonetic space. Within groups, NSDs trunc ending in / $\mathrm{f} /$ relative to those ending in $/ \mathrm{m} /$, and compress and Lom; CHDs didn't truncate any words, but compressed $t$ in / $\mathrm{f} /$; CLDs truncated the words ending in $/ \mathrm{f} /$, but did $\mathrm{n}$ any words.

The fact that there are no significant differences in $\mathrm{fO}$ excu. H1 or the relevant peaks) means that the pitch spans of the were not significantly different. Within the entire group, peaks were significantly different $(F[3,114]=11.5, \mathrm{p}<00$ while the interaction between groups and target words wa $\left(\mathrm{F}[6,114]=4.0, \mathrm{p}=.001, \eta^{2}=.174\right)$. Target words had effe peaks, and different groups produced different the peaks $i$ words. 


\section{The Fall-rise}

In the falling part of the Fall-rise, shown in Figures 5.13 to 5.15, the three groups had longer $\mathrm{f} 0$ durations in the target words with longer sonorant rimes, except that both CHDs and NSDs had a longer $\mathrm{fO}$ fall in Loof than in Lom, whose sonorant portion is longer than that of Loof (Figure 5.6). The difference in fall duration was significant between the three groups $\left(\mathrm{F}[2,38]=6.4, \mathrm{p}<.05, \eta^{2}=.251\right)$. CLDs' were the longest and NSDs' were the shortest. No significant differences were found by multiple comparisons between CLDs and CHDs or between CHDs and NSD, but the difference between CLDs and NSDs was significant.

Again in the falling movement of the contour, the rate f0 change was faster for Lof than for Loof, and that for Lom was faster than that for Loom for all three groups. This means that target words with long vowels had lower rates of change than those with short vowels, as is to be expected. However, although the differences in the rate of $\mathrm{f} 0$ change for these three groups failed to reach significance, target words with different codas showed different patterns in the three groups. For the NSDs, it was slower in Loom than in Loof, but unexpectedly it was faster in Lom than in Lof, for the CHDs, oddly, the target words with $/ \mathrm{m} / \mathrm{had}$ faster rates than those with /f/; for CLDs, the tendency was the opposite of that for NSDs, that is, the rate of change was faster in Loom than in Loof, but in Lom it was slower than in Lof.

In the rising movement of the contour, the NSDs had wider f0 excursions in the target words with longer sonorant rimes. The CHDs had the same tendency, but the f0 excursion in Loof was wider than that in Lom and in Loom. However, the f0 excursion in the pronunciation of Loom by the CLDs was narrower than that in their Lom. As in the falling movement of the contour, CLDs had the widest $\mathrm{f0}$ excursions, while the NSDs had the narrowest. The differences in $\mathrm{f} 0$ excursion between the three groups were significant $\left(F[2,38]=6.4, p<.05, \eta^{2}=.25\right)$. Multiple comparisons showed that differences were significant between CLDs and NSDs, between CLDs and CHDs and between CHDs and NSDs.

The rate of $\mathrm{f} 0$ change in the rising movement of the Fall-rise was found to be slower, overall, in Lof than in Lom, while in Loof it was the fastest. In Lom, it was faster than Loom for CLDs and CHDs, but not for NSDs. The differences between the three groups were not significant $(F[2,38]$ 
$\left.=.93, \mathrm{p}>.05, \eta^{2}=.047\right)$. Unlike what we found for movements, the Fall and the Rise, speakers tended to increas fo change in the Fall-rise in longer sonorant rimes.

In both the falling and rising movements of the Fall-1 excursions by NSDs were significantly narrower than those $b$ but no significant differences were found between NSDs an between CLDs and CHDs. The rates of f0 change betwee groups were not significantly different. Looking at the two within the groups, NSDs truncated Lof, Loof and Lom, and Lof and Loof. CHDs truncated Lof and Lom, and compres Loof. CLDs truncated Lof and Loof, and compressed Lof. analysis, we learn again that $\mathrm{CHDs}$ pronounced the Fall-rises did the CLDs.

In the Fall-rises, the relevant peaks to L1 were significan within group $\left(F[3,114]=13.04, p<.001, \eta^{2}=.255\right)$, and the between target words and group were not significant ( $F[6,11$ $\left.>.05, \eta^{2}=.078\right)$. Between groups, The differences in the not significant $(F[2,38]<1)$. This shows that target words on the peaks, but different groups behaved similarly in ter height.

Neither the $\mathrm{fo}$ of $\mathrm{H} 1$ and of $\mathrm{H} 2$ (relative to L1) in the $\mathrm{F}$ significantly different between the three groups $(\mathrm{F}[2,35]<1$ $1.1, \mathrm{p}>.05, \eta^{2}=.052 ; \mathrm{F}[2,38]<1 ; \mathrm{F}[2,38)<1$, respective significant differences were found in the case of the Fall a either, no difference in pitch span was found between the n? speakers. This result is not in line with Chen's findings (20 pitch span by Chinese learners of English was narrower native speakers and that the pitch spans by subjects proficiency were more similar to those by the native speak subjects with lower proficiency.

\subsection{Conclusions}

As in the other experiments reported in this dissertation, subjects with higher proficiency performed more like nat 
than those with lower proficiency in the experiment reported in this chapter. This is true for a large number of measures. First, the more advanced group (CHD) was more successful in producing recognizable versions of the IP-final nuclear Fall, Rise and Fall-rise. Second, the CHDs could pronounce the short and the long vowels correctly in the three sentence types, in fact much like the native speakers, but Chinese speakers with lower proficiency (CLDs) did not differentiate properly between the short vowel / $/$ / and the long vowel /o:/. The durations of the sonorant rimes by CLDs were all longer than the corresponding ones by the native speakers and also longer than the corresponding ones by CHDs, except for Loof when pronounced with the Fall and the Rise. With Falls, CLDs' sonorant rime durations were significantly longer than those of the NSDs, but not significantly longer than those by the CHDs. NSDs' sonorant rimes were also significantly shorter than those by the CHDs. With Rises, CLD sonorant rimes were significantly longer than those by NSDs. In the Fall-rises, the sonorant rimes by CLDs were significantly longer than those by CHDs and NSDs, and those by CHDs significantly longer than those by NSDs.

The pitch spans and the peaks relative to the valleys in the three contours were not found to be significantly different between the native speakers and the Chinese speakers of Dutch. This contradicts Chen's findings (2008) that the pitch span by Chinese learners of English was narrower than that by native speakers. We provisionally attribute this discrepancy to the fact that the pitch span of Dutch is narrower than that of English (Willems, Collier \& 't Hart, 1988).

The monosyllabic (phrase-final) Fall-rise is the most difficult contour for the Chinese speakers of Dutch. They could not produce it correctly even after training, and some subjects replaced it with a Rise. In the Fall-rises, CLDs' $f 0$ excursions were the longest, while those by the NSDs were the shortest, a significant differnce. The differences in the rate of fo change for the three groups, however, were not significant. Speakers tended to increase the rates of $\mathrm{f} 0$ change in Fall-rises when sonorant rimes got longer. Overall, CHDs pronounced the target words in Fall-rises better than did CLDs.

Neither subgroup managed to reproduce the behaviour of NSDs in the realization of the Fall-rise, which reflects the fact this pattern does not 
occur in their L1. While phrase-final Tone 3 has a general contour, in terms of Dutch phonology it is equivalent to a lo the fall begins outside the rime instead of well within it (see 1 For this reason, the Fall-rise is more appropriately labeled rise'.

The three group adopted different stategies to the experimer time pressure. In the Falls, the native speakers truncated $L$ The Mandarin speakers of Dutch with high proficiency tr but the ones with low proficiency didn't adopt such a stra Rises, the native speakers of Dutch truncated Lof and compressed Lof, Loof and Lom. The Mandarin speakers of high proficiency truncated no words, but compressed Lof a ones with low proficiency truncated Lof and Loof, but did n any words. In the Fall-rises, the native speakers of Dutch tr Loof and Lom and compressed Lof and Loof. The Mandarin Dutch with high proficiency truncated Lof and Lom, and con and Loof. The ones with low proficiency truncated Lof an compressed Lof. Chinese learners of Dutch approach nati more in the execution of three intonation contours on IP- $\mathrm{fl}$ when their general proficiency is higher. 


\subsection{References}

Caspers, J. \& van Heuven, V. J. (1993). Effects of time pressure on the phonetic realization of the Dutch accent lending pitch rise and fall. Phonetica, 50, 161-171.

Chen, H. (2008). On Cbinese EFL Learner's English Intonation Patterns. Shanghai: Shanghai Foreign Language Education Press.

Bannert, R. \& Bredvad, A. (1975). Temporal organization of Swedish tonal accent: The effect of vowel duration. Working papers Pbonetics Laboratory, 10, Department of General Linguistics, Lund University.

D'Imperio, M. \& House, D. (1997). Perception of questions and statements in Neapolitan Italian. EUROSPEECH-1997, 251-254.

Erikson, Y. \& Weenink, M. (1972). Fundamental frequency correlates of the grave word accent in Swedish: the effect of vowel duration. Speech Transmission Laboratory, Quarterly Papers and Status Report 2-3 (pp. 53-60), KTH, Sweden.

Gósy, M. \& Terken, J. (1994). Question marking in Hungarian: Timing and Height of pitch peaks, Joumal of Phonetics, 22, 269-281.

Grabe, E. (1998a). Comparative Intonational Phonology: English and German. Ph.D. dissertation, University of Nijmegen.

Grabe, E. (1998b). Pitch accent realization in English and German. Journal of Phonetics, 26, 129-143.

Grabe, E., Post, B., Nolan, F. \& Farrar, K. (2000). Pitch accent realization in four varieties of British English. Journal of Phonetics, 28, 161-185.

Grosser, W. (1997). On the acquisition of tonal and accentual features of English by Austrian learner. In A. James \& J. Leather (Eds.), Second Language Speech: Structure and Process (pp. 211-228). Berlin: Mouton de Gruyter.

Grønnum, N. (1989). Stress group patterns, sentence accents and sentence intonation in South Jutland (Sønderborg and Tønder) with a view to German. Annual Report of the Institute of Phonetics, Universtiy of Copenhagen (ARIPUC), 23, 1-85.

Gussenhoven. C. (2005). Transcription of Dutch intonation. In S.-A. Jun (Ed.), Prosodic Typology: The Phonology of Intonation and Phrasing (pp. 118-145). Oxford: Oxford University Press.

Gut, U. (2009). Non-native Speech. Frankfurt: Peter Lang.

Hanssen, J., Peters, J. \& Gussenhoven, C. (2007). Phrase-final pitch accommodation effects in Dutch. Proceedings of the 16th International Congress of Pbonetic Sciences, Saarbrücken, 1077-1080. 
House, D. (2004). Final rises and Swedish question intonatio of FONETIK 2004, Dept. of Linguistics, Stockholm Uni Ladd, D.R. (2008). Intonational Phonology. Cambridge: University Press. $2^{\text {nd }}$ Edition.

Ladd, D. R., Mennen, I, \& Schepman, A. (2000). P conditioning of peak alignment of rising pitch accent: Journal of the Acoustical Society of America, 107, 2685-2696.

Lin, M. (2006), Zhao's view point of Chinese intonation an tone. Report of Phonetics, 1-4.

Mücke, D., Grice, M., Becker, J. \& Hermes, A. (2009). variation in tonal alignment: Evidence from acoustic an data. Journal of Phonetics, 7, 321-338.

Prieto, P., van Santen, J. \& Hirschberg, J. (1995). Tona patterns in Spanish. Journal of Phonetics, 23, 429-451.

Peng, Shu-hui, M., Chan, K. M., Tseng, Chiu-yu, Huang, Ts Joo \& Beckman, M. E. (2005). Towards a Pan-Mandarir prosodic transcription. In S.-A. Jun (Ed.), Prosodic 1 Phonology of Intonation and Phrasing (pp. 230-270). Oxfo University Press.

Pierrehumbert, J. B. (1980). The Phonetics and Phonology of Engl Ph.D. Thesis, MIT.

Rietveld, T. \& Gussenhoven, C. (1995). Aligning pitch targe synthesis: Effects of syllable structure. Journal of Phonetics Shen, X. S. (1990). Ability of learning the prosody of an language by speakers of a tonal language: Chinese speak French prosody. International Review of Applied linguistics in 119-134.

van den Berg, R., Gussenhoven, C. \& Rietveld, T. (1992). I Dutch: Implications for a model. In G. Docherty \& (Eds.), Papers in Laboratory Phonology II: Gesture, Segment, 335-359). Cambridge: Cambridge University Press.

Wang Hongyan \& van Heuven, V. J. (2006). Acoustical English vowels produced by Chinese, Dutch and Americ In J. M. van de Weijer \& B. Los (Eds.), Linguistics in t 2006, (pp. 237-248). Amsterdam: John Benjamins.

Warren, M. (2004). A corpus-driven analysis of the use of in assert dominance and control. In U. Connor \& T. U Applied Corpus Linguistics: A Multidimensional Perspective Amsterdam: Rodopi. 
$\mathrm{Xu}, \mathrm{Y}$. (1997). Contextual tonal variations in Mandarin. Joumal of Pbonetics, $25,61-83$.

$\mathrm{Xu}, \mathrm{Y}$. (1999). Effects of tone and focus on the formation and alignment of f0 contours. Journal of Pbonetics, 27, 55-105.

$\mathrm{Xu}, \mathrm{Y}$. (2001). Fundamental frequency peak delay in Mandarin. Phonetica, $58,26-52$.

Willems, N., Collier, R., 't Hart, J. (1988). A synthesis scheme for British English intonation. Journal of the Acoustical Society of America, 84, 1250-1261. 



\section{Chapter 6}

\section{Prosodic effects of focus in Dutch declaratives by L1 Chinese speakers ${ }^{1}$}

\subsection{Introduction}

Focus is the informative part of an utterance which is marked by relative prominence. It can be 'broad' or 'narrow' in size (Ladd, 2008). In Dutch as shown in (1a) and (1b, c), the whole response Ik zou wel naar Momberen willen fietsen to the question Wat qijn de plannen voor morgen? in (1a) is the focus constituent, while the focus constituent is restricted to the word Momberen in the response sentences to their respective questions in $(1 \mathrm{~b}$, c). In all three cases, the new information is given by the focus constituent. A distinction between 'information focus' and 'corrective focus' can additionally be made (Gussenhoven, 2007), as shown in (1b) and (1c). Although the word Momberen is the focus constituent in both (1b) and (1c), the information status is different. Momberen in (1b) provides the requested information ('where'), but Momberen in (1c) is the correction to old information Zaltbommel in the addressee's preceding statement.

\section{A: Wat rijn de plannen voor morgen?}

'What are your plans for tomorrow?'

B: [Ik rou wel naar Momberen willen fietsen $]$

'I would like to cycle to Momberen'

(1b) A: Waar zou Karel je been willen brengen?

'Where would Karel like to take you?'

B: Hij zou me naar [Momberen] willen brengen.

'He would like to take me to Momberen'

(1c) A: Had je moeder je naar Zaltbommel willen sturen?

'Did your mother want to send you to Zaltbommel?'

${ }^{1}$ An earlier and shorter version of this chapter appeared as $\mathrm{He}$, van Heuven \& Gussenhoven (2011) in the Proceedings of the 17th International Congress of Phonetic Sciences (Hong Kong). 
B: Nee, ze had me naar [Momberen] willen sturen.

'No, she wanted to send me to Momberen.'

Speakers of different languages can adopt phonetically logically different strategies to express the meanings in dif conditions. These strategies include pitch accent distribut boundary, pitch range and duration.

In English, focus is marked by pitch accents. Additionally, British English increase the duration of the accented syllab narrow and corrective focus as compared with broad for significant differences were found in peak height and peak t the three focus conditions by Sityaev (2003). However, American English did realize narrow focus in short English sentences with an expanded pitch range for the accented supressed the pitch range of postfocus syllables. By contra syllables had the usual wide pitch range, just as did speakers in the same conditions ( $\mathrm{Xu} \& \mathrm{Xu}, 2005)$. In the focus co peak of $\mathrm{f} 0$, the size of rise, the speed of rise toward the $\mathrm{fO} \mathrm{f}$ duration of the stressed syllable became significantly enlarg fo peak was found to align well before the word-final stre offset under focus but the f0 valley consistently align with stressed syllable.

The marking of focus in Standard French and Toulousian reported to be different. In addition to post-focus deaccer phrasing, Toulousian French also uses a certain tonal patt focus (Chen \& Destruel, 2010).

A study by Baumann, Becker, Grice \& Mücke (2007) on r speech shows that speakers produced more downsteps $l$ focus and more upsteps under contrastive focus than in conditions. From contrastive focus to narrow focus and to the f0 peak was delayed, the f0 height became lower, the pit towards the peak decreased, the duration of nuclear syllab were shortened. The vowels in the accented syllables peripheral in the vowel space under contrastive or narrow under broad focus. 
Speakers of Korean and Japanese used different phrasings to mark focus differences Jun, 1996; Pierrehumbert \& Beckman, 1998; Selkirk \& Tateishi, 1991; Ueyama \& Jun, 1998). Focused words in Korean were additionally realized by increased $\mathrm{f} 0$, duration and intensity independent of the phrasing effect on focus. As in English and Mandarin, Korean post-focus elements were compressed, and this post-focus compression was found to be absent in in Taiwanese and Cantonese (Lee \& Xu, 2010; Wu \& Xu, 2010).

Hanssen, Peters and Gussenhoven (2008) studied the impact of different focus conditions in utterances with falling intonation $\left(\mathrm{H}^{*} \mathrm{~L} \mathrm{~L} \%\right.$ ) in Standard Dutch. The corpus consisted of declaratives with broad, narrow informational and narrow corrective focus. Focus condition significantly affected onset duration and coda duration, but not the duration of the syllable nucleus. The onset in both narrow focus (NF) and corrective focus $(\mathrm{CF})$ was longer than in broad focus $(\mathrm{BF})$ and coda durations were significantly longer in $\mathrm{BF}$ and $\mathrm{NF}$ than in $\mathrm{CF}$. The focus conditions also significantly affected the $\mathrm{f} 0$ of the peak, which was higher in both $\mathrm{BF}$ and $\mathrm{CF}$ than in NF. The f0 of the first elbow did not differ significantly under the three focus conditions, but the $f 0$ of the second elbow, the end of the fall, was significantly higher in BF than in NF and $\mathrm{CF}$, and the same was true for the $\mathrm{f} 0$ of the beginning of vowel of first postnuclear stressed syllable. Rate of f0 slope was constant for the rise, but increased significantly going from broad focus to the two narrow focus conditions. The $\mathrm{f} 0$ peak occurred later in $\mathrm{BF}$ than in NF and CF. Thus, (informational and corrective) narrow focus caused the onset and coda consonants of the accented syllable to be lengthened, and the falls of the rising-falling accentual contour to start earlier and to descend more steeply. All four measures indicate that their speakers aimed to create a firmer fall located within the syllable rime of the accented syllable.

Mandarin is a tone language whose focus cannot be realized by the provision of pitch accent as in West-Germanic languages. Focus in Mandarin was shown to be marked by longer duaration and f0 range expansion (Chen, 2006; Chen \& Braun, 2006; Greif, 2010; Peng et al., 2005; $\mathrm{Xu}, 1999)$. The pitch range of the syllable in focus was expanded, pitch range of postfocal syllables was suppressed and the pitch range of prefocus syllables was kept largely intact ( $\mathrm{Xu} \& \mathrm{Xu}, 2005)$. 
Characteristics of a learner's first language (L1) may transfer language (L2). It was found that Japanese and Korean Engl were inspired by the intonation patterns in their mother realize focus in English and speakers with higher proficienc were more naitve-speaker like (Ueyama \& Jun, 1998). Tl transfers were also reported in the studies by Goad and he and therefore they proposed the Prosodic Transfer Hypoth Mandarin does not permit adjunction to the prosodic word, $t$ necessary to represent tense and agreement in English. The u of adjunction in Mandarin phonology can explain the fact th speakers of English delete the inflection in their oral produc White \& Steele, 2003). Due to the difference in prosodi between Turkish and English, Turkish speakers of English eit substituted or stressed English articles (Goad \& White, 2009 was further supported by Prévost (2010).

Swerts \& Zerbian (2010) also found that speakers of Engli Africa marked focus in different ways from the native spe proficient speakers of English realized the focus like L1 Engl but less proficient ones transferred features from L1 signalling focus, resulting in a different perceived promin words from the L1 English speakers.

The stategies adopted by German speakers of English to re narrow and corrective focus in their read and semi-spontan in L1 German and L2 English were different in the pitch a alignments and the phonetic extent of rises (O'Brien \& Gut differences in tonal alignment in the three focus conditio explained totally by L1 influence. Many differences in La from the native speech were caused by the phonetic realizatic phonological categories rather than a divergent phonology O’Brien \& Gut, 2010).

In this study, we tried to answer two questions:

a. Do Chinese speakers of Dutch adopt the same stategies three focus conditions as native speakers of the Standare

b. If there are differences, do these reflect differences in the levels of the Chinese speakers of Dutch? 


\subsection{Method}

\subsubsection{Materials}

We used contextualized declarative sentences from the corpus used in the Nijmegen project Intonation in Varieties of Dutch that were intended to elicit broad, narrow, and corrective focus in three sets of sentences. Each set has four target words (Manderen, Momberen, Memberen, Munderen) which are pseudo placenames, thus resulting in 12 test sentences altogether. They were arranged in mini-dialogues as shown in (1) above, in which ' $A$ ' is context and ' $B$ ' the response to ' $A$ ', the test sentence. The nuclear accent word were underlined. The nuclear pitch accent in all sentences is expected to occur on the target words. Sonorants in the stressed syllable (CVC) of target words are used because they have shown to behave similarly in peak timing, at least in American English (Van Santen \& Hirschberg, 1994). The stress patterns of all target words and test sentences were identical.

\subsubsection{Procedure}

The three focus conditions were blocked. Two practice dialogues and the four randomized mini-dialogues for each focus condition were put into a Powerpoint file with a practice mini-dialogue at the beginning of each block. Subjects were asked to practise the response sentence in these practice mini-dialogues, which were played from a powerpoint presentation on a laptop, before the recording of the block took place. Their performance was checked by the experimenter, who went ahead with the recording if the subjects imitated the correct accent placement and intonation contour. During the recording, the experimenter played the context sentences in the experimental mini-dialogues, and the subjects read aloud the response sentence from a page in a booklet on which the dialogue was printed. Subjects were recorded with a Zoom $\mathrm{H} 4$ Handy Digital Recorder in different places: in the home, in classrooms or libraries; one subject was recorded in the studio of the Arts Faculty of Radboud University Nijmegen and three in the sound treated booth at the University of Groningen. All response sentences including the ones in the examples were recorded and subjects were allowed to repeat sentences when they felt their earlier attempt was not their best reading. 
As a baseline for Standard Dutch, we selected the resf Manderen for the three focus conditions.

\subsubsection{Subjects}

The Chinese participants in this study were the same as thos part in the experiments described in Chapter 2 (see section 2 also described the way in which they were divided into two one with higher (CHD) and one with lower proficiency in D The native speakers of Standard Dutch in the corpus were 13 females, aged from 14 to 49 . No speakers reported they $n$ or had hearing problems.

\subsubsection{Acoustic measurements and analysis}

\subsubsection{Labellings}

We followed the method used by Hanssen et al. (20 annotation of our Mandarin Dutch data. A textgrid with th created for each test sentence using a script in Praat Weenink, 2009). The tonal labels of the fo minima and ma target words were placed on the first tier. The segmental bo the test words were labeled on the second. The identifyir nuclear contour as transcribed with ToDI (Gussenhoven and comments on the sound file were provided on the thir and Figure 6.1 show these labels. 
Table 6.1. Two tiers of labels on the target words

\begin{tabular}{ll}
\hline Name & Position \\
\hline $\mathrm{L}_{1}$ & elbow before the nuclear peak \\
$\mathrm{H}$ & maximum f0 of the pitch accent \\
$\mathrm{L}_{2}$ & elbow after the nuclear peak \\
$\mathrm{O}_{1}$ & beginning of nuclear onset \\
$\mathrm{N}_{1}$ & beginning of nuclear vowel \\
$\mathrm{C}$ & beginning of nuclear coda \\
$\mathrm{O}_{2}$ & beginning of the onset in the $2^{\text {nd }}$ syllable \\
$\mathrm{N}_{2}$ & beginging of the vowel in the $2^{\text {nd }}$ syllable \\
$\mathrm{O}_{3}$ & beginging of the onset in the $3^{\text {rd }}$ syllable \\
$\mathrm{N}_{3}$ & beginging of the wowel in the $3^{\text {rd }}$ syllable \\
$\mathrm{O}_{4}$ & beginging of the onset in the postnuclear stressed syllable \\
$\mathrm{N}_{4}$ & beginning of vowel in the postnuclear stressed syllable \\
$\mathrm{E}$ & end of the postnuclear word \\
\hline
\end{tabular}




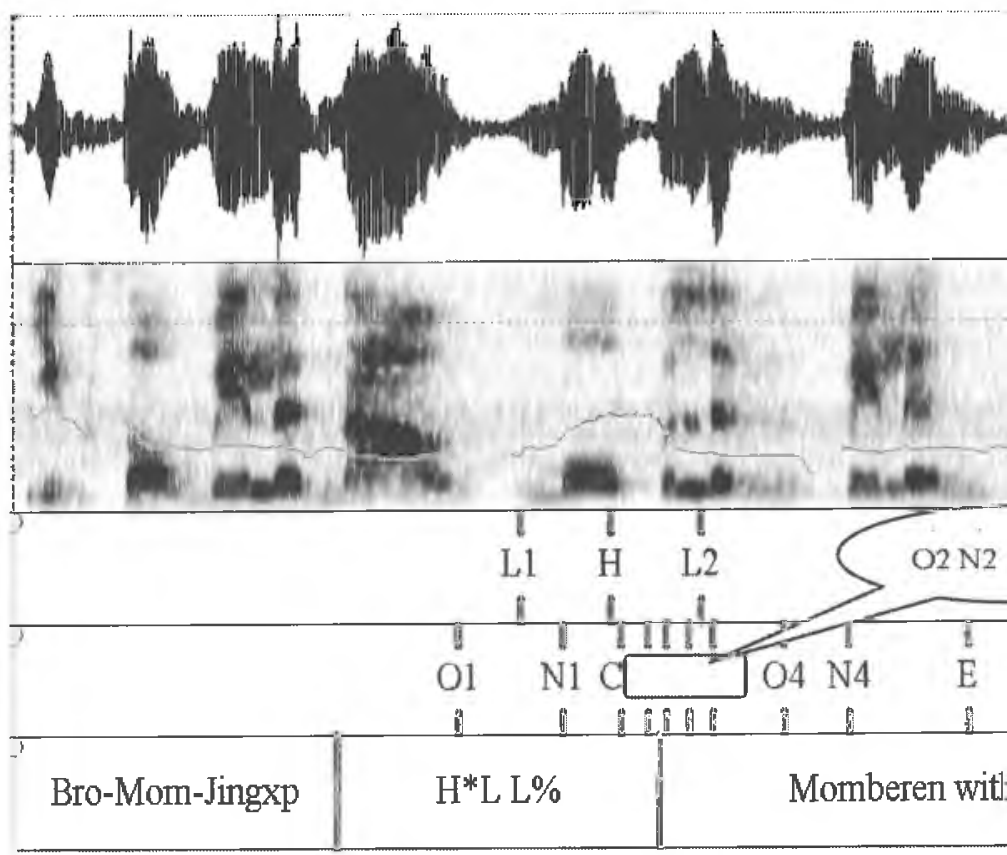

Figure 6.1. Tonal and segmental labels for a target word under broad $f$ the auditory information and visual inspection of the waveform, pit spectrogram for Ik zou wel naar Momberen willen fietsen, read by a Chine Dutch. The tonal labels of the fo minima and maxima are placed on the segmental boundaries of the test word $\left(\mathrm{O}_{1}-\mathrm{O}_{4}\right)$ and willen $\left(\mathrm{O}_{4}-\mathrm{E}\right)$ are second. The third tier gives, from left to right, the identification lat sentence, the nuclear contour and a comment.

The label for the $\mathrm{f} 0$ maxima $(\mathrm{H})$ of the pitch accent automatically; we used the Praat function that gives the loc highest pitch in a selected interval. Placing the labels for the the beginning of the contour $\left(\mathrm{L}_{1}\right)$ and at the end of the nucl was less straightforward, however. Considering that the ris slope (which is calculated by dividing fo excursion by $\mathrm{f} 0 \mathrm{du}$ important variable in the study, it is essential that the lal placed too early or too late. We defined the elbow as the pitch signal where a sudden change in slope is visible and lab turning point manually as the elbow of the fo contour.

The segmental boundaries on the second tier were label based on auditory information and visual inspection of the 
and the waveform. Since the boundaries between segments are rarely clear-cut, the point where phonemes least affected each other was chosen as the location of the boundary. All segmental boundaries on this tier were placed at negative-to-positive zero-crossings.

\subsubsection{Variables}

In the present study, we used the following variables, as in Table 6.2, to describe the prosodic and the phonetic features of the target words in different focus conditions. 
Table 6.2. Overview of 23 variables used in this chapter. Exc $=\mathrm{fO}$ excu duration. See Table 6.1 and figure 6.1 for definition of landmarks $O_{1}, V_{1}$, $\mathrm{N}_{1}, \mathrm{~N}_{2}, \mathrm{~N}_{4}, \mathrm{~L}_{1}, \mathrm{~L}_{2}$. All f0 values are in semitones (st), durations are in seco

\begin{tabular}{|c|c|c|}
\hline Nr. Variable & Variable meaning & Expression with \\
\hline 1. Odur & Onset duration & $\mathrm{O}_{1}$ to $\mathrm{V}_{1}$ \\
\hline 2. Vdur & Nuclear vowel duration & $\mathrm{V}_{1}$ to $\mathrm{C}_{1}$ \\
\hline 3. Cdur & Coda duration in nucleus & $\mathrm{C}_{1}$ to $\mathrm{O}_{2}$ \\
\hline 4. Rdur & Rime duration in nucleus & $\mathrm{N}_{1}$ to $\mathrm{O}_{2}$ \\
\hline 5. Sylldur & Duration of accented syllable & $\mathrm{O}_{1}$ to $\mathrm{O}_{2}$ \\
\hline 6. Wdur & Accented word duration & $\mathrm{O}_{1}$ to $\mathrm{O}_{2}$ \\
\hline 7. Postwd & Duation of willen & $\mathrm{O}_{4}$ to $\mathrm{E}$ \\
\hline 8. $\mathrm{O}_{1} \mathrm{Hexc}$ & Excursion from onset to peak & f0 excursion fron \\
\hline 9. Fallexc & Excursion of fall & f0 excursion fron \\
\hline $\begin{array}{l}\text { 10. Nucleus } \\
\text { fall exc }\end{array}$ & Excursion of nucleus fall & f0 excursion fror \\
\hline 11. $\mathrm{H}-\mathrm{N}_{2} \mathrm{exc}$ & $\begin{array}{l}\text { Excursion from peak to the } \\
\text { second vowel }\end{array}$ & f0 excursion fros \\
\hline 12. $\mathrm{H}-\mathrm{N}_{4}$ exc & $\begin{array}{l}\text { Exurison from peak to the } \\
\text { vowel in willen }\end{array}$ & fo excursion fro \\
\hline 13. pd & $\begin{array}{l}\text { Peak relative to nuclear vowel } \\
\text { (peak delay) }\end{array}$ & Timing from $\mathrm{H}$ \\
\hline 14. $\mathrm{Pd} /$ rime & Percentage pd in the rime & $\mathrm{Pd} /$ duration of $\mathrm{r}$ \\
\hline 15. Falldur & Duration of Fall & Duration from $\mathrm{F}$ \\
\hline 16. Risedur & Duration of Rise & Duration from L \\
\hline 17. HfO-EfO & Peak relative to end of willen & fo excursion fror \\
\hline 18. $\mathrm{L}_{1}-\mathrm{Hexc}$ & $\begin{array}{l}\text { Excursion from the first } \\
\text { elbow to peak }\end{array}$ & fo excursion fro \\
\hline 19. Risesp & Speed of Rise & $\left(\mathrm{H}(\mathrm{st})-\mathrm{L}_{1}(\mathrm{st})\right)$ \\
\hline 20. Fallsp & Speed of Fall & $\left(\mathrm{H}(\mathrm{st})-\mathrm{L}_{2}(\mathrm{st})\right)$ \\
\hline 21. $\mathrm{O}_{1} \mathrm{fO}-\mathrm{EfO}$ & $\begin{array}{l}\text { Onset f0 relative to the end } \\
\text { of the post word }\end{array}$ & $\mathrm{O}_{1} \mathrm{fO}-\mathrm{EfO}$ \\
\hline 22. $\mathrm{L}_{1} \mathrm{fO}-\mathrm{EfO}$ & $\begin{array}{l}\text { f0 of the first elbow relative } \\
\text { to the end of willen }\end{array}$ & $\mathrm{L}_{1} \mathrm{fO}-\mathrm{EfO}$ \\
\hline 23. $\mathrm{L}_{2} \mathrm{fO}-\mathrm{EfO}$ & $\begin{array}{l}\mathrm{f} 0 \text { of the second elbow } \\
\text { relative to the end of willen }\end{array}$ & $\mathrm{L}_{2} \mathrm{fO}-\mathrm{EfO}$ \\
\hline
\end{tabular}




\subsection{Results}

\subsubsection{Missing data}

The three-syllable-target words Manderen, Momberen, Memberen and Munderen are pseudo placenames and were difficult for some Chinese speakers of Dutch to pronouce in some test sentences. There are generally four types of error they made, as Table 6.3 shows. Though we trained the Chinese subjects before the recording, there were still 62 $(25.8 \%)$ utterances that could not be used for statistical analysis due to various errors in the target words. More than half $(56.5 \%)$ of these errors were due to incorrect stress on the target words (e.g. Mandéren instead of Mánderen), 35.5\% from incorrect accentuation, either because subjects deaccented the target word or accented the last word of the sentence. The remaining $8 \%$ was made up of to cases of incorrect intonation by the CLDs and CHDs each and three cases of incorrect pronunciation by the CLDs. The choice of three-syllabled words was based on an original interest in the effect of the right-edge word boundary on the timing of the end of the fall, a variable that was later abandoned.

Table 6.3. Absolute (N) and relative (\%) frequency of production errors by Chinese speakers of Dutch with higher proficiency in Dutch (CHD) and lower proficiency (CLD) under broad focus (BF), corrective focus (CF) and narrow focus (NF); PRO= proficiency, WST $=$ wrong stress, WAC $=$ wrong accent, WIN $=$ wrong intonation, $\mathrm{WPR}=$ wrong pronunciation

\begin{tabular}{|c|c|c|c|c|c|c|c|c|c|c|c|}
\hline \multirow[t]{2}{*}{ Focus } & \multirow[t]{2}{*}{ PRO } & \multicolumn{2}{|c|}{ WST } & \multicolumn{2}{|c|}{ WAC } & \multicolumn{2}{|c|}{ WIN } & \multicolumn{2}{|c|}{ WPR } & \multicolumn{2}{|c|}{ sum } \\
\hline & & $\mathrm{N}$ & $\%$ & $\mathrm{~N}$ & $\%$ & $\mathrm{~N}$ & $\%$ & $\mathbf{N}$ & $\%$ & $\mathrm{~N}$ & $\%$ \\
\hline \multirow[t]{2}{*}{$\mathrm{BF}$} & CHD & 2 & 3.2 & 3 & 4.8 & 1 & 1.6 & 0 & 0 & 6 & 9.7 \\
\hline & CLD & 10 & 16.1 & 10 & 16.1 & 1 & 1.6 & 0 & 0 & 21 & 33.9 \\
\hline \multirow[t]{2}{*}{ CF } & $\mathrm{CHD}$ & 4 & 6.5 & 0 & 0 & 0 & 0 & 0 & 0 & 4 & 6.5 \\
\hline & CLD & 4 & 6.5 & 4 & 6.5 & 0 & 0 & 0 & 0 & 8 & 12.9 \\
\hline \multirow[t]{3}{*}{ NF } & CHD & 4 & 6.5 & 0 & 0 & 0 & 0 & 0 & 0 & 4 & 6.5 \\
\hline & CLD & 11 & 11.7 & 5 & 8.1 & 0 & 0 & 3 & 4.8 & 19 & 30.9 \\
\hline & sum & 35 & 56.5 & 22 & 35.5 & 2 & 3.2 & 3 & 4.8 & 62 & 100 \\
\hline
\end{tabular}

One CHD subject mispronounced all the target words under corrective and narrow focus. Of the CLD subjects, one could not pronouce the target words correctly in any focus condition; one could only produce the target words correctly under corrective focus, and one could not 
pronounce them correctly under broad focus. We decided these four subjects from the analysis. Out of the 62 sen missing data, this left 14 sentences with missing data fo participants. We replaced these missing values with the me focus condition concerned.

\subsubsection{Comparing focus effects across groups}

Figure 6.2 shows the average pitch contours in the conditions for the three groups, based on a hundred extracted from the stretch of speech from the onset of the ta the end of the postnuclear word with the help of a Praat timing was expressed relative to $\mathrm{O}_{1}$ and pitch was expressed with reference to the end of the postnuclear word, a low utterance. This enabled us to compare fo across male speakers. The marks in the averaged contours give $t$ boundaries of the target words and the postnuclear words.

We analysed the data with a General Linear Model (GL) (repeated measures ANOVA) for each of the 23 variable focus as the within-subject factor with three levels (i.e., the conditions), and the groups as between-subjects var significance level was set at .05 . When the assumption of $\mathrm{st}$ violated, we reported Huynh-Feldt corrected $p$ values, rath Greenhouse-Geisser correction, which is very conservativ shows the results of the analysis. 


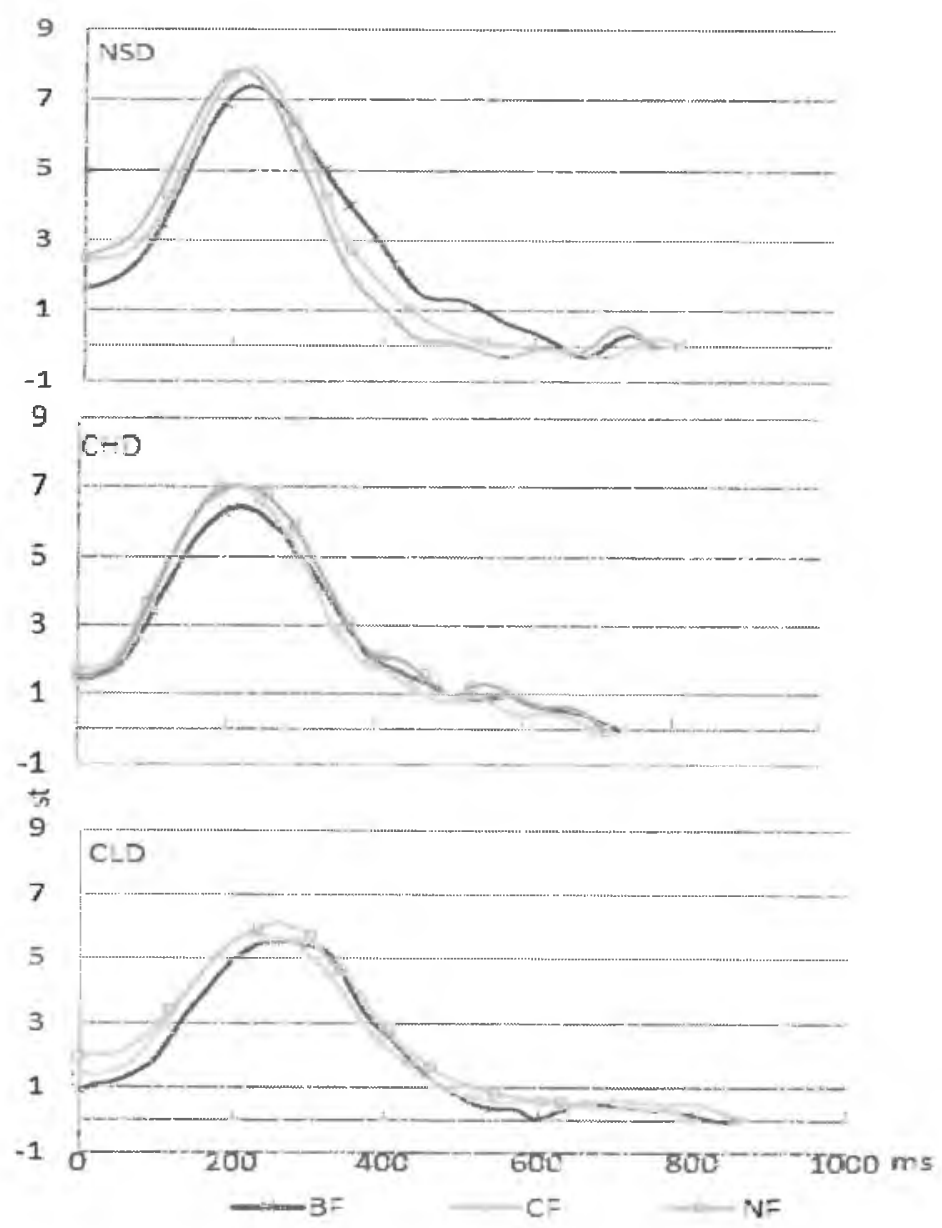

Figure 6.2. Averaged contours for three focus conditions (BF: Broad focus; NF: Narrow Focus; CF: Corrective focus) by native speakers of Standard Dutch (NSD), Chinese speakers of Dutch with higher proficiency (CHD) and Chinese speakers of Dutch with lower proficiency (CLD). The contours are aligned at the onset of the target word and the offset of the next word, willen. Crosses, circles and squares are the segmental boundaries in the target word and the post-nuclear word. f0 (semitones) is expressed relative to the end of the post-target word. 
Table 6.4. Results of RM-ANOVA (* = significant)

\begin{tabular}{|c|c|c|c|c|}
\hline \multirow[t]{2}{*}{$\mathrm{NO}$} & \multirow[t]{2}{*}{ Variable } & \multicolumn{2}{|c|}{ Within groups } & \multirow{2}{*}{$\begin{array}{l}\text { Between } \\
\text { groups }\end{array}$} \\
\hline & & focus & focus $\times$ groups & \\
\hline 1 & Odur & & $*$ & $*$ \\
\hline 2 & Vdur & & & $*$ \\
\hline 3 & Cdur & $*$ & * & * \\
\hline 4 & Rdur & & * & \\
\hline 5 & Sylldur & & & $*$ \\
\hline 6 & Wdur & $*$ & & * \\
\hline 7 & Postwd & * & & $*$ \\
\hline 8 & $\mathrm{O}_{1} \mathrm{Hexc}$ & & & \\
\hline 9 & Fallexc & & & $*$ \\
\hline 10 & $\begin{array}{l}\text { Nucleus } \\
\text { fall exc }\end{array}$ & & * & * \\
\hline 11 & $\mathrm{H}-\mathrm{N}_{2} \mathrm{exc}$ & & & \\
\hline 12 & $\mathrm{H}-\mathrm{N}_{4} \mathrm{exc}$ & & & \\
\hline 13 & $\mathrm{pd}$ & & & $*$ \\
\hline 14 & $\mathrm{Pd} /$ rime & & $*$ & * \\
\hline 15 & Falldur & & $*$ & $*$ \\
\hline 16 & Risedur & & & \\
\hline 17 & Hfo- Efo & & & \\
\hline 18 & $\mathrm{~L}_{1}-\mathrm{Hexc}$ & & & \\
\hline 19 & risesp & & & \\
\hline 20 & fallsp & & & \\
\hline 21 & $\mathrm{O}_{1} \mathrm{fO}-\mathrm{EfO}$ & & & \\
\hline 22 & $\mathrm{~L}_{1} \mathrm{fO}-\mathrm{EfO}$ & & & \\
\hline 23 & $\mathrm{~L}_{2} \mathrm{fO}-\mathrm{Ef0}$ & & & $*$ \\
\hline
\end{tabular}

Since we are interested in the differences in the focus effects groups, we will focus on the significant interactions bet conditions and groups.

\section{Syllable Onset duration}

While the focus condition did not yield significantly diffe within groups $\left(\mathrm{F}[2,68]=2.1, \mathrm{p}>.05, \eta^{2}=.01\right)$, the interact groups and focus condition is significant $(F[4,68]=2.6, \mathrm{p}<$ From broad to narrow and corrective focus, both $\mathrm{L} 2$ grou the onset duration, but L1 speakers increased it by $7 \mathrm{~ms}$ broad to narrow and corrective. There was a main effect for $34]=4.6, \mathrm{p}<.05, \eta^{2}=.20$ ), with Bonferroni multiple showing significantly longer onset duration by CLDs thar 
There are no significant differences between CLDs and NSDs or between CHDs and NSDs.

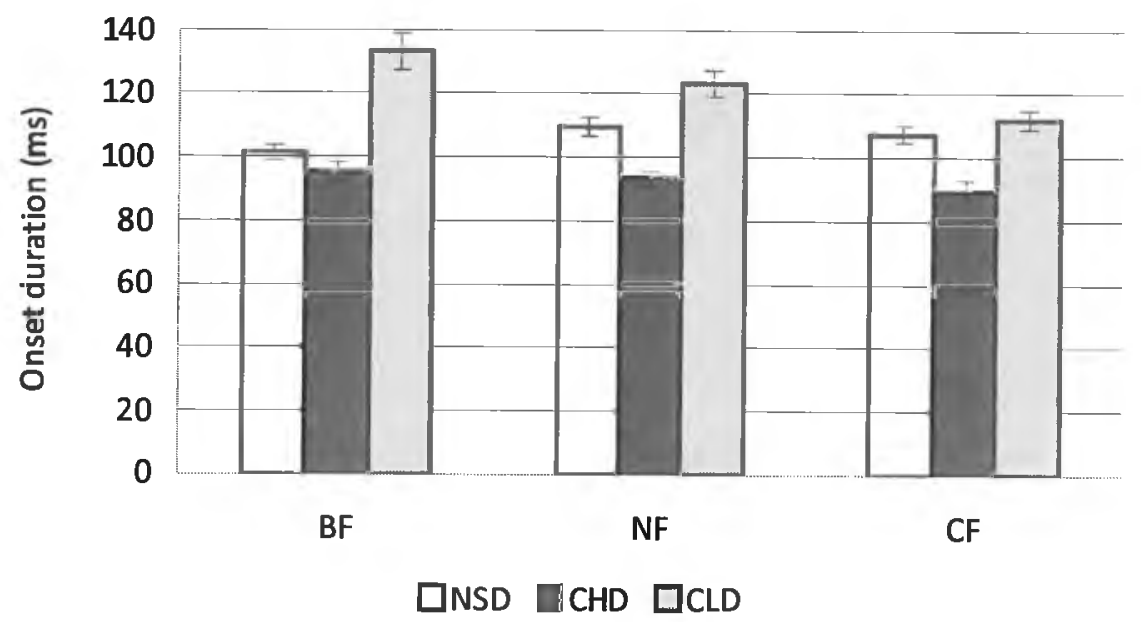

Figure 6.3. The onset duration $(\mathrm{O} 1-\mathrm{V} 1)$ of the accented sjllable in the three focus conditions (BF: Broad focus; NF: Narrow Focus; CF: Corrective focus) by native speakers of Standard Dutch (NSD), Chinese speakers of Dutch with higher proficiency (CHD) and Chinese speakers of Dutch with lower proficiency (CLD).

\section{Coda duration}

A main effect of focus was found $\left(\mathrm{F}[2,68]=3.3, \mathrm{p}<.05, \eta^{2}=.10\right)$ as well as an interaction between group and focus $(\mathrm{F}[4,68]=2.8, \mathrm{p}<.05$, $\left.\eta^{2}=.10\right)$. Both CLDs and NSDs have their longest coda durations under narrow focus and the shortest under corrective focus, but CHDs have longest coda duration under broad focus the shortest coda duration under narrow focus. Between subjects, a main effect of group $(\mathrm{F}[2,34]=$ 8.8, $\mathrm{p}<.01, \eta^{2}=.30$ ) was largely due to the fact that coda durations in the NSDs are significantly longer than those by CHDs and CLDs. No significant differences were found between CHDs and CLDs. 


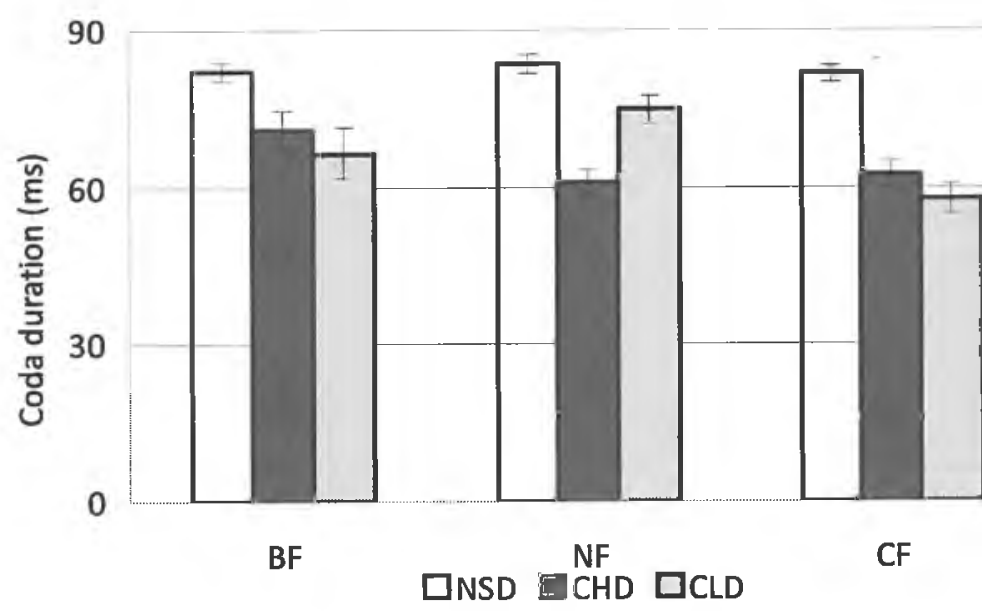

Figure 6.4. The coda duration $(\mathrm{C} 1-\mathrm{O} 2)$ of the accented syllable in th conditions (BF: Broad focus; NF: Narrow focus; CF: Corrective for speakers of Standard Dutch (NSD), Chinese speakers of Dutch with higt (CHD) and Chinese speakers of Dutch with lower proficiency (CLD).

\section{Rime duration}

Focus effects on rime duration are not significant $(F[2,68]=$ $\eta^{2}=.10$ ), but a significant interaction between group anc found $\left(\mathrm{F}[4,68]=3.4, \mathrm{p}<.05, \eta^{2}=.17\right.$. The rime duratio decreased from broad to narrow to corrective focus, a patte neither of the other groups. NSDs have longer rimes in $n$ : but shorter rimes in corrective focus, than in neutral focus narrow focus yielded longer rimes than the other two conditi shortest occurred under broad focus. The differences in $r$ between the three groups are not significant $(F[2,34]=2.6$ $=.13$ ). 


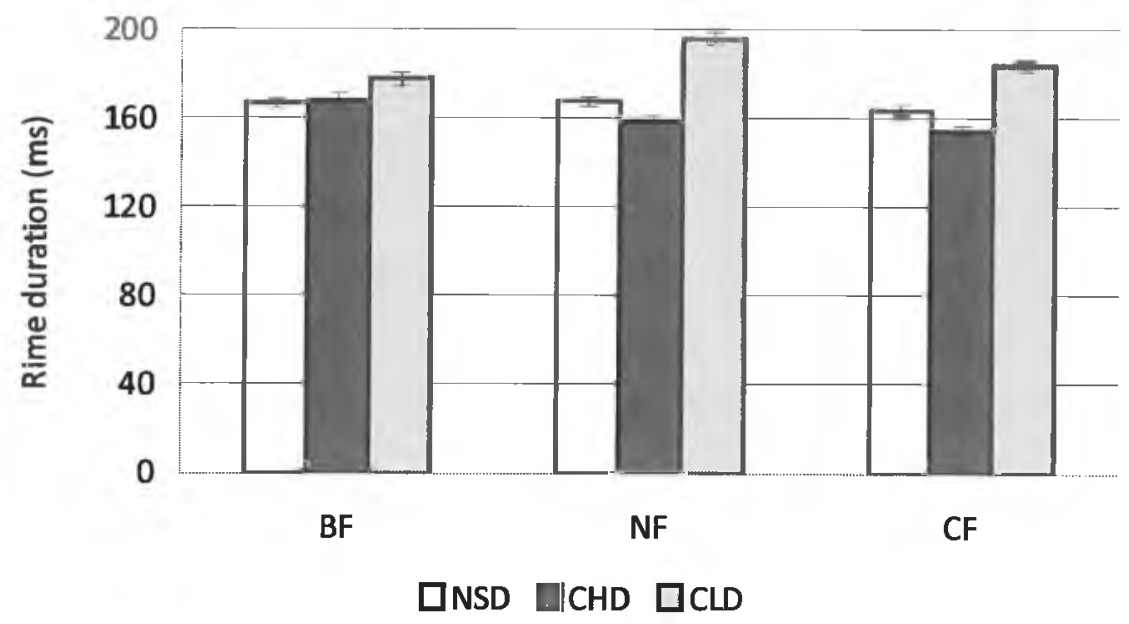

Figure 6.5. The rime duration $(\mathrm{N} 1-\mathrm{O} 2)$ of the accented syllable in the three focus conditions (Broad focus: BF, Narrow focus: NF, Corrective focus: CF) by native speakers of Standard Dutch (NSD), Chinese speakers of Dutch with higher proficiency (CHD) and Chinese speakers of Dutch with lower proficiency (CLD).

\section{Nuclear fall excursion}

Within subjects, the focus effects on nuclear fall excursion are not significant $\left(\mathrm{F}[2,68]=2.4, \mathrm{p}>.05, \eta^{2}=.10\right)$, but the interaction between groups and focus conditions is significant $\left(F[4,68]=3.8, \mathrm{p}<.05, \eta^{2}\right.$ $=.20)$. The nuclear fall excursions by NSDs increased from broad to narrow to corrective focus, but those by CHDs decreased. For CLDs, no regular pattern was found. The differences in the nuclear fall excursion between groups are significant $\left(\mathrm{F}[2,68]=4.7, \mathrm{p}<.05, \eta^{2}=.20\right)$. Multiple comparisons showed that excursions by NSDs were significantly greater than those by CLDs, but those by CHDs did not significantly differ from those of the other groups. 


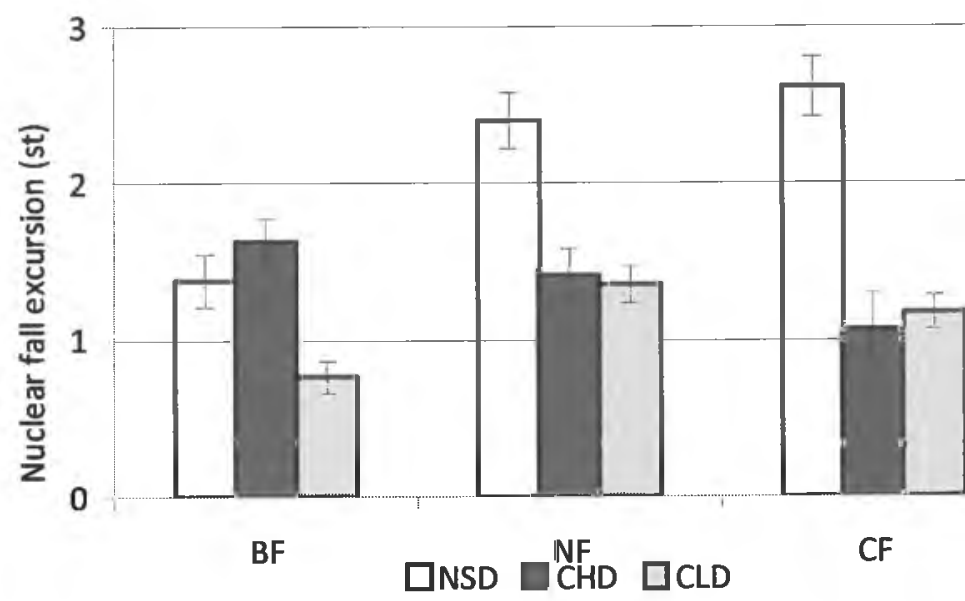

Figure 6.6. The nuclear fall $\mathrm{fO}$ excursion $(\mathrm{H}-\mathrm{O} 2)$ in the three focus $\mathrm{c}$ Broad focus; NF: Narrow focus; CF: Corrective focus) by native speake Dutch (NSD), Chinese speakers of Dutch with higher proficiency (CHD speakers of Dutch with lower proficiency (CLD).

\section{Relative Peak Delay in the rime}

The focus effects on the peak delay relative to the rime insignificant $\left(\mathrm{F}[2,68]=.56, \mathrm{p}>.05, \eta^{2}=.02\right)$, but interaction between group and focus was found $(\mathrm{F}[4,64.7]=$ $\eta^{2}=.20$ ). Relative peak delay decreases from broad to corrective for the NSDs. For CLDs, it is largest under broa smallest under narrow focus, while for CHDs the oppo Overall differences between groups are also significant $(\mathrm{F}[2$, $<.05, \eta^{2}=.20$ ), with CHDs' peak delays being later than the No significant differences were found between CLDs an between NSDs and CLDs. 


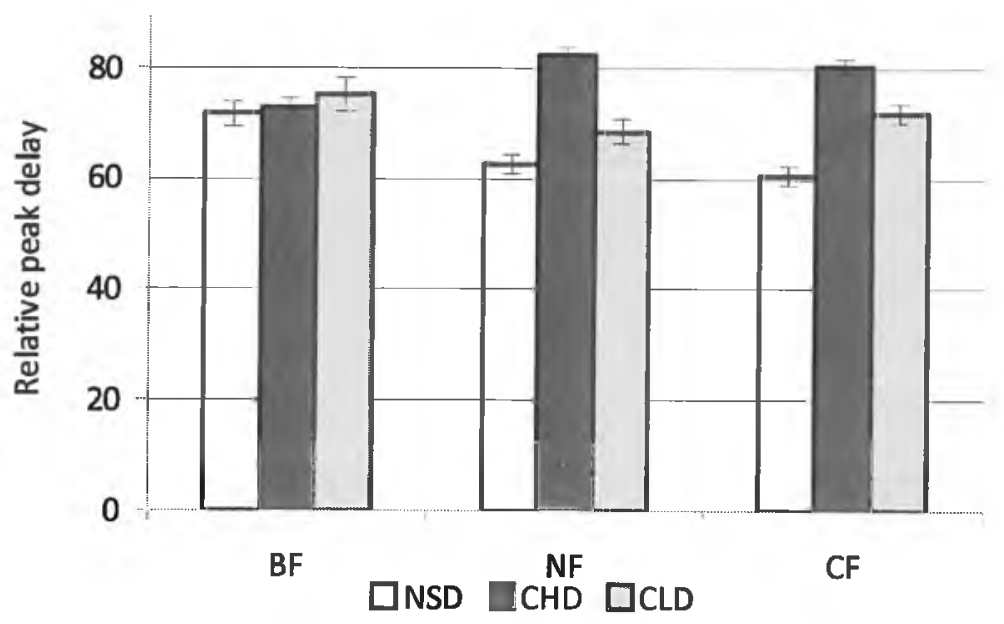

Figure 6.7. Relative peak delay (peak delay from rime onset divided by the rime duration) in three focus conditions (BF: Broad focus; NF: Narrow focus; CF: Corrective focus) by native speakers of Standard Dutch (NSD), Chinese speakers of Dutch with higher proficiency (CHD) and Chinese speakers of Dutch with lower proficiency (CLD).

\section{Fall duration}

No significant effects of focus condition on Fall duration were found $\left(\mathrm{F}[1.4,47.8]=2.8, \mathrm{p}>.05, \eta^{2}=.10\right)$, but a significant interaction was found between group and focus $\left(F[2.8,47.8]=3.8, p<.05, \eta^{2}=.20\right)$. The Fall durations for NSDs decreased from broad to narrow to corrective focus, but neither the CHDs nor the CLDs showed this behaviour. The effect of group is significant $\left(\mathrm{F}[2,34]=3.8, \mathrm{p}<.05, \eta^{2}\right.$ $=.20$ ), but only CHD and NSD differ from each other. 


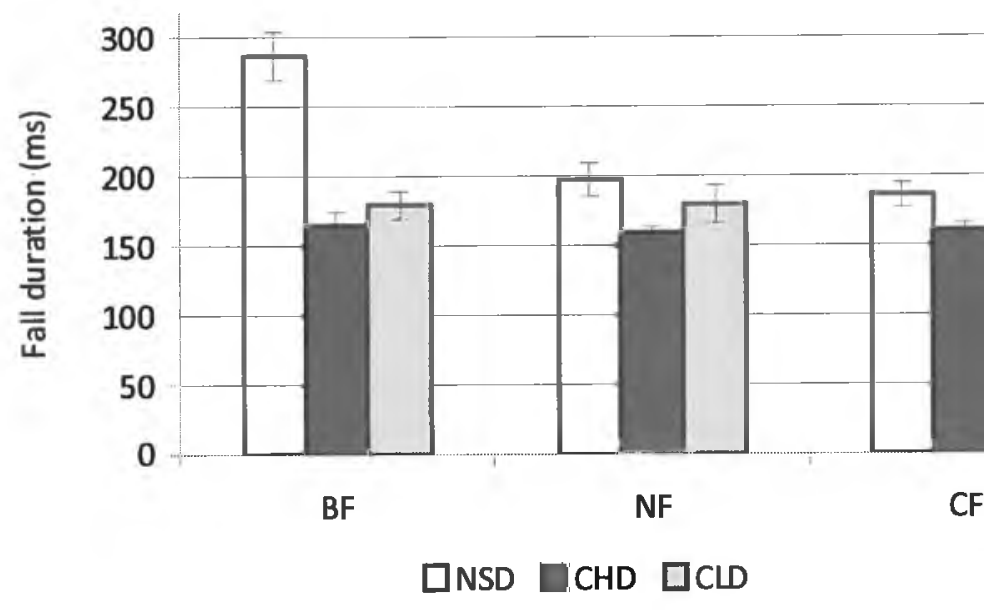

Figure 6.8. The fall duration ( $\mathrm{H}-\mathrm{L} 2)$ in the three focus conditions (BF NF: Narrow focus; CF: Corrective focus) by native speakers of Standard Chinese speakers of Dutch with higher proficiency ( $\mathrm{CHD}$ ) and Chine Dutch with lower proficiency (CLD).

In summary, NSDs increase the onset duration and the excursion going from broad to narrow and corrective fo decrease them, and CLDs decrease the onset duration and nuclear Fall excursion. NSDs additionally decrease both th relative to the rime and the Fall duration in the same series o Neither CHDs nor CLDs show a coherent pattern here. decrease the Fall duration going from broad to the two $n$ conditions The coda duration and the rime duration by NSDs 1 across the focus conditions for the NSDs and CHDs, bu increased these in the narrow informational condition. Rin increase across the three focus conditions in the data for the CHDs cannot be said to have outperformed the CI experiment. In fact, a case could be made that in a numbe CLD behaviour was closer to that of the NSDs. 


\subsection{Discussion}

Overall, these results indicate that the phonetic detail in the realization of $\mathrm{H}^{* \mathrm{~L}}$ falling contours in IP-internal syllables is specific to Standard Dutch. Chinese speakers of Dutch perform pitch falls that resemble the Dutch pitch falls both in shape and approximate timing, but neither the detailed phonetics of these falls nor the systematic variation across different focus conditions match the phonetic patterning of the native speakers. The differences lie in the durations of onset, coda, rime and the fall, in the relative peak delay in the rime and in the $\mathrm{f} 0$ excursions of the nuclear syllable. Summarizing the findings for the native speakers, we find that, going from broad informational via narrow informational to narrow corrective focus, NSDs increase the onset duration, increase the fall excursion, move the beginning of the fall forward and decrease the fall duration. The increase in $\mathrm{fO}$ excursion together with the decrease in fall duration mean that slopes are steeper as the focus is more specific. These findings have parallels in earlier research. Tendencies to lengthen onset consonants under stress have been widely noted (e.g. Huss, 1978; Gussenhoven, 1999, for English). Second, the increase in the excursion of the fall is a commonly reported effect of emphasis and focus. Third, early peak placements under enhancing focus conditions have been reported for other languages (Smiljanic \& Hualde, 2000). Even when peak delay is expressed in absolute distance from the rime beginning rather than in terms of a percentage of the rime duration, the regularity holds for the NSDs (from broad via narrow informational to narrow contrastive the absolute values are 118, 104 and $99 \mathrm{~ms}$ ). Fourth, steeper falls were reported by Hanssen et al. (2008), who interpreted their data as hyper-articulation of the $\mathrm{H} * \mathrm{~L}$ pitch accent. Because the rising movement towards the peak remains unaffected, they took this finding as evidence for the analysis of the pitch peak as due to a $\mathrm{H}^{*} \mathrm{~L}$ pitch accent preceded by a L-tone as opposed for a $\mathrm{LH}^{*}$ pitch accent followed by a L-tone. In the data presented here, the regularity is stronger, with a gradient decrease in Fall duration across the three focus conditions. The NSDs therefore produced higher, earlier and faster Falls, i.e. $\mathrm{H}^{*} \mathrm{~L}$ pitch accents. as the communicative situation demanded greater articulatory precision. One phonetic measure failed to show the same gradient pattern. The NSDs produced the longest coda and rime durations in the intermediate narrow informational condition, and differences with the two other focus conditions were small. This shows that rime lengthening is not necessarily a concomitant of hyper-articulation. Rather, we suggest that it 
can be that the effort to hyper-articulate the fall by making it lead to a shortening not just of the falling pitch movement, the rime on which it was executed. The fine phonetic behavior of the NSDs thus constitutes a coherent set of increase articulatory precision.

By comparison, the Chinese speakers of Dutch displ behaviour. Even though there are many significant differes measures we have chosen, these do not obviously add up to pattern. Perhaps it is best characterized as 'uncertain'. Signifi and Gussenhoven (2008) found that speakers of Standard display regular hyperarticulation responses in a similar task. ' such responses are in part a matter of choice may mear speaking a foreign language, speakers will at first not commi to any specific response. The uncertain patterns, which somewhere in their interlangage system, may contribute to accent.

Although He et al. (2011; also chapter 2) found that our mo group, the CHDs, got better scores in judging the accer including those that are governed by focus, and to be most their choices. The present study shows that the CHDs did n than CLDs in a production test. They failed to produce diffe the native speakers, and in fact the CLDs did better in some the CHDs. This shows that the relationship between pro perception is complex (Llisterri, 1995). Abrahamsson \& (2009) found that early Spanish learners of Swedish wer native speakers as native-like, but that only a few of them native-like and their behaviour under detailed linguistic scr phonetic measures. In our case, only some subjects amon were native-like. Still, it is fair to conclude that the features producing different focus conditions are so detailed that th realization apparently takes a great deal of L2 exposure an before it can be learnt.

The fact that the CLDs did better on some measures than th no ready explanation, other than that these are chance $c$ Possibly, however, the CLDs took the pre-recording trai more seriously, paying more attention to what they had $j$ their reading than did the $\mathrm{CHDs}$. 
Finally, we found more differences than did Hansen at al. (2008) with similar data. As Table 3 shows, focus condition affected the durations of onset, coda, rime and the duration of the fall, the nuclear fall excursion and the peak delay relative to the rime duration. But no significant differences were found in peak height, the two elbows and the speed of Fall and Rise by Hanssen et al. (2008). Our Dutch data included only a single test word from the Dutch corpus, whereas Hanssen et al. used four words with the same stress patterns that inevitably had different segmental compositions. Another difference is that we nomalized f0 relative to the end of the post nuclear stressed word rather than the speaker's final low, as in Hanssen et al. (2008). 


\subsection{References}

Abrahamsson, N. \& Hyltenstam, K. (2009). Age of nativelikeness in a second language: Listener percep linguistic scrutiny. Language Learning, 59, 249-306.

Baumann, S., Becker, J., Grice, M. \& Mücke, D. (2007). articulatory marking of focus in German. Proceedings International Congress of Phonetic Sciences, Saarbrücken, 1029

Boersma, P. \& Weenink, D. (2009). Praat: Doing phonetics (Version 5.1.05) [Computer program]. <http://www.prc Chen, A. \& Destruel, E. (2010). Intonational encoding Toulousian French. Proceedings of Speech Prosody 2010, Chic Chen, Y. (2006). Durational adjustment under correctiv Standard Chinese. Journal of Phonetics, 34, 176-201.

Chen, Y. \& Braun, B. (2006). Prosodic realization of informa categories in Stanadard Chinese. Proceedings of Speech $F$ Dresden.

Chen Y. \& Gussenhoven, C. (2008). Emphasis and tonal imp in Standard Chinese. Journal of Phonetics, 36, 724-746.

Goad, H., White, L. \& Steele, J. (2003). Missing inflec acquisition: Defective syntax or L1-constrained representation? Canadian Journal of L inguistics, 48, 243-26.

Goad, H. \& White, L. (2009). Prosodic transfer and det Turkish-English interlanguage. In N. Snape, Y-k. I. I Sharwood Smith (Eds.), Representational deficits in L2 acqui 26). Amsterdam: John Benjamins.

Greif, M. (2010). Contrastive focus in Mandarin Chinese. Speech Prosody 2010, Chicago.

Gussenhoven, C. (1999). Discreteness and gradience in contrasts. Language and Speech, 42, 283-305.

Gussenhoven, C. (2007). Types of focus in English. In C Gordon \& D. Büring (Eds.), Topic and focus: Cross-linguis on meaning and intonation (pp. 83-100). Dordrecht: Spring

Gussenhoven, C., Rietveld, A., Kerkhoff, J. \& Terken Transcription of Dutch Intonation. 2nd Edition.

$<$ http://todi.let.kun.nl $>$

Hanssen, J., Peters, J. \& Gussenhoven, C. (2008). Prosodi focus in Dutch declaratives. Proceedings of $S p$ 2008, Campiñas, 609-612. 
He, X., van Heuven, V. J. \& Gussenhoven, C. (2011). Choosing the optimal pitch accent location in Dutch by Chinese learners and native listeners. In M. Wrembel, M. Kul \& K. Dziubalska-Kolaczyk (Eds.), Acbievements and perspectives in SLA of speech: New Sounds 2010 (pp. 125-137). Frankfurt am Main: Peter Lang Verlag.

Huss, V. (1978). English word stress in post-nuclear position. Phonetica, $35,86-105$.

Ladd, D.R. (2008). Intonational Phonology. Cambridge: Cambridge University Press.

Jun, S.-A. (1996). The Phonetics and Phonology of Korean Prosody. New York: Garland Publishing.

Lee, Y.-C \& Xu, Y. (2010). Phonetic realization of contrastive focus in Korean. Proceedings of Speech Prosody 2010, Chicago.

Llisterri, J. (1995). Relationships between speech production and speech perception in a second language. Proceedings of the 13th International Congress of Phonetic Sciences, Vol 4, Stockholm, 92-97.

O'Brien, M. \& Gut, U. (2010). Phonological and phonetic realization of different types of focus in L2 speech. In M. Wrembel, M. Kul \& K. Dziubalska-Kolaczyk (Eds.), Acbievements and perspectives in SLA of speecb: New Sounds 2010 (pp. 205-217). Frankfurt am Main: Peter Lang Verlag.

Peng, S., Chan, M. K. M., Tseng, C., Lee, O. J. \& Beckman, M. E. (2005). Towards a Pan-Mandarin prosodic annotation system. In S.-A. Jun (Ed.), Prosodic Typology: The Phonology of Intonation and Pbrasing (pp. 230-270). Oxford: Oxford University Press.

Pierrehumbert, J.E. \& Beckman, M. E. (1998). Japanese Tone Structure. Cambridge MA: MIT Press.

Selkirk, E. \& Tateishi, K. (1991). Syntax and downstep in Japanese. In C. Georgopoulos \& R. Ishihara (Eds.), Interdisciplinary Approaches to Language: Essays in Honor of S-Y Kuroda (pp. 519-544). Dordrecht: Kluwer.

Prévost, A.-E. (2010). Prosodic transfer: an event-related potentials approach. Proceedings of Speech Prosody 2010, Chicago.

Smiljanić, R. \& Hualde, J. I. (2000). Lexical and pragmatic functions of tonal alignment in two varieties of Serbo-Croatian. Cbicago Linguistic Society, 36. Vol 1: The Main Session, 469-482.

Swerts, M. \& Zebian, S. (2010). Intonational differences between L1 and L2 English in South Africa. Pbonetica, 67, 127-146. 
Sityaev, D. \& House, J. (2003). Phonetic and phonological broad, narrow and contrastive focus in English. Proceedi International Congress of Phonetic Sciences, Barcelona, Spain, Ueyama, M. \& Jun, S.-A. (1998). Focus realization in Japar and Korean English intonation, Japanese and Korean Ling 629-645, CSLI. Cambridge University Press.

Wu, W. L. \& Xu, Y. (2010). Prosodic focus in Hong Kon without Post-focus Compression. Proceedings of Speech 1 Chicago.

$\mathrm{Xu}, \mathrm{Y} .(1999)$. Effects of tone and focus on the formation ar of F0 contours. Journal of Phonetics, 27, 55-105.

$\mathrm{Xu}, \mathrm{Y} . \& \mathrm{Xu}, \mathrm{C} . \mathrm{X}$. (2005). Phonetic realization of focus declarative intonation. Journal of Phonetics, 33, 159-197. 


\section{Chapter 7}

\section{Conclusions}

The main contents of this dissertation can be summarized as in Figure 7.1. Two perception experiments (Experiments 1 and 2) and three production experiments (Experiments 3, 4 and 5) were designed to reveal different aspects of the prosody of Mandarin-accented Dutch. The perception experiments and the production experiments are essentially complementary. Initially, there are a number of possible reasons why the prosody of non-native speakers sounds foreign, and the first task therefore is to establish what the foreign accent derives from. The perception experiments in this dissertation therefore address the question whether Chinese learners of English recognize native Dutch prosody as correct, as authentically Dutch, or whether they cannot tell the difference between a correct and an incorrect prosodic structure. If native Dutch utterances do not strike the Chinese learners as different from Dutch utterances with inappropriate or evidently incorrect prosody, then we cannot expect that their production will be correct. However, if the learners appear to be able to tell correct and incorrect prosodic structures apart, any inability on their part to produce correct prosody must be attributed to an inability to produce phonetically realistic renderings of those prosodic structures. Practically, the first situation would call for a training course in which learners are exposed more to Dutch prosody in context, in the second situation they will need phonetic tuition.

The production experiments were of two kinds. Experiment 3 investigated the extent to which Mandarin speakers of Dutch were able to choose the right melodic contour in a limited number of idiomatic sentence types. This experiment tests their knowledge of the usage of intonation contours in a production task. Experiments 1,2 and 3 thus together concern the assessment of semantic and morphological knowledge of Dutch intonation by Mandarin Chinese L1 speakers of the langirage. The other two experiments addressed their ability to execute the pitch movements of Dutch. Independently of whether learners know what prosodic 
structure to use in a given situation, their production of thos may be more or less foreign. The question addressed in ex and 5 is to what extent Chinese learners of Dutch are able the phonetic features of Dutch intonation. For instance, do pitch falls in the same way as native speakers do? And do the pronunciation of a pitch fall in the same way as native spe they speak with more emphasis, or when the fall is executed of the utterance? So rather than studying the competence learners in their morphological contour choices, in these exp are interested in their competence in the phonetic realizati contours.

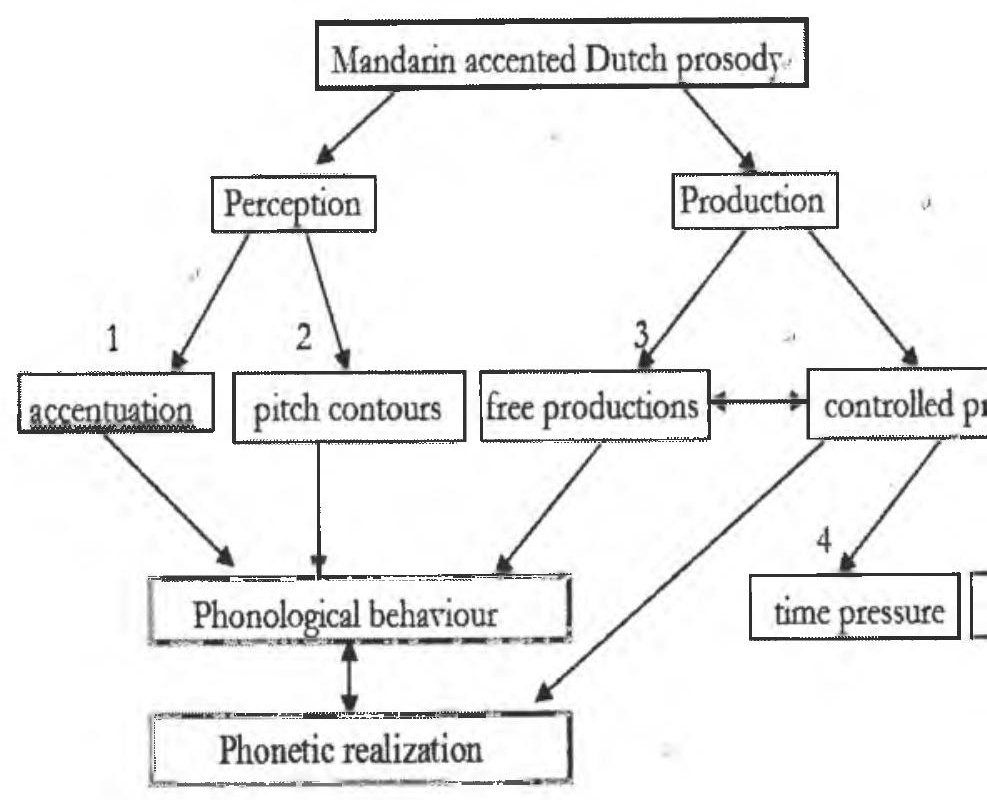

Figure 7.1: Mandarin-accented Dutch prosody was investigated in th through perception experiments addressing Mandarin L1 speakers' knc appropriateness of the location and type of pitch accents (accentua contours), through a production experiment that tested their knowledge idioms, and two production experiments investigating the phonetic fo pitch contours.

The first perception experiment was conducted to see how learners of Dutch identify the correct accentuation patterns gories of Dutch sentences. Thirty-six stimuli ( 6 sentences $x$ were presented to 20 Dutch native listeners (NSD) and $20 \mathrm{C}$ 
ers of Dutch as a second language (CSD). In this forced-choice task, listeners had to decide whether one of two versions of each sentence was pronounced with optimal prosody, and to indicate how confident they were about their choice on a five-point scale. Per test item only one accent placement was prosodically optimal ('correct'), as determined prior to the test by a panel of Dutch intonologists. Subjects only judged one version.

NSDs' correctness scores were significantly higher than those by the Chinese learners with high proficiency in Dutch (CHD), and the correctness scores of the latter were significantly higher than those obtained for the low-proficiency learners (CLD). Along with the correctness scores, confidence ratings decreased from NSDs to CHDs to CLDs. The results show that Chinese learners of English have imperfect knowledge of where the pitch accents should be located in Dutch sentences, and that they are aware of this lack of knowledge, because of their lower confidence scores. It was found that accentuation for new information is easier to evaluate for Chinese listeners than accentuations due to morphological rules.

The second perception experiment was designed to explore to what extent Chinese learners of Dutch are able to identify the most appropriate intonation contour for sentences in context, where 'appropriate' is defined as the choice made by a large majority of native speakers. We presented the subjects with 26 written sentences in the order they came in a story. Subjects were given a choice from four intonation contours, which differed per sentence. In each case, they were instructed to select the most appropriate intonation contour for the sentence in a forced choice task. The results show that the Chinese subjects selected the most appropriate version less often than the native speakers did, that their selections from the three less appropriate competitors were more chaotic than those of the control group, and that the performance by the CHDs was closer to that of the native speakers than the performance by the CLDs. The assignment of an intonation contour to a contextualized sentence is argued to be a precisely defined, if little understood part of the linguistic competence of native speakers of Dutch, which is only very partly present in Chinese learners. Our search for any alternative strategies the Chinese subjects might have used led to the identification of a policy to assign rising contours to orthographic sentences closed by a question mark and falling contours to sentences closed by a full stop, a 
comma or an exclamation mark. In addition, we found that avoided choosing intonation contours ending in downste pitch or a falling-rising pitch, which we interpreted as $c$ strategy of favouring pitch contours that resemble Chinese 1 The general acquisition profile follows findings in oth linguistic competence in that their performance correlated arrival (AOA), not with either age or length of time they $h$ posed to Dutch. As far as we are aware, this is the firs investigation of L2 learners' competence in melody selection.

Experiment 3 was designed to study the melodic choices in based on seven sets of sentences composed so as to elicit par contours. Each of these seven sets of sentences rep intonational 'idiom', meaning that typically only one pitch available for them. For example, a sentence ending in the pa have a $\mathrm{H}^{*} \mathrm{~L} \mathrm{H} \%$ contour on the last accented syllable. A c readings of these $(6 \times 7 \Rightarrow) 42$ sentences by a small group 0 speakers of Standard Dutch is established as the baseline 'correct' contours are. 'Errors' by Chinese readers were we when the consensus was higher in the Dutch group.

The Chinese subjects chose an appropriate intonation cont of these seven structures to some degree. They had fewer pr wat-exclamations and alternative questions, for which falls are used in Standard Dutch. The more difficult structures a with toch in the sense of 'self-evidence', sentences with echt, echt zo goedkoop?, reporting clauses and vocative chants. Chir did better in choosing optimal contours for the type of ser particles boor or bè than for the questions with toch, even $t$ three cases the same fall-rise intonation contour is to be use they found the fall-rise harder to produce than the fall a Chinese speakers of Dutch with low proficiency made signif nuclear pitch accent errors and boundary errors than the jects with high proficiency, and the Chinese subjects wit ficiency made significantly more boundary errors than the 1 ers. These production data were analysed in terms of a additional features. First, we found that the Chinese speake produced more IPs than the native speakers. Moreover, w Chinese speakers of Dutch paused more often than the nat 
but the durations of the pauses were not significantly different. Third, speech rate and articulation rate of the Chinese speakers with lower proficiency in Dutch were significantly slower than their counterparts with high proficiency and the native speakers. The native speakers' nPVI (normalised Pairwise Variability Index, for which low values indicate that the speech is relatively 'staccato') was significantly larger than those of the Chinese speakers and the nPVI of the Chinese speakers with higher proficiency in Dutch was significantly larger than the Chinese speakers of Dutch with lower proficiency. Also, the Chinese speakers with lower proficiency have significantly more prenuclear pitch accents than their counterparts with higher proficiency and the native speakers. The Chinese speakers of Dutch with higher proficiency in fact accented the sentences in a similar way as the native speakers, although they do sometimes accent function words expressing given information. It was striking that some Chinese subjects, both in the higher and lower proficiency groups, incorrectly placed pitch accents on the second component of compound words.

Experiment 4 was designed to study how Chinese speakers of Dutch (CSD) produced three Dutch pitch contours $(\mathrm{H} * \mathrm{~L} \mathrm{~L} \%$; L*H H\%; H*L $\mathrm{H} \%$ ) under time pressure, that is, when segmental material on which the pitch contours are to be produced is in short supply. Increasing degrees of time pressure were created by placing the four Dutch monosyllabic proper names Loom, Lom, Loof and Lof in final position in the IP (intonational phrase). These words vary in the duration of the sonorant portion of the rime, because the vowels have phonologically different lengths and because of the variation in the sonorant status of the coda $(/ \mathrm{f} /$ and $/ \mathrm{m} /$ ). These test words were embedded in three short carrier sentences, a declarative with narrow-information focus, a yes-no question, and a rhetorical question with corrective focus, so as to elicit three nuclear intonation contours, the Fall, the Rise and the Fall-rise. Unlike less proficient Chinese learners of Dutch, more advanced learners produce Rises and Falls much the way native speakers do. As sonorant rimes are shorter, these contours are compressed by native speakers and by the more proficient learners in the group of Chinese subjects. The detailed patterning of these adjustments is not exactly the same, however. In particular, in the case of the Fall, NSD end the fall for Lom earlier than in the longer Loom. In these data, the striking findings are that the lower proficiency group does not follow the pattern of NSD in any respect except that Lom, Loom have later falls than Lof, Loof. This suggests that, 
to them, there is no distinction between the long and sho Dutch. In fact, all CHDs, but not the CLDs, were able to pr short and the long vowels correctly in the three sentence suggests that the CLDs made no quantity difference. Genera tions of the sonorant rimes by CLDs were longer than the co ones by the native speakers and also longer than the corresp by CHDs except for Loof in the Fall and the Rise. Fin Chinese subgroup managed to reproduce the behaviour of realization of the Fall-rise, which reflects the fact that no occurs on single syllables in their native language. No pitch ences were found between the three groups.

In Experiment 5, we studied the impact of different types position of target word on the falling intonation $(\mathrm{H} * \mathrm{~L} \mathrm{~L} \%$ a Three sets of Dutch declaratives were used to elicit broad, narrow corrective focus conditions. Each set had four targe pseudo-place names Manderen, Momberen, Memberen and Mun 23 potentially sensitive phonetic measures were found to hav effects. These variables are the durations of the onset, the ris of the accented syllable, the duration of the fall, the fo exct fall and the time alignment of the f0 peak. The participants proficiency did not outperform those with lower proficienc the phonetic realization of focus conditions should be learn ing this is more difficult than learning how to accent fo instance. The features investigated in Experiment 5 are sub bably fall below a level of perception that would be reach ception experiment with native speakers.

Chinese speakers of Dutch have some linguistic knowledge accentuation and intonation. They can choose certain pitch contours to express themselves according to textual conter the Chinese speakers of Dutch and the native speakers phonologically and phonetically in their read speech. More $\mathrm{p}$ more pauses in IPs, lower speech and articulation rate, anc wise Variability Indices. In the phonetic realization of intona as investigated in Experiments 4 and 5, differences in spec variables between the groups were found. These would have if Chinese learners of Dutch are to speak the language in native speakers speak, but it must be remembered that th effect of this phonetic knowledge is likely to be low. 
As summarized above, this dissertation mainly describes the prosodic features of Mandarin-accented Dutch phonologically and phonetically. Further research can be done on a number of topics.

Firstly, the Chinese speakers of Dutch, regardless of their proficiency level, have problems with the morphological rules in Dutch, because they cannot identify the correct accentuation in the sentences in Experiment 1 or put the pitch accent appropriately on certain words of everyday Dutch in Experiment 3. This leaves ample room for language teaching in a linguistic environment in which Chinese, a tone language, is used as the first language.

Secondly, some pitch contours, like the fall-rise, the half fall and the high rise are difficult to produce for Chinese speakers of Dutch. The question how to teach leamers to choose pitch contours on the basis of the syntactic structure and their meaning of the sentences in context, and how to teach them to produce these correctly is of great importance. Although the pedagogical issue was never really touched on in this dissertation, we have speculated on the reasons why certain structures are difficult for the Chinese speakers of Dutch.

Thirdly, as there are more prenuclear pitch accents in the Dutch of Chinese speakers than in the speech of native speakers, it is worthwhile to study their phonetic realization, as well as to devise training material for the production of unaccented stretches of speech.

Fourthly, the materials on which the dissertation is based all represent scripted speech, and speech style may affect the prosody. In future studies, we could study Chinese speakers' Dutch prosody in spontaneous speech and find the prosodic differences between the speech styles.

Last but not least, not all of the theories and models in phonological acquisition which were discussed in the first chapter were called upon in the explanation of the results of the five experiments. Most of them are concerned with the acquisition of phonemes or phonetic segments and this dissertation generally focused on sentence accent and intonation. It is difficult to apply them therefore to explain the experiment results directly. In addition, these theories or models concern issues of transfer, markedness and age. Age was touched upon in the discussion of the perception experiments, but not in the production experiments, due to the 
lack of variation in age in those groups, making any divisi groups for statistical analyses hard. We did establish that thos to the Netherlands earlier (Age of Arrival, or AOA) had levels in Dutch, see Chapter 2 \& 3), and evidently AOA portant role in the participants' behaviour in the experi dissertation has focused on the description of the features of of Mandarin-accented Dutch against a background of pros and theories in second language acquisition. Transfer or th was noted whenever we found data that enabled us to do case of the non-transfer of phonetic enhancement for emph ment 5). A more systematic evaluation of these latter theorie results will have to await future study. 


\section{Samenvatting}

Het Mandarijn (of: Standaard Chinees) is met zijn 1,25 miljard sprekers een van de meest gebruikte talen op aarde. Het is een toontaal waarin vier lexicale tonen (vier verschillende woordmelodieën) worden gebruikt om woorden van elkaar te laten verschillen. Het Nederlands heeft geen woordtonen, maar gebruikt verschillen in melodie om verschillende pragmatische betekenissen te onderscheiden op het niveau van de zin. Er is op dit moment nog weinig bekend over de moeilijkheden die sprekers met een toontaalachtergrond (zoals Mandarijn) ondervinden als zij een tweede of vreemde taal moeten verwerven zonder woordtonen maar met veel verschillende zinsmelodieën met pragmatische betekenissen (zoals het Nederlands). Dit proefschrift is bedoeld als een eerste poging om deze lacune in onze kennis op te vullen.

Dit proefschrift geeft op hoofdlijnen een fonetische en fonologische beschrijving van de prosodische eigenschappen van Nederlands gesproken met een Chinees accent. Het omvat twee perceptie-experimenten (Experiment $1 \& 2$ ) en drie productie-experimenten (Experiment $3,4 \& 5)$ die zijn afgenomen met het doel verschillende aspecten bloot te leggen van de prosodie van Nederlands gesproken met een Chinees accent. Er waren twee soorten productie-experimenten. Experiment 3 onderzocht de mate waarin Mandarijnsprekers van het Nederlands is staat waren de juiste melodische contour te kiezen bij een beperkt aantal idiomatische zinstypen. Dit experiment test hun gebruikskennis van intonatiecontouren in een productietaak. Op deze manier vormen de twee perceptie-experimenten en Experiment 3 samen een poging om de semantische en morfologische kennis van de Nederlandse zinsmelodie vast te stellen bij Nederlandssprekenden met Mandarijn als moedertaal. Experimenten 4 \& 5 richtten zich op het vermogen bij deze sprekers om de toonhoogtebewegingen van het Nederlands te maken. Ongeacht de vraag of leerders weten welke prosodische structuur ze in een gegeven situatie moeten gebruiken, kan hun productie van deze structuren in meerdere of mindere mate buitenlands klinken. De vraag die in experimenten 4 en 5 wordt gesteld is hoe goed Chinese leerders van het 
Nederlands de fonetische kenmerken van de Nederland kunnen produceren. Ik onderzocht hier dus niet hun beheer Nederlands op basis van hun keuze voor een specifieke melc hoeverre zij de fonetische realisatie van specifieke toonhoog beheersen.

De productie- en perceptie-experimenten zijn complemen een aantal redenen aan te wijzen waarom de prosodie van $t$ taalsprekers buitenlands klinkt. De eerste taak is daarom va waardoor het buitenlandse accent wordt veroorzaakt. De per rimenten richten zich op de vraag of Chinese leerde Nederlands de prosodie van moedertaalsprekers van het Ne correct herkennen, d.w.z. als authentiek Nederlands, dan w correcte en een incorrecte prosodische structuur niet uit el houden. Als Nederlandse spraakuitingen van moedertaalsp oren van Chinese leerders even goed klinken als Nederlar uitingen met minder geslaagde of zelfs apert foute prosodie, we niet verwachten dat hun productie correct zal zijn. Als de leerders wél in staat blijken correcte en foute structuren houden, dan moet hun onvermogen om correcte prosodisch te produceren worden toegeschreven aan een onvermogen o authentieke weergaven van deze prosodische structuren voor In de onderwijspraktijk zou her eerste scenario onderwijs ve leerders worden blootgesteld aan veel Nederlandse prosodi in de tweede situatie hebben de leerders vooral behoefte a onderricht.

Twintig Chinese sprekers van het Nederlands namen deel aa experimenten. Daarnaast namen 20 moedertaalsprekers va daardnederlands deel aan de twee perceptie-experimenten. spraak van vijf moedertaalsprekers van het Standaardneder als ijkpuntwaartegen de prestaties van de niet-moedertaalspr periment 3 konden worden afgezet. De data in Experime werden afgeleid van het corpus Standaardnederlands (Proje Variëteiten van bet Nederlands) aan het CLS (Centre for Langl van de Radboud Universiteit Nijmegen. Alle Chinese de mannen, 17 vrouwen, met leeftijden tussen 17 en 53 jaar), dertaalsprekers van het Mandarijn en afkomstig uit het no van China. Allen hadden voldoende Nederlands geleerd om rimenten te kunnen deelnemen. $\mathrm{Zij}$ werden door drie $\mathrm{Nec}$ 
perts ingedeeld in een groep met een relatief hoge beheersingsgraad van het Nederlands $(\mathrm{CHN})$ of een met een relatief lage beheersing van het Nederlands (CLN) aan de hand van hun uitspraak en prosodie in een aantal voorgelezen spraakfragmenten. De Nederlandse deelnemers waren naar eigen zeggen moedertaalsprekers van het Standaardnederlands in de leeftijd van 18 tot 54 jaar.

\section{Experiment 1}

Het eerste experiment is een perceptieproef dat is uitgevoerd om na te gaan hoe goed Chinese leerders van het Nederlands de correcte accentuering kunnen vaststellen in zes typen Nederlandse zinnen. Zesendertig stimuli ( 6 zinnen $\times 6$ categorieën) werden voorgelegd aan 20 moedertaalluisteraars van het Nederlands (NT1) en 20 Chinese leerders van het Nederlands als tweede taal (NT2). In deze gedwongen-keuzetaak moesten de luisteraars beslissen welke van twee versies van elke zin was uitgesproken met optimale prosodie en op een vijfpunt-schaal aangeven hoe zeker zij waren van hun keuze. Voor ieder testitem was maar één accentplaatsing prosodisch optimaal ('correct'), zoals eerder vastgesteld door een panel van Nederlandse intonologen. Elke proefpersoon beoordeelde slechts één versie van elke zin.

De correctheidsscores van de NT1 luisteraars lagen significant hoger dan die van de Chinese leerders met hoge beheersingsgraad van het Nederlands (CHN) en de correctheidsscores van deze groep lagen weer significant hoger dan die van de leerders met een lagere beheersingsgraad (CLN). Parallel aan de correctheidsscores liepen ook de zekerheidsscores af van NT1 via CHN naar CLN. De resultaten tonen aan dat Chinese leerders van het Nederlands een gebrekkige kennis bezitten van waar de toonhoogteaccenten in Nederlandse zinnen moeten liggen en zich bewust zijn van de mate van dat kennisgebrek (wat immers blijkt uit hun lagere zekerheidsscores). Een tweede bevinding was dat het accentueren van nieuwe informatie gemakkelijker te beoordelen was voor de Chinese luisteraars dan accentuering op grond van morfologische regels. 


\section{Experiment 2}

Experiment 2 was opgezet om na te gaan in hoeverre Chin van het Nederlands in staat zijn om de meest toepasselijk contour te kiezen voor zinnen in context, waar 'toepasselijk' is als de keus van de grote meerderheid van de moedertaals boden de proefpersonen 26 geschreven zinnen aan in de volg die in een verhaal voorkwamen. De proefpersonen hadder keus uit vier intonatiecontouren, die per zin verschilden. I was steeds om de meest toepasselijke intonatiecontour te sel gedwongen keuzen uit de vier voorgegeven mogelijkheden). ten wijzen uit dat de Chinese proefpersonen de meest toepas minder vaak kozen dan de moedertaalluisteraars, dat hun 1 drie minder toepasselijke contouren chaotischer was bij de cc en dat de prestaties van de CHN-groep dichter lagen bij moedertaalluisteraars dan het geval was bij de prestaties va groep. Mijn stelling is dat de toewijzing van een intonatiecon zin in context een precies gedefinieerd, zij het nog slecht be derdeel is van de taalcompetentie van moedertaalsprekers var lands en dat dit vermogen slechts in zeer beperkte mate aar Chinese leerders. Aanvullende pogingen om alternatieve st het spoor te komen die de Chinese proefpersonen zouden 1 nen gebruiken bracht aan het licht dat deze systematis melodieën toewijzen aan zinnen die in hun geschreven vorr worden met een vraagteken, en dalende melodieën aan zi papier eindigen met een punt, komma of uitroepteken. $I$ vinden we dat de Chinese deelnemers over de gehele lin contouren schuwden die eindigden met gedownstepte toon gen of met een stijging-dalingcontour. Wij interpreteren dez dens als een strategie die de voorkeur geeft aan toonhoogtec overeenkomen met Chinese woordtonen. Het algemene taal profiel komt overeen met wat gevonden is bij andere gebiec beheersing. Zo correleerde het prestatieniveau met de leef komst in Nederland, maar niet met de kalenderleeftijd van sonen of met de tijd die zij al waren blootgesteld aan Ned anbod. Voor zover wij hebben kunnen nagaan is dit het ee tische onderzoek naar de rol van de beheersingsgraad van de/vreemde taal) bij de selectie van zinsmelodieën. 


\section{Experiment 3}

Experiment 3 was opgezet om de melodische keuzes te onderzoeken in de spraakproductie aan de hand van zeven groepen zinnen die erop gericht waren om specifieke toonhoogtecontouren te ontlokken aan de proefpersonen. Elk van die zeven groepen zinnen vertegenwoordigde een intonationeel 'idioom', wat inhoudt dat per set slechts één specifieke toonhoogtecontour in aanmerking komt. Bij voorbeeld, een zin die eindigt met het partikel bè zal een $\mathrm{H}^{*} \mathrm{~L} \mathrm{H} \%$ contour hebben op de laatste geaccentueerde lettergreep. Een corpus van voorgelezen realisaties van deze $(6 \times 7=42$ zinnen door vijf moedertaalsprekers van het Standaardnederlands werd gebruikt om vast te stellen wat de 'correcte' contouren zijn. 'Fouten' die gemakkt waren door de Chinese lezers werden zwaarder meegewogen naar mate de consensus bij de Nederlandse groep hoger was.

De Chinese proefpersonen slaagden er tot op zekere hoogte in een passende intonatiecontour bij een aantal van de zeven zinnen te kiezen. Zij hadden relatief weinig moeite met wat-uitroepen en met alternatieve vragen, voor welke zinstypen het Standaardnederlands hele of halve dalingen gebruikt. Moeilijker structuren zijn vragen met toch (zoals in de reclameslagzin $I k$ ben toch niet gek:), zinnen met echt, als in Was bet echt qo goedkoop?, en in zinsdelen volgend op stukken directe rede en in de roeptoon (vocative chant). Chinese proefpersonen presteerden beter als zij optmale contouren moesten kiezen bij zinstypen die eindigden op de partikels hoor of bè dan bij vragen die eindigden op toch, ook al zou in alle drie deze gevallen dezelfde daling-stijging contour gebruikt moeten worden. Algemeen gesproken vonden zij de daling-stijging contour moeilijker dan een daling of een stijging alleen. Chinese sprekers van het Nederlands met een relatief lage beheersingsgraad maakten significant meer fouten bij nucleaire toonhoogteaccenten en grenstonen dan de Chinese proefpersonen met een hogere beheersingsgraad, en deze produceerden weer significant meer fouten bij de grenstonen dan de moedertaalsprekers. Deze productiedata zijn gebruikt om aanvullende vragen over de uitspraak van Chinese sprekers van het Nederlands te onderzoeken. Allereerst vonden we dat de Chinese sprekers van het Nederlands meer Intonatiefrases (IP's) produceerden dan de moedertaalsprekers. Ten tweede maakten de Chinese sprekers van het Nederlands hinnen de IP's meer en vaker pauzes dan de moedertaalsprekers, al waren de duren van deze pauzes niet significant verschillend. Ten derde, de spreeksnelheid en 
de articulatiesnelheid van de Chinese sprekers met een lage graad (CLN) in het Nederlands lagen significant lager dan kers met een hoge beheersingsgraad van het Nederlands (C) de moedertaalsprekers. Bij de moedertaalsprekers was de $\mathrm{nP}$ sed Painvise Variability Index, waarvoor geldt dat lage waard dat de spraak relatief 'staccato' is) significant groter dan bij sprekers en de nPVI bij de CHN-groep was weer significan bij de CLN-groep. Ook maakten de CLN-sprekers significar nucleaire toonhoogteaccenten dan de CHN-groep en de controlegroep. Over het algemeen accentueerden de $\mathrm{CHN}$. zinnen vrijwel op dezelfde manier als de moedertaalspreker: zij af en toe een accent legden op een functiewoord of eer gegeven informatie uitdrukt. Het was opvallend dat somm proefpersonen, zowel in de CHN-groep als in de CLN-gro keerd toonhoogteaccent plaatsten op het tweede deel van sa woorden.

\section{Experiment 4}

Experiment 4 had tot doel om na te gaan hoe Chinese spre Nederlands drie Nederlandse toonhoogtecontouren ( $\mathrm{H}^{*} \mathrm{~L} L$, $\mathrm{H}^{*} \mathrm{~L} \mathrm{H} \%$ ) produceerden onder tijdsdruk, d.w.z. als segment waarop de toonhoogtecontouren moeten worden geproduc beperkt voorhanden is. Oplopende graden van tijdsdruk w eerd door vier eenlettergrepige Nederlandse eigennamen Loo and $L$ of in de eindpositie van een Intonatiefrase (IP) op te $r$ namen variëren in de duur van het sonorante rijm van de omdat de klinkers fonologisch verschillende duren hebben coda's verschillen in sonorantie $(/ \mathrm{m} /$ is sonorant maar $/ \mathrm{f} /$ testwoorden werden ingebed in drie korte draagzinnen, een zin met verengd informatiefocus, een ja-neevraag en een retc met correctief focus, ten einde drie nucleaire intonatiec ontlokken: de daling, de stijging en de daling-stijging. In teg de CLN-sprekers produceerden de CHN-sprekers stijgingen veelal op dezelfde manier als de moedertaalsprekers. Naarm rante rijmdelen korter zijn, worden deze contouren in de samengedrukt door zowel de moedertaalsprekers als de $\mathrm{CH}$ De vormaanpassingen zijn echter niet tot in alle details hetze twee groepen. Zo laten de moedertaalsprekers de daling late Lom dan in het langere Loom. Een opvallend resultaat is c 
groep in geen enkel opzicht het patroon volgt van de moedertaalsprekers behalve dat Lom en Loom latere dalingen hebben dan Lof en Loof. Dit suggereert dat er, voor deze sprekers, geen verschil is tussen de lange en de korte klinkers van het Nederlands. Alle CHN-sprekers, maar niet de CLN-sprekers, waren in staat de korte en lange klinkers correct uit te spreken in de drie zinstypen. De CLN-sprekers maken dus geen fonologisch duuronderscheid. Meer in het algemeen waren de duren van de sonorante rijmdelen bij de CLN-sprekers langer dan bij de moedertaalsprekers en ook langer dan bij de CHN-sprekers, met uitzondering van Loof in de daling en in de stijging. Ten slotte bleek geen van de twee Chinese sprekergroepen in staat het gedrag van de moedertaalsprekers te reproduceren bij de realisatie van de daling-stijging, wat het feit weerspiegelt dat dit patroon niet kan voorkomen op één enkele lettergreep in hun moedertaal. Tussen de drie sprekergroepen zijn geen verschillen gevonden in toonbereik, het verschil tussen hoogste en laagste toon.

\section{Experiment 5}

In Experiment 5 bestudeerden we het effect van verschillende typen focus en van positie van het doelwoord op dalende zinsmelodieën $\left(\mathrm{H}^{*} \mathrm{~L}\right.$ $\mathrm{L} \%$ and $\mathrm{H}^{*} \mathrm{~L} \%$ ). Drie groepen Nederlands declaratieve zinnen werden gebruikt in brede, verengde en verengd-correctieve focuscondities. Elke groep bevatte vier doelwoorden, namelijk de pseudo-plaatsnamen Manderen, Momberen, Memberen en Munderen. Zes van 23 potentieel gevoelige fonetische maten bleken significante effecten op te leveren. Deze maten zijn de duren van de onset, het rijm en de coda van de geaccentueerde lettergreep, de duur van de daling, de fo excursie van de daling en de segmentele oplijning van de f0-piek. De CHN-sprekers deden het niet beter dan de CLN-groep. Duidelijk is dat de fonetische realisatie van focuscondities geleerd moet worden en dat dit moeilijker is dan, bij voorbeeld, leren om gegeven referenten niet te accentueren. De kenmerken die in Experiment 5 onderzocht zijn, zijn subtiel en blijven waarschijnlijk onder de perceptieve drempel van moedertaalsprekers.

Chinese sprekers van het Nederlands hebben al met al enige taalkundige kennis van zinsaccentuering en intonatie. Zij kunnen bepaalde toonhoogteaccenten en contouren kiezen om zich daarmee binnen context passend uit te drukken. Niettemin verschillen de Chinese sprekers van het Nederlands en de moedertaalsprekers zowel fonologisch als fonetisch in hun voorleesspraak. De scores die de (Mandarijn-) Chinese 
sprekers van het Nederlands behaalden, waren vaak aanzienl die van de moedertaalsprekers. De voornaamste conclu onderzoek is dat de Chinese sprekers van het Nederlanc kennis hebben van waar in de zin toonhoogteaccenten mo geplaatst en van welke intonatiemelodie gebruikt moet wo zin in context. Daarnaast blijkt dat de voorleesspraak van de sprekers gekenmerkt wordt door meer toonhoogteaccenten, binnen de Intonatiefrase, langzamere spreeksnelheid en wein de duren van lettergrepen (lagere Pairwise Variability Indexde fonetische realisatie van de intonatiepatronen zoals onder perimenten 4 en 5 zijn verschillen gevonden tussen de groep nier waarop focus en de beschikbaarheid van sonorante klan satie van toonhoogtedalingen beïnvloeden. Deze verschi moeten worden geëlimineerd als Chinese leerders het $\mathrm{Ne}$ precies dezelfde manier willen uitspreken als de moedertaa laat het zich aanzien dat de perceptieve effecten van deze $v$ gering zullen zijn. 


\section{总结}

汉语官话或普通话是声调语言, 有四个字调, 以区别词汇的意 义。荷语无字调, 句子语用意义的表达依赖语调。以字调语言 (如汉语官话) 为母语的学习者习得没有字调但依赖声调区别句子 语用意义的声调语言 (如荷语) 的外语或二语时, 究竟会遇到哪 些困难, 目前研究尚少。本论文毕其力初步弥补其空缺。

论文主要从音系层面和语音层面描述带有汉语官话口音的荷语的 韵律特征, 由五个实验组成。第一和第二个实验是听觉感知实 验, 其他三个是产出实验; 实验从不同角度研究带汉语官话口音 的荷语韵律。产出实验分两种: 第三个实验调查母语为汉语官话 的荷语学习者朗读六类荷语句子, 选择语调的正确性, 考察被试 的语调知识。第三个实验和两个听觉感知实验测试中国被试的荷 语语调意义和词形学知识。第四和第五个产出实验探讨中国被试 实现荷语语调音高走势的语音能力; 研究他们荷语语调的语音特 征。无论中国被试是否具有在一定的语境中选用荷语韵律结构的 能力, 他们朗读这些韵律结构时或多或少带有口音。所以, 听觉 实验探究中国被试正确选用语调的能力, 产出实验研究他们语调 的声学特征。

听觉实验和产出实验是互相补充的。诸多原因造成二语或外语学 习者在韵律方面的“外国腔”。论文首要是确定“外国腔”从何而 来: 是音系上的差别还是语音上的差别? 听觉感知实验要解决的 是中国被试者能否正确辨别真实语境中的荷语韵律, 即: 能否识 别正确和错误的韵律结构。如果中国被试认为荷兰本族语者正确 的发音不恰当或不正确, 那么就不企望中国被试能够正确地发 音。如果他们在感知上能够区别正确和错误的读音, 但不能正确 地产出这些韵律结构, 那就归因于他们的语音实现能力的欠缺。 
从实践上看, 前种情况需要让学习者更多地接触荷语 情况学习者则需要学习荷语的发音。

20 个中国被试参加上述 5 个实验和 20 个荷兰本族语 个听觉感知实验。第三个实验中, 五个荷兰本族语者 句子的朗读作为比较标准, 探讨中国被试的荷语韵律 个和第五个实验中荷兰本族语者的数据来源于荷兰拉 言研究中心的“荷语方言的语调”研究项目所建立的“木 料库”。20个中国被试 3 男 7 女, 年龄最小 17 岁, 最大 们都来自于中国大陆北方, 母语为汉语官话。实验前, 荷语充分, 有足够完成实验所需的荷语语言能力。3 根据他们朗读中的发音和韵律表现, 把他们分成高水 和低水平组 (CLD)。参加实验的本族语者年龄从 18 岁 等, 能操标准荷语。

实验 (一)

实验 (一) 是听觉感知实验, 研究中国荷语学习者识 类句子重音方式。在强迫选择任务中, 20 个学习者和 本族语者听 36 个荷语句子, 判断这些句子重音是否 五分制的利克特量表 (Likert) 上表明他们对判断的信 子中只考察一处句子重音是否正确, 测试前由荷语专 音; 录音有正确和错误两种形式, 形成两个对立版本 子录音, 被试选择其中的一个版本进行测试。 荷兰本族语者的得分显著高于中国学习者中的高水平 习者中的高水平组的得分显著地高于学习者中的低 分; 他们的信心度也是由荷兰本族语者向低分组下 同。实验结果表明：荷语学习者对于荷语句子重音 好, 但他们清楚这一点, 如果得分低, 他们的信心) 时, 中国学习者对信息焦点处的重音判断比荷语中由 定的句子重音要容易。

实验 (二)

实验（二）也是一个强迫选择的听觉实验, 研究中国 能否根据故事的语境, 给故事中的句子选用最为得当 谓 “得当” 指的是在特定语境下, 绝大多数荷语本族 
语调。实验材料是一篇经过改写的荷语故事, 由 26 个句子组 成, 每句给出四个不同的语调并录音。按故事发生顺序, 被试者 听这些句子的四个语调, 根据语境选最佳的一个。实验结果表明 中国被试选择得分不及荷兰本族语者高而且他们的选择和本族语 者相比显得非常不一致; 高水平组比低水平组接近本族语者的选 择。语境中句子最佳语调的选用虽有争议, 但明确界定, 反映, 本 族语者的语言能力。如果本族语言能力没有表现出来, 学习者也 不可能表现出来。学习者还可能采用其他的策略：问号结尾的句 子用升调, 问号、逗号和感叹号结尾的句子用降调。另外我们还 发现: 学习者大多趋向避免选择渐降的降调 (downstepped falling pitch) 和降升调 (falling-rising pitch), 这可能和他们偏爱与汉语字调 类似的语调有关。中国被试的测试成绩和到达荷兰的年龄 (AOA) 显著相关, 与年龄 (Age)、居留荷兰年限 (Length of Residence) 无 显著关, 和二语习得其他方面的研究结论基本一致。就我们所 知, 该实验是首次对二语学习者韵律选用的系统研究。

\section{实验 (三)}

实验 (三) 是产出实验, 以七类荷语句子为语料, 每类句子代表 一类语调 “成语”, 而只有一种最合适的语调。该实验旨在调查中 国荷语学习者朗读七类荷语句子的语调选择。譬如, 荷语中以小 品词 be 结尾的句子最后一个重读音节用降升调 $\left(\mathrm{H}^{*} \mathrm{~L} \mathrm{H} \%\right)$ 。以五 个荷兰本族语者朗读七类 42 个句子 (每类六个句子) 作为 “正 确” 的语调标准, 比较学习者朗读中语调的选用。如果本族语者 的语调选用一致性很高, 那么学习者的错误程度就更严重。

中国学习者一定程度上能够选用最得当的语调朗读七大类荷语句 子。他们能够使用降调或半降调朗读标准荷语中 wat 形式的感叹 句和选择疑问句, 这两类句子在标准荷语中使用降调或半降调。 中国学习者在朗读含有 toch 问句、含有 ecbt 的问句, 如Was bet ecbt zo goedkoop? 句末汇报语 (reporting clauses) 和呼语 (vocative chants) 这些句子时, 出现很多错误。虽然标准荷语中带有 hoor、 bè 或 toch 的问句都使用降升调, 但中国学习者朗读前面两类问句要比后一 种好, 能够选用正确的语调进行朗读。对于中国学习者来说, 普 遍的规律是: 降调和升调简单, 降升调较难。低水平的学习者比 高水平的学习者出现更多的调核错误和边界调的错误, 但高水平 
的学习者比荷兰本族语者出现更多的边界调的错误, 这些差异显著。这些朗读材料的其他特点如语调短语 量、语调短语内的停顿和其时长、语速 (speech rate) (articulation rate)、毗邻配对变化系数 (nPVI) 也加以分木 在朗读中产生的语调短语、停顿显著地多于本族语者, 长没有显著差别。低水平学习者的语速和发音速度显 平学习者和本族语者慢。本族语者的毗邻配对变化系 于高水平学习者, 而后者的毗邻配对变化系数又显著 平的学习者。毗邻配对变化系数越低表明发音不连贯。 习者的调头重音显著地多于高水平学习者和本族语者。 习者的句子重音形式实际上和本族语者的句子重音开 几, 但是他们有时侯重读功能词和重读已知信息; 是, 中国学习者中, 无论高水平学习者和低水平学习 重读合成词的第二个组成成分。

实验（四）

实验（四）研究中国荷语学习者在有时间压力下如何 的降调 $\left(\mathrm{H}^{*} \mathrm{~L}\right.$ L\%)、升调 $\left(\mathrm{L}^{*} \mathrm{H} \mathrm{H} \%\right)$ 和降升调 $\left(\mathrm{H}^{*} \mathrm{~L} \mathrm{H} \mathrm{H}^{\circ}\right.$ 力, 即语调所在的音段时长受限制。虚构专有名词 $L$ Loof 和 Lof 四个单音节词分别置于语调短语的末尾, 压力逐渐增强, 因为他们的韵部时长不同: 长元音和 有别, 尾音 $/ \mathrm{f} /$ 和 $/ \mathrm{m} /$ 的响度不同。各个测试单词分 的陈述句和一般疑问句的信息焦点以及反问句中的纠 要求被试分别用降调、升调和降升调朗读。随着测试 短, 虽然调节方式具体细节不尽相同, 但高水平学习 者都压缩升调和降调, 低水平学习者没有采用此策略 族语者 Lom 的降调降得要比 Loom 的迟。除了 Lom、I Lof、Loof 迟外，低水平学习者没有采取任何类似于本) 取的策略, 低水平学习者发音甚至不能区分长元音和 水平学习者发音中能够区别长元音和短元音。低水平 单词的韵部比本族语者的韵部长; 也比高水平组测试 长, 但除降调和升调下的 Loof 外。中国学习者的降升 的降升调完全不一样, 这反映了他们的母语在单音节 这样复合的语调。三组之间的音域没有显著差别。 
实验 (五)

实验 (五) 研究被试如何实现不同类型的信息焦点以及陈述句中 使用降调的信息焦点词位置的影响。以虚拟地名 Manderen、 Momberen、Memberen 和 Munderen 为信息焦点词, 分别置于宽焦点 (broad focus)、窄焦点 (narrow focus) 和纠正焦点 (corrective focus) 形成三套 12 个陈述句。三组被试相比较, 23 个语音变量中, 只 有重读音节首音、韵部和尾音的时长, 降调的时长, 降调基频高 低差异以及音高峰值时间对应等 6 个变量显著不同。高水平学习 者实现不同信息焦点并不能胜过低水平学习者, 虽然在句子重音 听觉实验中, 中国学习者感知新信息重音得分较高, 这说明感知 能力不能迁移成为产出能力, 如何实现不同信息焦点必须习得。 和感知实验相比, 实验 (五) 所调查的语音特点很精细, 即使是 本族语者也达不到像感知实验所取得的理想结果。

中国荷语学习者掌握了一定的句子重音和语调的语言知识, 能够 根据篇章语境选择一定的重音和语调表达自己思想。但是, 他们 朗读材料的韵律在音系特征和语音特征两方面都不同于荷兰本族 语者。在两个听觉实验中他们的得分显著少于本族语者的得分, 表明他们的音系知识不及本族语者; 朗读产出实验里, 学习者有 富余的句子重音; 有更多的语调短语; 语速、发音速度和毗邻配 对变化系数都远远低于族语者; 实验(四)和实验 (五) 也发现学 习者的语音实现中的一些变量也不同于本族者。所以, 如果学习 者要产出地道的荷语, 这些方面都得习得, 虽然语音知识的感知 微妙, 效果低。 



\section{Appendices}

\section{Appendix 1: Corpus belonging to Chapter 2}

\section{A Word stress}

1. Er staat een OOievaar in de wei/ooieVAAR in de wei. There's a stork in the field.

2. Toen vochten de Nederlanders tegen de SPANjaarden/spanIAARden. At that time, the Dutch fought against the Spanish

3. Er is een Adelaar ontsnapt/adeLAAR ontsnapt An eagle has escaped

4. Er is een Olifantje geboren/oliF ANtje geboren. An elephant has been born.

5. Zijn vrous houdt van SIEraden/sieRAden. His wife likes jewelry.

6. Dat is de DOminee/domiNEE. That's the vicar.

B Compounds

1. Ze bebben een grote GROENtetuin/groenteTUIN. They have a large kitchen garden.

2. Op zondag eten ze altijd KRENtenbrood/krentenBROOD. On Sundays they always have raisin bread.

3. Je kunt bem beter in de FIETsenkelder stallen/fietsenKEL der stallen. You'd better park it in the bicycle parking space in the basement.

4. Ik wil een nieune KOEkenpan/koekenPAN.

I'd like a new frying pan.

5. Luister's naar dat ORgelspel/ongelSPEL. Listen to the playing of the organ.

6. Er is daar een leuke BOEKwinkel/ boekWINkel. There's a nice bookshop there. 
C Proper names

1. Dit is mevrown VROEGindenvei/vroegindeWEI.

This is mrs. Vroegindewei (literally 'early in the field').

2. Hij heet NAAKTgeboren/naaktgeBOren.

His name is Naaktgeboren.

3. Dat is voor Jan LEEFlang/leefLANG.

That's for Jan Leeflang.

4. Ken jij Mia ZELdenthuis/zeldenTHUIS?

Do you know Mia Zeldenthuis?

5. Vraag dat maar aan Ria ZONdervan/zonderV $V A N$.

Please just ask Ria Zondervan.

6. De beste verf komt van VETtewinkel/vetteWINkel.

The best paint is produced by Vettewinkel.

D SAAR (eventive sentences)

1. Ze bebben een aantal niewwe WERken aangekocht/werken $A$ ANgekocht. They've acquired a number of new works of art.

2. Waar kan ik schone BORden vinden/ borden VINden? Where can I find clean plates?

3. Wanneer moeten we de VUILnisqakken buiten zetten/vuilnisqakken buiten ZI When should be put the garbage out?

4. Is er een ONgeluk gebeurd/ongeluk geBEURD? Has there been an accident?

5. Moeten we niet een DOKter waarschuwen/dokter WAARschunen? Shouldn't we call a doctor?

6. De vuilnisman heeft de verkeerde $Z A K$ meegenomen/ zak MEEgenomen. The garbage man has taken the wrong bag. 
E Non-eventive sentences

1. U wordt verzocht eventuele schade te $M E L$ den/SCHAde te melden. You are requested to report any damage.

2. Ik zou die misstap TOEgeven/MISstap toegeven. I'd own up to that misdemeanor.

3. Je moet een bond $A$ ANkijken/ een HOND aankijken. You must look a dog in the eyes.

4. $U$ wordt verzocht un lege glazen bier $A C H$ ter te laten/GIAzen bier achter te laten. You are requested to leave your empty glasses behind.

5. De wereld draait DOOR/WEreld draait door.

The world goes on.

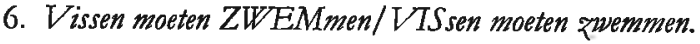
Fish must swim.

F Focus

1. Ik beb wel een mooie BRUIne jas gerien. Maar ik zocbt eigenlijk een ZW ARte jas/ quarte JAS. I did see a nice brown coat. But I was really looking for a black coat.

2. Er zijn DRIE ROde KNIKKkers. Maar ik zoek nog een paar BLAUwe knikkers/blawwe KNIKkers.

There are three red marbles. But I'm still looking forsome blue marbles.

3. GErard rijdt in een jaPANse auto, maar wil eigenlijk een FRANse auto/franse AUto. Gerard drives a Japanese car, but he would really like a French car.

4. Laat je je auto Overspuiten? Je kunt ook je auto laten $W A S$ sen/je $A U$ to laten wassen. Are you having your car repainted? You might just have your car washed.

5. Veel dieren leven onder de GROND. Er zijn ook SLANGen die ondergronds leven/slangen die onderGRONDS leven.

Many animals live underground. There are also snakes that live underground.

6. Het sceNArio van quartboek is van gerard SOEteman, maar paul verboeven beeft de film geregisSEERD/ FILM geregisseerd.

The scenario of Zwartboek is by Gerard Soetman, but Paul Verhoeven directed the film. 


\section{Appendix 2: Corpus belonging to Chapter 3}

Each of the 26 text tragments is given with an English translation and $p$ representations. For each fragment, the text in bold print indicates the plonolo phonetically raviable portions of the four speech files, with any cross-splicing being the point where the bold-faced text begins, which have been provided with stylize realizations. Any preceding text indicates an invariable portion of the four speech phonological transcriptions of the vaciable portions are in bold print if they differ acr versions. The scores by the Dutch and Chinese subjects for each of the four conton before and after the slash, respectively.

Fragment 0

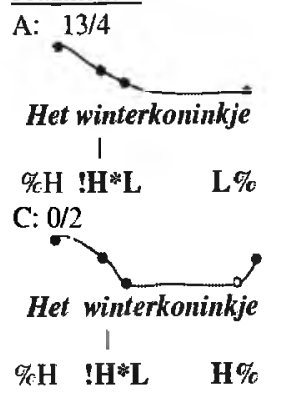

B: $6 / 7$

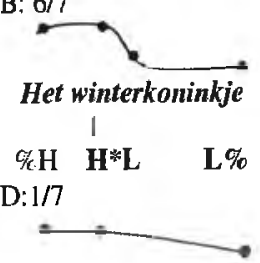

The willow wren

Fragment 1

Het winterkoninkje en zijn vrouw

\% $\mathrm{H}^{* \mathrm{~L}} \quad \mathrm{~L}^{*} \mathrm{H} \mathrm{H} \%$

The willow wren and his wife
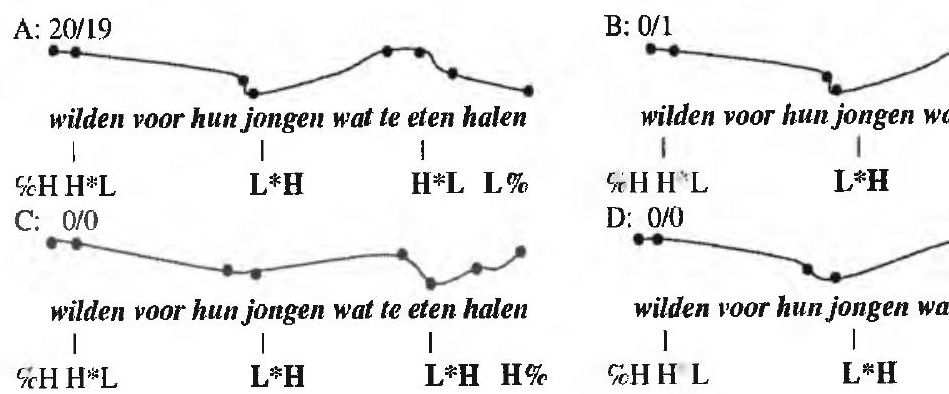

wanted to go and get some food for their children

Fragment 2

Omdat hun kinderen op die dag jarig waren
$\% \mathrm{~L}$
$\mathrm{H} * \mathrm{~L}$
$\mathrm{H} * \mathrm{~L} \quad \mathrm{H} \%$ 
A: $19 / 12$

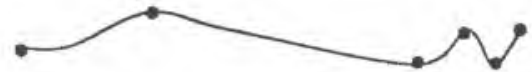

ze waren één maand geleden geboren

$\% \mathrm{~L} \quad \mathrm{H}=\mathrm{L}$

C: $0 / 3$

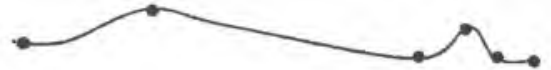

ze waren één maand geleden geboren

$\% \mathrm{~L} \quad \mathrm{H}^{*} \mathrm{~L}$
B: $0 / 3$

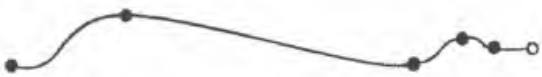

ze waren één maand geleden ge bo-ren

\section{1}

$H^{*} \mathrm{~L}$

$\mathrm{D}: \mathrm{L} / 2$

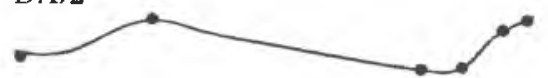

ze waren één maand geleden geboren

I

$\mathrm{H}^{*} \mathrm{~L}$

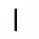

$\mathbf{H}^{*}+\mathbf{H} \%$

$\mathrm{H}^{*} \mathrm{LL} \%$ \%L

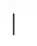

L*H H\%

they were born one month earlier

wilden ze extra lekker woedsel meebrengen

\% L $\quad H \% \mathrm{~L} \quad ! \mathrm{H} \mathrm{L} \quad \mathrm{L} \%$

they wanted to bring especially nice food for them.

Fragment 3

Ze vlogen naar de eiken, $\quad$ en de beuken, en de dennenbomen,

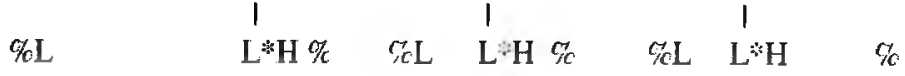

They flew to the oaks, and the beeches, and the fir-trees,

A: $20 / 17$

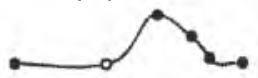

ze zochten overal!

I 1

$\% \mathrm{~L} \quad \mathrm{H}^{*} ! \mathrm{H} * \mathbf{L L} \%$

C: $0 / 0$

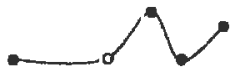

ze zochten overal!

\%L H*L H\%
B:0/3

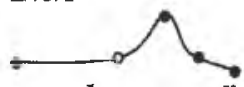

ze zochten overal!

I

'They searched everywhere!'

D: $0 / 0$

$\mathrm{H}^{*} \mathrm{~L} \mathbf{L} \%$

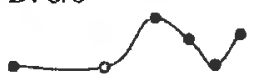

ze zochten overal!

\% L H*!H*L H\%

Fragment 4

Na één uur

hadden ze een hele smulpartij verzameld:

\%L H* L*H H\% \%L

$\mathrm{H}^{*} \quad \mathrm{H}^{*}$

H*L L\%

After an hour they had collected a large amount of delicacies: 
A: $20 / 9$

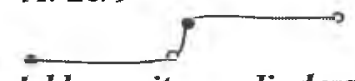

lekkere citroenvlinders, malse mestkevers,

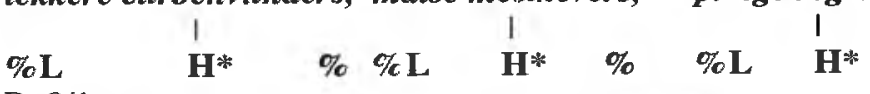

B: $0 / 1$

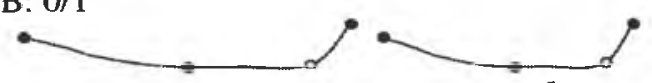

lekkere citroenvlinders, malse mestkevers, pittige regenwo

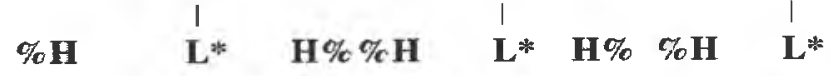

C: $0 / 4$

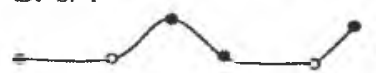

lekkere citroenvlinders, malse mestkevers,

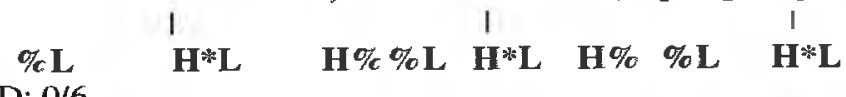

D: $0 / 6$

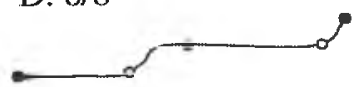

lekkere citroenvlinders,

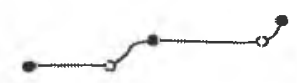

malse mestkevers, pittige regenw

$\% \mathbf{L}$

$\mathbf{H}^{*}$

H\% \% L

H*

H\% \%L

$H^{*}$

delicious brimstone butterflies, juicy earthworms, spicy dung beet en een heleboel andere lekkere dingetjes.
\%L $\mathrm{H}^{*}$
1
L\%
! H*L

and many more delicacies.

Fragment 5

A: $19 / 10$

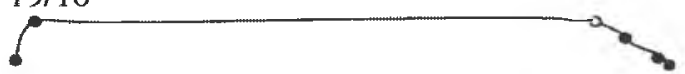

Eindelijk kwam het winterkoninkje weer thuis.

$c / c \mathbf{L H}$

B: $0 / 10$

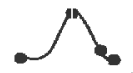

Eindelijk

:

$\% \mathbf{L H} * \mathbf{L} \mathbf{L} \%$
!H*L L\%

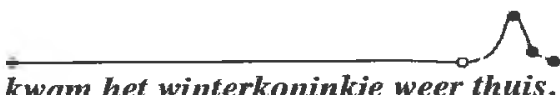

kwam het winterkoninkje weer thuis.

$\% \mathrm{~L}$

C: $1 / 0$

Eindelijk kwam het winterkoninkje weer thuis.

1

$\% \mathrm{LL} * \mathrm{H}$
H*L L\% 


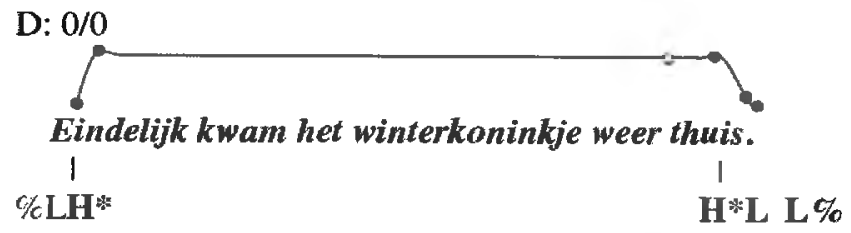

Finally the willow wren returned to the nest.

Fragment 6

Toen er zeven kleine vogeltjes,

$\% \mathrm{~L} \quad \mathrm{H}^{*} \mathrm{~L} \quad \mathrm{H}^{* i 2} \mathrm{~L} \quad \%$

when seven little birds,
A: $3 / 2$
B: $5 / 10$

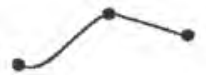
z'n kinderen, I z'n kinderen,
$\% \mathrm{~L} \quad \mathrm{H}^{*} \mathrm{~L} \quad \%$ I
C: $0 / 3$
$\% \mathbf{L} \quad \mathbf{H}$ L L \%
C. $0 / 3$
z'n kinderen,
D: $12 / 5$
z'n kinderen,
\%

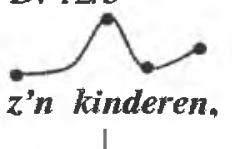
$\% \mathbf{L} \quad \mathbf{H}$ L H\%
his children,

te voorschijn kwamen,

$\stackrel{1}{\%} \mathrm{H}^{* \mathrm{~L}}$

made their appearance.

\section{zag-ie dat ze bibberden van angst!}

\% L H* !H L L\%

Fragment 7

A: $19 / 3$

Wat is er met jullie gebeurd?

\%L

1

B: $1 / 7$

H*L \%

Jullie zijn helemaal in de war!

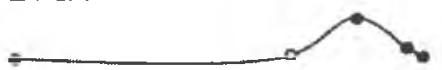

Wat is er met jullie gebeurd?

$\% \mathrm{~L}$

$\% \mathrm{~L}$

H*L \%

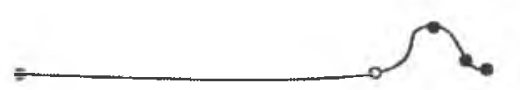

Jullie zijn helemaal in de war! 
C: $0 / 0$

Wat is er met jullie gebeurd?

I

\% L

D: $0 / 10$
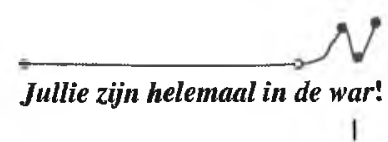

H*L H\%

Wat is er met jullie gebeurd? Jullie zijin helemaal in de war

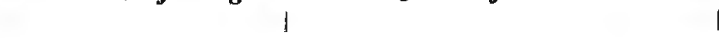

FL

L*H H\% \% L

L*HH\%

What has happened to you? You are all confused!

Fragment 8

Ach, vader

I I

$\% \mathrm{LH}^{*} \mathrm{~L} \mathrm{H}^{*} \mathrm{LL} \%$

Oh, daddy.

A: $16 / 5$

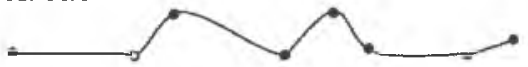

er kwam net zo'n grote boeman voorbij!

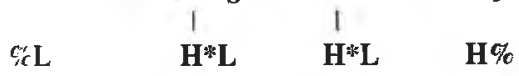

C: $0 / 0$

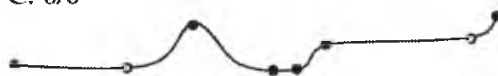

er kwam net zo'n grote boeman voorbij!

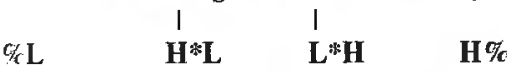

A big bogeyman just came along!

Fragment 9

A: $18 / 11$

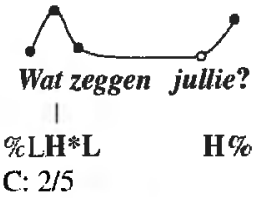

C: $2 / 5$

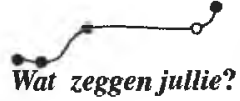

1

\%LL*H

$\mathbf{H} \%$

What's that you're saying?
B: $1 / 6$

er kwam net zo'n grote boem

$\% \mathrm{~L}$

D: $3 / 9$

H*L

H*I

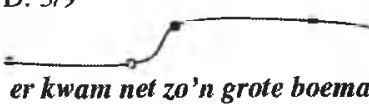

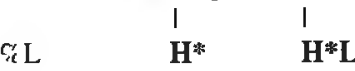
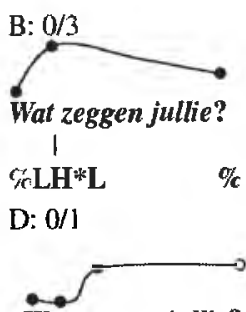

Wat zeggen jullie?

1

cLL*H

$\%$ 
Fragment 10

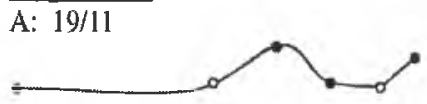

Er kwam een grote boeman voorbij?

C L

C: $0 / 5$

H*I
H\%

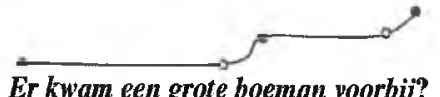

Er kwam een grote boeman voorbij?

$\% \mathrm{~L}$ H* $\mathbf{H} \%$

A big bogeyman came along?

Fragment 11 $J a$. I \%L H*LL\% Yes
B: $1 / 2$

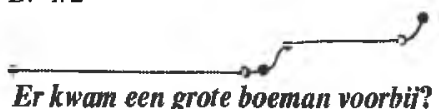

I

F $\mathrm{L}$

D: $0 / 2$

$\mathbf{L} * \mathbf{H} \quad \mathbf{H} \%$

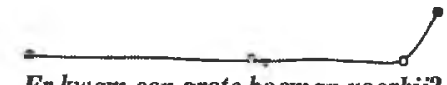

Er kwam een grote boeman voorbij?

$\% \mathrm{~L}$

H\%
A: $14 / 5$

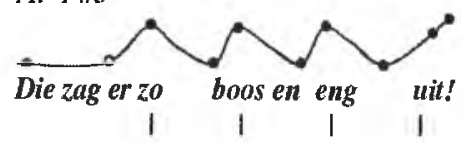

$\% \mathrm{~L} \quad \mathrm{H}^{*} \mathrm{~L} \quad \mathrm{H} \mathrm{L} \quad \mathrm{H}^{*} \mathrm{~L} \quad \mathrm{H}^{*} \mathrm{H} \%$

C: $0 / 11$

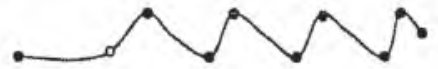

Diezagerzo boos en eng uit!

\% $\quad H * L \quad H * L \quad H * L \quad H * L *$

He looked so angry and frightening!

Fragment 12

A: $19 / 18$

En hij probeerde op onze boom te klimmen!

$\% \mathrm{~L}$

C: $0 / 0$

H*L $\quad \mathrm{L} \%$

En hij probeerde op onze boom te klimmen?

絃 $\mathbf{L} * \mathbf{H}$

And he tried to clinb our tree!
B: $0 / 2$

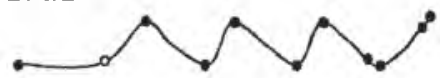

Die zagerzo boosen eng uit! $\begin{array}{llll}1 & 1\end{array}$ $\% \mathrm{~L} \quad \mathrm{H} * \mathrm{~L} \quad \mathrm{H} * \mathrm{~L} \quad \mathrm{H} * \mathrm{~L} \quad \mathrm{~L} * \mathrm{HH} \%$

D: $6 / 2$

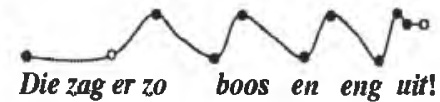

$\% \mathrm{~L} \quad \mathrm{H} \mathrm{L} \quad \mathrm{H}^{*} \mathrm{~L} \quad \mathrm{H}^{*} \mathrm{LH}^{*}+\mathrm{H} \%$
B: $0 / 1$

En hij probeerde op onze boom te klimmen!

coL

H*L $\quad H \%$

D: $1 / 1$

En hij probeerde op onze boom te klimmen! H\% $\% \mathrm{~L}$

H\% 
Fragment 13

A: $17 / 5$

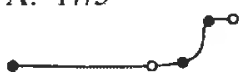

En hij klom hoger

I

$\% \mathrm{~L}$

B: $0 / 0$

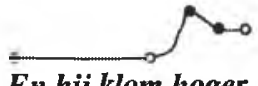

En hij klom hoger...
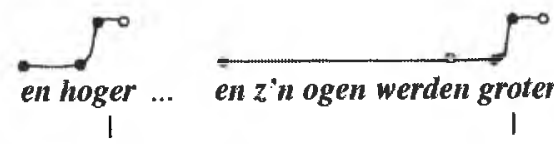

en z'n ogen werden grot

$\mathbf{L} * \mathbf{H} \% \% \mathrm{~L}$

$\mathrm{L} * \mathrm{H} \% \% \mathrm{~L} \mathrm{~L} * \mathrm{H} \% \% \mathrm{~L}$

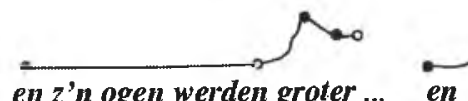

$\% \mathrm{~L}$

C: $0 / 1$

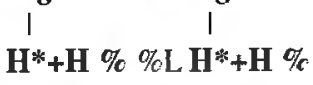

\% L

I

$\mathbf{H} * \mathbf{H} \% \quad \%$

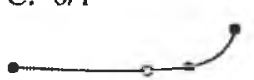

En hij klom hoger ... en hoger..
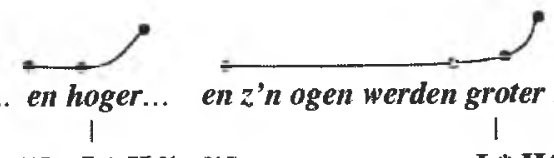

$\% \mathrm{~L}$

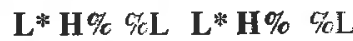

en z'n ogen werden groter ... en grot

L*H\% \% L L*H\% \%

$\mathbf{L}^{*} \mathbf{H} \%$ \% L*

D: $3 / 14$

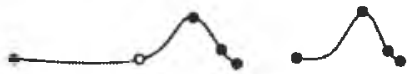

En hij klom hoger ... en hoger..

$\% \mathrm{~L}$ I

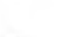

H*LL\% \% $\%$ H L L \% \%

en z'n ogen werden groter ... en gro

He climbed higher... and higher and his eyes grew bigger...and bigger.

Fragment $] 4$

A: $19 / 8$

Dat alles heeft ons zo bang gemaakt!

\% $\mathrm{L}$

C: $0 / 0$

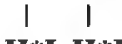

$H^{*} \mathbf{L} H^{*} \mathbf{L}$
B: $1 / 12$

Dat alles heeft ons zo bang ge

$\% \mathrm{~L}$

D: $0 / 0$

$\mathbf{H} * \mathbf{L} H * \mathbf{L}$

Dat alles heeft ons zo bang gemaakt! Dat alles heeft ons zo bang

\% L

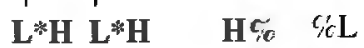

We were so frightened by all that!

Fragment 15

A: $14 / 5$

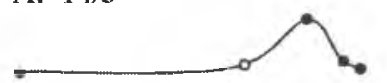

Is het misschien de leeuw

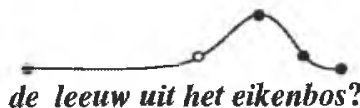

$c^{\prime} \mathrm{L}$

H*L L\% \%L

H*L L\% 
B: $1 / 5$
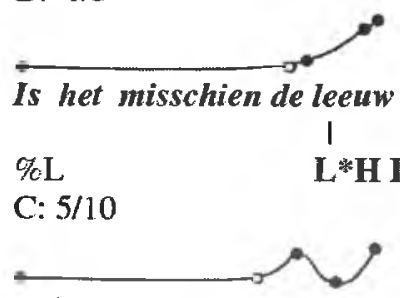

Is het misschien de leeuw

$\% \mathrm{~L}$

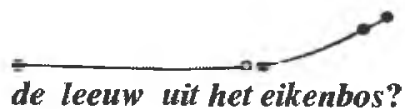

de leeuw uit het eikenbos?

\%L
L*H H\%

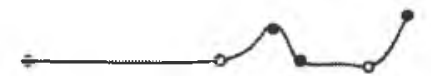

de leeuw uit het eikenbos?

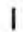

H*L $\quad \mathrm{H} \%$

D: $0 / 0$

Is het misschien de leeuw

rcL

Could it be the lion,

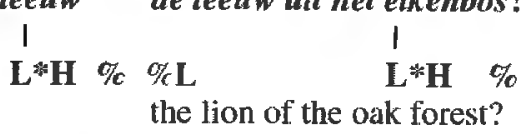

the lion of the oak forest?

Fragment 16

A: $12 / 6$

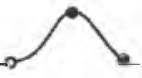

Maar dat weten we toch niet!

$\% \mathrm{~L} \quad \mathrm{H}^{*} \mathrm{~L} \quad \mathrm{H} \%$

C: $4 / 2$

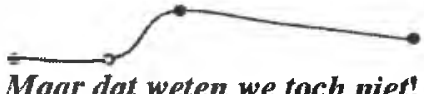

$\% \mathrm{~L}$ II*L

But we don't know, do we now!

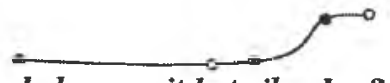

de leeuw uit het eikenbos?

\section{Fragment 17}

A: $4 / 4$

Rustig maar, kinderen! En zeg 's: Waar is-ie gebleven?

$\% \mathrm{~L}$

B: $0 / 4$

\section{B: $3 / 11$}

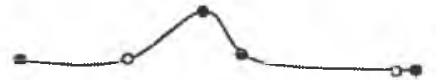

Maar dat weten we toch niet!

\% L $\quad \mathrm{H} * \mathrm{~L} \quad \mathrm{~L} \%$

D: $1 / 1$

Maar dat weten we toch niet!

$\% \mathrm{~L}$

$\%$

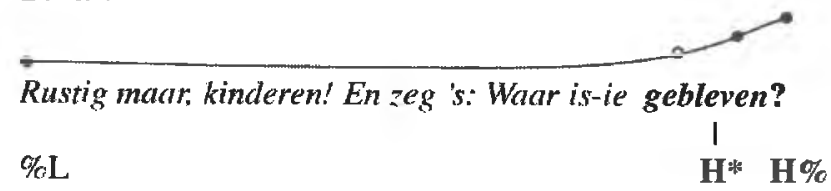


C: $2 / 7$

Rustig maar, kinderen! En zeg 's: Waar is-ie gebleven?

$\% \mathrm{~L}$

H嵝 H\%

D: $14 / 5$

Rustig maar, kinderen!' En zeg 's: Waar is-ie gebleven?

$\% \mathbf{L}$

L*H $\mathbf{H} \%$

Calm down, children, and tell me: Where did he go?

Fragment 18

Hij is daarheen gegaan!

\% L. H H

$\mathrm{LCC}$

He went there!

En de kinderen wezen naar het don

$$
\text { \% L H: }
$$

And the children pointed at the da

Wacht maar, oude leeun:

\% L H

L\%

Just you wait, old lion!

Als ik je op het spoor kom,

\% L $\quad$ H* $\mathrm{H} \%$

If I track you down,

A: $19 / 18$

B: $0 / 0$

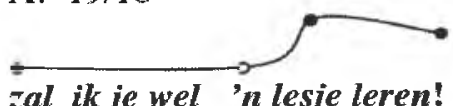

zal ikje wel 'n lesje leren!

$\% \mathrm{~L}$

$\mathbf{H}^{*} \mathrm{~L} \quad \%$

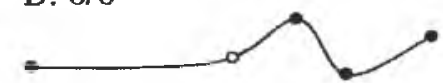

zal ik je wel 'n lesje leren!

$\% \mathrm{~L}$

H*L $\mathbf{H} \%$

C: $0 / 0$

D: $1 / 2$

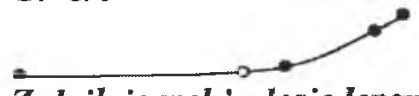

Zal ik je wel 'n lesje leren!

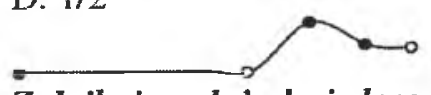

Zal ik je wel 'n lesje leren!

\% L

$\mathrm{L} * \mathrm{H} \quad \mathrm{H} \%$ cic

$\mathbf{H}+! \mathbf{H} \%$

I'll teach you a lesson!

Fragment 19

Toen woogde vader het bos in, en zocht overal. I I 1 11

$\% \mathrm{LH} \mathrm{L} \quad ! \mathrm{H} * \mathrm{~L} \quad ! \mathrm{H}^{*} \mathrm{~L} \quad ! \mathrm{H} * \mathrm{~L} \mathrm{~L} \% \quad \% \mathrm{~L} \quad \mathrm{H}^{*} ! \mathrm{H}^{*} \mathrm{~L}$ Then the father flew into the forest.

He searched everyv

Viteindelijk -ag-ie de leeuw achter de braamstruiken $\begin{array}{ccccc}1 & 1 & 1 & & 1 \\ \% \mathrm{LH} * \mathrm{LH} \% & \% \mathrm{LH}^{*} \mathrm{~L} & \mathrm{~L}^{*} \mathrm{H}^{*} & \% \mathrm{~L} & \mathrm{H}^{*} \mathrm{~L}\end{array}$

finally he found the lion strolling behind some blackberry bushe 
B: $1 / 5$

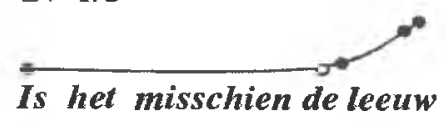

$\% \mathrm{~L}$

C: $5 / 10$

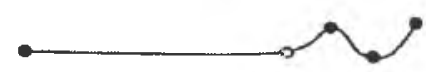

Is het misschien de leeuw

$\% \mathrm{~L} \quad \mathrm{H} * \mathrm{~L} H \%$ \%

\section{L*H H\%}

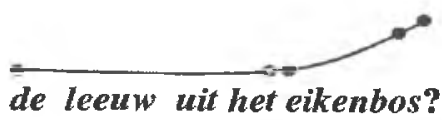
L*H H\%

$\% \mathrm{~L}$

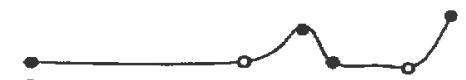

de leeuw uit het eikenbos?

D: $0 / 0$

Is het misschien de leeuw

\% $\mathrm{L}$

Could it be the lion,

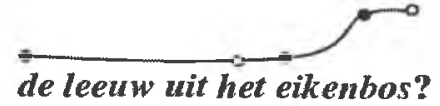

I

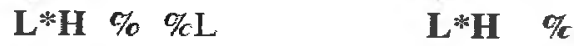

the lion of the oak forest?

\section{Fragment 16}

A: $12 / 6$

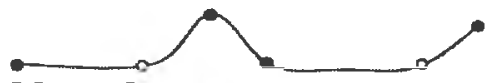

Maar dat weten we toch niet!

$\% \mathrm{~L}$

C: $4 / 2$

H*L

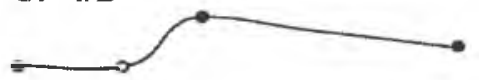

Maar dat weten we toch niet!

\%L H*L

But we don"t know, do we now!
B: 3/11

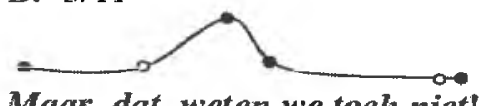

Maar dat weten we toch niet!

1

H*L

L\%

D: $1 / 1$

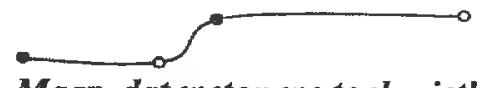

Maar dat weten we toch niet!

$7 \mathrm{~L}$

H*

$\%$

\section{Fragment 17}

A: $4 / 4$

Rustig maar, kinderen! En zeg 's: Waar is-iegebleven?

\%L

B: $0 / 4$

Rustig maar, kinderen! En zeg 's: Waar is-ie gebleven?

\% 
De leeun

I

\% L L

The lion

zag er heel gevaarlijk uit

maar it winterkoninkje

dat was niet

I

\% L $\quad \mathrm{H}^{*} \quad$ !H*L L\% $\% \mathrm{~L} \quad \mathrm{~L} * \mathrm{HL} \quad \mathrm{H} \% \quad \% \mathrm{LH} * \mathrm{LH}$

looked very dangerous, but the willow wren he wasn't afrai

Hij streek neer op de leeuw :'n rug en begon op ' $m$ te schelden.

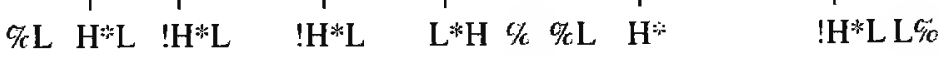

He landed on the lion's back, and started to scold him.

A: $17 / 19$

Wat heb jij bij mijn nest te zoeken!

1

reL

$\mathrm{H} * \mathrm{~L} \% \% \mathrm{~L}$

Hoe durf je mijn kindertjes ban

B: $0 / 0$

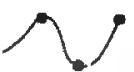

Wat heb jij bij mijn nest te zoeken! Hoe durf je mijn kinder

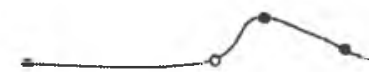

$\% \mathrm{~L}$

H*L H\% \%L

$\mathbf{H} * \mathbf{L}$

C: $0 / 1$

Wat heb jij bij mijn nest te zoeken!

$\% \mathrm{~L}$

1

D: $3 / 0$

L*H H\% \%

$\mathbf{L} * \mathbf{H}$

Wat heb jij bij mijn nest te zoeken!

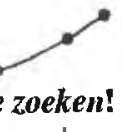

$\mathbf{H}^{*} \mathbf{H} \% \mathrm{qL}$

Hoe durf je mijn kindertjes ban

\%L

$\mathbf{H} \mathbf{H} \%$ \%

H*

What are you doing near my nest! How dare you frighten my children!

Fragment 20

A: $15 / 14$

Maar de leeuw trok zich er niets van aan

\% L $\quad \mathrm{H} * \mathrm{~L}$

H* !H*L L\% 
B: $1 / 3$

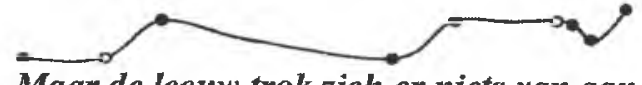

Maar de leeuw trok zich er niets van aan

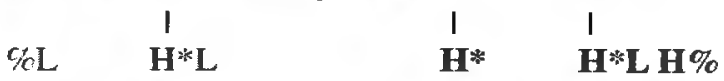

C: $4 / 1$

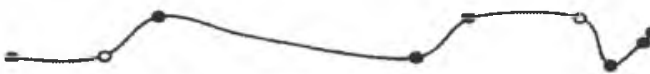

Maar de leeuw trok zich er niets van aan

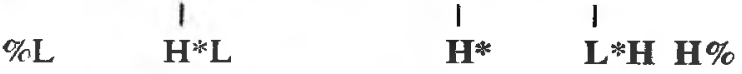

D: $0 / 2$

Maar de leeuw trok zich er niets van aan

$\begin{array}{cccc} & \mathrm{I} & \mathrm{I} & \mathbf{1} \\ \mathrm{H} & \mathrm{H} \mathbf{L} & \mathbf{H}^{*} & \mathbf{H} * \mathbf{H} \%\end{array}$

But the lion was unperturbed,

en liep gewoon door.

$\% \mathrm{~L} \quad \mathrm{H}^{*} ! \mathrm{H} * \mathrm{~L} \mathrm{~L} \%$

and just kept walking.

Fragment 21

Toen het winterkoninkje zag dat de leeuw wilde ophoepelen

$\% \mathrm{~L} \quad \mathrm{H} * \mathrm{~L} \quad \mathrm{H} * \mathrm{~L} \quad \mathrm{H} * \mathrm{~L} \quad \mathrm{H} \%$

When the willow-wren saw that the lion just wanted to walk away.

A: $18 / 14$

Ging-ie nog veel heviger tekeer, 't kleine opdondertje.

$\% \mathrm{~L}$

$\mathbf{H} * \mathbf{L} \quad \mathbf{L} \% \mathbf{L}$

L\%

B: $0 / 0$

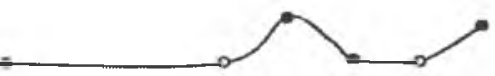

Ging-ie nog veel heviger tekeer, 't kleine opdondertje.

$\% \mathrm{~L}$

C: $1 / 0$

$\begin{array}{llll}H & \mathrm{H} \% & \mathrm{~L} & \mathrm{H} \%\end{array}$

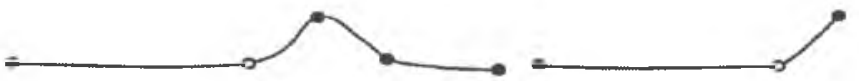

Ging-ie nog veel heviger tekeer, 't kleine opdondertje.

$\% \mathrm{~L}$

$\mathbf{H} * \mathbf{L} \quad \mathbf{L} \% \mathbf{L}$

$\mathbf{H} \%$ 
D: $1 / 6$

Ging-ie nog veel heviger tekeer, th kleine opdondertje.

$\% \mathrm{~L} \quad \mathrm{H}^{*} \mathrm{~L} \quad \mathrm{H} \% \mathrm{~L} \quad \mathrm{~L} \%$

he vented his rage even more fiercely, the tiny animal

Fragment 22

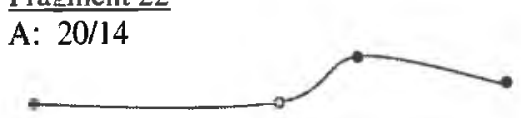

Jij hebt daar niks te zoeken, zeg ik je!

$\% \mathrm{~L}$

C: $0 / 4$

H*L

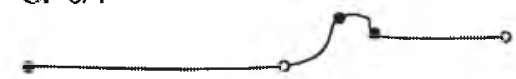

Jij hebt daar niks te zoeken, zeg ik je!

$\% \mathrm{~L}$

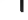

B: $0 / 1$

Jij hebt daar niks te zoekes

$\% \% \mathrm{~L}$

D: $0 / 1$

$H^{*} \mathbf{L}$

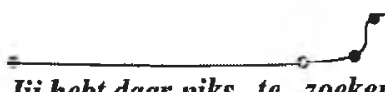

$\% \mathrm{~L}$

You have no business there, I tell you!

Fragment 23

En als je nog eens terughomt

\%L $\quad \mathrm{H}^{*} \mathrm{~L} \quad \mathrm{H} \%$

And if you dare to come back,

A: $19 / 19$

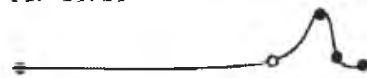

dan zul je wel eens zien!

$\% \mathrm{~L}$

C: $0 / 0$

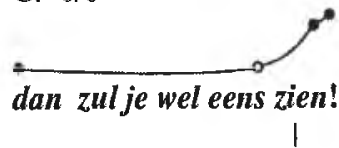

$\% \mathrm{~L}$
B: $1 / 0$

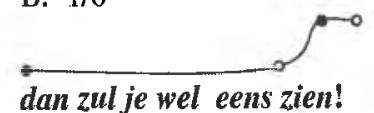

H*L L\%

$\% \mathrm{~L}$

D: $0 / 1$

dan zul je wel eens zien!

$\% \mathrm{~L}$

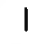

H*L H\%

you'll see what's going to happen!

Fragment 24

Ik zal het niet graag doen,

$\% \mathrm{~L} \quad \mathrm{H}$ ' 1

I wouldn't like to do this at all, 
A: $20 / 13$

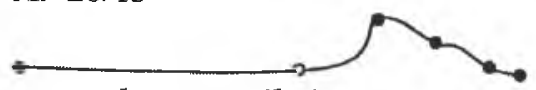

maar dan trap ik je zo je rug in!

$\% \mathrm{~L}$

C: $0 / 0$
B: $0 / 7$

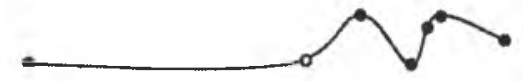

maar dan trap ik je zoje rug in! H*LH H*L \%

$\% \mathrm{~L}$

D: $0 / 0$

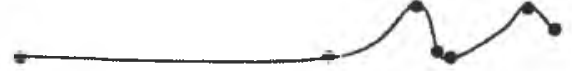

maar dan trap ik je zo je rug in!

\%L L*HL L*HL \% \%L

but I'll jump on you and break your back!

Fragment 25

Daarop vloog-ie weer terug naar z' $n$ nest

$\% \mathrm{~L} \quad \mathrm{H}$

He then flew back to his nest en sprak tegen z'n kleintjes:

\section{L*H H\% $\% \mathrm{H} \quad \mathrm{H}$ L $\quad \%$} and said to his children:

A: $20 / 12$

Zo kinderen I

$\% \mathrm{~L} \mathrm{H} * \mathrm{~L} \quad \mathrm{~L} \%$

B: $0 / 3$

\section{Zo kinderen} I

\%L H*L L\%

C: $0 / 3$

\section{Zo kinderen}

$\frac{}{\text { die }}$

$\% \mathrm{~L} \mathrm{H} \mathrm{H}^{*}$

D: $0 / 2$

\section{Zo kinderen} 1 $\% \mathrm{LH} * \mathrm{~L}$ $\mathbf{L} \% \quad \mathbf{H} * \mathbf{L}$ die he
$\mathrm{H} * \mathrm{~L}$ die

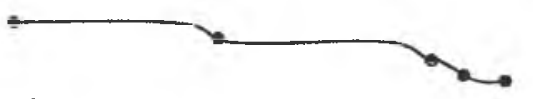

in lesje wel geleerd.

H*

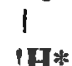

!H*

\section{!H*L L\%}

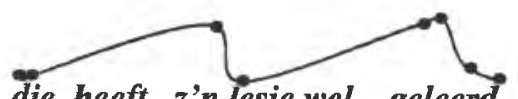

Now, children, that lion will have learned his lesson. 


\section{Appendix 3: Corpus belonging to Chapter 4}

\section{A. $\mathrm{H} * \mathrm{~L} \mathrm{~L} \%$ ' of nie? / end of list}

1. Je moet kiezen: wil je liever fruitsalade of wil je liever ijs?

You will have to choose: would you rather have fruit salad or ice crea

2. Weet je 't al? Krijg je nou wel een visum of krijg je geen visum?

Do you know yet? Will you or will you not get a visa?

3. Wat een raar weer. Zou 't nou gaan regenen of niet?

What strange weather! Is it going to rain or not?

4. Het is niet go ver naar Zwolle. Ga je met de auto of met de trein?

It's not that far to Zwolle. Are you taking the car or the train?

5. We eten kip. Heb je daar liever rijst bij of aardappelen?

We're having chicken. Would you rather have rice with that or potato

6. We bebben twee mogelijkheden: willen we op gas koken of elektrisch?

We have two options: do we want to cook on gas or on electricity?

B. $\mathbf{H} * \mathbf{L} \mathbf{H} \%$ 'toch' / self evidence

1. Je boeft niet meer te werken. Je bebt toch al genoeg gedaan deze week? You don't have to work any more. Haven't you done enough for the

2. Je kan niet naar school. Je bent toch ziek?

You can't go to school. You're sick, aren't you?

3. Ga je nou weer naar de supermarkt? We bebben alle boodschappen toch al gedaa Are you going to the supermarket again? But haven't we done all our

4. Waarom geef je een feest? Je bent toch niet jarig?

Why are you throwing a party? It's not your birthday, is it?

5. We bebben wel een huisdier! We bebben toch een bond?

We do have a pet! We have a dog, don't we?

6. Waarom veeg je je banden aan je broek af? Er zijn toch handdoeken? Why are you wiping your hands on your trousers? We have towels, $d$

C. $\mathrm{H}^{*} \mathrm{H} \%$ 'echt?"/surprised question

1. Zei je nou echt dat je naar buiten wilde? In de regen?

Did you really say you were going to go out? In the rain? 
2. Heeft ze echt een negen gehaald? Zonder te leren?

Has she really got a top mark? Without doing any work for it?

3. Staat er echt een politieauto voor de deur? Met zwaailichten?

Is there really a police car in front of the house? With flashing lights?

4. Is bij echt te laat gekomen? $O p q^{\prime} n$ examen?

Did he really arrive late? For his exam?

5. Was bet echt qo goedkoop? In de uitverkoop?

Was it really that cheap? In the sales?

6. Heb jij dat echt zelf getekend? Met dat potlood?

Did you really draw this yourself? With that pencil?

D. $H^{*} \mathbf{L} \%$ 'he said'/reporting clause

1. Hij keek ons de bele tijd strak aan. Toen zei-die: Dat nooit!

He looked hard at us the whole time. 'Then he said: 'That, never!'

2. Ze wist bet niet. Daarom vroeg qe: Wie gaat er mee?

She didn't know. 'That's why she asked: 'Who's coming?'

3. Hij keek baar na. Toen riep-ie: Vergeet de bloemen niet!

He followed her with his eyes as she left. Then he shouted: Don't forget the flowers!'

4. Ik was het niet met bem eens. En dus zei ik: 't Klopt niet!

I didn't agree with him. So I said: 'It's not right!'

5. Ik geloofde hem niet. Daarom vroeg ik: Is 't echt waar?

I didn't believe him. That's why I asked: 'Is it really true?'

6. We verdienen er niks aan! Daarom zeg ik: Niet doen!

We're not gaining anything by it. That's why I'm saying: 'Don't do it!'

E. $H^{*}+$ ! $H$ vocative chant

1. Schat-je! We bebben weer kaa-aas! Honey! We have cheese again!

2. Jo-ban-na! Ik wil niet naar de tand-arts! Johanna! I don't want to go to the dentist!

3. Kin-de-ren! Het is e-tens-tijd!

Children! Dinner time! 
4. Ja-an! Je bemd hangt uit je broek!

Jan! Your shirt is hanging out of your trousers!

5. Ji-ip! Je moet naar schoo-ool!

Jip! You should go to school!

6. Jan-ne-ke! Je moet je huis-werk nog ma-ken!

Janneke! You still have to do your homework!

\section{F. H*L H\% 'hè, hoor'/hearer appeal}

1. Het wordt laat. Maar je moet wel je eten opeten, hoor! It's getting late. But you should finish you meal!

2. De televisie doet 't niet. Dat vind je zeker jammer, bè?

The TV isn't working. You don't like that, now do you?

3. We rijden om 9 uur weg. Dat is vroeg genoeg, hoor!

We're leaving at nine. Don't worry, that's early enough!

4. Heb je weer wat te klagen? Je gaat niet zeuren, bè?

Are you complaining again? No whining, okay?

5. Wil je naar die tekenfilm? Die is leuk, hoor!

Do you want to see that animation film? It's funny, you know!

6. Wat sta je nou te treuzelen? Je bent bang, bè??

What are you tarrying for? You're afraid, aren't you?

G. $\mathbf{H} * \mathbf{L}(\mathbf{L} \%)$ wat-exclamations

1. Kijk daar 's! Wat is dat een rare fiets!

Look over there! What a funny bike!

2. Er is geen thee meer. Wat drinken jullie toch veel!

We're out of tea. You're drinking so much!

3. Ik ben vanmorgen in de stad geweest. Wat leuk is het daar!

I was in town this morning. It's ever so nice there!

4. Het is erg warm. Wat stoken jullie veel!

It's very hot. Your heating is turned up really high!

5. Kijk 's uit het raam naar de overkant. Wat een grote berg stenen!

Look out of the window across the street. What a large pile of bricks

6. Ik ga niet meer zwemmen bier. Wat is bet water koud!

I won't swim here anymore. The water is so cold! 


\section{Appendix 4: Corpus belonging to Chapter 5}

I. Listen to and practise two examples with the contour $H^{*} \mathrm{~L} L \%$

1. A. Met wie zijn ze naar de film genveest? Who did they go to the cinema with?

B. Ze waren meegegaan met Bernadette. They'd gone with Bernadette

2. A. Van wie is die auto? Whose car is that?

B. Die is van Bakker Bart. It belongs to Bart's Bakery

\section{Test sentences:}

3. A. Met wie gaat Roel naar't concert? Who is Roel going to the concert with?

B. Hij gaat met Marjel de Lof. $\mathrm{He}$ is going with Marjel de Lof.

4. A. Van wie is dat dikke boek? Who does that thick book belong to?

B. Dat is van Professor Loof. That is Professor Loof's.

5. A. Met wie gingen de kinderen naar de dierentuin? Who did the children go to the zoo with?

B. Ze gingen met meester Lom. They went with Mr Lom, their teacher.

6. A. Met wie gaat je baas morgen trouwen? Who is your boss marrying tomorrow?

B. Hij trount met merround de Loom. $\mathrm{He}$ is going to marry Ms de Loom.

II. Listen to and practise two examples with the contour L*H H\%

1. A. Was dat Jan? Ik had bem niet berkend.

Was that Jan? I hadn't recognized him.

B. Je broer liep ook mee in de optocht.

Your brother was also in the procession. 
2. A. We moeten de gordijnen opbalen bij de stomerij.

We should pick up the curtains from the cleaners.

B. Zijn ze bij Palthe? Daar brengen we de kleren toch altijd?

Are they at Palthe's? That's where we always take them, right?

\section{Test sentences}

3. A. Trek je jas aan; we vertrekken zo naar Eindhoven.

Put your coat on; we're leaving for Eindhoven soon.

B. Gaan we daar naar tante Lof? Gezellig!

Are we visiting Aunt Lof? Nice!

4. A. We gaan qo onze caravan ophalen voor de vakantie.

We will pick up our caravan for the holiday in a minute.

B. Staat-ie bij familie Loof:Daar stallen wij' $m$ ook altijd.

Is it parked at the Loof family's place? That's where we always keet

5. A. Ik zag net je broer Koen met je buurvroun langslopen.

I just saw your brother Koen and your neighbour walk by.

B. Liep-ie naast mevroun de Lom? Wat raar, die kennen elkaar toch niet?

Did he walk beside Mrs de Lom? Odd, I thought they didn't know

6. A. Ik moet straks naar de baas komen, omdat ik weer te laat was vanmorgen.

will have to go to the boss in a minute, because I was late again th

B. Moet je naar dokter Loom? Oei, maak je borst dan maar nat.

Do you have to go and see doctor Loom? Ouch! Then you can ex!

III. Listen to and practise two examples with the contour $\mathrm{H} * \mathrm{~L} \mathrm{H} \%$

1. A. Roelant Dalweide komt straks ook.

Roelant Dalweide will come too.

B. Die beet toch Roelant Weijendaal?

Isn't his name Roelant Weijendaal?

2. A. Ik zag net Jan van de Korde.

I just saw Jan van de Korde.

B. Jan van de Korde? Wat raar, die was toch in bet buitenland?

How odd. Wasn't he abroad? 


\section{Test sentences}

3. A. Ga je mee naar Bakkerij 't Stoepje?

Are you coming to the Stoepje Bakery?

B. We gaan toch naar Bakker Lof?

But aren't we going to Lof's Bakery?

4. A. Meester Boelens gaat mee op schoolreis.

Mr. Boelens, the teacher, will join the school trip

B. Je ging toch met meester Loof?

But weren't you going with Mr. Loof?

5. A. Pepijn de Heer komt straks ook naar't feest.

Pepijn de Heer komt will come to the party too.

B. Hij beet toch Pepijn de Lom?

Isn't his name Pepijn de Lom?

6. A. Dit antieke horloge is nog van opa Thijssen geweest.

This ancient wristwatch belonged to grandfather Thijssen.

B. Het was toch van opa Loom?

Wasn't it grandfather Loom's? 


\section{Appendix 5: Corpus belonging to Chapter 6}

Listen to and practise two examples with $H^{*} \mathrm{~L} I \%$ (broad focu focus)

1. A. Wat gaan jullie vandaag doen?

What are you going to do today?

B. We gaan naar Harlingen fietsen.

We're going to cycle to Harlingen.

2. A. Waar fietsen jullie morgen naartoe?

Where are you going to ride your bicycle today?

B. We gaan naar Laren fietsen.

We're going to cycle to Laren.

\section{Test sentences}

3. A. Wat zijn de plannen voor morgen?

What are the plans for tomorrow?

B. Ik qou wel naar Momberen willen fietsen. I would like to cycle to Momberen

4. A. Zijn er voor vanavond al plannen gemaakt?

Do we already have plans for tonight?

B. Ja, we zouden bij Memberen willen eten.

Yes, we would like to eat out near Memberen.

5. A. Zijn er al vakantieplannen?

Do we already have holiday plans?

B. We zouden naar Munderen willen liften.

We would like to hitchhike to Munderen

6. A. Wat is er?

What is it?

B. Ik had je naar Manderen willen rijden.

I had wanted to drive you to Manderen.

7. A. Waar zouden de Janssens been willen lopen?

Where would the Janssens want to walk to?

B. Ze zouden naar Memberen willen lopen.

They would like to walk to Memberen.

8. A. Waar zouden je oom en tante willen wonen?

Where would your uncle and your aunt like to live?

B. Ze zouden bij Manderen willen wonen.

They would like to live near Manderen. 
9. A. Waar qouden jullie willen blijven?

Where would you like to stay?

B. We qouden bij Munderen willen blijven.

We would like to stay near Munderen.

10. A. Waar zou Karel je been willen brengen?

Where would Karel like to take you?

B. Hij zou me naar Momberen willen brengen.

He would like to take me to Momberen.

11. A. Had je me uit Bevervijk willen balen?

Had you wanted to fetch me from Beverwijk?

B. Nee, ik bad je uit Munderen willen balen.

No, I had wanted to fetch you from Munderen.

12. A. Zouden de piloten bij Eindhoven willen landen?

Would the pilots want to land near Eindhoven?

B. Nee, ze zouden bij Memberen willen landen.

No, they would like to land near Memberen.

13. A. Had je moeder je naar Zaltbommel willen sturen?

Had your mother wanted to send you to Zaltbommel?

B. Nee, ze had me naar Momberen willen sturen.

No, she had wanted to send me to Momberen.

14. A. Zouden jullie naar Montfort willen rennen?

Would you like to run to Montfort?

B. Nee, we zouden naar Manderea willen rennen.

No, we would like to run to Manderen. 



\section{Curriculum Vitae}

He Xuliang was born in Huangmei in Hubei province, China, on 9 August 1971. He went to Hubei Normal University to major in English Language and Literature in 1991 and obtained his Bachelor degree in 1995. He was employed by that university after his graduation and worked there as an English instructor for four years. He enrolled in Shaaxi Normal University to study Foreign Languages and Applied Linguistics in September 1999, where he took his MA in June 2002. After his graduation he returned to Hubei Normal University to work in the English Department. In 2003 he obtained a teaching position in the School of Foreign Studies in Nantong University, Nantong, Jiangsu Province. During that engagement, he went to Queensland University of Science and Technology, Australia, to study Communicative Teaching for three months. At Radboud University Nijmegen, he worked on the $\mathrm{PhD}$ project which resulted in this dissertation from 15 December 2008 to 15 September 2011. He is now an associate professor in the School of Foreign Studies at Nantong University. 




\section{Xuliang He}

\section{Mandarin-accented Dutch Proso}

The dissertation reports on two perception experiments (Experimen. three production experiments (Experiments 3, $4 \& 5$ ) that explore $t$ I and phonetics of the prosody of Mandarin-accented Dutch. Expe conducted to see how well Chinese speakers of Dutch (CSD) identi accentuation patterns in Dutch sentences, while Experiment 2 explo 0 which they are able to identify the most appropriate intonatio 5 sentences in context. Experiment 3 studied their choice of intonatic the production of seven 'intonational idioms'. Experiment 4 inve CSDs produced Dutch monosyllabic Falls, Rises and Fall-rises unc ff the availability of sonorant sounds. Experiment 5 studied how $d$ if focus affected the pronunciation of falling intonation.

The perception experiments showed that CSDs do not know what in ern to use and what words to accent when faced with contextualiz his finding reveals that CSDs could not be expected to produce corre Dutch even if their command of the phonetics was perfect. Experim 3 hat this conclusion is correct on the basis of a production experi SDs failed to produce the right melody in 'intonational idioms'. I xperiments 4 and 5, this experiment also showed that CSDs do $\mathrm{n} \longrightarrow \mathrm{C}$

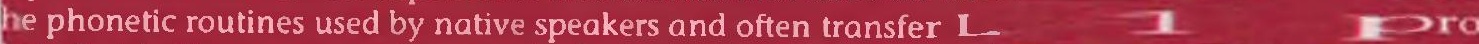
heir Dutch. The one exception was the lack of any transfer from he pronunciation of pitch falls as a function of focus.

his dissertation will be of interest to all those working on phone $\mathrm{C}$ utch and Mandarin Chinese phonology as well as second language

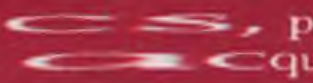

Netherlands

Graduate

- LOI school of

Linguistics 